University of Nebraska - Lincoln

DigitalCommons@University of Nebraska - Lincoln

$1-3-2020$

\title{
The Abyssinian Art of Louis Agassiz Fuertes in the Field Museum
}

Paul A. Johnsgard

University of Nebraska-Lincoln, pajohnsgard@gmail.com

Follow this and additional works at: https://digitalcommons.unl.edu/zeabook

Part of the Art Practice Commons, Book and Paper Commons, Illustration Commons, Terrestrial and Aquatic Ecology Commons, and the Zoology Commons

\section{Recommended Citation}

Johnsgard, Paul A., "The Abyssinian Art of Louis Agassiz Fuertes in the Field Museum" (2020). Zea EBooks Collection. 83.

https://digitalcommons.unl.edu/zeabook/83

This Book is brought to you for free and open access by the Zea E-Books at DigitalCommons@University of Nebraska - Lincoln. It has been accepted for inclusion in Zea E-Books Collection by an authorized administrator of DigitalCommons@University of Nebraska - Lincoln. 


\section{The Abyssinian Art of}

Louis Agassiz Fuertes

in the Field Museum

Paul A. Johnsgard 


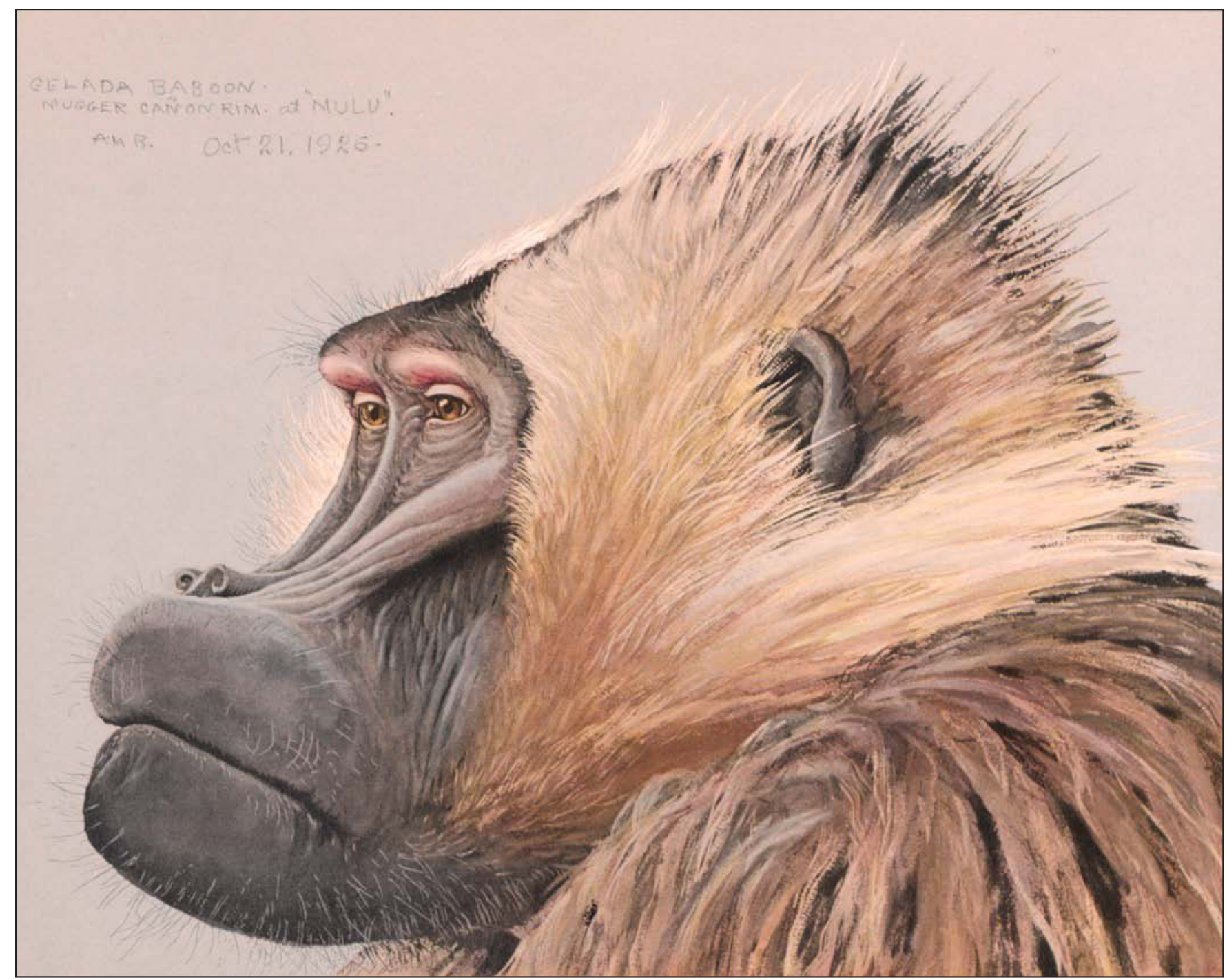

This book documents the paintings and drawings executed by Louis Agassiz Fuertes during the Field Museum of Natural History's seven-month expedition to Ethiopia (Abyssinia) in 1926-27. During that time Fuertes completed 70 field watercolors that illustrate 55 species of birds and four species of mammals. He also executed 34 pencil drawings, which illustrate 13 species of mammals and 11 species of birds, plus numerous miscellaneous sketches and small watercolors. This book identifies and describes the biology of all 69 species of birds and mammals illustrated by Fuertes and includes 32 color reproductions of Fuertes's watercolors that were published as a limited-edition album in 1930 by the Field Museum. The 60,000-word text provides brief summaries of all these species' ecology, behavior, and reproductive biology as well as information about their current populations and conservation status. A review of Fuertes's life, his influence on modern bird and wildlife art, and his participation in and artistic contributions to the Field Museum's Abyssinian Expedition is also included, as well as more than 250 bibliographic citations.

Zea Books

Lincoln, Nebraska 


\section{The Abyssinian Art}

of

Louis Agassiz Fuertes

in the Field Museum

\section{Paul A. Johnsgard}

School of Biological Sciences

University of Nebraska-Lincoln

Zea Books

Lincoln, Nebraska

2020 
Text copyright (C) 2020 Paul A. Johnsgard

ISBN: 978-1-60962-165-0

doi 10.32873/unl.dc.zea.1097

Composed in Bookman Old Style and Elephant types.

Zea Books are published by the University of Nebraska-Lincoln Libraries

Electronic (pdf) edition available online at

https://digitalcommons.unl.edu/zeabook/

Print edition available from

http://www.lulu.com/spotlight/unllib

UNL does not discriminate based upon any protected status.

Please go to http://www.unl.edu/equity/notice-nondiscrimination

\title{
Nebraska \\ Lincoln
}

\author{
Follow this and additional works at: \\ http://digitalcommons.unl.edu/biosciornithology \\ Part of the Art Practice Commons, Ornithology Commons, \\ and the Zoology Commons.
}

pajohnsgard@gmail.com

\begin{abstract}
This book documents the paintings and drawings executed by Louis Agassiz Fuertes during the Field Museum of Natural History's seven-month expedition to Ethiopia (Abyssinia) in 1926-27. During that time Fuertes completed 70 field watercolors that illustrate 55 species of birds and four species of mammals. He also executed 34 pencil drawings, which illustrate 13 species of mammals and 11 species of birds, plus numerous miscellaneous sketches and small watercolors. This book identifies and describes the biology of all 69 species of birds and mammals illustrated by Fuertes and includes 32 color reproductions of Fuertes's watercolors that were published as a limited-edition album in 1930 by the Field Museum. The 60,000-word text provides brief summaries of all these species' ecology, behavior, and reproductive biology as well as information about their current populations and conservation status. A review of Fuertes's life, his influence on modern bird and wildlife art, and his participation in and artistic contributions to the Field Museum's Abyssinian Expedition is also included, as well as more than 250 bibliographic citations.
\end{abstract}




\section{Contents}

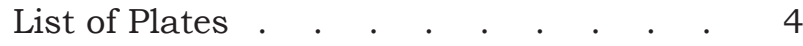

Preface and Acknowledgments . . . . 5

Compiler's Note . . . . . . . . 7

\section{Historical Introduction}

Louis Agassiz Fuertes: His Beginnings, Birds, and Art . . . . . . . . . 9

Fuertes's Artistic Legacy . . . . . 11

The Abyssinian Expedition . . . . . 13

\section{Bird Paintings and Drawings}

Family Podicipedidae (Grebes) . . . . 17

Family Ardeidae (Herons and Bitterns) . 19

Family Ciconidae (Storks) . . . . . 20

Family Threskiornithidae (Ibises and Spoonbills) . . . . . . . . . 21

Family Phoenicopteridae (Flamingoes) 22

Family Anatidae (Swans, Geese, and

Ducks) . . . . . . . . . . 23

Family Accipitridae (Vultures, Eagles, Hawks, and Relatives) . . . . . 28

Family Sagittariidae (Secretary Bird) . . 62

Family Falconidae (Falcons) . . . . 63

Family Numididae (Guineafowl) . . . 65

Family Phasianidae (Pheasants,

Francolins, and Quails) . . . . . 66

Family Gruidae (Cranes) . . . . . . 67

Family Otididae (Bustards) . . . . . 67

Family Jacanidae (Jacanas) • • • • 70

Family Burhinidae (Thick-knees) . . . 71

Family Charadriidae (Plovers and Lapwings) . . . . . . . . . 72

Family Pteroclididae (Sandgrouse). . . 75

Family Columbidae (Pigeons and Doves) . 77

Family Musophagidae (Turacos and

Plantain-eaters) ..$\quad$. . . . . 78

Family Cuculidae (Cuckoos and Coucals) 81

Family Trogonidae (Trogons) . . . . 82

Family Alcedinidae (Kingfishers) . . . 84

Family Upupidae (Hoopoes). . . . . 88

Family Bucerotidae (Hornbills) . . . . 89

Family Capitonidae (Barbets) . . . . 93
Family Platysteiridae (Batises and

Wattle-eyes) . . . . . . . . . 94

Family Prionopidae (Helmetshrikes) . . 94

Family Corvidae (Ravens, Crows, and Relatives) . . . . . . . . . 96

Family Sturnidae (Starlings and Oxpeckers) . . . . . . . . . 99

\section{Mammal Paintings and Drawings}

Family Colobidae (Colobid Monkeys) . . 101

Family Cercopithidae (Cheek-pouch

Monkeys) . . . . . . . . . 103

Subfamily Papioninae

(Baboon-macaques). . . . . . 103

Subfamily Cercopithinae (Guenons) 110

Family Muridae (Murid Rats and Mice) . 111

Family Rhizomyidae (Root-rats) . . 111

Family Canidae (Dogs and Relatives) . . 112

Family Herpestidae (Mongooses) . . . 114

Family Procavidae (Hyraxes) . . . . 115

Family Bovidae (Horned Artiodactyls) . 117

Tribe Tragelaphini (Spiral-horned

Bovines) . . . . . . . . . 117

Tribe Cephalophini (Duikers) . . . 117

Tribe Neotragini (Dwarf Antelopes) . . 120

Tribe Reduncini (Reduncine

Antelopes and Kobs) . . . . . . 121

\section{Appendices}

1. Fuertes's Abyssinian Art, Listed

Alphabetically by Generic Names . 122

2. Fuertes's Abyssinian Art, Listed

Alphabetically by English Names . . 125

3. Miscellaneous Graphite Sketches and

Small Watercolors . . . . . . 128

4. Summary of Fuertes's Abyssinian Art

Collection in the Field Museum . . 128

References . . . . . . . . . 129

Internet Sources . . . . . . . . 136

Index to Species Accounts . . . . . 137 


\section{Plates*}

1. White-backed Night Heron (African Night Heron) . . . . . . 18

2. Spur-winged Goose . . . . . . . . . . . . . . . . . . . 24

3. Cape Teal . . . . . . . . . . . . . . . . . . . . . . . .

4. Black-winged (Black-shouldered) Kite . . . . . . . . . 28-29

5. Scissor-tailed (African Swallow-tailed) Kite . . . . . . . . . . 31

6. African Fish Eagle (African Sea Eagle) . . . . . . . . . . 34

7. African Fish Eagle, immature (African Sea Eagle) . . . . . . . 35

8. Lammergeier (Bearded Vulture) . . . . . . . . . . . 38-39

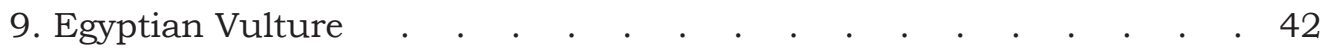

10. Hooded Vulture (White-necked Vulture) . . . . . . . . . 44

11. Eared (Lappet-faced) Vulture . . . . . . . . . . . . . 47

12. White-headed Vulture . . . . . . . . . . . . . . . . . . 49

13. Bateleur (Bateleur Eagle) . . . . . . . . . . . . . 51

14. Bateleur, group in flight (Bateleur Eagle) . . . . . . . . . 53

15. African Harrier Hawk . . . . . . . . . . . . . . 55

16. Tawny Eagle (African Tawny Eagle) . . . . . . . . . . 58

17. Secretary Bird . . . . . . . . . . . . . . . . 60-61

18. Lanner Falcon (Abyssinian Lanner) . . . . . . . . . . 64

19. Black-bellied Bustard . . . . . . . . . . . . . . . . . 69

20. Four-banded Sandgrouse (Lowe's Sand-grouse) . . . . . . 74-75

21. Bruce's Green Pigeon (Green Pigeon) . . . . . . . . . 76-77

22. Eastern Gray Plantain-eater (Gray Plantain Eater) . . . . . . . 79

23. Narina Trogon . . . . . . . . . . . . . . . . . 83

24. Gray-headed Kingfisher . . . . . . . . . . . . . 85

25. Malachite Kingfisher (Pigmy Kingfisher) . . . . . . . . 87

26. Silvery-cheeked Hornbill (Crested Hornbill) . . . . . . . . 92-93

27. White-crested Helmetshrike (Nile Helmet Shrike) . . . . . . 95

28. Thick-billed Raven $\quad . \quad$. . . . . . . . . . . . . . . . 97

29. Gelada, group (Gelada Baboon) . . . . . . . . . . . . 106

30. Gelada (Gelada Baboon) . . . . . . . . . . . . 108-109

31. Ethiopian Wolf (Abyssinian Wolf) . . . . . . . . . 112-113

32. Bush Duiker (Abyssinian Duiker) . . . . . . . . . 118-119

*Note: The species names appearing in the Album of Abyssinian Birds and Mammals from Paintings by Louis Agassiz Fuertes are shown in parentheses where they differ from those in current use. 


\section{Preface and Acknowledgments}

The year 2019 marked the 120th anniversary of the first colored reproduction of a Louis Agassiz Fuertes painting - a watercolor of two seaside sparrows-published in the ornithological journal Auk when Fuertes was about 25 years old. Although Fuertes's life spanned little more than a half-century, and nearly all living ornithologists today were born after his tragic 1927 death, his influence on natural history art has not lessened. This publication is a testimony to his enduring artistic legacy and is dedicated to his memory.

During a 1995 visit to the Field Museum of Natural History in Chicago, and with the permission of Benjamin W. Williams, Special Collections librarian of the museum, I was allowed to see the original set of paintings and drawings that Fuertes executed during a 1926-27 expedition to Ethiopia. Like many other lovers of fine bird art, I had long marveled at the Field Museum's album with 32 of his Abyssinian paintings (Album of Abyssinian Birds and Mammals from Paintings by Louis Agassiz Fuertes), but the sight of roughly 100 original images representing nearly 70 species was overwhelming. I inquired at the time about the museum's plans for possible publication of the entire collection and was told that this was under consideration.

During the same visit I was shown the museum's recently acquired set of 35 baby bird watercolors by George M. Sutton, and I immediately broached the possibility of publishing these in book form with associated short essays by me. That idea met with quick approval, and in the spring of 1998 resulted in the publi- cation of Baby Bird Portraits by George Miksch Sutton: Watercolors in the Field Museum.

As soon as that book appeared I began wistfully thinking again of Fuertes's African birds. In the summer of 1998 I made a formal suggestion to Mr. Williams that we consider producing a book containing all the bird paintings and their associated graphite drawings, with the text by me, and the hope that perhaps similar descriptions of the relatively few mammal images could be separately produced by someone more qualified than I. In September I followed up with a proposed outline for the book and a preliminary text. I visited the Field Museum again during November 1998 to examine the paintings and drawings more closely and to discuss possible publication plans.

Mr. Williams convinced me that the mammal plates also needed inclusion in any book on Fuertes's Ethiopian art because there were too few to warrant a separate publication. Available time to access the artwork and perform these studies thoroughly proved to be much more limited than I had anticipated, but I quickly inventoried all the Fuertes drawings and watercolors, and photographed many of the unpublished images for personal reference.

Mr. Williams left the museum not long afterward, so my manuscript was necessarily set aside and neglected for several years. However, in May 2008, Elizabeth Babcock of the museum staff encountered a copy of my manuscript among the museum files. She contacted me and inquired about its fate, which I then decided should receive some resolution. I thus approached Dr. Paul Royster of the University 
of Nebraska-Lincoln's Office of Scholarly Communications and asked if I could place the still-unfinished manuscript online in the university's Digital Commons institutional repository. After this had been achieved (Johnsgard, 2009), I again set the manuscript aside and returned to other projects.

A decade later, I decided to revisit, correct, and supplement the manuscript, with the hope of incorporating reproductions from a collection of 32 watercolors that Fuertes had executed during the Abyssinian expedition and were published by the Field Museum (FMNH, 1930). This album had been published without copyright notice and thus was in the public domain, so a set of the plates were placed in the University of Nebraska-Lincoln's Digital Commons repository (https://digitalcommons.unl. edu/biosciornithology/49/) and now are incorporated into the present text. With this new book, I have supplemented the text substantially, adding more life history and ecological information on the species Fuertes depicted, wherever available. I have also summarized the conservation status of all 69 of these species, some of which have declined from a seemingly secure population situation in the early 2000s to being species of current conservation concern. In a few cases, species have become critically endangered within only two decades.

In discussing each of the species depicted by Fuertes, I have varied the lengths of my essays according to the number of images he devoted to the species, reflecting his apparent relative interest in it. Thus, species with only a single image typically have less than 500 words devoted to them, whereas those such as the bateleur eagle (with four paintings) have a 1,700word description, and the colobus monkey (with three paintings and two drawings) has an approximately 1,800-word description.

Mainly for reasons of taxonomic conservatism and nomenclatural consistency, I have left taxonomic sequences and nomenclatures unchanged from those I adopted in 2009, in spite of some more recent but still evolving systematic changes that have been proposed in both groups. The avian nomenclature of this book is thus based on Fry, Keith \& Urban (1982-2004) and Zimmerman, Turner \& Pearson (1996), whereas the mammalian nomenclature follows Kingdom (1997).

One nomenclatural difficulty when referring to the Fuertes plates is that about onethird of the species he illustrated have undergone changes in their English vernacular and/ or Latin names since 1930. Thus, two appendices have been provided, organized by both the older and current Latin and English vernacular names to help navigate the anomalies between names used in this work and those attached to Fuertes's original images.

As a related difficulty, three of Fuertes's images seemed to me to have been incorrectly labeled as to species, and I have ventured some reidentifications. I believe these problems resulted from a lack of reference materials available to Fuertes during the expedition, and the fact that his death only a few months later meant that little or no oversight may have occurred prior to the publication of the 1930 album. Dr. David Willard, collections manager emeritus of the Field Museum's Ornithology Division, kindly helped me resolve these problematic identifications, but any taxonomic or other factual errors are my own responsibility.

Referring to locality names in Ethiopia has proven to be equally problematic. Although even today there seems to be little if any agreement as to the proper spelling of Ethiopian place names, I have modified some of the locality spellings used in the Album of Abyssinian Birds and Mammals and associated publications to try to conform with more recent usage. I have also used some newer spellings for various Ethiopian geographical and political entities, such as lakes and provinces.

In preparing this book I have received assistance from many people. I owe Benjamin Williams and the Field Museum a great debt of 
gratitude for permitting me to study the original Fuertes images in the museum's Rare Book Room and to photograph some of them for later reference. Ms. Linda Brown helped me catalog and photograph the images, and provided a great deal of constructive advice and encouragement during the project's two-decade-long gestation period.

Professor Paul Royster had very kindly placed the 2009 version of my manuscript into the University of Nebraska-Lincoln's Digital
Commons online repository and later agreed to incorporate all 32 of the expedition's published color plates into this new and expanded edition. Linnea Fredrickson, copy editor for the Digital Commons' Zea Books, did her usual splendid job in ferreting out textual errors and improving my sometimes crippled syntax. Most of all I am especially indebted to the memory of Louis Agassiz Fuertes and the opportunity to see and study his magnificent creations firsthand.

Paul A. Johnsgard

Lincoln, Nebraska

Compiler's Note - The Fuertes plates included here were originally published by the Field Museum of Natural History in 1930 in an edition consisting of a slipcased set of 32 separate 10-by-12-inch lithographed plates on 10-point (approximately) naturalwhite stock. Each image was backed with a brief description. The images were presented within warm gray borders of approximately one inch. The portfolio also included a four-page folio leaflet containing a three-page essay by Wilfred Osgood and a "List of Subjects." The portfolio was published without copyright notice, making it public domain according to the law at that time.

The plates in this book were prepared from a copy of the published portfolio held by the Special Collections Department of the University of Nebraska-Lincoln Libraries. This copy was received as a gift from Mrs. C. Harold Claytor. Scanning was done by the Center for Digital Research in the Humanities. Images were scanned at 300 dots per inch (dpi) and saved as RGB files in JPEG format. Minor color corrections were made using Adobe Photoshop. For this edition, the borders have been eliminated and the artwork has been resized at approximately $115 \%$. 


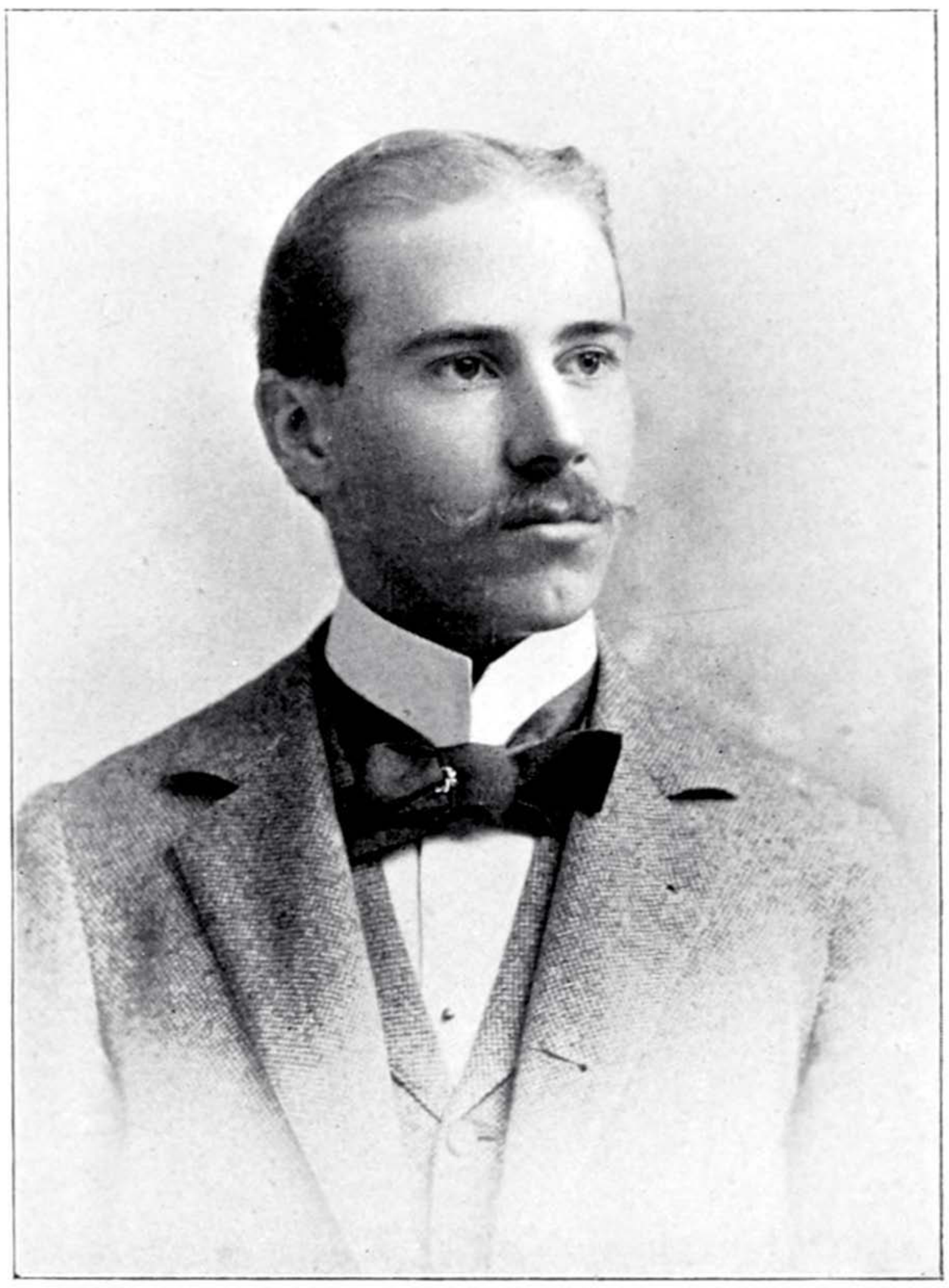




\section{Historical Introduction}

\section{Louis Agassiz Fuertes: His Beginnings, Birds, and Art}

I think it is interesting that, like John James Audubon, Roger Tory Peterson, and George Miksch Sutton, we would never think of referring to Louis Agassiz Fuertes in any other way than with his middle name. It is not that there has ever been or will ever be another Louis Fuertes with whom we might possibly confuse him; Fuertes had no comparable antecedent. Dr. Livingstone Farrand, Cornell University's president at the time of Fuertes's tragic death, did not hesitate to schedule a memorial service for him in Willard Straight Hall on the university campus on October 30, 1927. When reminded that such action was without precedent in Cornell's history, Dr. Farrand simply replied, "There is no precedent for Louis Agassiz Fuertes." Indeed, there was none. Like Mozart, he arose from obscurity, exploded in a shower of unmatched talent, and disappeared all too soon, leaving the world not only to cherish his work but also to grieve and wonder what sort of elemental mix could ever have produced such a person.

It is true that Fuertes came from fine parental stock. His father was a professor of civil engineering (and later dean of the engineering college) at Cornell University, and his mother was noted for her outstanding musical talent. He had three brothers and two sisters, but none of these would ever attain the heights of fame that Louis eventually scaled. It is also true that his father had high hopes that Louis might become an outstanding architect or engineer, and when Louis entered Cornell in the fall of 1893 he enrolled as an architecture student. He had traveled in Europe with his parents the previous year, studying for a time in Switzerland, and began to exhibit the sort of drawing talent that an architect might need. However, as for Charles Darwin, the fathers' dreams were not to materialize. Louis was far more interested in studying nature directly than in pursuing academic studies.

It is perhaps unintentionally appropriate that his father had bestowed the name "Louis Agassiz" on his son in honor of the internationally famous geologist, whose primary maxim was "Study nature, not books." It is also perhaps apocryphal, but quite possibly true, that once during a class Louis escaped out a side window of the Cornell lecture hall in order to track down the identity of a bird he heard singing outside. Finally, his exasperated father sought the advice of Cornell's renowned botanist Liberty Hyde Bailey as to what he might possibly do about his wayward son. Bailey's simple and sage advice was "Let him go."

And did Louis go! Although his talents would certainly have become known eventually, he was fortunate enough to be discovered by none other than Elliott Coues, then president of the American Ornithologists' Union (AOU) and perhaps the greatest ornithologist that America has ever produced. Serendipitously, Coues was the uncle of a friend and fellow member of the Cornell glee club. The critical initial meeting of Fuertes and Coues occurred in 1894 when Louis was only a sophomore and during a trip of the glee club to Washington, DC. From their first meeting it was already apparent to Coues, who was known universally for his sharply critical tongue, and was feared as an implacable enemy of mediocrity in all forms, that Louis had an artistic talent of immense proportions. Coues urged Louis to consider becoming a professional bird artist (never mind that such a profession did not exist at that 
time-even John James Audubon had died in poverty). Thanks to Coues's professional influence, Fuertes was able to have his artwork exhibited at the 1895 annual meeting of the AOU. This group then had about 600 members nationwide, including all of America's best-known ornithologists, and its journal, the Auk, was already the primary scientific ornithological periodical in America. Furthermore, Coues invited Fuertes to illustrate a children's book, Citizen Bird, that Coues was then writing with Mabel Wright. Thus his painting career was launched.

Although Fuertes was not able to attend the 1895 meeting of the AOU, he did so the following year. There he fell under the strong and pervasive influence of Abbott $\mathrm{H}$. Thayer, who was already a nationally known nature artist. Thayer absorbed Fuertes as a sort of surrogate son, and he spent a great deal of time with the Thayer family at their homes in New York and New Hampshire. Thayer had undergone four years of artistic training in Paris and urged Fuertes to develop his already keen powers of observation to new levels. Thus, within only two years Fuertes suddenly had the advice of a highly talented and successful painter and of America's most competent and famous ornithologist. Additionally, Coues commissioned Fuertes to illustrate the fifth edition of Coues's forthcoming (in 1903) Key to North American Birds, a reference work that was destined to become the bible of American ornithology and which even today receives occasional use by professional ornithologists such as myself.

The artistic influence of Abbott Thayer was a powerful one, for it had become an overriding belief of Thayer that animals such as birds had evolved their distinctive colors and patterns primarily for protective (concealment) reasons rather than perhaps for achieving conspicuousness (advertisement) in their environment. Included among the means of achieving concealment are such devices as disruptive patterning (patterns such as bars, spots, or stripes that tend break up the body into many confusing or distracting forms) and background-matching colors (cryptic coloration).

Another optical adaptation for achieving camouflage is countershading (the tendency of most birds and mammals to have pale underparts and dark upperparts, thus counteracting the shading effects of the underparts caused by overhead light). This concealment argument obviously makes sense for some species, such as for many ground-dwelling or ground-nesting birds that might be vulnerable to visual predators. However, Thayer applied it in some extreme cases, such as trying to account for the pink coloration of flamingos and roseate spoonbills by suggesting that they would become virtually invisible at sunrise and sunset, when the general coloration of their surroundings is briefly pink to reddish.

Although some of Thayer's arguments, such as those regarding countershading, were compelling and eventually accepted by biologists, they thrust Fuertes into a nearly lifelong dilemma. He must not only try to satisfy the controversial artistic views of Thayer, who constantly urged Fuertes to hide the birds effectively within their background, he must also attempt to deal with the equally understandable views of virtually all publishers, who always urged him to make the birds more conspicuous and contrasting against their surroundings. Fuertes additionally had to cope with the economics of expensive color printing, which dictated that as many birds as possible must be crowded into a single plate, regardless of the possible straining of credulity that such crowding of subjects might produce. However, an inherent advantage of such grouping, as later exploited by field-guide artists, is the instructional potential for easy interspecies visual comparisons by people wishing to learn field identification traits. It is a testament to Fuertes's compositional ability that one might marvel at the multispecies plates in, for example, Birds of New York or Birds of Massachusetts and Other New England States without first thinking about the ecological or behavioral problems inherent in such groupings.

Evidently, Fuertes decided quite early that he would be primarily a painter of bird "portraits" rather than a painter of scenes in which birds might play an important role within a much broader landscape, in the manner of the great contemporary Swedish nature artist Bruno Liljefors. Thus, in a self-written 1910 article in the Amateur Sportsman, Fuertes described himself as "a bird portrait painter." In 1915 his friend Frank M. Chapman similarly described Fuertes 
as a "great portrait painter of birds."

In a 1937 obituary, Chapman described Fuertes's genius and compared his approach to art with that of John James Audubon, the other great historic figure in American bird art. Chapman believed that both men possessed an extreme love for birds, possessing "some rare and precious heritage" as well as a "loving sympathy" for birds. Both artists killed thousands of birds, either for preservation as scientific specimens or providing a factual basis for their artwork, yet both obviously and paradoxically loved their subjects intensely. In the words of Wilfred Osgood, Fuertes might sit with a freshly killed bird in hand, "stroking its feathers in detached ecstasy, and crooning over it in a manner that in another might have seemed ridiculous."

In his Abyssinian memoirs, Osgood also wrote (Fuertes \& Osgood, 1936) that Fuertes was uniquely able to "spread the charm and beauty of birds, not merely by accuracy of line and color, but in the expression of subtle intangible qualities approaching spirituality." Chapman (1937) similarly stated that whereas Audubon attempted to produce the visual effect of life by painting his subjects in motion (often inaccurately), Fuertes achieved his visual magic through "his ability to produce facial expressions which could be worn only by living birds."

Besides an intense appreciation for the appearance of a bird, Fuertes could thus consign to memory a bird's special qualities that gave it a unique character or "personality," and delay converting these impressions to paper for several hours after experiencing the scene or event. Frank Chapman commented that "his mind appears to be a delicately sensitized plate designed especially to catch and fix images of bird life" (Chapman, 1927).

I have personally known only one artist of similar visual retentive abilities. Paul Geraghty, a South African artist of rare talent, once visited me while I was doing fieldwork in Grand Teton National Park during the mid-1970s. Paul could spend an entire day in the field with only binoculars in hand, but that night would sit down with pencil and paper and draw dozens of scenes of birds and mammals with camera-like precision, sketching as fast as the graphite would flow from his pencil. Chapman believed that this photographic-like retention of form and color (and even recollection of complex bird songs) gave Fuertes a special capacity for achieving authenticity. It is unlikely that a knowledgeable ornithologist will fail to recognize a Fuertes painting even before seeing his distinctive L.A.F. initials or signature. Only the works of a few other more recent artists, such as George Miksch Sutton, can so readily carry the cachet of authenticity that is present in any Fuertes bird portrait.

Starting with a trip to Florida with the Thayer family in 1898, Fuertes soon participated in a series of field expeditions to observe and collect specimens in such remote places as Alaska, western Canada, Mexico, Colombia, and the American West. He even took time to go collecting on his honeymoon, and on one occasion had to be rescued from a steep cliff he had climbed down while trying to recover a zone-tailed hawk that he had shot. On such collecting expeditions he would hunt from sunrise until about noon. In the afternoon he would skin and prepare study specimens of the birds he had collected and then paint selected examples while it was still early enough to paint by natural light. In the evening he would enter his journal notes and catch up on correspondence.

Fuertes was especially careful to note fugitive "soft-part" features, such as eye color and colors of bare skin, bill, and even the inside of the mouth, or what the bird had been eating when shot. Pencil sketches, washes, and watercolors were variously used. Fuertes's ability to depict soft feathers with a brush are legendary and totally different from the "hard-edged" feathers of Audubon and his followers. Probably many of these field sketches were intended only as preliminary studies for future, more finished works, but they have an immediacy and visual power that is unmatched and are far superior to what would be expected as specimen sketches that might supplement a biologist's field notes.

\section{Fuertes's Artistic Legacy}

The artistic legacy left by Fuertes is both physically and symbolically monumental. Frank Chapman (1928) summarized Fuertes's list of "more 
important" published bird illustrations, which represent a lasting, substantive artistic legacy. A partial list of his published images was also provided by M. F. Boynton (1956). They total at least 400 monochrome illustrations (about half of which appeared in Coues's Key to North American Birds). At least 700 color plates of Fuertes's birds have been published, with the largest number (250) appearing in the National Geographic Society's The Book of Birds (1918) and a lesser number (106) in E. H. Eaton's Birds of New York (1910-14). There were also 68 plates in E. H. Forbush's three-volume Birds of Massachusetts and Other New England States (1925-29), which along with Birds of New York are often considered Fuertes's best representations of regional birds, given the limitations of sometimes crowding several species on a single plate. Nearly 50 years after Fuertes's death, a total of 35 color plates and 35 halftones appeared in The Bird Life of Texas by H. C. Oberholser (1974).

Hundreds of mammal paintings by Fuertes were also published in National Geographic and in several popular books, such as those in Wild Animals of North America (1918), The Burgess Animal Book for Children (1920), and The Book of Dogs: An Intimate Study of Man's Best Friend (1919). There are also probably hundreds of published illustrations of other wildlife and more general subjects, including landscapes and plant life. A selected list of books illustrated by Fuertes can be found in a section of this book's references.

Additionally, there have been many reproductions of his paintings in magazines and other popular media. More than 100 plates appeared in the National Audubon Society's Bird Lore magazine between 1903 and 1926. These latter plates typically appeared as frontispiece illustrations and collectively included most American passerines as well as later series on swifts, hummingbirds, woodpeckers, and herons.

Lastly, a series of 90 simple but charming paintings by Fuertes was printed by Church $\&$ Dwight and reproduced in color on small (2-by3-inch) cards between the 1920s and 1964 and were included free in boxes of Arm \& Hammer baking soda. These cards were avidly collected by children and introduced many of them (including me, at about eight years of age) to Fuertes and to many American bird species for the first time. A final set of ten cards showing hawks, owls, and the bald eagle were not distributed until 1976 as part of the nation's bicentennial celebrations, having been held back earlier because of widely held negative perceptions of predators. In addition, Fuertes completed many paintings of birds as privately commissioned works or simply used them as gifts.

In 1982 Robert Peck provided a summary of holdings of Fuertes's artwork and related materials in eight major institutional collections. Cornell University's Louis Agassiz Fuertes ornithological artwork database is a searchable database of 2,500 ornithological illustrations by Fuertes (see Internet Sources section of references) and also includes most of Fuertes's surviving papers. His overall output of published and unpublished paintings and drawings might easily exceed 3,000 images but no complete accounting exists.

Fuertes left a powerful and lasting mark on subsequent generations of American nature artists. Because he received extensive instruction in bird art directly from the master, George Miksch Sutton was perhaps the artist most directly influenced by Fuertes. The summer of 1916 that Sutton spent in the Fuertes household as a teenager transformed his art and shaped his life. Sutton went on to become the premier bird artist of America following the death of Fuertes, and especially his early work is sometimes so close in style to that of Fuertes that it is sometimes necessary to examine the artist's signature to be certain of its origin.

Sutton himself was a great teacher as well as an outstanding scientist, giving advice and encouragement to many talented artists. These have included Robert Verity Clem, whose shorebird paintings carry the authentic smell of tundra and marshland; the tragically short-lived Donald L. Malick, whose African field studies often bear an uncanny resemblance to those of Fuertes; and John P. O'Neill, who portrays the visual world of the American tropics like few others can. No bird artist alive is likely to be ignorant of Fuertes's work and probably most have gazed at his work in wonder, asking "How in the world did he do that?" 


\section{The Abyssinian Expedition}

It was during a 1925 trip to Wyoming that Fuertes encountered James E. Baum, a wealthy Chicago sportsman and big-game hunter who was also a writer with connections to the Chicago Daily News. The following spring Baum proposed making a hunting trip to Ethiopia (classically referred to as Abyssinia), a remote region in the great Rift Valley of northeastern Africa that was rich in wildlife but had few, if any, restrictions on the killing of game. Shortly after their exchange, Fuertes and Baum visited with Wilfred $\mathrm{H}$. Osgood, curator of mammals at Chicago's Field Museum of Natural History.

The three men prepared a proposal to have the museum underwrite a scientific collecting expedition to this little-visited and biologically unknown country. They also approached the Chicago Daily News for financial support and soon received word that the paper would pay $\$ 25,000$ to help finance the trip. It thus became known as the Field Museum/Chicago Daily News Abyssinian Expedition. It would be Fuertes's last but most productive expedition. He was 52 years old at the trip's outset in the fall of 1926, at the peak of his artistic powers.

The zoologists of the expedition included Fuertes, W. H. Osgood, and Alfred M. Bailey, a young ornithologist who had very recently been hired as a collector and curator by the Denver Museum of Natural History. He would later publish his field journal entries documenting the expedition (Bailey, 1926-27). J. E. Baum also joined the party, probably in part to participate in the hunting of the larger game animals, and later wrote of his experiences in a 1927 book titled Savage Abyssinia. The final member was C. Suydam Cutting, a wealthy museum patron and volunteer participant in the expedition, who made a $16 \mathrm{~mm}$ documentary film of its highlights.

After traveling to Europe, the expedition went by boat across the Mediterranean from France, through the Suez Canal, and arrived in Djibouti (then part of French Somaliland) in early October 1926. The group then went by train to Addis Ababa, capital of Ethiopia (the historic name Abyssinia was officially replaced by Ethiopia in the 4th century $\mathrm{AD}$ with the arrival of Orthodox Christianity).
After a few weeks of settling in at the Imperial Hotel of Addis Ababa, the group obtained an audience with Ras Tafari, who at that time was 34 years old and prince regent but later would become emperor and internationally known as Haile Selassie. He was highly receptive to and favorably impressed by the group and provided them all the documents they would need for travel and collecting throughout the entire country.

Before leaving Addis Ababa, Fuertes was devastated to learn that his personal gear, including clothing, field equipment, and all of his drawing and painting supplies had not arrived and was apparently lost en route. Fortunately, he was able to buy a small set of watercolors in Addis Ababa and evidently made do with such paper and brushes as were also locally available for his drawing and painting needs. Most of the paintings were done from freshly killed specimens on paper measuring approximately $11 \times 15$ inches $(28 \times 38 \mathrm{~cm})$, but some sketches are on sheets as small as $7 \times 9$ inches $(18 \times 23 \mathrm{~cm})$. A few formally composed and more scenic watercolors, such as the group studies of colobus monkeys, whiteeared turacos, and mountain nyalas, were done on larger sheets approximately $14 \times 18$ inches $(35 \times 46 \mathrm{~cm})$. These are all undated and were probably all executed or completed after his return to the United States.

By the latter part of October, before setting out on their main expedition, Fuertes and "Bill" Bailey had each collected and prepared more than 80 specimens in less than a week's time while staying eight days (October 18-26) at a ranch north of Addis Ababa, in Shoa (Shewa) Province. On October 21, Fuertes painted the first of his bird studies, of an African harrier-hawk, and a day later painted a thick-billed raven. These and the remaining watercolor studies were all done in natural size, and thus most of the larger species were simply head and shoulder portraits, often with small whole-animal images in the background. Fuertes also began a large series of variably detailed graphite sketches while at the ranch.

On October 30 the five Americans reassembled and began to get the caravan assembled. They departed from Addis Ababa on November 2 with nearly 50 mules and 2 horses, and 35 hired men, including about 15 muleteers, 5 guards, 5 
personal "tent boys," 2 interpreters, and 2 head packers. The group headed south into what were then Arusi (Arsi), Bale, and Sidamo provinces. There they interacted with the indigenous Galla (Oromo) people, a nomadic and pastoral culture and the current majority population of Ethiopia.

By this time they had entered the East African Rift Valley, a 1,700-mile, north-south crease in Africa's continental crust that extends from Mozambique north to the Red Sea and marks a time about 22 million to 25 million years ago when the two-billion-year-old African tectonic plate split and the two sections began to diverge (Pavitt, 2001). Today the bottom of the East African Rift Valley is marked by savanna grasslands and dozens of alkaline and freshwater lakes that extend from Malawi to Ethiopia. In Ethiopia the alkaline or "soda" rift lakes include Abiata, Awasa, Chamo, Lagano, and Shalla; its larger freshwater lakes are Awasa and Ziway. At altitudes averaging about 5,000 feet, these lakes are bounded on both sides by high volcanic peaks, producing a wide range of wetland to alpine habitats. The volcanic peaks associated with the overall East African Rift Valley complex include Mount Kenya, the highest of all of Africa's mountains, which exceeds 17,000 feet $(5,200 \mathrm{~m})$.

In Ethiopia the rift extends from the north end of Lake Turkana (= Lake Rudolf) at the KenyaUganda border north through the Afar Depression along the Eritrean border and on into the Red Sea. This rift region of Ethiopia and Kenya is where the earliest humanlike primates (Australopithecus afarensis) made their homes more than two million years ago (Leakey, 1981). The mountains bordering the Ethiopian rift (the Ethiopian Highlands) form the highest continuous region of highlands in all of Africa, reaching a maximum elevation of 14,938 feet $(4,550 \mathrm{~m})$.

After nearly three months of exploring and collecting specimens along the Rift Valley's lakes and adjacent mountain slopes, the expedition returned to Addis Ababa, arriving there on January 21, 1927. By then Fuertes had preserved 559 bird skins that he had obtained during more than 40 field camps and had already painted nearly 40 field portraits of birds and mammals. He had also produced about 20 pencil drawings and sketches.

During their second month-long stay in Addis
Ababa, the expeditioners again visited Ras Tafari. Fuertes offered Regent Tafari his choice of a finished painting, to be based on one of Fuertes's field studies. Tafari chose Fuertes's portrait of the Narina trogon. On his 53rd birthday, February 7 , Fuertes was still in Addis Ababa, packing trunks for shipment to Khartoum and eager to get back in the field. The group left two days later.

Again leaving Addis Ababa, the party headed north toward Gojjam Province, another volcanic mountainous region bordering the Ethiopian Highlands, and into the valley of the Blue Nile. From there they headed west past Lake Tana, the largest lake in Ethiopia and the source of the Blue Nile. Meantime, Bailey, Baum, and Cutting made a side trip into the Simien Mountains in search of other elusive targets, including Simien wolves and possibly lions. During this final phase, Fuertes completed about 30 more watercolors and at least a dozen pencil sketches. One of the last birds Fuertes collected and painted was the African scissor-tailed kite. It was obtained on April 15 near the Sudan border (Bailey, 1977).

By the time the group finally crossed into Sudan to begin their long trip home, the expedition had traveled more than 2,000 miles, mostly by mule-train safari over largely unmapped and often challenging terrain, and made nearly 200 camps. They had encountered malaria-carrying mosquitoes, tormenting "face-flies" that incessantly tried to land on their faces and other exposed skin, weather conditions that varied from hot and sunny to freezing rain, and altitudes ranging from less than 5,000 feet along the Rift Valley lakes up to 11,200 feet on Mt. Albassa. They also encountered such diverse obstacles as various illnesses among the men and animals, armed gangs who threatened them, and nefarious customs officials who tried to extort money from them. All the horses and many of the mules either succumbed or had to be replaced during the expedition. Potentially the most serious incident occurred when Fuertes was "pricked" by the fangs of a six-foot mamba, the most venomous snake in Africa, that he had shot and picked up thinking it was already dead. Luckily he escaped serious effects, and indeed, evidently no life-threatening accidents or fatalities occurred 
among the native employees during the entire expedition.

The very last Ethiopian subject for Fuertes's brush was a four-banded sandgrouse, obtained on April 17. The group then crossed the SudanEthiopia border and arrived in Khartoum on April 24. They then began to pack and prepare for shipment 22 cases of their accumulated specimens, including some 2,000 birds and about 1,400 mammals. From Khartoum they headed down the Nile to Cairo and Alexandria, and then on to Europe, where Fuertes was reunited with his wife and daughter in London on May 12, 1927 (Mary Boynton, pers. comm.).

On his return to Ithaca, Fuertes had nearly a year's worth of work to catch up on, but he could not resist showing the plates to friends and colleagues. During a chance encounter with a young acquaintance, Henry Guerlac, Fuertes called him over, and the two sat down on a sidewalk in Ithaca, feet in the gutter, and "gloated over" the illustrations, oblivious to both oncoming traffic and pedestrians (Marcham, 1971). In a letter written to George Miksch Sutton on June 26, 1927, he excitedly reported, "We had a marvelous trip in Abyssinia, and among other things I got far the best lot of field studies I ever did on one trip; a hundred color studies and a lot of drawings" (Sutton, 1979).

During the nearly 180 days between the day that Fuertes painted his first African bird (October 21, 1926) until his last (April 1, 1927), he had produced more than 100 major bird and mammal images and about a dozen minor sketches and watercolors. According to Fuertes's own numbering system, the total number of sheets of paintings and drawings he executed in Ethiopia was 110. A few of these sheets illustrate more than one species, such as the lapwings (sheet no. 48) and raptors (sheet no. 78).

During my brief overview and inventory of the collection, I encountered 62 watercolors illustrating 55 bird species and 15 graphite drawings of 11 bird species. There were also 7 watercolors and 10 graphite studies of 11 mammalian species. Additionally, there were 9 small graphite sketches of mammals, 4 watercolors of unidentified plants, and 1 watercolor of an unidentified insect, probably of the hemipteran family
Pentatomidae (see lists in Appendixes 1-3). A few items from the Abyssinian expedition are in Cornell University's collection of Fuertes's materials: a watercolor $(11 \times 15$ inches $)$ of two white-eared turacos dated August 14, 1927, only eight days before his death, is in Cornell's Lab of Ornithology and a pencil sketch of a black-bellied bustard is in the Cornell archives.

Three of Fuertes's most elaborate compositions-colobus, mountain nyala, and whitecheeked plantain-eater-were not included in his 110 numbered images and might have been completed after Fuertes returned to the States. If so, these three works were probably among his very last paintings, as he no doubt had many more immediate obligations needing attention after about eight months of absence. These responsibilities probably included plans for publishing a joint compellation of his and W. H. Osgood's expedition field journals that, however, were not published until nearly ten years later (Fuertes \& Osgood, 1936).

Fuertes's amazingly lifelike Abyssinian watercolors are generally accepted as marking an apex in his artistic virtuosity and are made all the more remarkable from the fact they were produced while sitting under an open tent amid variable weather conditions, following a full day of hunting and preparing specimens, and using brushes, pigments and art paper that had been obtained as last-minute substitutes for his personal art supplies. The well-known American ornithologist Frank Chapman (1928) described Fuertes's Abyssinian studies as "incomparably the best he ever made in the field." Chapman saw them during an August visit that Fuertes and his wife had made to their home in Tannersville, New York, during which Fuertes had told them of the expedition and had shown them his entire collection of artwork.

Tragically, while on their return trip to Ithaca on August 22, 1927, Louis Fuertes died near Unadilla, New York. At a rural railroad crossing, the view of which had been obscured by a load of hay, a train struck the car in which he and his wife Margaret were traveling, killing Louis. Margaret was also thrown out of their car by the train's impact and was seriously hurt. Incredibly, the packet of paintings was also thrown free of 
the demolished car but remained intact and later was returned to Mrs. Fuertes.

The entire collection of Fuertes's Abyssinian field studies was later purchased from Mrs. Fuertes by C. Suydam Cutting, patron of the Field Museum and a participant in the expedition; in due course these were presented to the Field Museum. Mr. Cutting later undertook the cost of reproducing 32 of the watercolors, including 28 bird subjects and 4 mammals, which comprised nearly a third of the total set of expedition paintings done by Fuertes. They were published (FMNH, 1930) as $8 \times 10$ inch color images with gray margins, printed on $10 \times 12$ inch sheets of very heavy (ca. 10-point) white paper. Up to nine photo-offset lithographed colors were employed, and the set was housed in an associated cardboard slipcase. A text insert by Winfred Hudson Osgood offered some introductory comments about the expedition and described the challenging environmental conditions under which Fuertes had executed his artwork.

In 1936, 16 of these 32 plates (14 birds, 2 mammals) were included in a book that represented the combined journal notes of Fuertes and Osgood (Fuertes \& Osgood, 1936). These plates were reproduced at a slightly smaller size (7.5 $\times 9.5$ inches) than those in the album, and had much narrower borders. Both publications have since become sought-after collector's items.

Some of Fuertes's Abyssinian studies have been reproduced more recently, most notably in the biography of Fuertes by F. G. Marcham (1971), which included portraits of 12 birds and 2 mammals. A biography by R. M. Peck (1982) included ten color and eight halftone reproductions of Abyssinian birds, and a book of Fuertes's watercolors by F. Roux (1996) included 18 color plates from the Abyssinian collection.

The Ethiopian environment has changed greatly over the 90-plus years that have passed since the mid-1920s expedition, and, like most African countries, its human population has exploded and its natural resources, such as its pristine montane forests and grasslands that Fuertes and
Osgood described, have been increasingly eliminated. Compared to the essentially frontier town that Fuertes and Osgood witnessed, Addis Ababa had a population of about 4 million people by 2019 and was growing at a rate of about 4 percent annually. The Ethiopian human population reached about 113 million by 2018 and has been increasing at an annual rate of slightly more than 3 percent, so that by 2050 it is likely to reach 188 million.

Ethiopia is currently (2019) the second most populous county in Africa after Nigeria and the fourteenth most populous country in the world. It is not only one of the most rapidly growing countries in the world but also one of the world's poorest, with the lowest incomes per capita. Access to clean water and sanitation are major national threats to health; AIDS, tuberculosis, and malaria are the primary diseases. The majority of the population is less than 25 years of age, and the median age is 18 years; less than half of Ethiopia's mid-teenagers are literate.

In 2000 Ethiopia was the world's third poorest country and had the highest poverty rate (more than 50 percent) of any country in the world. Ethiopia's economy has improved slightly since 2000, although recent droughts in the Horn of Africa and the Sahel have produced periods of starvation and ensuing population influxes (mostly from Sudan, Eritrea, and Somalia) that are a recurrent threat to Ethiopia, the African continent, and the world.

Because of associated environmental changes, within a few decades Ethiopia is likely to lose the Simien wolf, the mountain nyala, and two or more raptors to extinction, without even shedding a tear, as both the African and the entire world human population might by then be at risk through global climate changes and uncontrolled human growth rates.

What happens in Ethiopia does not stay in Ethiopia. We are all an inextricable part of the world's increasingly unstable ecosystem, and we ignore what happens in Africa at our collective peril. 


\section{Bird Paintings and Drawings}

\section{Family Podicipedidae (Grebes)}

\section{Little Grebe Tachybaptus ruficollis}

The little grebe, or "dabchick," is a small, inconspicuous water bird more closely associated with sleepy African backwaters and stagnant lagoons bordered by or overgrown with emergent vegetation than open lakes. It bears strong similarities to the least grebe (Tachybaptus dominicus) of North America, but its pointed bill has a distinctive yellowish green to whitish base. Like other small grebes, it is more often seen than heard, and it has a distinctive high-pitched whinnying trill that is uttered during courtship. Its Latin name, which translates as a "rapid-diving rufous-necked bird," is highly appropriate. Like all grebes, it can quickly submerge from sight and is able to remain under water for several minutes, if necessary.

The little grebe's food mostly consists of animal materials, especially invertebrates such as crustaceans and mollusks, and also small aquatic vertebrates, mainly fish and amphibians, which are captured while swimming among underwater plants. Like the North American pied-billed grebe (Podilymbus podiceps), the courtship displays of the little grebe are not nearly so conspicuous and elaborate as in the larger grebes. They largely consist of mutual interactions, such as swimming side by side, often while holding plant materials in their bills, and facing one another while paddling rapidly and uttering trilled notes, or pattering noisily over the water surface.
Nesting is done on semifloating platforms of aquatic plants, the eggs scarcely raised above the water surface, so the female can enter or leave the nest with little effort. Clutch sizes range from about four to six eggs, and incubation duties are shared by the pair. Incubation lasts 20 to 21 days. As in most grebes, the young chicks, usually numbering three or four, are charmingly patterned with stripes and spots, but unlike most grebe species, the chicks lack bare areas of skin on the crown. In common with other grebe chicks, they often ride about on the backs of their parents and might remain closely associated with them for a considerable period after fledging. The little grebe's fledging period has been estimated at 44 to 48 days, but grebes only rarely fly except during migration, which typically occurs at night.

This species is widespread across Africa, Europe, and the rest of Eurasia east to Japan, with an estimated world population of 610,000 to $3,500,000$ individuals. It was considered to be a species of "least concern" by the International Union for Conservation of Nature in 2016. Most eBird reports from Ethiopia indicate it extends from northernmost to southernmost Ethiopia and has been most often observed in the Rift Valley from Addis Ababa south.

Suggested reading: Brown, Urban \& Newman, 1982; Chapin, 1932; Cramp \& Simmons, 1977; Del Hoyo, Elliott \& Sargatal, 1992; Newman, 1971. 


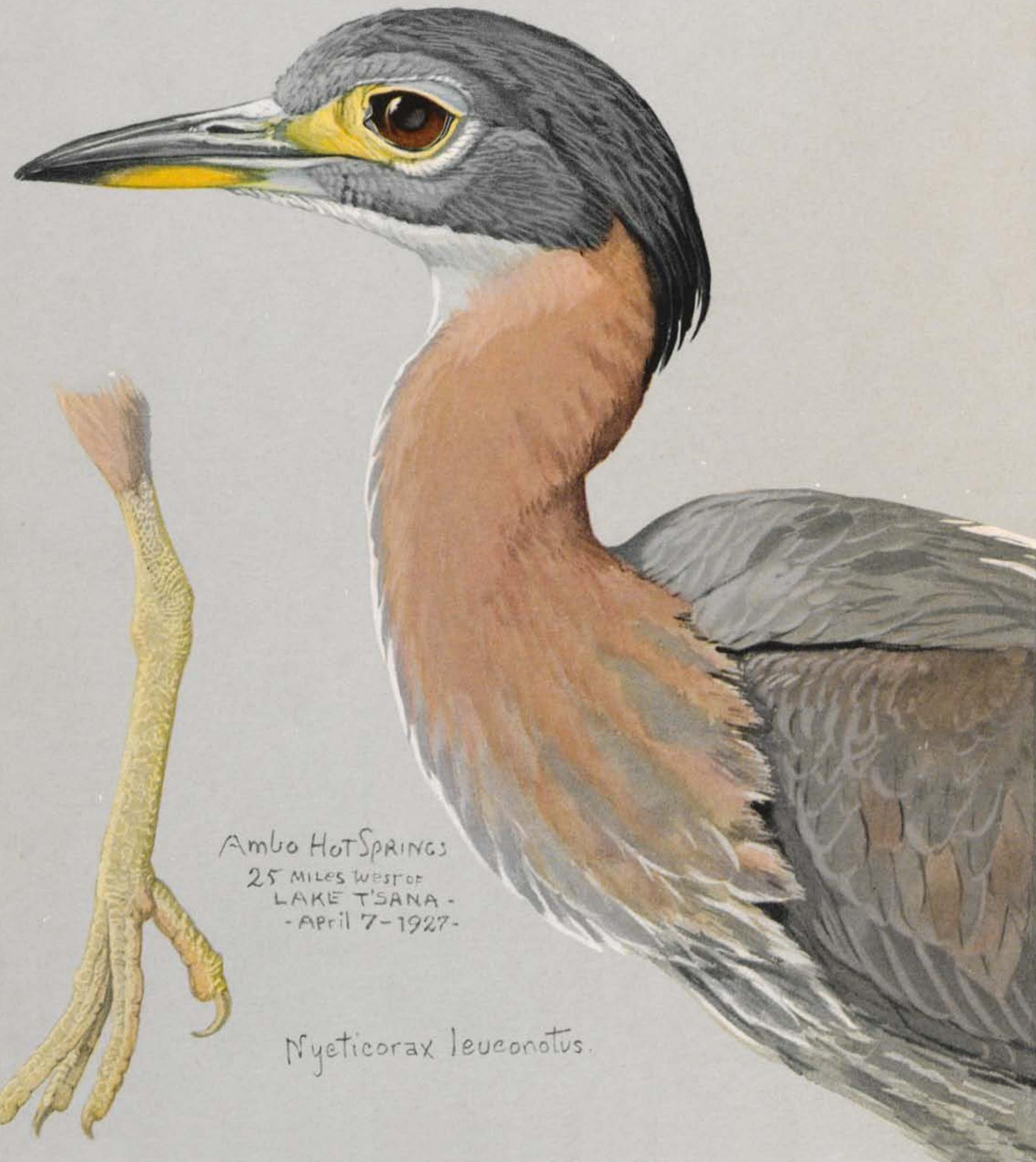




\section{Family Ardeidae (Herons and Bitterns)}

\section{White-backed Night Heron Gorsachius leuconotus}

The white-backed night heron's Latin species name and English name are both based on an inconspicuous patch of white feathers on the bird's upper back. The sexes are identically plumaged as adults, with no seasonal changes, although seasonal variations reportedly occur in eye color. Immatures are rather extensively spotted with white on their back and wing feathers. Perhaps its most obvious feature is the enormous size of the eyes, which are emphasized by whitefeathered "spectacles" and bright greenish yellow skin between the red eyes and the bill.

The large size of this heron's eyes is doubtless related to the seminocturnal foraging behavior of this and other species of night herons. The birds then feed on amphibians, small fish, and such invertebrates as mollusks and aquatic insects. During daytime hours they hide in dense forests with associated marshy waterways. Unlike the extremely widespread and less nocturnal blackcrowned night heron (Nycticorax nycticorax), this is a distinctly solitary species.

Like other nocturnal herons, these birds are fairly vocal, with loud growling or croaking calls. Also, as with most other herons, their nests are rather bulky constructions, built of sticks on reeds or branches, or more rarely placed on the ground or on a large rock. At times the location might even be on a tree branch overhanging water, often only a few feet above the water surface.

Typically two or three pale greenish blue eggs are laid, probably at intervals of about two days, late in the rainy season or early dry season. Like other herons, incubation begins with the laying of the first or second egg, so the young hatch at staggered intervals, in the same sequence that the eggs were deposited. Incubation lasts 23 to 26 days, the task apparently being shared by both sexes, and is followed by a fledging period of 40 to 41 days. Probably the birds reach maturity by the end of their first year.

This species is widespread across sub-Saharan
Africa and is considered to be a species of least concern by the International Union for Conservation of Nature. The few available eBird reports for this species from Ethiopia are widely scattered.

Suggested reading: Brown, Urban \& Newman, 1982; Del Hoyo, Elliott \& Sargatal, 1992; Hancock \& Elliott, 1978; Newman, 1971.

\section{Black-headed Heron Ardea melanocephala}

The stunningly beautiful black-headed heron not only has a black head and hindneck but the rest of its body is also dark gray to sooty black, except for some pale gray to white on the upper wing coverts, white on the foreneck and chin, and usually a white stripe that extends from the back of the eye above it and around the forehead. The sexes are alike. Young birds are more extensively white on their underparts and are generally paler dorsally. It is slightly smaller than the North American great blue heron (Ardea herodias), and has a somewhat similar elongated black crest and shaggy lower breast feathers.

The species consumes a wide array of animal materials, from fishes, frogs, and crustaceans in water to lizards, rodents, birds, and large insects on land, where it most often forages. The lizards and birds must be stalked cautiously; birds as large as doves are sometimes captured. Occasionally this heron also scavenges for offal or carrion. Probably it has benefited from the ecological changes occurring recently in Africa, as it readily tolerates humans and often exploits agricultural areas.

Like most herons, this species roosts and nests colonially, mostly breeding during the rainy season. Their bulky stick nests are often located in trees but might also be placed in papyrus thickets or on reedy islands. Occasionally these birds even nest within cities. In common with many herons, males arrive on nesting areas first and claim territories, either old nests or potential nest sites. When females arrive they choose mates, after which the males begin to gather nesting materials while the females perform the actual nest construction. 
Copulation occurs on the nest platform of sticks, and usually the nest is part of a breeding colony. From two to four (rarely five or six) pale bluish eggs are laid at intervals of about two days. Incubation lasts 25 days and begins with the first egg, so in a large clutch about two weeks might separate the hatching times of the youngest and oldest chicks. Only rarely do all the young of large clutches survive, however; the older chicks dominate the young ones whenever food is presented, often leaving the weaker ones to starve. The fledging period is probably similar to that of the great blue heron, namely about 60 days, but the young birds might remain in the nest for as long as about 90 days.

This species is widespread across sub-Saharan Africa and is considered to be a species of least concern by the International Union for Conservation of Nature. The numerous eBird reports from Ethiopia for this species are widespread from the northernmost to southernmost parts of the country and west to the South Sudan border.

Suggested reading: Brown, Urban \& Newman, 1982; Chapin, 1932; Del Hoyo, Elliott \& Sargatal, 1992; Hancock \& Elliott, 1978; North, 1963.

\section{Family Ciconidae (Storks)}

\section{Saddle-billed Stork Ephippiorhynchus senegalensis}

The saddle-billed stork has a unique black-andwhite overall plumage pattern and an extraordinarily long beak that is banded with black and red. A bright yellow "saddle" perches on the beak's top in front of the bird's forehead. Although both sexes are identical in plumage, adult females differ from males in having yellow rather than dark brown eyes. A red patch of bare skin on the breast darkens during the breeding season. Young birds of both sexes are duller in color than adults and require three years to attain their mature plumage and brilliant bill coloration.

One cannot help but wonder at the size and function of the massive bill of this wonderful stork; its cumbersome generic name is appropriate and translates as the saddle-billed bird from Senegal. It is one of the tallest of all storks; males stand up to 59 inches $(150 \mathrm{~cm})$ in height, weigh up to 16.6 pounds $(7.5 \mathrm{~kg})$, and have wingspreads up to 6.9 feet $(2 \mathrm{~m})$. It is substantially larger than the North American great blue heron (Ardea herodias), and is a much more terrestrial species, sometimes occurring far from water.

This species' long and colorful bill is almost as robust as that of the carrion-eating and grotesque marabou stork (Leptoptilus crumeniferus), and it likewise sometimes scavenges dead fish that have been regurgitated by cormorants. However, it often forages in shallow water, stabbing or grabbing almost any available prey. These include fish, frogs, crabs, shrimp, and even large aquatic insects such as beetles, evidently at times finding them by tactile rather than visual means. It also stalks and captures prey on land, including lizards, small birds, and rodents.

Adults seem to be completely mute but do perform typical stork-like bill-clattering at the nest; perhaps the colorful and spectacular bill compensates for the species' deficiencies in vocal communication. In contrast to herons and some storks, breeding occurs solitarily, with the birds maintaining permanent pair bonds. What little is known of their pair-forming display indicates that it is virtually nonexistent beyond the usual stork bill-clattering; storks lack the syringeal structures needed to vocalize.

The saddle-bill's nest is a surprisingly bulky structure and is usually built near the top of a tree from branches, vegetation, and earthen components. Like the similar large nests of hawks and eagles, the nest of a pair might be used in successive years. Also like raptors, males closely attend the nest and might incubate during much of the day, at night, or when the female is away foraging. The clutch size is two to three eggs with a 30- to 35-day incubation period and a very long fledging period of 70 to 100 days.

This species is widespread across sub-Saharan Africa and is considered to be a species of least concern by the International Union for Conservation of Nature. The numerous eBird reports for this species from Ethiopia are mostly from the central Rift Valley region. 
Suggested reading: Brown, Urban \& Newman, 1982; Del Hoyo, Elliott \& Sargatal, 1992; Hancock, Kushian \& Kahl, 1992; Kahl, 1973; Newman, 1971.

\section{Family Threskiornithidae (Ibises and Spoonbills)}

\section{Wattled Ibis Bostrychia carunculata}

This strange-looking ibis is endemic to Ethiopia's highlands and as such is one of this country's few endemic bird species, although its range spills over slightly into Eritrea. It occurs mostly in riverine areas lined by rocky cliffs but also extends to open country, marshlands, and developed areas, and sometimes even into villages or cities. Its Latin generic name refers to the species' hairlike crest rather than to the distinctive but inconspicuous wattles that hang from the throat of adults. The sexes are identical in plumage as adults, and both possess wattles, which have no apparent function except as probable speciesspecific social signals. Immatures lack wattles and are generally duller, lacking the white shoulder markings that contrast with the otherwise blackish plumage of adults. The species' closest relative is the very similar hadada ibis (Bostrychia hagedash), which lacks wattles and has a white cheek stripe.

Wattled ibis are terrestrial foragers, sometimes feeding socially, and typically walking slowly about, carefully examining and probing the ground, for insect larvae, dung beetles, and other insects. Occasionally small or baby mice are eaten, as well as frogs, but little or no foraging is done in water. Like other ibises, the birds are highly vocal, uttering a great array of shrieks and crowing calls, especially when alarmed. Choruses produced by flocks can be heard for up to two miles or more.

Nesting colonies of up to 500 or more birds occur in the Bale Mountains, where they have been reported on alpine moorlands at elevations up to about 14,000 feet $(4,250 \mathrm{~m})$. Their nest sites typically are rocky ledges, rocky cliffs, the tops of bushes, and in trees such as junipers and ol- ives, but they sometimes include even the ledges of city buildings. The nest is a platformlike structure of sticks and branches. Two or three whitish eggs constitute the clutch, which is laid from March to July. In related species incubation requires 25 to 30 days, which is followed by a fledging period of about 30 to 35 days. The juveniles only gradually leave the nest and its immediate vicinity, and are fed by their parents for some time after their actual fledging.

This species is endemic to Ethiopia, with an estimated population of 1,000 to 25,000 individuals. It is considered to be a species of least concern by the International Union for Conservation of Nature. The numerous eBird reports for this species from Ethiopia are widespread from the northernmost to southernmost parts of the country and west almost to the South Sudan border.

Suggested reading: Brown, Urban \& Newman, 1982; Del Hoyo, Elliott \& Sargatal, 1992; Hancock, Kushian \& Kahl, 1992.

\section{Sacred Ibis \\ Threskiornis a. aethiopica}

Adult sacred ibises lack sexual dimorphism; the head and neck are covered in black skin, and the lengthened back feathers (scapulars and elongated inner secondaries) of resting birds are also entirely black, the two body regions separated widely by white feathers. During the breeding season (March to May in Ethiopia) the birds exhibit ornamental iridescent plumes on their scapulars and innermost secondaries. There are also areas of blood-red skin visible on the wings and adjoining flanks. Immatures have feathered rather than bare black heads and necks. The species' wings are mostly white, but the flight feathers are tipped with black, which produces a distinctive contrasting color pattern in flight. The birds often fly in a gooselike $\mathrm{V}$-formation with outstretched rather than retracted necks, thus differing from herons. Unlike the highly vocal hadada ibis, this species is relatively silent.

These birds are quite social and nest in colonies of up to several thousand birds, their nests being placed in trees, bushes, or in safe locations 
on the ground. Pair-bonds are evidently renewed annually, with the males establishing pairing territories and trying to attract females by various postures and calls. These postures include erecting the males' ornamental back plumes while standing with the bill raised, a partial spreading of the wings and resultant exposure of the wings' bright red skin, and various threats or overt attacks on competing males.

Once pairing and copulation have occurred, the male begins to gather sticks and branches as nesting materials, which the female assembles into a nest. Often nests are very close together but only rarely in contact. From one to five eggs are laid, with incubation typically starting when the clutch is complete. Incubation is performed by both sexes, and lasts 21 to 29 days. The newly hatched chicks are downy and rather gooselike in appearance, but unlike goslings, they remain in the nest for two to three weeks, after which the young begin to leave their nests and gather in flightless groups. Both parents tend the young and feed them by regurgitation, even after the chicks have been merged into these crèchelike groups. Fledging occurs at 35-40 days, and sexual maturity is attained one to five years after hatching.

The Latin name of this species means "sacred bird from Ethiopia," Ethiopia being the European classical name for Africa. Specifically, the Egyptians regarded this ibis as a sacred embodiment of the god Toth, god of wisdom and scribe to the gods, and an ibis outline was used as a hieroglyphic symbol of a scribe. The Egyptians often mummified these birds' carcasses as votive offerings and buried them in mass graves. Collections of thousands of such mummies have been found in areas near historic breeding sites.

This species is widespread across sub-Saharan Africa, with an estimated population of 200,000 to 450,000 individuals. It is considered to be a species of least concern by the International Union for Conservation of Nature. The numerous eBird reports for this species from Ethiopia are widespread from northernmost to southernmost parts of the country, and west to the South Sudan and Sudan borders.

Suggested reading: Brown, Urban \& Newman, 1982; Chapin, 1932; Cramp \& Simmons, 1977;
Del Hoyo, Elliott \& Sargatal, 1992; Hancock, Kushian \& Kahl, 1992.

\section{Family Phoenicopteridae (Flamingoes)}

\section{Greater Flamingo \\ Phoenicopterus ruber roseus}

Most people have seen flamingos in zoos, but it is quite another experience to see flocks of thousands of them in the wild as, for example, at Lake Nakuro in Kenya, where much of the lake's surface might at times seem to be mostly pink. The kaleidoscopelike scene of flying birds overhead, mixed with white pelicans (Pelecanus onocrotalus), is dizzying. In eastern and northeastern Africa the greater flamingo is largely confined to the great Rift Valley lakes, especially those that are variously alkaline or brackish.

Alkaline water conditions favor the growth of brine shrimp and other small crustaceans that the birds depend upon for food and from which they obtain the carotenoids that are the basis for their red to pink coloration. The species' uropygial gland at the base of the tail also secretes carotenoids that, through preening, help to enhance the plumage color intensity. The generic name of the greater flamingo means "crimsonwinged," and both its specific and racial names refer to this color feature. It is the largest of the world's six flamingo species; adults range up to 59 inches $(80 \mathrm{~cm})$ in standing height, and males weigh up to 9.9 pounds $(4.5 \mathrm{~kg})$.

Like geese, flamingos are highly gregarious, and also in common with geese they have webbed toes, loud voices, and downy young. Yet these are only superficial similarities, and most recent evidence indicates that the two groups are not closely related. Instead, along with grebes, they are part of a large and surprisingly diverse group of phylogenetically related birds that also include the doves and sandgrouse.

Like all flamingos (and a few ducks such as shovelers), greater flamingos are filter-feeders. Their sievelike bills and muscular tongues make effective hydraulic pumps, pushing water through the sides of the bill while extracting the larger 
food particles. This process works best in shallow water, where the birds can wade and remain in place or move slowly about, stirring up the mud and sometimes swinging their bill from side to side in a scythelike fashion, gathering the food that is available immediately around it.

Flamingo reproductive displays are totally different from those of geese and swans, although both groups form strong monogamous pairbonds, with equal participation in parental responsibilities. Many of the apparent pair-bonding displays of flamingos involve highly rigid and stereotyped postures, such as neck-stretching, bowing, wing extending, and preening movements that bring to mind the highly stereotyped and synchronized pair-bonding displays of albatrosses.

Nesting occurs colonially; the birds fashion cone-shaped mud piles on coastal lagoons and mudflats, or rarely on rocks. A single white egg is laid, which is incubated by both sexes alternately for 28 to 32 days. The gosling-like young are raised in crèches, and fledging typically occurs at 65 to 90 days of age. The definitive adult plumage is reached at thee years of age, and sexual maturity probably occurs at 4 to 6 years. In an Australian zoo one individual lived to an incredible 83 years of age, a remarkable example of longevity for any bird!

The greater flamingo is considered to be a species of least concern by the International Union for Conservation of Nature. Its world population was recently estimated at 89,900 to 125,000 mature individuals and is believed to be increasing. The species has a disjunctive distribution across Africa, with many other isolated populations extending from Spain east to India and central Asia. Most eBird reports from Ethiopia indicate it is largely limited to alkaline Rift Valley lakes south of Addis Ababa. Not all of the alkaline lakes are known to harbor flamingos, but Abiata Lake supports both greater and lesser flamingos (Phoeniconaias minor).

Suggested reading: Brown, L. H., 1958, 1972; Brown, Urban \& Newman, 1982; Chapin, 1932; Cramp \& Simmons, 1977; Del Hoyo, Elliott \& Sargatal, 1992; Johnson \& Cézilly, 1975; Ogilvie \& Ogilvie, 1986.

\section{Family Anatidae (Swans, Geese, and Ducks)}

\section{Spur-winged Goose Plectropterus g. gambensis}

This strange-looking gooselike species evokes a sense of the primitive about it; its black-andwhite plumage and robust bill structure strongly resemble those of the magpie goose (Anseranas semipalmata) of Australia, and it once was classified with that highly archaic species. It more closely approximates such perching ducks as the comb duck (Sarkidiornis melanotis) and sheldgeese (Tadornini) in its anatomy and behavior, but some recent research has suggested it might be placed in a unique (monotypic) subfamily.

This species is highly terrestrial and formidable, with a sharp, bony spur on each of the goose's wrists that serve as deadly weapons. A captive pair I often watched while studying waterfowl behavior in England had a territory centered on a tall hill or "tump," from which the male kept a sharp lookout for intruders. Should any other large waterfowl species, up to the size of a swan, be foolish enough to climb the hill it would be fiercely attacked, sometimes fatally. Males occasionally weigh up to 15 pounds $(6.8 \mathrm{~kg})$ and rarely as much as 22 pounds ( $10 \mathrm{~kg}$ ), but females are only about 60 percent of the male's weight. They also lack the male's bare red facial patch and have smaller wrist spurs than adult males.

These birds are widespread in Africa and extend from Egypt, Ethiopia, and Sudan to South Africa. Their foods are diverse, but in some regions (such as the Gambia) they reportedly consume blister beetles (Meloidae), the poison of which (cantharidin) is sequestered in the bird's tissues, making it poisonous too. Spur-winged geese breed solitarily but are gregarious during the molting season after breeding, when, like most waterfowl, they become temporarily flightless. Their voice is weak compared to those of the true geese, and their pair-forming behavior seems to be rudimentary.

The social behavior of spur-winged geese appears to be closest to that of some of the more aberrant and seemingly primitive perching ducks (Cairina, Sarkidiornis) (Johnsgard, 1978), and the 


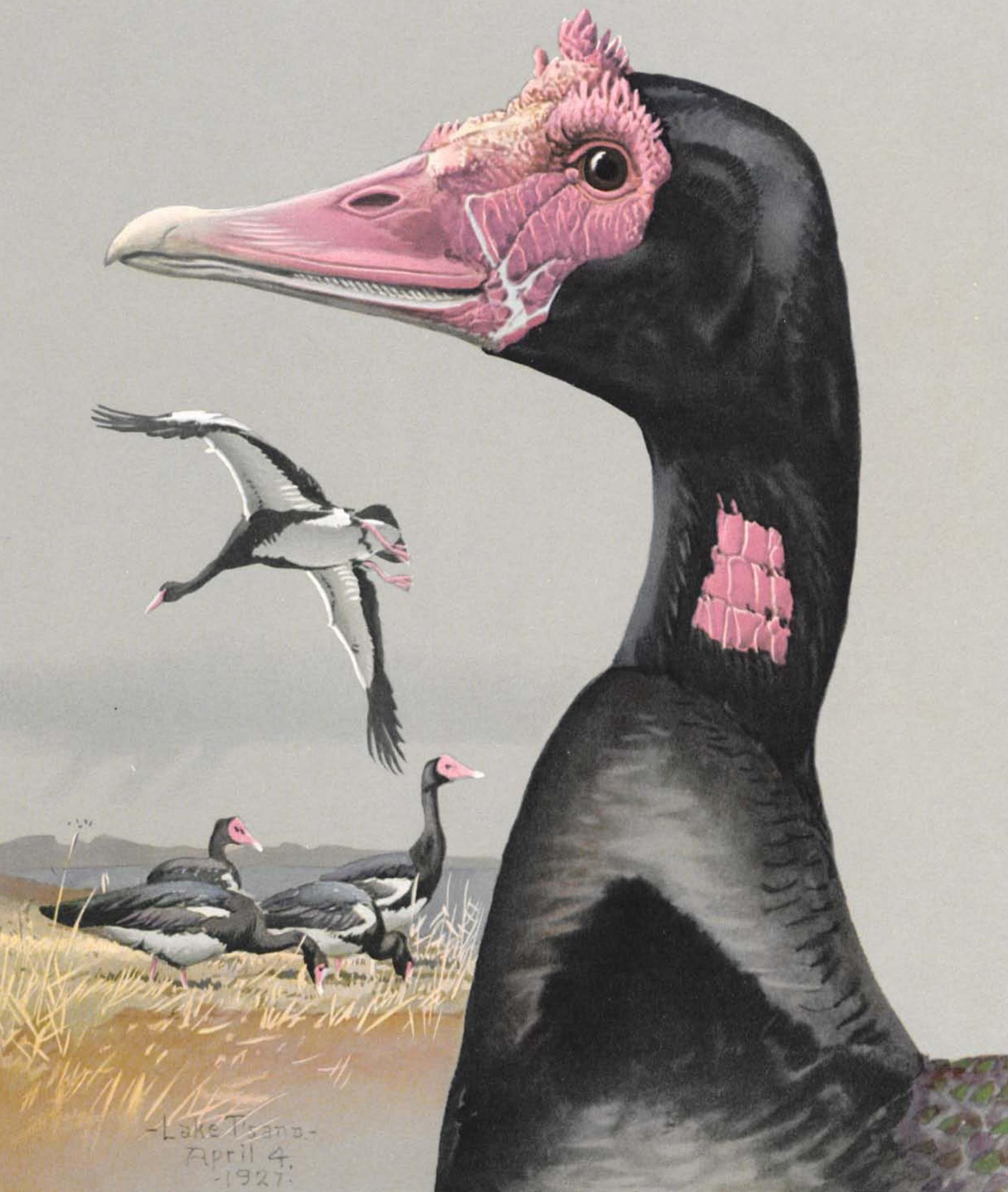


species has hybridized with Cairina. It is possible that the birds are polygynous in the wild, as wild males have been seen with more than one female, and their marked sexual dimorphism in body mass suggests that larger and stronger males might attract multiple females, as occurs in the perching ducks just mentioned.

Like most ducks, but unlike true geese and the magpie goose, male spur-winged geese play no role in breeding following fertilization; all incubation and rearing duties fall to the females. The species' large nests might be placed on the ground, in tree or termite cavities, or in trees, using an old nest of some other species. The usual clutch is six to seven eggs, but some much larger clutches have been found and might reflect egg laying by more than one female. Incubation requires 30 to 33 days, and the fledging period is apparently very long, perhaps over 75 days. Once they are capable of flight, the young are probably fairly secure from attacks by many land-based predators. The wing spurs appear within a month after hatching and gradually grow in size and defensive effectiveness.

This goose-sized waterfowl is widespread across sub-Saharan Africa and is considered to be a species of least concern by the International Union for Conservation of Nature. The numerous eBird reports for this species from Ethiopia are widespread from northern to southern parts of the country but are concentrated in the central Rift Valley region.

Suggested reading: Bartram and Boland, 2001; Brown, Urban \& Newman, 1982; Clark, 1980; Cramp \& Simmons, 1977; Del Hoyo, Elliott \& Sargatal, 1992; Johnsgard, 1978; Newman, 1971; Todd, 1996.

\section{Cape Teal Anas capensis}

In Fuertes's day, the Cape teal was often called the Cape wigeon, which perhaps is a clue to the uncertainty traditionally associated with its taxonomic classification. Certainly it has no affinities with the true wigeons, and its pale ash-gray plumage seemed to me to be ideal camouflage for living in sparsely vegetated ponds or alkaline lagoons. Indeed, these are favored habitats for the species, whose pallid colors are relieved only by a usually concealed iridescent green and black speculum on the secondary flight feathers that is much like that of a green-winged teal (Anas crecca).

The great waterfowl authority Jean Delacour taxonomically placed this enigmatic species among a small group of "spotted teal," including the African red-billed teal (A. erythrorhyncha) and Hottentot teal (A. hottentota), but that I had long believed to be an artificial taxonomic grouping. It came as one of my greatest surprises and pleasures when I observed that during courtship the Cape teal performs several displays typical of the green-winged teal $(A$. crecca) group but that are not found in the spotted teal, and I was finally able to find what I judged (Johnsgard, 1978) to be its proper taxonomic "home." Like greenwinged teal, the courtship behavior of Cape teal involves several elaborate displays, one of which involves a momentary exposure of its iridescent green wing pattern toward the courted female, which occurs so rapidly that, on first seeing it, a person might wonder if it had only been imagined. To my knowledge none of the "spotted teal" perform this display.

Cape teal, in spite of their name, are not limited to Africa's Cape region but are widespread over much of southern and eastern Africa and are especially common on the Rift Valley alkaline lakes. They forage at the surface, tipping-up in shallow water, and rarely dive. Their foods consist of small invertebrates and the seeds, stems, and leaves of aquatic plants. Pair-bonds in the Cape teal are quite long lasting, perhaps as an adaptation to allow for exploiting irregular breeding opportunities whenever conditions permit and laying clutches of seven to eight eggs. In association with this unusual trait that is also present in some other tropical surface-feeding ducks, males remain with their mates throughout the 26- to 30-day incubation period and help care for the young during their 50-day fledging period.

This species has a widespread but scattered distribution across sub-Saharan Africa, with an 


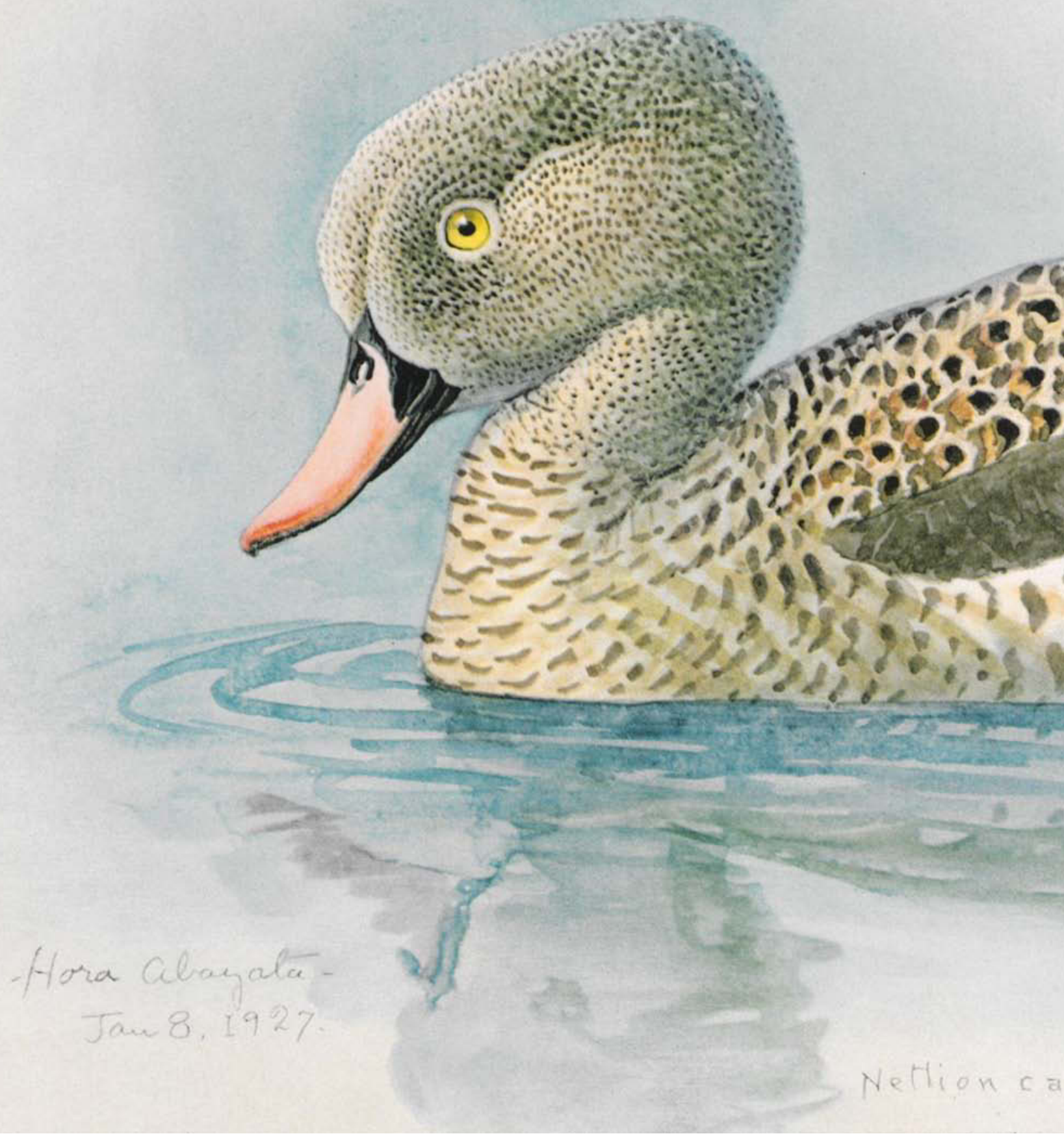

Plate 3. Cape Teal 
estimated population of at least 10,000 birds, and is considered to be a species of least concern by the International Union for Conservation of Nature. The relatively few eBird reports for this species from Ethiopia extend from Addis Abba south to Awassa and the Bale Mountains.

Suggested reading: Brown, Urban \& Newman, 1982; Cramp \& Simmons, 1977; Del Hoyo, Elliott \& Sargatal, 1992; Johnsgard, 1978; Newman, 1971; Todd, 1996; Winterbottom, 1974.

\section{Yellow-billed Duck Anas undulata rueppelli}

The yellow-billed duck is genetically little different from a common mallard (Anas platyrhynchos). In most parts of the world where mallards are absent, they have closely related "stand-ins" that occupy their ecological role as a generalized and medium-sized surface-feeding duck. In most of Africa it is the yellow-billed duck, a species much like the North American black duck (A. rubripes) in plumage but with bright yellow bills in both sexes, especially in the Ethiopian race rueppelli. Ethiopia is near the northern border of this species' range; over much of its geographic range it co-occurs with the African black duck ( $A$. sparsa). However, like the North American black duck, the African black duck is more a forestand river-dwelling species, whereas the yellowbilled duck is typically found in open country and still-water wetlands.

Like common mallards (A. platyrhynchos), yellow-billed ducks are quite gregarious, and especially after molting and during the nonbreeding period might gather in fairly large groups. At this time courtship begins, and pair-bonds are formed. Unlike the Cape teal, there is no evidence of long-lasting pair-bonds and prolonged breeding in yellow-billed ducks, whose breeding periods are generally timed to start regularly at the beginning of the rainy season between February and July and peak a few months later when invertebrate foods are maximally available.

Wintering mallards in Ethiopia have usually departed for their breeding grounds in Europe before the yellow-billed ducks' breeding gets 
underway. By the time the mallards return in the fall, breeding by the yellow-billed ducks has been completed. As a result, little or no hybridization occurs between these species under normal conditions. However, their hybrids are fully fertile, and the mallard poses a threat to the genetic integrity of all other Anas species wherever residential mallard populations have become established, as is locally the case in southern Africa. There they have bred with the yellow-billed duck, Cape teal, Cape shoveler (A. smithit), and possibly the African black duck (A. sparsa).

Courtship postures and calls are exactly like those of common mallards, so it is possible that some wintering mallards in Ethiopia might interact with the resident yellow-billed duck population. Yellow-billed ducks produce clutches of 6 to 12 eggs, and their incubation period of 26 to 29 days is essentially the same as that of the common mallard, but their fledgling period has been reported to be a much more protracted period of 65 to 70 days. Young birds are said to remain with their mother for about six weeks after fledging.

Yellow-billed ducks are widespread across subSaharan Africa and are considered to be a species of least concern by the International Union for Conservation of Nature. The numerous eBird reports for this species from Ethiopia are widespread from the northernmost areas to the southern Rift Valley region.

Suggested reading: Brown, Urban \& Newman, 1982; Chapin, 1932; Del Hoyo, Elliott \& Sargatal, 1992; Johnsgard, 1978; Newman, 1971; Rowan, 1963; Todd, 1996.

\section{Family Accipitridae (Vultures, Eagles, Hawks, and Relatives)}

\section{Black-winged (Black-shouldered) Kite Elanus c. caeruleus}

The raptorial kites of the world are well named; they can hover kitelike in the sky, remaining nearly motionless as they scan the land below for possible foods, then quickly swoop down and 


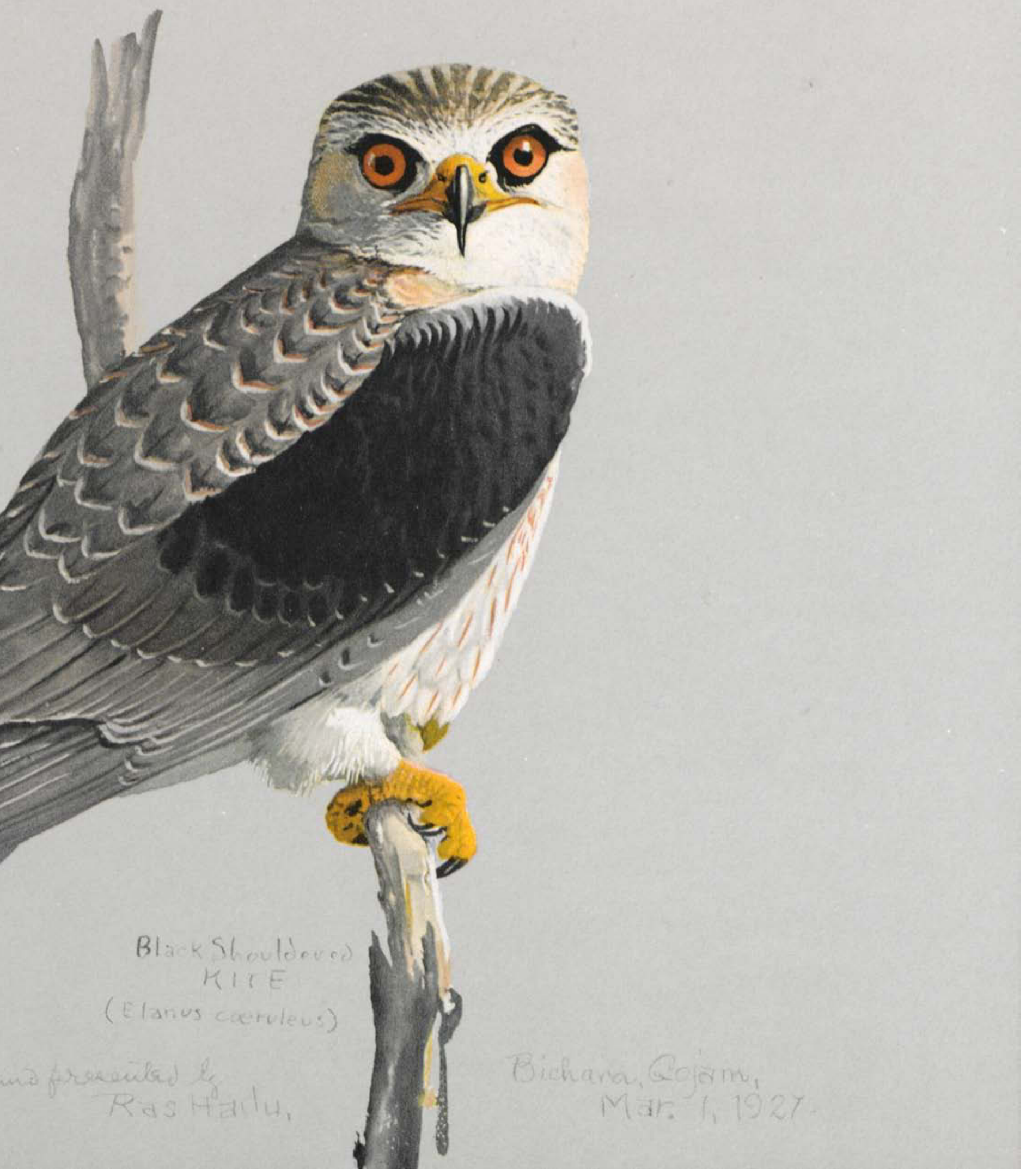


snatch it out of the air or off vegetation without losing any control or wasting a moment of time. The lines of the clean streamlined kites are also an artist's fantasy, and the large red eyes of this species, contrasting with its steelgray upperparts, make it especially appealing.

This African and Eurasian species was referred to by Fuertes as the black-shouldered kite, back then its generally accepted name, but a similar Australian species (Elanus axillaris) is known by the same English vernacular name, so adopting the name black-winged kite avoids that confusion. To add to the complexity, a North American counterpart of this kite, which until recently was often included in the same species, has fortunately been separated specifically as the whitetailed kite (E. leucurus). All of these taxa are considered parts of a collective superspecies, along with another Australian kite, the letter-winged kite (E. scriptus).

Like most hawks, the sexes of the blackwinged kite are identical in plumage, but the female is slightly larger. Many hypotheses have been advanced to account for such "reversed sexual dimorphism," which is common in raptors, but none has been universally accepted. One intriguing hypothesis is that smaller and swifter males can perform acrobatic display maneuvers more effectively than can bigger and slower albeit stronger males, and thus will be favored by females because of their greater associated abilities to obtain flying prey. Another hypothesis is that because females must not only help equally, or predominantly, to build a nest and produce a clutch of eggs but also undertake part or most of the incubation, having a greater body mass than the less-stressed males is a highly adaptive trait.

Kites maintain localized hunting territories, although roosting during the nonbreeding season is communal. Most foraging occurs during daylight, but the birds' large eyes also allow some foraging at dusk. Nearly all their prey in Africa consists of small rodents weighing from about a fifth to a seventh of the bird's weight. Variations in rodent abundance might dictate the time and even location of breeding, but many pairs seem to maintain strong breeding territories and might use the same nest in subsequent years.
Courtship consists of mutual soaring, some chasing, and a "butterfly flight" descent by the male. The nest is constructed loosely of twigs, and the clutch consists of three to four eggs. The incubation period is 28 to 30 days, and the fledging period is 35 to 40 days. Even after fledging the young might remain dependent on one of the parents for food for about 80 additional days. Young birds take about a year to attain their adult plumage, but the eye color of immatures becomes bright red by about six months of age.

The black-winged kite is distributed widely across sub-Saharan Africa. It also has large populations in India and southeast Asia, plus a small European population. It was considered to be a species of least concern by the International Union for Conservation of Nature in 2016. The numerous eBird reports for this species from Ethiopia are widespread from the northernmost areas to southernmost parts of the country but are concentrated in the Rift Valley region.

Suggested reading: Brown \& Amadon, 1968; Brown, Urban \& Newman, 1982; Burton, 1989; Chapin, 1932; Cramp \& Simmons, 1980; Del Hoyo, Elliott \& Sargatal, 1994; Ferguson-Lees \& Christie, 2001; Grossman \& Hamlet, 1964; Mendelsohn \& Leshim, 1983; Newman, 1971; Tarboton, 1989.

\section{Scissor-tailed Kite Chelictinia riocourii}

Few birds can be more beautiful or graceful in flight than the scissor-tailed kite. The generic name Chelictinia is from the Greek and means "swallow tail," and Fuertes identified it as the "swallow kite" on his painting. Like the similar fork-tailed species of the African red kite (Milvus milvus), several swallows, and many other aerialforaging birds, this unusual tail configuration seems associated with great aerobatic maneuvering abilities, especially at slow speeds. A counterpart American raptor is the American swallow-tailed kite (Elanoides forficatus), but these 


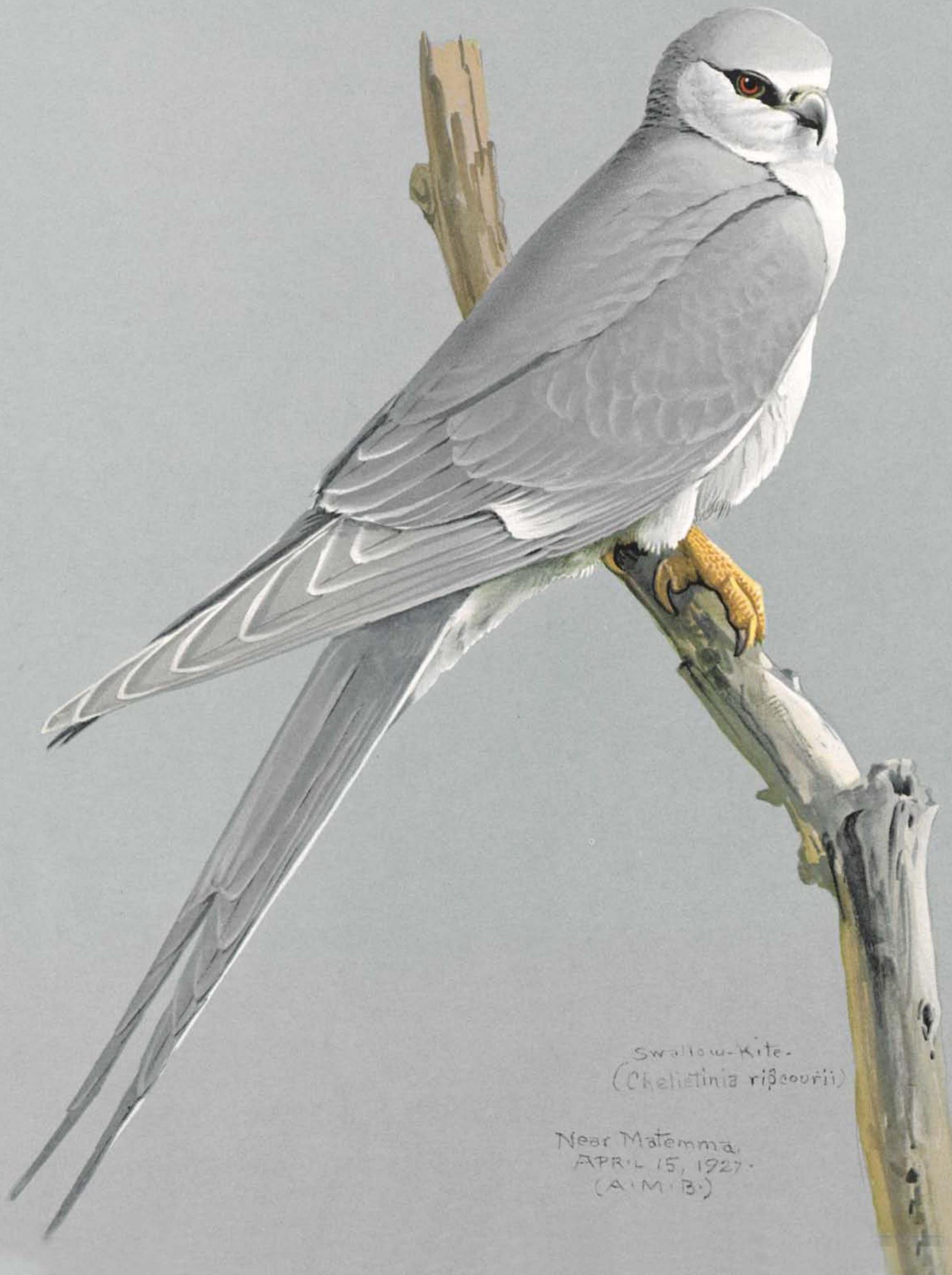


two kites are not closely related and share only similar flying skills, so the newer English name "scissor-tailed kite" for the African species helps to emphasize this taxonomic distinction.

African scissor-tailed kites are very nearly the same size and configuration as the black-winged kite, except for tail shape differences; both have large, red eyes as adults and species-specific black-and-white underwing patterning. Both also roost communally, but the foods of the scissortailed kite primarily consist of insects caught on the wing rather than small rodents. Unlike the black-winged kite, nesting by the scissor-tailed kite also occurs in a communal group of up to about 20 pairs; probably its dependence on generally abundant insects makes within-species competition for food during the breeding season much less severe.

Nothing is known of the courtship behavior of the scissor-tailed kite. There is almost no difference in the sizes of the sexes, and a monogamous pair-bonding system is assumed. It is believed that the female does the majority of the incubation, and she feeds the young with food brought in by the male. Nests are usually constructed anew each year, and are placed in thorny bushes or trees. The usual clutch is of four eggs, but the incubation and fledging periods are still unreported. They are likely to be very similar to the durations mentioned for the black-winged kite, namely about 29 days of incubation and 35 to 40 days for fledging.

This kite is distributed widely across subSahara Africa from Mauritania to Kenya. Its population was estimated as 5,000 to 25,000 and decreasing but was considered to be a species of least concern by the International Union for Conservation of Nature in 2016. The relatively few eBird reports for this species from Ethiopia are widely scattered from the northern to southern parts of the country.

Suggested reading: Brown \& Amadon, 1968; Brown, Urban \& Newman, 1982; Burton, 1989; Del Hoyo, Elliott \& Sargatal, 1994; Ferguson-Lees \& Christie, 2001; Grossman \& Hamlet, 1964; Tarboton, 1989.

\section{Black Kite Milvus migrans}

The black kite (which is actually reddish brown) is one of the commonest of the African raptors, especially in open-country habitats. It is also prevalent near human habitation, where the birds are effective scavengers. Fuertes mentioned the great skill with which black kites could swoop down and catch the carcasses of newly skinned rodents when they were tossed into the air for them. Nearly 60 years later I observed that very same behavior while eating lunch in Ngorongoro Crater, in the heart of Tanzania's Serengeti Plains. I tossed meat sandwich remains high into the sky while dozens of kites circled overhead, all waiting their opportunities.

The black kites seen in Africa include many European seasonal migrants, which have less deeply forked tails than the native African birds, and bills that are entirely black in front of the yellow cere. The African-breeding kites have yellow bills and a head color that is more brownish than grayish. However, immatures of the two are very difficult to separate. Unlike the closely related red kite ( $M$. milvus), black kites have only slightly forked tails but share that species' great maneuverability in the sky.

The wings of gliding black kites are held at an up-tilted angle similar to that of a harrier (Circus), which increases their aerial stability, and they constantly twist and spread their long tails as they adjust their directions in the air. Although they can certainly catch some prey such as flying insects with ease and will take both small live vertebrates and diverse invertebrates, probably the majority of their food comes from carrion. Kites often fly near the front of a grass fire, swooping down on any small animals trying to escape the flames.

Like other kites, the black kite is highly social, not only roosting in flocks but also sometimes even nesting in colonies, probably especially in those places where food is not limiting. As suggested by their specific name, these kites are rather migratory, but in spite of their mobility the birds seem to maintain permanent pair-bonds. Some courtship does occur among wintering flocks, and acrobatic flights, mutual 
talon-grappling by potential partners, and exciting pursuit-flights are part of these activities.

Nesting is done in bushes or, more often, in the branches or forks of trees. In coastal areas nests might also be placed on cliff ledges. Old nests are sometimes refurbished and used again, or a new nest is begun. Kite nests are distinctive in that they usually contain an untidy mess of waste materials such as paper, dried dung, and other rubbish. Nesting sometimes occurs close to the nesting colonies of herons, where eggs or vulnerable chicks might be available. In some areas with good food supplies the birds are semicolonial, with as many as 30 pairs breeding in a loose cluster.

The egg-laying period is evidently quite variable and might be locally linked to regional rainy periods. In nearby Somalia the breeding records are for December-January and possibly also March-April. Usually two to three eggs are laid at intervals of a day or two. Incubation begins with the first egg and is mainly performed by the female. However, the male feeds his mate during the incubation period and remains near the nest. When the female leaves to forage, he will take over sitting duties for short periods. Incubation requires 32 to 37 days; this rather extended range suggests that incubation periods might vary with influencing factors such as relative parental attentiveness.

The newly hatched chicks are covered initially with down, but contour feathers appear within a week of hatching, and by the time the nestlings are a month old they are well feathered and easily able to walk about. Fledging occurs by somewhat more than 40 days, but the juveniles remain close to the nest until they are about two months old. Normally two fledged offspring are produced per nesting effort, and somewhat more than half of the breeding efforts result in fledged young. As the juveniles gain independence, the family joins others and flocks gradually form. The age of sexual maturity and initial breeding is still uncertain, but in the closely related red kite they occur at two years.

Although generally considered to be one of the world's most numerous members of the hawk and eagle family, with early estimates of as many as 6 million individuals worldwide, recent estimates have been about 1 million to 2.5 million birds. It was considered to be a species of least concern by the International Union for Conservation of $\mathrm{Na}-$ ture in 2016. The abundant eBird reports for this species from Ethiopia are widespread from the northernmost to southernmost parts of the country, west to the South Sudan and Sudan borders and east to the Djibouti border.

Suggested reading: Brown \& Amadon, 1968; Brown, Urban \& Newman, 1982; Burton, 1989; Chapin, 1932; Cramp \& Simmons, 1980; Del Hoyo, Elliott \& Sargatal, 1994; Ferguson-Lees \& Christie, 2001; Grossman \& Hamlet, 1964; Newman, 1971; Steyn, 1982; Tarboton, 1989.

\section{African Fish Eagle \\ Haliaeetus vocifer (2 paintings)}

Few freshwater Rift Valley lakes are without their retinue of resident African fish eagles; seen at a distance one might imagine oneself at a remote North American lake, and that the birds are actually American bald eagles (H. leucocephalus). These two white-headed and white-tailed species are close relatives, and both are well adapted to capturing fish from the water surface, following a low-altitude approach, and a gaffing grab by the long talons. Their calls are also similar, the most common being a series of loud yelps, uttered while the head is thrown vertically back. The Latin name of the African species translates as "vociferous sea eagle," but the species also occurs on a wide variety of freshwater and alkaline wetlands.

These birds are common over most of subSaharan Africa, extending from coastal areas to at least 13,000 feet $(4,000 \mathrm{~m})$ in the Ethiopian highlands. They tend to be sedentary, occupying the same territory year-round and using the same nest year after year. A total of 27 years of continuous occupancy by a single pair has been the maximum duration reported. This fact would suggest that the birds are sometimes very longlived, but actual data on long-term survival rates are lacking. 


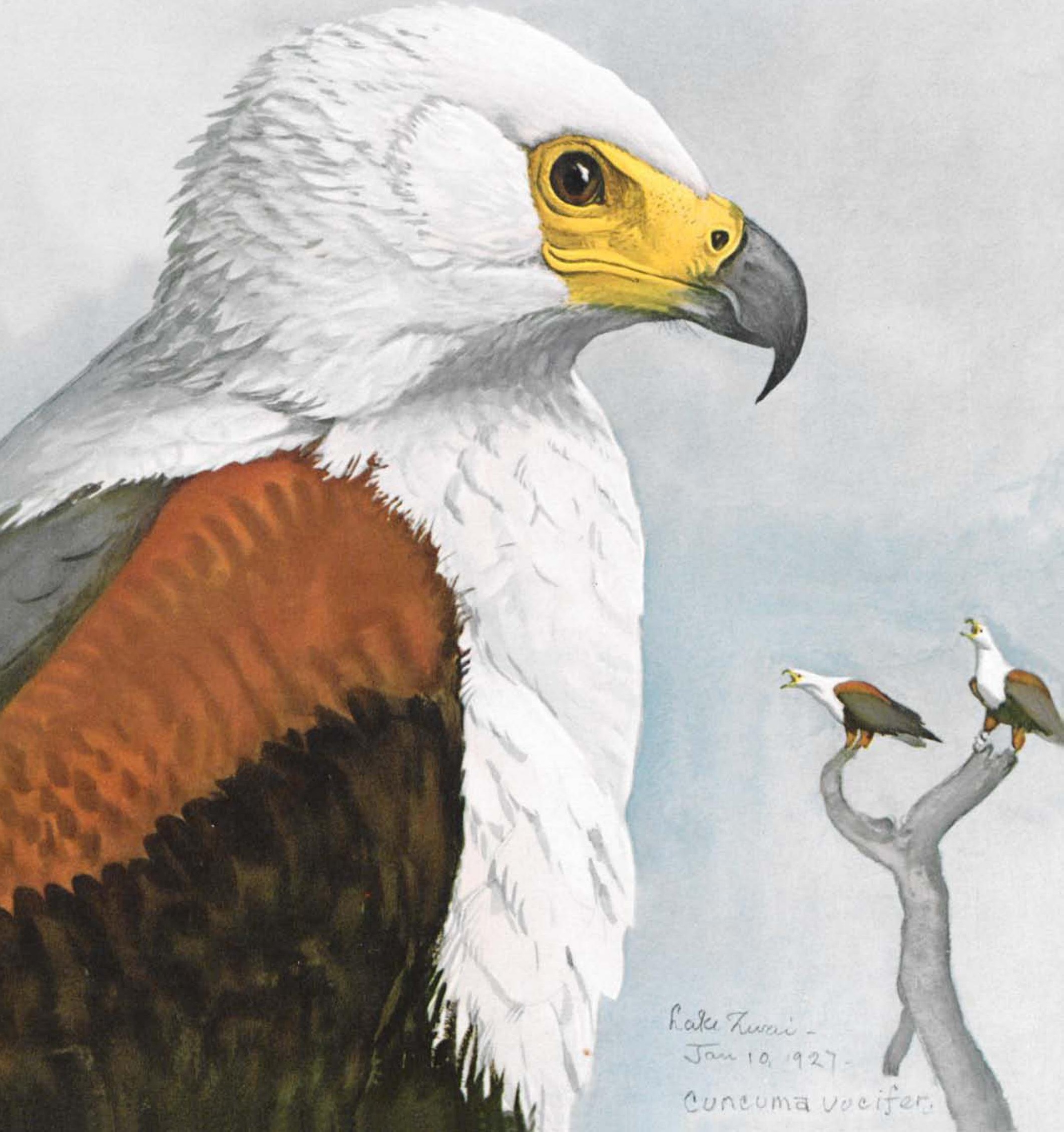


African fish eagles, like the American bald eagle, mature in about five years, when their entirely white head and tail coloration is attained. Their adult weight is probably acquired during the first year, when females might weigh up to 10 pounds $(4.5 \mathrm{~kg})$ or more, and males up to 7 pounds $(3.2 \mathrm{~kg})$. With such a large mass the birds can snag and reportedly carry off fish weighing up to at least 5 pounds, or about half their body weight. Some broad-winged eagles, such as golden eagles (Aquila chrysaetos), are able to lift objects of nearly their own weight, such as an adult red fox, which averages about 10 pounds $(4.5 \mathrm{~kg})$. It has even been reported (Bird Watcher's Digest, Sept.-Oct. 2019, p. 118) that an American bald eagle was observed lifting a 15-pound $(6.8 \mathrm{~kg})$ slab of venison, a mass about 25 percent heavier than an adult female bald eagle!

Not only fish but also other large prey are sometimes taken by fish eagles. Adult flamingos and cormorants, possibly as heavy as the eagles themselves, are sometimes attacked and killed by these great predators. However, immature birds that are still unskilled at hunting might have to rely on eating carrion until they acquire the adults' hunting techniques, or steal the nestlings of pelicans, herons, spoonbills, and cormorants.

African fish eagles spend most of their daylight hours perched at convenient lookout points, often a tall tree from which they can survey a large area of water surface. They consume prey that in mass represents an average of about 5 percent of their body weight per day, or well below amounts typically consumed daily by such more constantly active predators as pelicans and cormorants. This presumably reflects the fact that far less energy must be spent by fish eagles in obtaining their prey than is true of active preychasers such as cormorants.

The nests of African fish eagles are usually in trees, but they might also be constructed on rock outcrops or on bushes growing on promontories. In Ethiopia the nesting season occurs between August and October, at the end of the rainy period but when many immature and vulnerable prey species might be available. Similarly in Somalia there are breeding records for June and October. Both sexes aid in nest construc- tion, and over many years it might become so large that the supporting structure breaks and the nest collapses. The usual clutch is of two eggs (rarely three), with incubation starting with the laying of the first egg. Incubation is done by both sexes and probably lasts about 35 to 45 days, with the chicks hatching in the sequence that the eggs were laid.

The young eaglets are mostly fed by the female, who receives food brought to the nest by her partner. The young spend at least two months in the nest and only gradually do they venture far from it after fledging. Fledging in the closely related American bald eagle takes 10 to 11 weeks; a similar duration might be expected in the African fishing eagle. The eaglets might not begin to capture food for themselves until at least two months following fledging, and apparently are allowed to remain within their parents' territory until they leave by their own volition. The juveniles might then become somewhat gregarious, roosting in groups where adult breeding pairs will not harass them.

Although protected and generally not persecuted in Africa, the fish eagle has suffered to some degree the same fate as befell the American bald eagle, namely poisoning by ingestion of pesticides through its prey. Deaths by organochlorides such as dieldrin have been reported, as have egg-thinning effects similar to those that occurred in North America. This eagle is widespread across nearly all of sub-Saharan Africa and is considered to be stable; as of 2016 it was a species of least concern by the International Union for Conservation of Nature. The numerous eBird reports for this species from Ethiopia are widespread from the northernmost to southernmost parts of the country and locally west almost to the South Sudan border.

Suggested reading: Brown, Urban \& Newman, 1982: 312; Chapin, 1932; Cramp \& Simmons, 1980; Del Hoyo, Elliott \& Sargatal, 1994; Ferguson-Lees \& Christie, 2001; Grossman \& Hamlet, 1964; Newman, 1971; Steyn, 1960, 1982; Tarboton, 1989. 


\section{Lammergeier (Bearded Vulture) Gypaetus barbatus meridionalis (5 images)}

The lammergeier is one of those almost mythical birds that haunt our folklore and nourish our legends, if not our nightmares. Its English vernacular name is from a German name meaning "lamb vulture." An older but better Latin name for it is "ossifrage," or bone-breaker, from its near-legendary ability to drop its prey or their large bones from a great height, to break the bones on rocks below in order to consume them more easily.

The lammergeier's Latin name is equally interesting; Gypaetus means eagle-vulture, suggesting an intermediate ecological position between predator and carrion-eater, which is fairly descriptive. The species' name barbatus refers to its curious black "mustache" of bristly forward-pointed feathers and paired clusters of downwardly directed black chin feathers. The function of these stiff feathers is uncertain, but they might serve a tactile purpose. The lammergeier's head appears more like an eagle's than a vulture's, with very little bare facial skin in front of the eye. However, its beak is rather slender and somewhat vulturelike, and its toes are also rather small, but the talons are sharper and thus more lethal than those of typical vultures.

I well remember the first time I saw a live (albeit captive) lammergeier and being awestruck by its piercing yellow eyes encircled by a red sclerotic ring. Its unusually long and slightly pointed tail was also striking. The boat-shaped tail reminded me of the wedge-tailed eagles (Aquila audax) I had seen many years earlier in Australia. Presumably in both species this added tail surface area provides for increased aerial maneuverability, or perhaps improved braking potential when landing.

Fuertes must have been equally impressed by the lammergeiers; he did more illustrations of them (five) than of any other Ethiopian bird. On November 11, 1926, he watched "great lammergeyers, stateliest and hugest of them all, sail majestically by, sometimes getting with range of Bill's terrible gun." The next day Fuertes watched as a flock of 16 lammergeiers descended on a dead mountain nyala that he had just shot. On that same day he painted one of the birds that
A. M. "Bill" Bailey had shot on Mount Albassa at an altitude of 10,700 feet $(3,260 \mathrm{~m})$.

Lammergeiers are still probably more common in Ethiopia than anywhere else, where groups of the size mentioned by Fuertes might still be seen, and some still also occur in the South African highlands. In Ethiopia they have become tolerant of and even dependent upon humans, frequenting refuse heaps and other waste sites and gliding along urban streets to snatch waste from wherever they can find it. This would seem to be a sad fate for a majestic species that one would prefer to imagine skimming mountaintops and soaring above steep gorges, far from the nearest human.

Fuertes's plates show the beautiful tawny to rufous head, neck, and breast coloration of these birds, which is the result of staining by iron oxide. The means by which the birds acquire this color is uncertain, but it probably results from dusting or bathing in iron-rich sources. This is one of the rare if not unique cases of cosmetic coloration in raptors and is somewhat comparable to the self-painting of sandhill cranes (Antigone canadensis), which transform their plumage color from mouse-gray to various shades of brown or brownish red by smearing iron-rich mud over their feathers just prior to breeding. As with cranes, the function of this behavior remains speculative, but at least in the case of the cranes it helps to make incubating birds less conspicuous in their dead-grass surroundings.

Like many vultures, the lammergeier roosts on rock ledges or in mountainous caves at night, waiting in the morning for updraft winds to help it achieve flight in its daily search for food. Because of its low relative wing loading, associated with a tremendous wing area lifting a massive but proportionately small body mass (averaging about 14 pounds [6.4 kg]), the birds can exploit even slight updrafts to gain altitude and begin long searching flights. They have been seen soaring at heights as great as 25,600 feet $(7,800 \mathrm{~m})$ in the Himalayas. However, they usually fly rather close to the ground, using the lift provided by updrafts in hilly topography, rather than depending on thermals for maintaining their altitude.

The birds glide at rather slow speeds when scanning for food. They have relatively narrower 
wings as well as obviously longer tails than do most vultures, but a foraging pair might cover as large an area as 2,000 square miles $(5,000$ sq. $\mathrm{km}$ ) when searching for food. Like the other African vultures, the lammergeier has quite narrow nostrils (which are largely covered by feathers and thus invisible), and there is no evidence that olfaction aids in its food searches. Upon finding carrion, lammergeiers will quickly land but generally cannot compete effectively with the largest African vultures, such as the lappetfaced, or hold their own against domestic dogs.

It takes about seven years for the definitive adult plumage to be attained, at which time the two sexes become identical in appearance, with the female averaging only slightly larger than the male. Pair-bonding is long-term, and mated birds might remain on the same territory throughout the entire year, sometimes traveling about ten miles from their nocturnal roosting sites for daily foraging. Like other vultures they are nearly always silent, but a few weak whistled utterances have been detected during aggressive interactions and pairing display or when young are soliciting food.

As noted earlier, one of the most remarkable behaviors of the lammergeier is its trait of picking up large bones, lifting them to considerable heights, and then dropping them onto a flat and rocky surface so as to break the bones into smaller fragments that can be swallowed. Favored sites for such bone-breaking behavior are called ossuaries, and over decades or even centuries hundreds or thousands of bleached bones might gradually accumulate. It is possible that live prey might rarely be dropped; at least in Europe there is fairly good evidence that tortoises might thus be killed and cracked open. It has even been said that the Greek writer Aeschylus (525-456 BC) was killed when a turtle dropped by a lammergeier struck his bald head and produced a fatal concussion.

The behavior associated with bone breaking has been well studied. Typically the bird will carry a large bone aloft, turn downwind, and begin a rapid descending glide, releasing the bone about 500 to 150 feet (152-46 m) above the ground. The accuracy achieved in these drops is remarkable; the bones land on confined surface areas as small

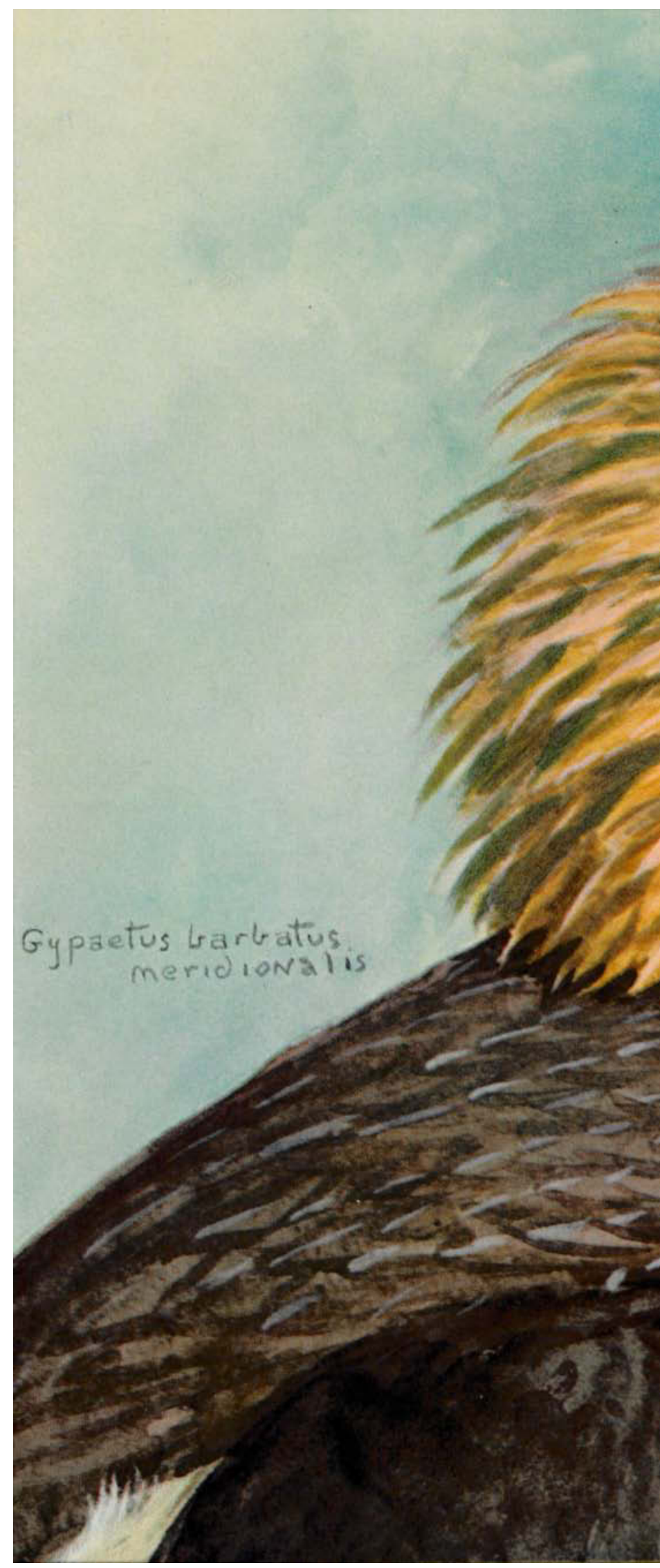




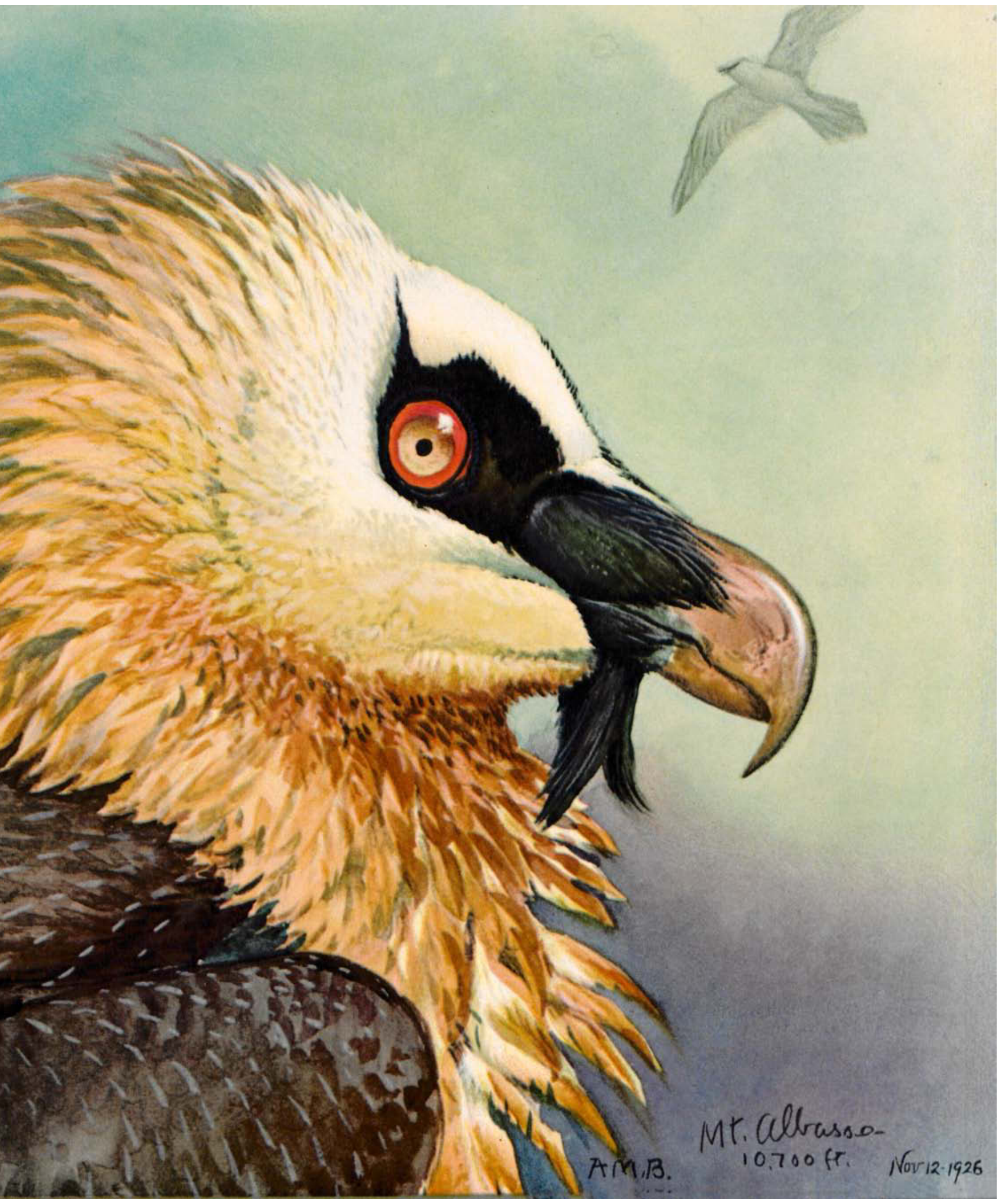

Plate 8. Lammergeier (Bearded Vulture) 
as about 12 square yards from even the greatest height. The bird then quickly wheels into the wind, braking its speed, and drops almost vertically downward to quickly gather the fragments before other birds steal them. These very large birds can swallow bone fragments up to about 10 inches long. Sometimes other lammergeiers might catch dropped bones while they are still in the air and carry them off to consume themselves.

The pairing behavior of the lammergeier is marked by wonderful aerial displays, such as spectacular dives, often performed close to the nest site, followed by quick climbing to regain height. Mutual talon-clutching displays are common, as with many eagles. Copulation occurs at the nest site, which might be a rocky ledge of a cliffside cave. Nests of adjacent pairs might be as close as three to six miles apart in good habitats. The nest is large and broad and constructed of almost any available materials, including refuse. Both sexes help construct the nest, and a good deal of mutual preening and copulatory behavior occurs during this period. Nests might be used repeatedly, or the materials from an old nest might be used to construct a new one.

One or two eggs are laid, the second at an average interval of about five days. Incubation begins with the first egg and is shared equally, with several nest-sitting exchanges per day. The incubation period is uncertain but is probably close to 50 days, judging from observations of captives. Both parents also feed the nestlings, the food usually being fresh meat. Adults also expel a fluid through their beaks, presumably semidigested food, to feed the young, as also occurs in some other vultures. Bones, especially small bones, might also be eaten by nestlings.

The fledging period is very long, probably requiring about 120 days. The fledglings remain near the nest and are dependent on their parents for some time even after fledging, and then they begin their long seven-year period to maturity. By five years of age the head feathering becomes white, and the distinctive black facial mask and mustache becomes conspicuous. Indirect data suggest there might be as much as 90 percent mortality of juveniles and immatures before adulthood is attained. Following that, at least in Ethiopia, breeding might be attempted only in alternate years; the arid climate as well as the long nesting and juvenile dependency periods might make more frequent breeding impossible. Limited data suggest that breeding pairs produce on average only about 0.5 successfully fledged offspring per attempt, so a long survivorship must be required if the population level can possibly be maintained indefinitely.

Lammergeiers had a very broad historic range in Europe, southern Asia east to Tibet, and Africa. The recent world population is thought to be 2,000 to 10,000 individuals, including 1,300 to 6,700 mature birds. In Europe, though, they have become very rare and are endangered in most regions, with probably 580 to 790 pairs as of 2015. In Africa their population is much more secure, with an estimated early 1990s population of about 1,400 to 2,200 pairs of the African race. In 2012 the lammergeier was classified in the category of least concern by the International Union for Conservation of Nature, but it has since (2016) been reclassified as near-threatened. The numerous eBird reports from Ethiopia for this species are widespread from the northernmost to southernmost parts of the country but with few records west of the Rift Valley and very few east of the Bale Mountains.

Other than in northeastern Africa and the Tibetan plateau, few places are left in the world where there is much hope of seeing lammergeiers in the wild. The use of poisoned bait set out for carnivorous mammals has caused the same kind of damage to lammergeiers in Europe as similar activities have affected California condors (Gymnogyps californianus) in the western United States. Like the situation with condors, reintroduction efforts are now underway in some areas, such as the Alps, where feeding stations have been provided to compensate for the reduction in available natural foods. However, birds such as California condors and lammergeiers evolved in wilderness environments and perhaps will be unable to wholly adjust to life in the twenty-first century. It would be sad indeed if this most magnificent of the world's vulturelike birds were to disappear from even the wildest of our planet's remote places.

Of all the birds in the world that I should someday like to see in its natural habitat, the lammergeier repeatedly creeps in to compete at 
the top of my list, along with species such as the great bustard (Otus tarda), the Steller's sea eagle (Haliaeetus pelagicus), and the pink-headed duck (Rhodonessa caryophyllacea) of India. I have encountered all but the last of these wonderful birds in captivity but have observed the now almost certainly extinct pink-headed duck only in museum trays, where its once incredibly pink head has faded to a depressing dingy tan. Its behavior in life will forever remain a mystery, as it disappeared about the time I was a youngster and had not yet heard of it.

Suggested reading: Brown, C. P., 1990; Brown \& Amadon, 1968; Brown, Urban \& Newman, 1982; Burton, 1989; Cramp \& Simmons, 1980; Del Hoyo, Elliott \& Sargatal, 1994; Ferguson-Lees \& Christie, 2001; Grossman \& Hamlet, 1964; Newman, 1971; Rudebeck, 1961; Steyn, 1982; Tarboton, 1989.

\section{Egyptian Vulture Neophron p. percnopterus}

The Egyptian vulture's Latin name translates as the "trickster-vulture with dark, hawklike wings." The generic component relates to Greek mythology, in which the mischievous trickster Neophron was transformed into a vulture by an annoyed Zeus. The species' epithet is also Greek and means "dusky wings," in reference to the bird's dark flight feathers. In spite of its small size (adults weigh up to about 5 pounds) and distinctive vulturine appearance, the nearest living relative of the Egyptian vulture might be the eagle-like lammergeier. The Egyptian vulture's head is almost entirely naked; its beak is long, very narrow, and only slightly hooked as compared with most raptors; and its legs are rather long with strong toes and talons.

Its small size would seem to place the Egyptian vulture at a distinct competitive foraging disadvantage compared to the other African vultures, and it does do best near human settlements, where it might be more adroit and better adapted to living in close quarters with humans than are some of the larger and more clumsy spe- cies. It is unique among African vultures in being mostly white in adult plumage, except for its black flight feathers. Adults have distinctive bare yellow facial skin and a black-tipped yellow bill. Immatures are dark brown with grayish facial skin and are somewhat similar to young American turkey vultures (Cathartes aura) in appearance, although the New World vultures (family Cathartidae) and Old World vultures (family Accipitridae) are only very distant relatives. At least five years are needed for young birds to attain the definitive adult plumage.

Egyptian vultures are rather solitary birds, not only avoiding larger vultures against which they can't compete but also not associating much with their own species. They sometimes are seen with hooded vultures; both have quite long and narrow beaks that allow them to get at food the larger-billed species can't reach.

Certainly the most remarkable aspect of the species' foraging behavior is its stone-throwing ability. Upon finding a clutch of hard-shelled eggs that can't be cracked with its bill, this vulture will pick up a small stone and throw it toward the eggs. However inaccurately it does this, one might eventually be struck and cracked enough that it can penetrate the shell with its beak and consume the contents. For smaller eggs, such as those of pelicans or flamingos, the vulture might pick up an egg and hurl it against a substrate until it is broken.

Nesting usually occurs on cliffs or rocky outcrops or in caves. Like the two American vultures, this species has a normal clutch of two eggs, which are incubated by both parents for 42 days. The fledging period varies from 70 to 90 days, and additional time is needed for the young to attain full independence.

Although this vulture has one of the broadest distributions of any of the African vultures, extending from Spain and western Africa east to India and central Asia, its global population is in rapid decline. Once numbering more than 100,000 birds, the species' population was estimated at 12,000 to 38,000 individuals in 2015 . It is considered to be a species critically endangered by the International Union for Conservation of Nature. Numerous eBird reports indicate that Ethiopian sightings have occurred from the 

country's northern to southern borders, west to the South Sudan border and east to Djibouti. The Ethiopian population includes both resident birds and migrants from Europe.

Suggested reading: Brown \& Amadon, 1968; Brown, Urban \& Newman, 1982; Burton, 1989; Chapin, 1932; Cramp \& Simmons, 1980; Del Hoyo, Elliott \& Sargatal, 1994; Ferguson-Lees \& Christie, 2001; Grossman \& Hamlet, 1964; Steyn, 1982; Tarboton, 1989.

\section{Hooded Vulture Necrosyrtes monachus}

Fuertes labeled his watercolor of a hooded vulture "Common African vulture." In the 1930 published album of his paintings, it was similarly identified as the "White-necked vulture (Pseudogyps africanus)," a species that is now known as the African white-backed vulture, Gyps africanus. It is apparent that Fuertes's image is actually that of a hooded vulture, and that corrected designation appeared in the 1936 account of the expedition by Fuertes and Osgood.

The hooded vulture has a rather ghoulish scientific name meaning "corpse-dragger," which is a fairly accurate description of its behavior. The beak is long and narrow, much like that of the Egyptian vulture, but unlike the heavy beak of the African white-backed vulture. Its body and wing feathers are rather uniformly blackish brown rather than medium brown. The hooded and white-backed also differ markedly in size; hooded adults of both sexes weigh on average about 5 pounds $(2.8 \mathrm{~kg})$ and thus are substantially smaller than most of the African white-backed vultures, which average about 12 pounds $(5.5 \mathrm{~kg})$.

The monk-like "hood" (thus the species' name, monachus) of adult hooded vultures consists of short white and downy feathers that extend from the middle of the crown back and downward to the base of the neck, in front of which is bare facial skin that becomes bright red in excitement. Juveniles have less colorful faces and grayish white down on the head.
Like Egyptian vultures, hooded vultures have adapted well to life with humans, often frequenting rubbish heaps and other places where meat scraps or other edible materials might be discarded. Live termites, insect larvae such as dung beetle grubs, and locusts are also eaten when they become available. Hooded vultures are among the earliest of the vultures to become active and start searching for food-soon after sunrise-which is probably because they are smaller than most other African vultures and can partly avoid competing with them by adopting an early morning reconnaissance and breakfast. The hooded vulture is most common at elevations below 5,800 feet $(1,770 \mathrm{~m})$, but its range extends as high as nearly 13,000 feet (3,960 m).

Hooded vultures apparently pair permanently, although little detailed information on this or on their courtship behavior is available. At least in Ethiopia they might not attempt to breed annually, and their nests are not clustered but might be organized into what could be termed loose colonies. The nest, like those of other African vultures, is a small collection of sticks plus an assortment of miscellaneous materials, typically placed in trees, especially baobabs (Adansonia).

Breeding in Ethiopia occurs from October to December during the early dry season (which usually extends from November to February in Ethiopia), and only a single egg is laid. As usual among vultures, both sexes incubate for the approximate 50-day period of incubation. The fledging period is reportedly rather variable and lasts about 80 to 130 days. Another three to four months are needed to achieve foraging independence. Breeding success seems to be quite low, averaging only about 0.2 to 0.3 fledged young per pair.

This species' population was estimated at a maximum of 197,000 individuals in 2015, but like several other African vultures it has been in sharp decline, specifically 83 percent downward over three generations. Because of this steep decline the hooded vulture was considered to be critically endangered by the International Union for Conservation of Nature in 2016. Numerous eBird reports indicate that Ethiopian sightings have occurred from the country's northern to 


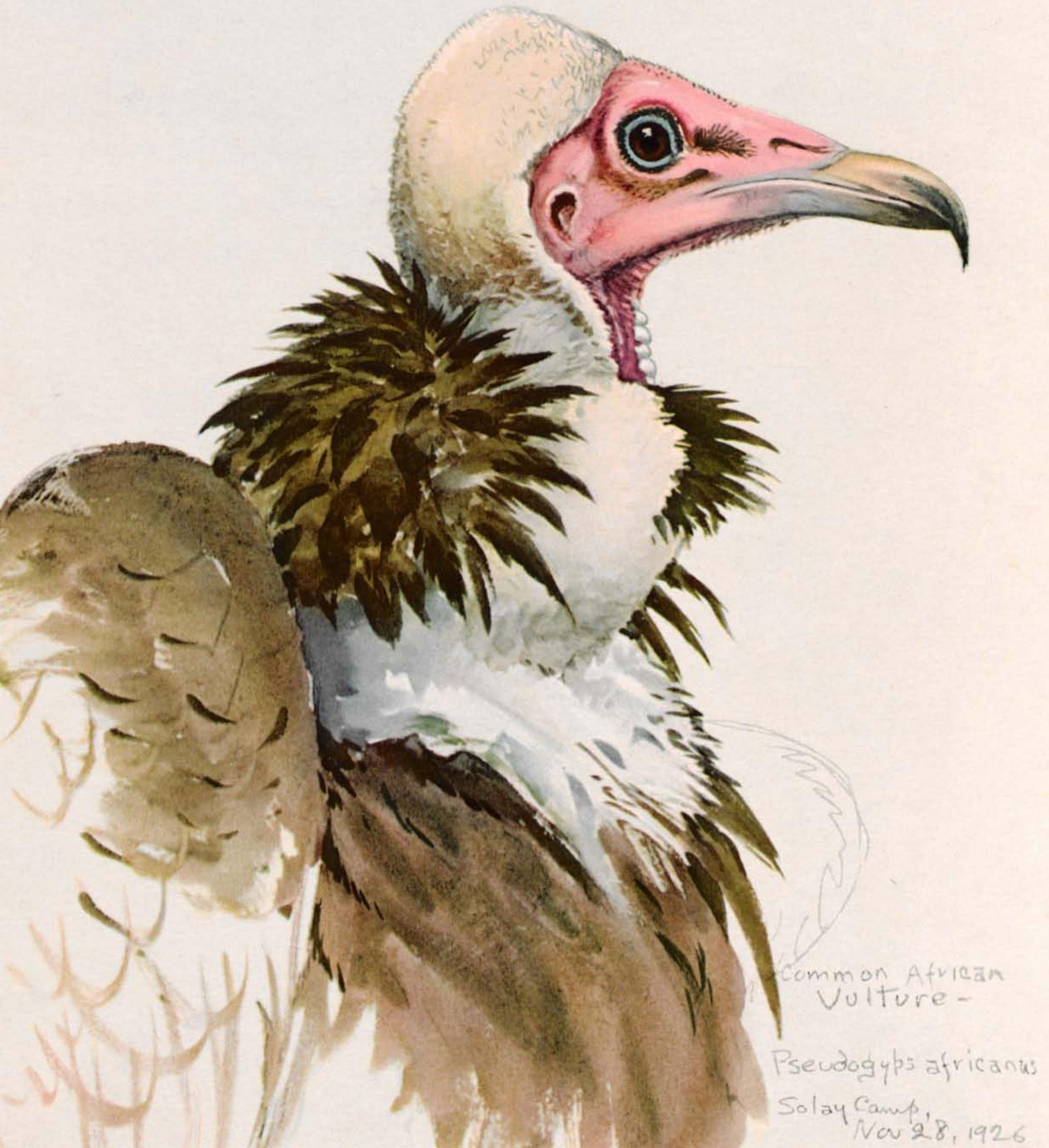


southern borders, west almost to South Sudan, and east to Djibouti.

Suggested reading: Brown \& Amadon, 1968; Brown, Urban \& Newman, 1982; Burton, 1989; Chapin, 1932; Cramp \& Simmons, 1980; Del Hoyo, Elliott \& Sargatal, 1994; Ferguson-Lees \& Christie, 2001; Grossman \& Hamlet, 1964; Steyn, 1982; Tarboton, 1989.

\section{African White-backed Vulture Gyps africanus}

This species is noticeably larger than the Egyptian and hooded vultures, averaging about 12 pounds $(5.5 \mathrm{~kg})$, but it is still not nearly so immense as the lappet-faced vulture. It is perhaps the most commonly encountered vulture on the plains of East Africa, and in Ethiopia is about equally as common as the similarly sized Rüppell's griffon vulture (Gyps ruepellii). Adults of the white-backed species are best separated from the Rüppell's by their slightly darker color, darker beak, and consistently dark brown eyes, rather than the yellow brown to pale gray eyes of an adult Rüppell's. Juveniles of the two are easily distinguished by the Rüppell's much paler, more "scaly" plumage pattern. The "white-backed" feature of this so-named species is evident only among adults and when seen in flight from behind or above. From below, its leading underwing edge exhibits a distinctive pattern of a strongly contrasting white stripe against an otherwise entirely blackish underwing and body.

Gyps is a classic Greek name for a vulture, and this species easily fits the typical vulturine mold. Its head is nearly bare of feathers except for some sparse yellowish down, and its beak is powerful and adapted for tearing or stripping flesh from bones (but not quite as strong as that of the largest vultures, such as the lappetfaced, and it thus has less ability to tear away the hide of thick-skinned mammals). Its feet and talons are relatively small and adapted for walking and grabbing carcasses rather than for killing prey.

Plate 10. Hooded Vulture (White-necked Vulture)
These vultures are scarcely territorial and defend only a small area immediately around their nest. Nests are usually in tall trees, especially thorny ones, and sometimes are organized into loose colonies of 10 to 20 pairs. Although they sometimes build their nest themselves, a pair is also likely to claim an abandoned nest of a stork or eagle or one of a similar size. Breeding in Ethiopia occurs between October and March, starting during the drier period, so the young are then being raised during the more productive spring rainy period. Usually only a single egg is laid, rarely as many as three. It is incubated by both sexes over the 56- to 58-day incubation period. As for other vultures, the fledging period is greatly prolonged and probably lasts about 120 to 130 days, with substantial variation according to the rate of parental feeding.

This species' population has been rapidly declining since the early 2000s. As recently as 2007 its status was changed from being a species of least concern to near-threatened, and in 2012 it was changed again to endangered. As of 2016 it was considered to be critically endangered by the International Union for Conservation of Nature. Poisoning, power line collisions, pesticides, and nesting tree losses caused by fires and elephant damage are among the many reasons for the species' decline, and especially the eating of carcasses that were purposefully poisoned. Poisoning is often committed by elephant poachers because the circling of vultures overhead might alert authorities to the location of an illegal kill. Numerous eBird reports indicate that Ethiopian sightings have occurred from the country's northern to southern borders, west almost to South Sudan and Sudan, and east almost to Djibouti.

Suggested reading: Brown \& Amadon, 1968; Brown, Urban \& Newman, 1982; Burton, 1989; Chapin, 1932; Del Hoyo, Elliott \& Sargatal, 1994; Ferguson-Lees \& Christie, 2001; Grossman \& Hamlet, 1964; Houston, 1976; Newman, 1971; Steyn, 1982; Tarboton, 1989. 
Lappet-faced Vulture

Aegypius tracheliotis (2 images)

The origin of this species' English name is selfevident: Aegypius tracheliotis similarly translates from the Greek as "gristle-eared vulture of Egypt." The extensive bare and wrinkled facial skin of this and many other vultures is apparently an adaptation to avoid facial overheating rather than a means of avoiding the accumulation of decaying flesh among its head feathers, as was once generally assumed.

This species and the lammergeier are the largest of the African vultures. Adult lappetfaced vultures average nearly 15 pounds $(6.8$ $\mathrm{kg}$ ), and one shot during the expedition had a wingspread of 9 feet 3 inches $(2.9 \mathrm{~m})$. However, it is not nearly as huge as the European griffon (Gyps fulvus), which might weigh more than 30 pounds $(13.6 \mathrm{~kg})$ and is one of the heaviest of flying birds. Both adult and young lappet-faced are mostly blackish brown with entirely bare heads and upper necks and massive, somewhat horncolored beaks. This vulture, or the hooded vulture, is probably the source for the totem present on the headdresses of high-born Egyptian women. The vulture motif represents the tutelary deity Nekht from the South, who gave protection to the queens of Egypt.

This historically was one of the commonest vultures of Ethiopia, where it ranges up to at least 13,000 feet $(3,960 \mathrm{~m})$, and breeds to about 9,000 feet $(2,740 \mathrm{~m})$. Studies of vultures on the Serengeti plains of Tanzania have shown that the birds can travel as far as 45 miles by exploiting a series of as few as six thermals, with each lifting them upward about 4,800 feet $(1,460 \mathrm{~m})$. When soaring, African vultures can reach remarkable altitudes. A Rüppell's griffon vulture once struck an airplane flying over the Ivory Coast at a height of 37,900 feet $(11,550 \mathrm{~m})$ !

The lappet-faced vulture's great size and its powerful beak allow it to dominate all the other African vultures at carcasses. Its huge beak also enables it to tear away tendons and skin more readily than most or all other East African species can do. They are often the last of the vultures to arrive at carrion, where they are able to rip apart the leftover bits of skin and bones. At times it will attack others with outstretched wings and neck, its back and tail feathers raised. Even at such times the birds are generally silent, a trait typical of both Old World and New World vultures. Hisses, grunts, and croaking sounds are the general limits of utterances by vultures, which lack the true syringeal structures that allow for precise sound modulation (fundamental frequency, harmonics, cadence, amplitude, etc.).

Like many other vultures, these birds spend the night roosting in trees, patiently waiting each morning for the sun to generate thermals strong enough to provide easy soaring. They then might spend as many as eight hours aloft in search of carrion. At times they will also take live prey, such as both young and adult flamingos, as well as their eggs. Prey as large as guineafowl and mongoose have also been reported. Insects such as locusts or termites might be consumed if they are easily available.

Breeding in Ethiopia and adjacent Somalia mainly occurs during the dry season between November and January, with extremes between October and April. These birds have long-term pairbonds, and each pair occupies a large territory that on the Serengeti plains might encompass from as little as two to as much as ten square miles. Within that territory nesting is usually solitary, but where food is abundant nests might be fairly close together, and sometimes even situated in apparent clusters.

Nests are typically constructed in the tops of trees, especially thorny species, and might be used for several years, unless they collapse or otherwise become unusable. Both sexes help construct the nest, and one or both birds will often roost beside it. As with other large vultures, a single egg is laid, but lost eggs might be replaced if the losses occur early in incubation. The long incubation period of 53 to 56 days is shared by both sexes. Even at hatching, the curious earlike head flaps are present. By 70 days of age the youngster is well feathered, but initial flight does not occur until 125 to 135 days, and normal flight occurs by about 135 days.

The entire breeding season for this huge species thus requires half a year, and dependence of 


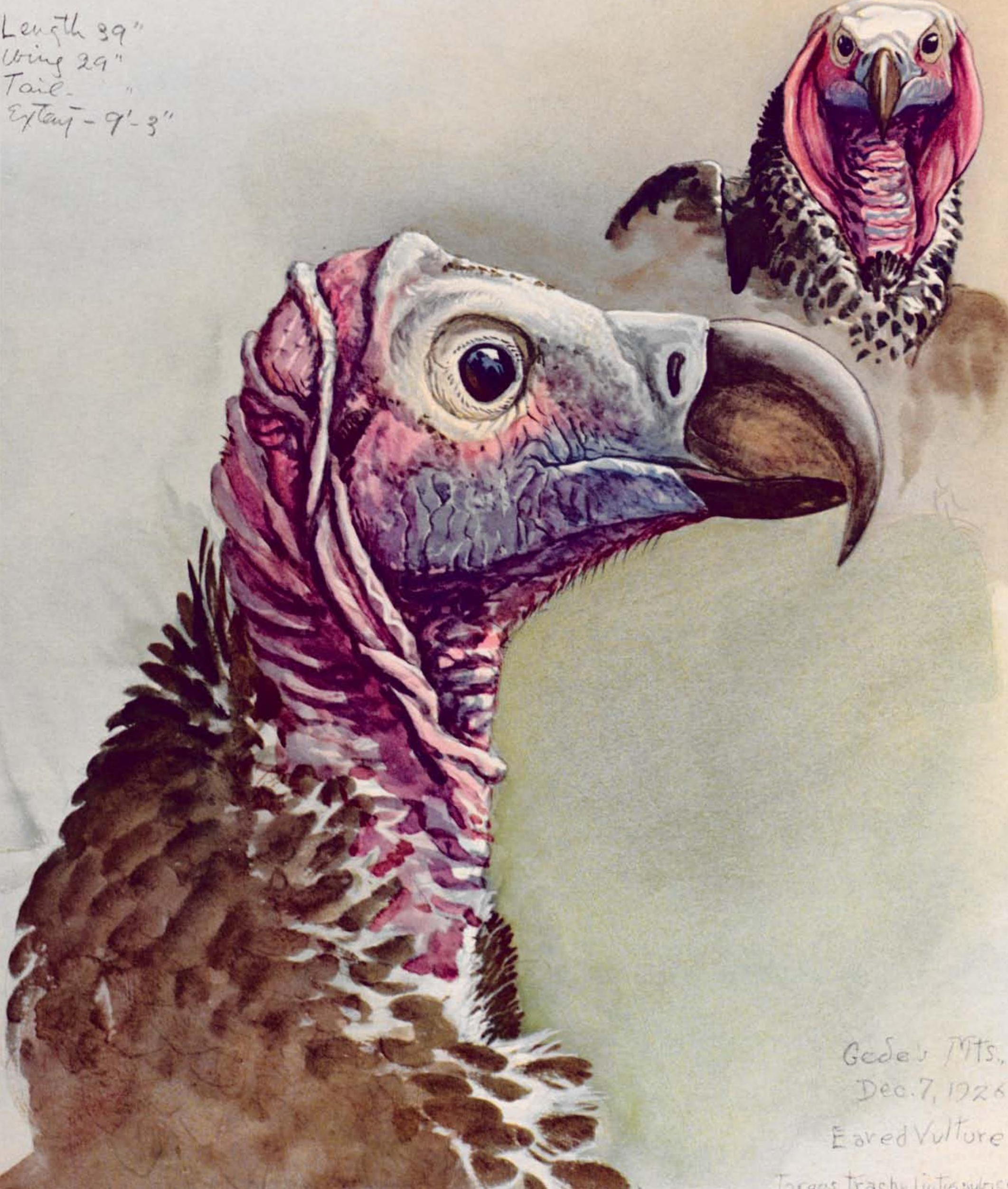


young on its parents for food might last another half year, with some young revisiting their nests as long as 293 days after initial fledging. It therefore seems likely that breeding might occur only in alternate years. The duration of immaturity is apparently still not certain, but probable sexual maturity and the definitive plumage with entirely white tarsal feathers have still not been attained by five to six years of age.

Overall nesting success is low, with an average of less than 0.5 young reared per breeding pair. Since it is likely that breeding efforts are not attempted annually, average overall breeding success is lower than this. This species' population was estimated at 5,700 individuals in 2016 and is considered to be endangered by the International Union for Conservation of Nature. Numerous eBird reports indicate that Ethiopian sightings have occurred from the country's northern to southern borders, west almost to South Sudan and east to Mile Serdo Wildlife Reserve.

Suggested reading: Brown \& Amadon, 1968; Brown, Urban \& Newman, 1982; Burton, 1989; Chapin, 1932; Cramp \& Simmons, 1980; Del Hoyo, Elliott \& Sargatal, 1994; Ferguson-Lees \& Christie, 2001; Grossman \& Hamlet, 1964; Mendelsohn \& Leshim, 1983; Newman, 1971; Pennycuick, 1976; Steyn, 1982; Tarboton, 1989.

\section{White-headed Vulture Trigonceps (Aegypius) occipitalis (2 images)}

This species, sometimes called the "white-necked vulture," is one of Africa's smaller vultures (averaging about 9 pounds), adults of which are unique in their short downy white head feathers and their white secondary feathers. The species' name Trigonceps occipitalis refers to its distinctive triangular head shape and its curious occipital "bump" of white feathers at the back of the head. Its beak is large, short, and mostly bright pink with a bluish base. The bare facial and chin skin can be pink or bright red, depending on the bird's level of excitement. Immatures also have a peaked head profile, but the head feathers are brownish, the bill is less colorful than in adults, and their secondary feathers are dark brown rather than white.

Females differ from males in the extent of white on their flight feathers; like the bateleur, females exhibit more white. When seen from below in flight adults show a similarly distinctive pattern, with their white secondaries contrasting with the blackish primaries. This arrangement is quite different from the underwing pattern of the white-backed and lappet-faced vultures, whose wings are all black from below, except for a white stripe along the leading edge. It also differs from the much larger Rüppell's vulture, which not only has a white leading edge but also two additional white stripes on the otherwise blackish under wing-coverts. Immature whiteheaded vultures are harder to identify in flight, but they have a narrow white line between their blackish under wing coverts and the slightly paler flight feathers.

This species is an increasingly rare vulture in eastern and northeastern Africa. Because of its relatively small size, it cannot effectively compete at carcasses with the largest vultures, such as the lappet-faced and white-faced. When scouting for carrion, it is a persistent searcher and sometimes seems to follow the sharp-eyed bateleurs. It is often the first of the vultures to arrive at carrion, only to be evicted as the larger vultures also find the carcass. However, by being first at a carcass it might be able to obtain a substantial meal before larger and more aggressive species arrive. Or, it may remain at the perimeter of a feeding group, settling for morsels that are too small for the larger vultures to fight over. The species' long neck also allows it to reach far inside the carcass where the soft interior organs lie. It also is a rapid eater, able to fill its crop is as little as two minutes. Like the lappet-faced, the white-headed vulture sometimes raids flamingo breeding colonies, eating the eggs and chicks, and it might also catch an occasional lizard.

In adjacent Somalia, the species' breeding season extends from October to March, with a peak in December and January. At least historically, up to ten nests occurred in semicolonial proximity. These increasingly rare birds now occur 

as widely spaced pairs and, like the lappet-faced and some other vultures, typically place their nests at the tops of trees, especially thorny ones. Little is known of pair-forming and pair-maintaining displays, but mutual soaring with the birds' wingtips close together has been reported as a possible display.

Presumably both sexes help build the nest of sticks, but there is no hard evidence of this. Only a single egg is laid, and the incubation period lasts 51 to 56 days. Although in most vultures both sexes participate in incubation, it has been suggested that in this species only the female incubates. Fledging requires about 110 to 120 days. After fledging the young bird remains close to the nest for several months. Adults weigh up to about 11 pounds.

There is only a small amount of information on reproductive success in this species, but it would appear that about 75 percent of the eggs that are laid succeed in hatching and that about half of the hatched chicks survive to fledging. Thus, perhaps about 40 percent of the breeding pairs succeed in rearing an offspring to fledging. Since not all pairs breed every year, the annual adult mortality rate must be quite low if the population is to remain viable.

The species' population was estimated at 5,500 individuals in 2015, and it is considered to be critically endangered by the International Union for Conservation of Nature. Numerous eBird reports indicate that Ethiopian sightings have occurred from the country's northern to southern borders, west almost to South Sudan and east almost to Djibouti.

Suggested reading: Brown \& Amadon, 1968; Brown, Urban \& Newman, 1982; Burton, 1989; Chapin, 1932; Del Hoyo, Elliott \& Sargatal, 1994; Ferguson-Lees \& Christie, 2001; Hustler \& Howells, 1988; Newman, 1971; Pennycuick, 1976; Steyn, 1982; Tarboton, 1989.

\section{Bateleur}

Terathopius ecaudatus (4 images)

The bateleur is second only to the lammergeier in the number of images Fuertes devoted to birds on his African expedition. He had a special love for the raptors and could depict them as few, if any, artists had done before or have done since. Perhaps the only peer of Fuertes in this regard was the nineteenth-century German artist Joseph Wolf, who also painted magnificent raptor portraits, especially of falcons.

The majestic appearance of the bateleur has also found its way into African folklore. The Maasai of the East African plains, known for their impassive courage in the face of lions while armed only with spears, believe the bateleur carries off the spirits of their dead, and especially those of tribal elders or chiefs. Other cultures have also associated this bird with warfare or death. Yet, in captivity the birds often become very tame and make spectacular zoo exhibits.

Hardly anyone familiar with raptors can remain unimpressed on first seeing this bird in flight; it would seem to be an unusually largeheaded and long-winged eagle that has somehow lost its tail. Its appropriate Latin name means "tailless bird with a marvelous appearance." The common name provides a better clue to its distinctive, seemingly unstable flight behavior; "bateleur" in French means a tightrope walker, who often tilts a bar from side to side to maintain balance. In older birds the feet extend back beyond the tip of the tail in flight. Fuertes noted that because of its short tail and large head, the bird sometimes seems to be flying backward. The species' very short tail contrasts with remarkably long, rather pointed wings, producing a flight profile similar to that of a lightweight glider. From below the birds present a black-and-white appearance, with the head and body black while the under wing coverts are pure white except for the contrasting black tips of the flight feathers.

Adult bateleurs have average weights of about 4.8 pounds $(2.2 \mathrm{~kg})$. Both sexes have thick, rufflike black neck plumage, and an area of bright red skin extends from in front of the nostrils back to and around the brown eyes. The tip of 


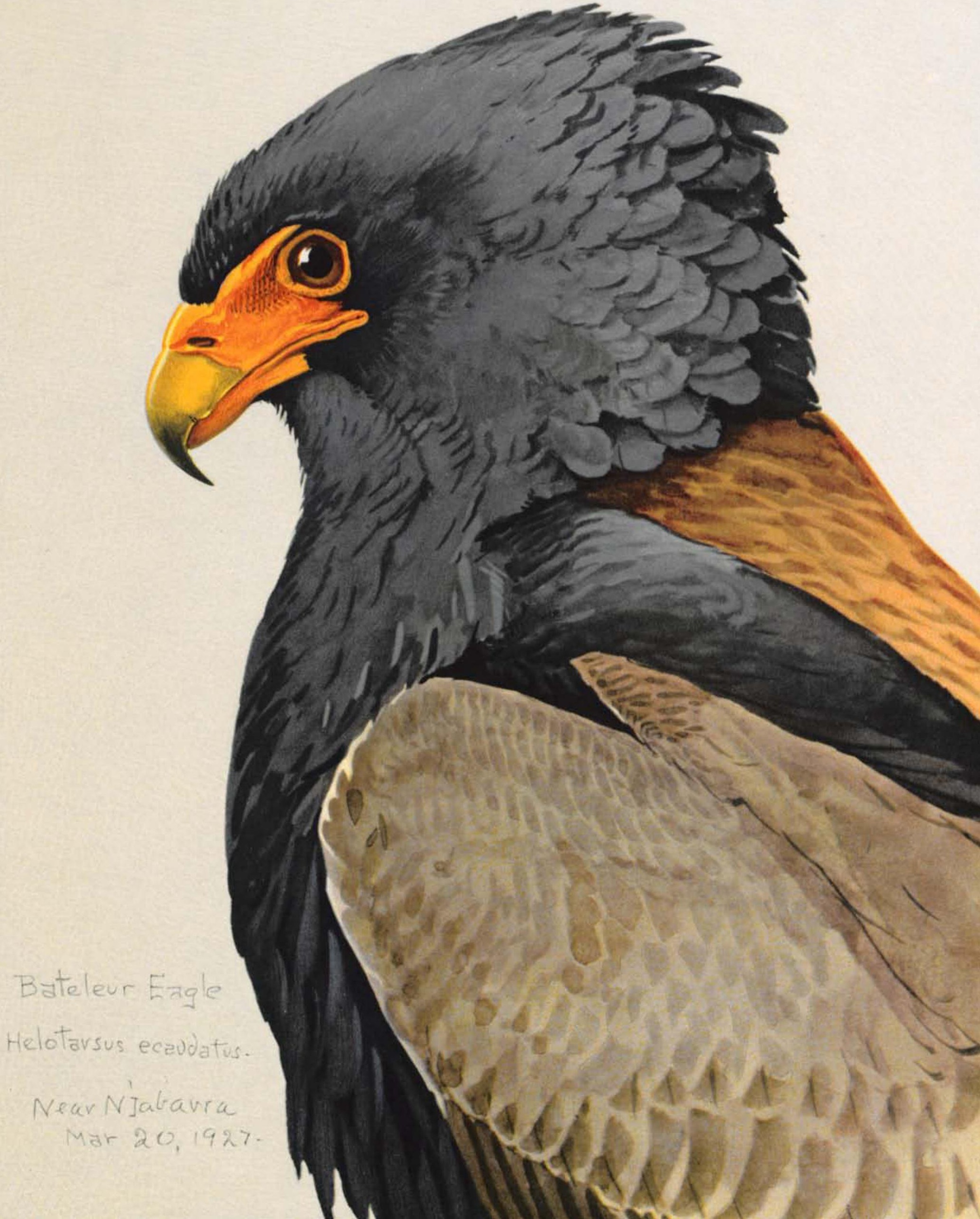


the upper mandible is orange, and the feet are also bright red. Unlike most eagles, the adults are sexually dimorphic; males have all their upper wing coverts brown, and their secondaries are mostly gray to whitish, whereas females have black secondaries and greater secondary coverts. In both sexes there are two distinct color "morphs," one with chestnut on the upper back (the type illustrated by Fuertes) and the other with cream-colored or pale brown feathers in this area. The latter morph might be more common in drier areas, or its existence may be age-related.

Immature birds are rather distinctive; it might take seven years for the definitive adult plumage to be attained. In first-year birds, the tail is longer than the extended legs, and by the second year they are about equal in length. In older birds the tail is still shorter and not visible from below. Gradually the predominantly brown colors of young birds are replaced, and sexual dimorphism in plumages begins to become apparent by the time they are at least five years old. Probably by their sixth or seventh year immatures begin the pair-forming activities that will eventually lead to the establishment of breeding territories. By then their plumage is also nearly adultlike, with sexual differences in their flight feathers appearing and their facial skin turning red. Lastly their under wing coverts change from mottled brown to pure white. Eight years are required to attain the definite adult plumage with entirely gray scapulars.

Bateleurs are fairly vocal eagles and possess loud screaming and barking calls along with various softer vocalizations. They vocalize during aerial display, in aggressive encounters, and when defending the nest as well as in other situations. More common in well-grassed and woodland habitats than in arid lands, these birds in Ethiopia are sometimes seen at altitudes as high as about 15,000 feet $(4,570 \mathrm{~m})$.

Like vultures, bateleurs rise soon after sunrise, as the temperature increases, and spend much of the day in flight, cruising at surprisingly rapid air speeds of about 35 to 45 miles per hour, sometimes soaring to substantial heights. It is possible that at least 200 miles might be covered during a single day's activities. During such soaring and especially during long glides the wings often are slightly swept backward, presumably to gain air speed. Fuertes's plate shows the somewhat swept-wing appearance of these birds very well. The birds do not fly in tight circles but rather course about in broad arcs, rarely landing except to feed or drink.

On sighting prey, bateleur eagles undertake powerful attacks, sometimes swooping down from hundreds of yards above and striking with their strong toes and sharp talons. Prey includes snakes, mammals up to about nine pounds in weight, birds as large as guineafowl or small bustards, and fairly large lizards. They are opportunistic foragers, taking more mammals in some areas or at different times and more birds in others. At times even insects might be eaten, as well as carrion, and the birds must have remarkably fine eyesight, as they can locate small items of carrion with surprising speed. The average adult weight is nearly five pounds.

Pairs are permanently formed, and adults appear to be sedentary, with breeding territories scattered over ranges of about one pair per 20 to 75 square miles. During courtship or territorial advertisement display, the male might perform rapid barrel rolls while in level flight above his territory, or rock from side to side. He might also dive from a great height while screaming loudly, narrowly passing the female as she rolls upside down to present her talons to him. The same or a very similar display might be performed toward territorial intruders, during which actual talon grappling occurs.

Nests are constructed of the usual array of branches and sticks, and are usually placed in the main fork of open-country thorny trees, such as acacias. I remember passing below such a nest on the Serengeti plains in a Land Rover, while the parents screamed defiantly from the tree above. At least in some areas the birds seem to prefer nesting near a road or trail, presumably allowing a better view of incoming human traffic. The nest is lined with green leaves but nevertheless might smell as bad as a vulture's nest. Both sexes participate in building or rehabilitating old nests. In Ethiopia nesting occurs between June and December, the birds avoiding the driest period 
Bateleur Eagles

(Hielotaysus eoradotus)

Tf'J barra, Gojan

- Mlar. 20, 1927.
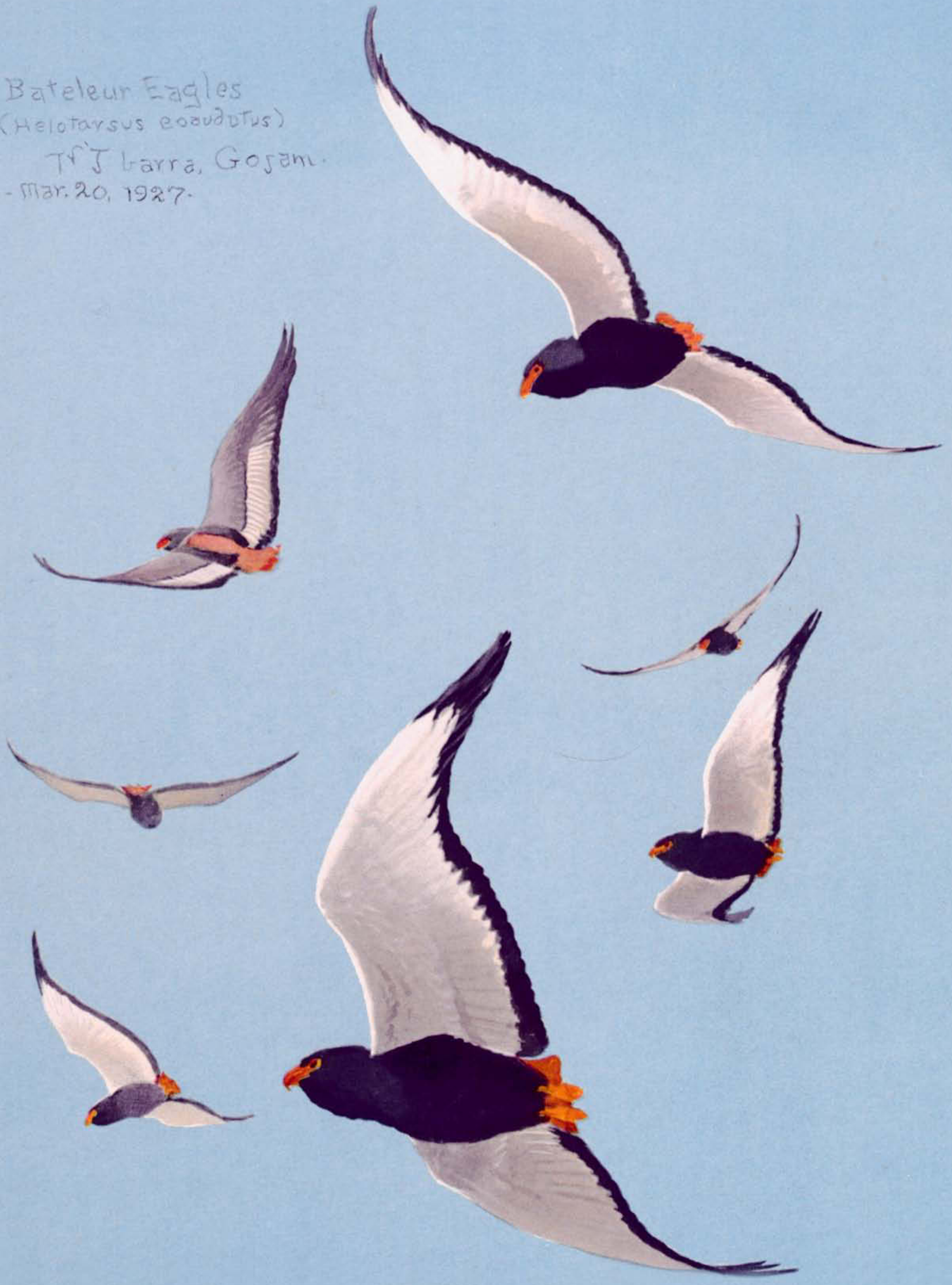
that occurs early in the year. In adjacent Somalia the breeding season is similarly from July to December.

One unusual feature of the bateleur's breeding biology lies in the fact that a third adult is sometimes present, both during early and later phases of the nesting cycle. This extra bird has been found to be a male in the observed cases. It has been seen roosting with the paired male as the female incubates and perhaps will help defend the nest when disturbance occurs. However, it has not been seen at the nest, nor has it been observed gathering food for the young. It is possible that this extra bird is actually a subadult associating with a breeding pair, and it might be tolerated even after the assumption of its adult plumage.

A single egg is the invariable clutch, an unusual number for eagles, which often have twoor three-egg clutches. The female performs most of the incubation, but she receives some help from the male, and on warm days the nest might remain untended for some time. The incubation period lasts 52 to 59 days, and the downy young is mostly white below and dark brown above. By two weeks of age the chick will have increased in weight fivefold, and by 42 days approximately eleven-fold.

The chick's maximum weight, about 20 times that of the hatching weight, is attained by about 70 days, and thereafter there is a slight weight decline. Fledging often occurs at 110 to 115 days, with some occasionally considerably longer or shorter extremes (93 to 194 days reported) probably depending on the rate and amount of feeding. These are unusually long incubation and fledging periods for eagles. Much of the daytime period is spent with the adults away from the nest, presumably foraging, and the eaglet's first flight is often made without parental involvement.

After a few days, the fledgling eagle leaves the nest vicinity, but it remains dependent upon its parents for some time thereafter, probably about four months. As with most raptors, breeding success appears to be rather low; a pair can be expected to produce about 0.5 fledged young per breeding cycle. Mortality among immatures is high in all raptors, and by the time sexual maturity occurs at seven years of age probably as many as 97 to 98 percent of the fledged young have died. This means the breeding population must include many quite old breeders, and it is possible that a few wild birds might live for 20 to 25 years.

Little good information on bateleur populations exists, but the species has evidently declined everywhere, owing to such things as loss of nesting trees and favorable foraging habitats. In some areas consumption of purposefully poisoned carcasses has affected the eagles' populations, and there are also some indications of general pesticide poisoning affecting them. They are now most likely to be seen in national parks and wildlife reserves, and at the start of the twenty-first century were thought to number less than 100,000 birds.

The bateleur is not yet globally threatened but its decline in most areas has been substantial and warrants its continued monitoring. Numerous eBird reports indicate that Ethiopian sightings have occurred from the country's northern to southern borders, west almost to South Sudan and east to Yangudi Rasso National Park. In 2016 it was classified by the International Union for Conservation of Nature as near-threatened.

Suggested reading: Brown \& Amadon, 1968; Brown, Urban \& Newman, 1982; Burton, 1989; Chapin, 1932; Cramp \& Simmons, 1980; Del Hoyo, Elliott \& Sargatal, 1994; Ferguson-Lees \& Christie, 2001; Moreau, 1945; Newman, 1971; Steyn, 1965, 1980, 1982; Tarboton, 1989; Watson, 1990.

\section{African Harrier Hawk Polyboroides $\boldsymbol{t}$. typus (2 images)}

This rather strange-looking hawk has a Latin generic name meaning "resembling a caracara," in reference to its similarity to the New World caracaras of the genus Polyborus. It is not a very apt comparison since caracaras tend to be scavengers, whereas the harrier hawk is an active predator, with unusually long, oddly "double-jointed" legs. These allow the feet to be bent backward as well as forward, so the bird can reach into a tree cavity for prey and bend its feet downward enough to 


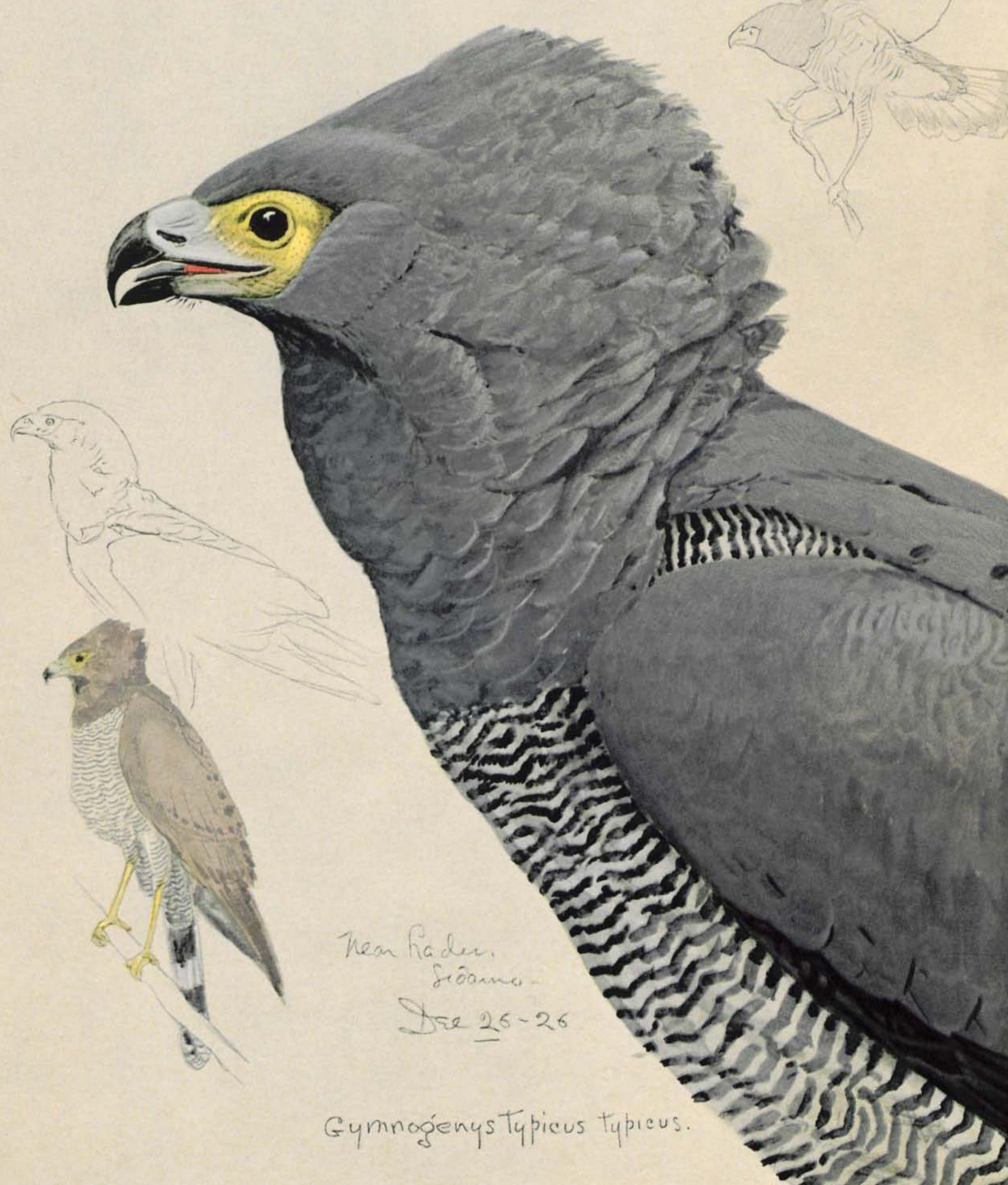


clutch objects at the base of the cavity. Such prey often include the young of cavity-nesting birds, such as kingfishers, rollers, and barbets.

Another odd feature of this species is its "blushing" ability. Its alternative vernacular name "gymnogene" is Latin and means "bare cheeks," referring to its mostly unfeathered face, which is usually pale yellow. However, when excited or perhaps threatened this facial skin can rapidly turn bright red, which might represent a type of appeasement signal between paired birds or have other social functions.

Harrier hawks are mostly uniformly gray as adults, with darker wings, somewhat like male northern harriers (Circus hudsonicus) and the hen harrier (Circus cyaneus) of Britain. Females are larger than males and have more black spotting on the wing coverts. However, instead of a white rump as in the northern harrier, the tail is banded with black and white, and the lower flanks and legs are finely barred with black. Immatures similarly resemble the brown females of northern harriers to some degree but again lack white rump patches and vary in color from buffy ginger to medium brown.

The flight profiles of harrier hawks and harriers are also dissimilar. The harrier hawk has a slow, buoyant, and rather "floppy" flight on horizontal broad and rounded wings rather than the low, coursing flights of true harriers, which remain close to the ground and glide with the wings held upward at a slight dihedral angle to help increase their aerial stability.

Harrier hawks often hunt by high or low soaring or might scan their surroundings from perches in a buteolike style, waiting patiently for prey to show itself. Or, one might climb about on tree trunks, cliff faces, or embankments, looking for small or large cavities into which it can insert a leg and feel about for living prey. When robbing the nests of colonial weaver birds, it might hang upside down from a branch above, flapping its wings as necessary to maintain its position.

In some areas of West Africa, harrier hawks regularly hunt among the fronds of certain fruiting oil palms (Borassus) not only to try to locate live hidden prey but also to find and eat the fruit that might be present. Their legs can be bent backward to an angle of about 70 degrees but are also flexible from side to side, an adaptation perhaps unique to predatory birds as well as birds generally.

Harrier hawks are sedentary birds, with paired adults remaining on their territories year-round. These territories are advertised by undulating flight displays or circular flights that are not very different from the rather circular advertisement flights of true harriers (hence their generic name Circus). The birds might also fly in tandem, the female directly below the male. The male will then approach the female and lower his feet to touch her back, at which time she flips over on her back and presents her feet to his. The pair-bond is reinforced by repeated matings, both before and during the nesting cycle.

Nests are usually placed in trees but sometimes are in rock crevices at the base of a tree. Seasonality of breeding for Ethiopia and Somalia seems to be unreported. There are usually two eggs in the clutch, and incubation requires about 35 days. Both sexes incubate, but it's mainly the female, while the male gathers food for her. Typically only a single nestling lives long enough to fledge; the younger and weaker one usually starves. Fledging requires about 50 to 55 days, but juveniles remain dependent upon their parents for some time thereafter. The young birds initially concentrate on easy targets, such as insects, before slowly learning how to become effective predators of more difficult prey. Average breeding success is about 0.5 young fledged per pair, counting nonbreeding pairs.

This species is widespread across sub-Saharan Africa and was considered to be a species of least concern as of 2016 by the International Union for Conservation of Nature. A closely related species occurs in Madagascar. Numerous eBird reports indicate that Ethiopian sightings have occurred from the country's northern to southern borders, west almost to South Sudan and east to about Awash.

Suggested reading: Brown, L. H., 1972; Brown \& Amadon, 1968; Brown, Urban \& Newman, 1982; Chapin, 1932; Del Hoyo, Elliott \& Sargatal, 1994; Ferguson-Lees \& Christie, 2001; Grossman \& Hamlet, 1964; Newman, 1971; Steyn, 1982; Tarboton, 1989. 


\section{Tawny Eagle}

Aquila rapax belisarius (3 images)

This eagle is very similar to and a fairly close relative of the transhemispheric golden eagle ( $A q$ uila chrysaetos) but is only about half as heavy. Fuertes's group sketch shows a tawny eagle in frontal head view (below), progressively above which in a tree are a white-headed vulture, two thick-billed ravens, a tawny eagle, a black kite, and another tawny eagle.

In common with other eagles, the period to sexual maturity and fully adult plumage is a prolonged one, requiring several years, probably four. Immature birds tend to be more streaky or blotchy in plumage pattern and usually have more white on their upper tail coverts than do adults. They also tend to have broader pale edgings to their larger feathers. Both immatures and adults have barking voices, somewhat like those of corvids, but-except during aggressive encounters or during courtship-they are fairly quiet birds.

Like all other eagles, females are the larger sex, and adults average about six pounds $(2.7 \mathrm{~kg})$, with a maximum of about eight pounds $(3.6 \mathrm{~kg})$ (in the African population), whereas males average about five pounds $(2.3 \mathrm{~kg})$. Prey weighing up to about their own weight might be killed, including very small antelopes, gazelle calves, and bustards weighing up to about four pounds. Thus the birds are very effective predators on fairly large prey, including many so large that they cannot be carried off. Tawny eagles also regularly gather to forage on carrion, and even eat insects, especially exploiting swarms of locusts or termites. They also eat lizards and snakes and are proficient hunters at flamingo colonies, where perhaps they are primarily scavengers. They are also excellent pirates, taking food away from vultures, other raptors, and storks. Mammals may be their most important prey when judged by collective weight, but birds are more significant when judged by number of prey items taken.

This species is one of the most migratory of eagles; in Asia the birds breeding in Russia must cross the Himalayas during migration. Carcasses of these birds have been found at 26,000 feet $(7,927 \mathrm{~m})$ on the slope of Mount Everest, appar- ently having failed in their efforts to cross this mighty mountain range. Both resident tawny eagles and migrants from Europe are likely to occur in Ethiopia; Fuertes painted the resident Ethiopian race "rapax" (now included within belisarius) rather than the larger and darker Eurasian race orientalis. There is an even larger far-eastern race nipalensis, which sometimes reaches Africa and might be almost as large as the golden eagle.

In Ethiopia the birds occur in the highlands up to at least 14,000 feet $(4,500 \mathrm{~m})$, and at these altitudes the birds often forage on mole rats. The European migrants also funnel down the Rift Valley of Ethiopia on fall migration, sometimes in substantial flocks. These autumn flocks pass through Ethiopia in October. Spring migration northward occurs during March and April. Breeding by the resident Ethiopian birds occurs from November through December and lasts to as late as March. Breeding records from nearby northern Somalia similarly extend from September to February.

Whether migrants or residents, tawny eagles roost from about two hours before sundown until a similar time after sunrise, which leaves only eight or nine hours for hunting. After roosting, they move to convenient lookout posts and begin scanning their surroundings for possible prey. Birds might be captured from a diving stoop, or overtaken in level flight, or sometimes taken by surprise on the ground. Flamingos can be knocked out of the air, and it is likely that most mammals are chased down. At times garbage sites might be visited, either for the waste materials there or perhaps to capture rats. Tawny eagles are also effective pirates, frequently stealing food from bateleurs through persistent harassment.

As with other eagles, pair-bonding is permanent, and a breeding pair might occupy a hunting territory of about 11 to 20 square miles (2555 square $\mathrm{km}$ ). This breeding and hunting range might occur within an overall range or population density of about a pair per 40 square miles (100 square $\mathrm{km}$ ), with pairs scattered at distances of about 12 miles $(20 \mathrm{~km})$.

Within this territory the pair advertises and defends their location. Both birds might soar overhead in tandem, and the male might repeatedly dive and regain altitude, or might descend to- 


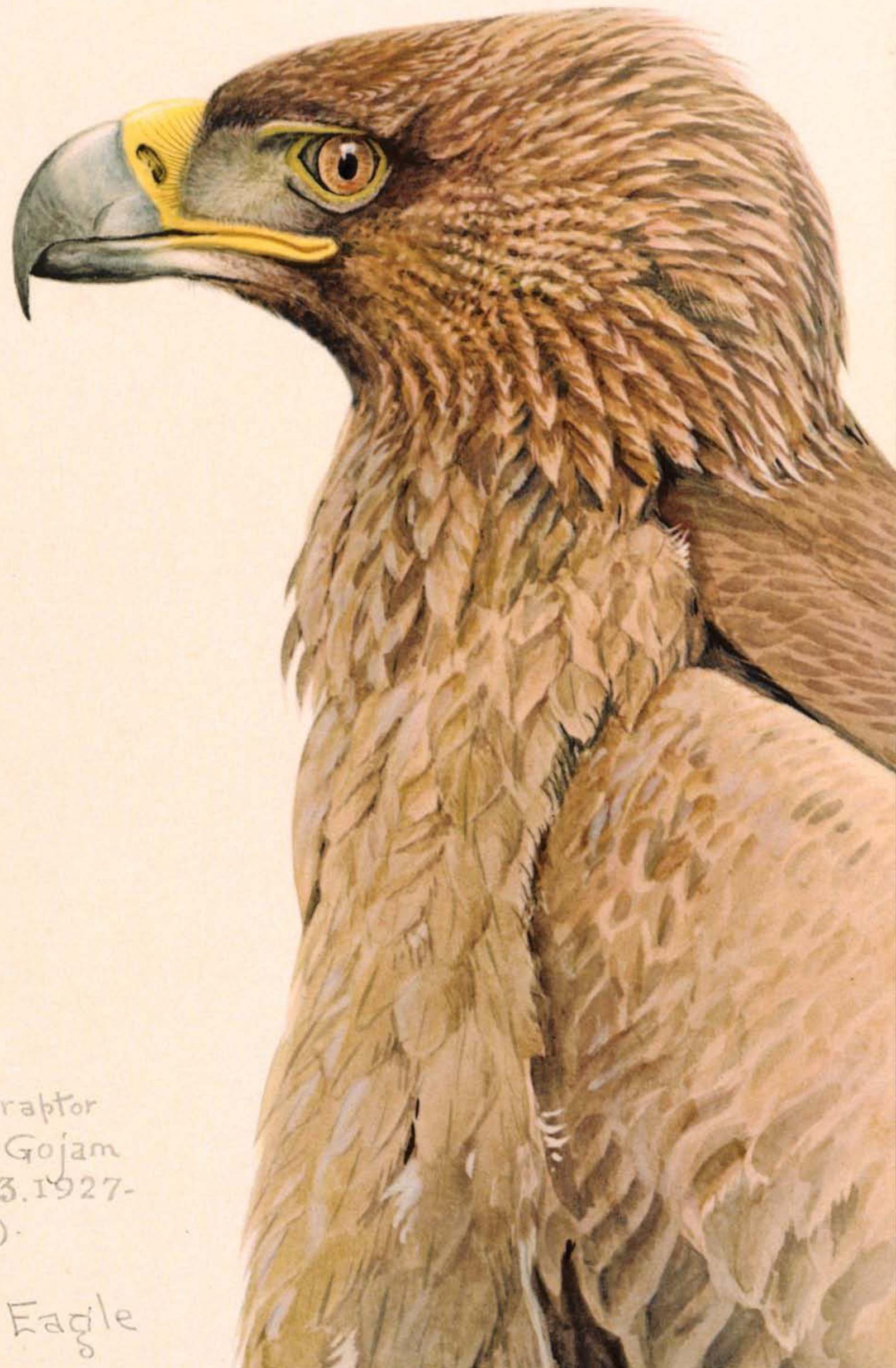


ward the female, who in turn will roll over on her back and present her talons to him. This apparent mock fighting is scarcely different from the swooping attacks of a male on a potential rival intruding into the pair's territory, and it might be impossible for humans to distinguish such behavioral differences, except perhaps from their outcomes.

Like other eagles, nests are typically placed where a commanding view is available, such as at the tops of tall trees, especially thorny or spiny ones. A single nest might be used repeatedly for up to about three years, after which time it might be abandoned and a new one begun nearby. The nest is constructed of sticks and might become quite large, especially after repeated use.

Two eggs usually make up a clutch (sometimes one or three), laid at three-day intervals. Incubation begins immediately and lasts about 40 to 45 days, usually closer to the latter, with the female doing most incubation. Predation by crows is apparently a serious threat. The chicks hatch at intervals of two or three days, and by two weeks have increased their weight tenfold. By 56 days they average heavier than their parents, and at that stage are fully feathered. First flights are likely to occur at 75 to 85 days. Gradually the young develop independence, probably by eating carrion until they become proficient hunters. Within a year the young might drift as far as 150 miles from the nest.

Several races of the tawny eagle extend over much of Eurasia, where they are sometimes also called the steppe eagle. It might be the most numerous of all the larger eagles, and it occupies a wide range of fairly open habitats. In Africa the total population might have been about 250,000 birds during the late 1970s, but because of its carrion-eating tendencies it is susceptible to indirect pesticide poisoning or purposeful poisoning by poachers. Such poisoning could be a major cause of recent population declines in southern Africa. A recent African estimate is about 74,000 pairs; in Ethiopia it is still the most common species of eagle. Numerous eBird reports indicate that Ethiopian sightings have occurred from the country's northern to southern borders, west almost to South Sudan and east to Mile Serdo Wildlife Reserve.
Suggested reading: Brown \& Amadon, 1968; Brown, Urban \& Newman, 1982; Burton, 1989; Chapin, 1932; Cramp \& Simmons, 1980; Del Hoyo, Elliott \& Sargatal, 1994; Ferguson-Lees \& Christie, 2001; Grossman \& Hamlet, 1964; Newman, 1971; Steyn, 1970, 1982; Tarboton, 1989.

\section{Long-crested Eagle Lophaetus occipitalis (2 images)}

Few African eagles are more attractive than the long-crested eagle; its long, rakish crest alone identifies it, but additionally the bird appears almost entirely black when perched, with contrasting white edging along the front of the wings and a boldly banded black-and-white tail. Immatures are scarcely different from adults; the crest is slightly shorter and the eyes of young birds might be more brownish rather than the golden yellow of the adults. The feet and the fleshy base of the bill (the cere) are also yellow in the young as well as adults. Noisier than the tawny eagle's, a longcrested eagle's screaming call from a nearby tree suddenly woke me up one morning as I slept on the rim of the Ngorongoro Crater, providing an indelible memory of wild Africa.

These are not very large eagles; adult females average about four pounds $(1.8 \mathrm{~kg})$ and males perhaps slightly over three $(1.4 \mathrm{~kg})$. As a result, they take few of the prey species used by the tawny eagle and rather concentrate on small rodents, much like some of the Buteo hawks of North America. Probably in some regions both tawny and long-crested eagles compete for mole rats, as this is a common prey item for both. Long-crested eagles are a woodland and woodland-edge species rather than an open-country bird like the tawny eagles, and in early morning they are likely to be seen on a tall tree or other elevated site, searching intently for prey. Later in the day they often soar over more open country and, like many other rodent-eating raptors, are quickly attracted to grassland fires, where they can opportunistically pounce on small rodents as they become exposed and try to escape the flames. 
Because they are such good rodent hunters, long-crested eagles are attracted to cultivated areas, where they are distinctly beneficial from a human standpoint. Luckily, they evidently do not take poultry so pose no apparent threat to poultry-raisers. They do, however, take an occasional guineafowl or francolin. Probably more than 95 percent of their food consists of small rodents, especially medium-sized rats. They might also prey on hatchery-raised trout or even eat fruit occasionally.

Breeding pairs occupy fairly large hunting and breeding territories, perhaps averaging at least 1,000 acres (405 ha), and generally are found at lower rather than higher elevations. Breeding occurs from June to August in northeastern Africa, and few if any migratory movements during the nonbreeding season are typical. In some favorable years or areas, two broods might be raised in a single year. Pair-forming behavior is not particularly conspicuous, and it is possible that vocalizations are more important than is aerial maneuvering when advertising territories. Some undulating flights, swoops, and dives have been seen, however, so the general usual pattern of raptor territorial advertisement is probably present.

Nests are built in trees, often not in thorny species but instead in introduced eucalyptus trees, whose twigs and leaves make effective nest components. The nests are surprisingly small, often barely hiding the incubating or brooding bird. They might be constructed annually but sometimes are reused for as many as three years. Sometimes the nest of another species might be adapted to fit their needs.

Single-egg and two-egg clutches are equally frequent; larger clutches are apparently rare or absent. Incubation begins with the first egg; the male might incubate for short periods, but the female handles most of the 42- to 44-day incubation period. If two young are hatched, the second could be considerably younger (up to 14 days) than the first-hatched sibling. In spite of such large age differences, little or no sibling aggression is typical. It takes about three weeks for a chick to increase its hatching weight tenfold, and a maximum weight is attained by about 80 days.

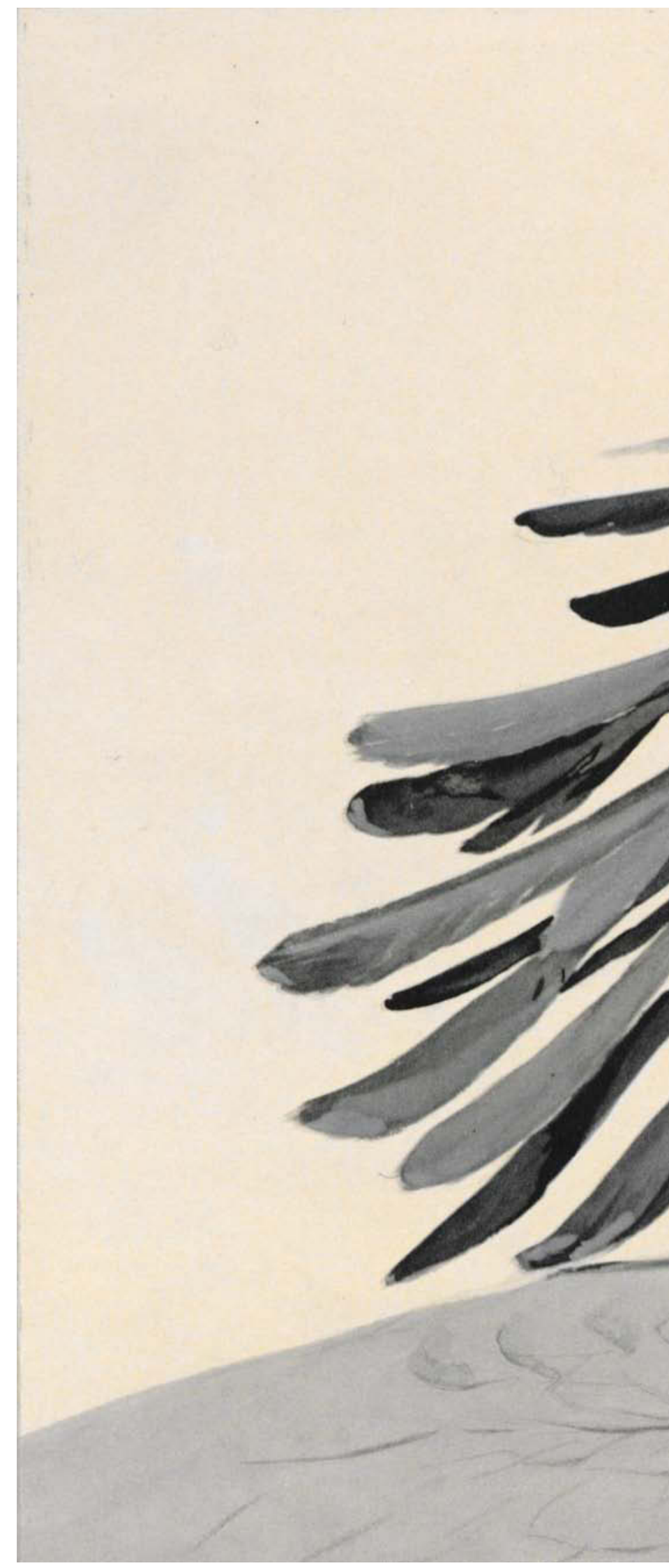




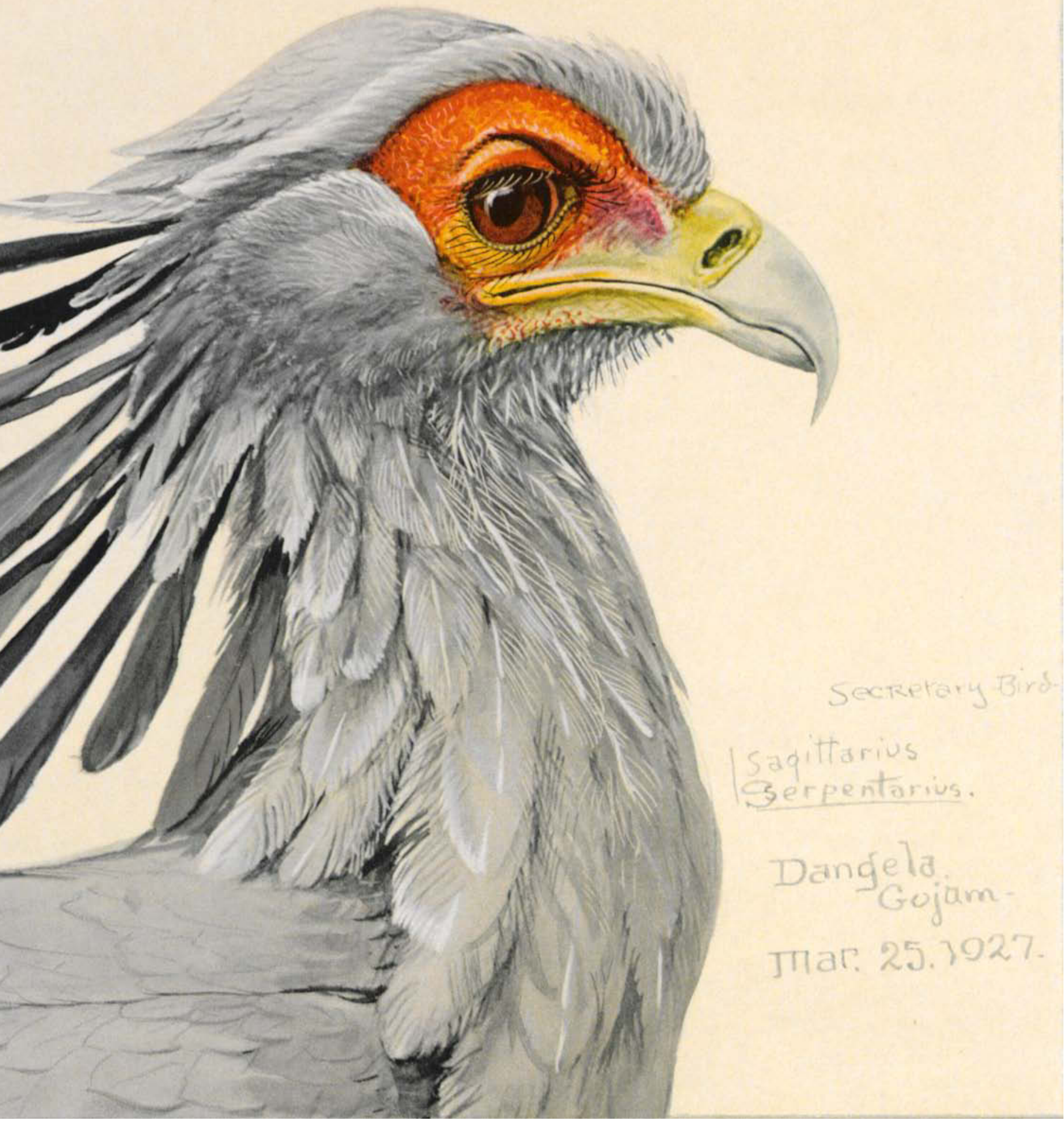


Initial flight attempts occur by around 55 to 58 days. On average, less than one youngster is raised per nest; in one 16-year study the average was 0.65 young reared per nesting effort. An adult-like plumage is attained during the first year, but presumably initial breeding occurs only after at least two years.

This species is widespread across Africa, with an estimated population of 10,000 to 100,000 individuals in 2009, and as of 2016 it was considered to be a species of least concern by the International Union for Conservation of Nature. Numerous eBird reports indicate that Ethiopian sightings have occurred from the country's northern to southern borders, west to South Sudan and east to about Yangudi Rassa National Park.

Suggested reading: Brown \& Amadon, 1968; Brown, Urban \& Newman, 1982; Burton, 1989; Del Hoyo, Elliott \& Sargatal, 1994; FergusonLees \& Christie, 2001; Grossman \& Hamlet, 1964; Newman, 1971; Steyn, 1978; Tarboton, 1989.

\section{Family Sagittariidae (Secretary Bird)}

\section{Secretary Bird \\ Sagittarius serpentarius ( 2 images)}

The secretary bird is as much a "signature bird" of the African plains as are the ungulates or the kori bustard. It can often be seen at a distance, striding purposefully about in the low grasses, its crest sometimes waving about in the breeze, and its bright orange-yellow facial skin conspicuous against its otherwise mostly grayish plumage. At times it seems to be a hawk pretending to be a stork: its long legs and striding gait are storklike; the neck is long and extended in flight like a stork's, and its short toes have rather short claws that are seemingly not very effective in subduing prey. Its prey mainly consists of small mammals, the eggs and flightless chicks of ground-nesting birds, lizards, and snakes.
Snakes are probably less important prey than was believed to be true in the past, and that was the basis for the bird's specific name serpentarius. Its common name probably derives from the long, somewhat spatulate-tipped and blackish crest feathers, which extend backward in a way that brings to mind pencils rather randomly protruding from the hair of a pre-computer era secretary or the quill pens of a scribe. However, sagittarius means "archer," and perhaps the crest feathers reminded J. Hermann, the person who named the genus, of a quiver of arrows. These feathers are usually erected halo-like during attacks on prey, perhaps simply as an excitement response or possibly to help scare and expose prey.

Other wonderful features of the secretary bird are its large, hazel-brown eyes and their associated eyelash-like bristles, beautifully shown by Fuertes. Another unusual trait is the long pair of central tail feathers, which extend well beyond the others. Its beak is sharply hooked and certainly raptorlike, but prey are often subdued by strong kicking movements rather than by crushing the neck vertebrae with the beak in the manner of many raptors. Probably the kicking method allows the bird to deal with venomous snakes while still keeping its more vulnerable areas away from the snake's fangs. Even cobras and adders might be attacked by secretary birds, which are remarkably quick and dexterous in avoiding being struck.

The eggs of larger birds such as francolins and guineafowl are apparently favorite foods and might be swallowed whole; even lost golf balls have sometimes been mistaken for eggs and swallowed. Secretary birds are still fairly common in the drier parts of Africa, and their snakeeating abilities have generally earned them both respect and protection.

Secretary birds range fairly widely in their daily hunting expeditions; the birds usually hunt in pairs, and a pair might occupy a remarkably large hunting and breeding territory of about 8 to 27 square miles (20-70 square $\mathrm{km})$. To traverse this broad area the birds might resort to flight; on warm days they use thermals to gain altitude and circle about, presumably to scan the land 
below for possible prey, or perhaps to advertise their territorial ownership. Aerial display also occurs during courtship, when soaring and calling are common, as are "pendulum flights," when the bird stalls, swoops down with wings mostly closed, then pulls out of its dive only to gain altitude again and repeat the process.

Within their territory the pair selects a low but thorny tree, usually a flat-topped acacia, for their nest. This is a surprisingly large and bulky structure up to as much as about eight feet in diameter. The usual clutch is of two eggs; curiously they are rather chalky in texture, looking more like those of storks than hawks. However, like typical hawks and eagles, the female is slightly larger than the male and performs most or sometimes even all the incubation. On returning to the nest to take a turn at incubation, a leafy branch or other green vegetation is typically presented to the incubating bird, who then rises and performs a bowing display while calling and fanning its tail. This unusual nest-relief ceremony also has some similarities to those of storks.

Incubation lasts about 45 days. The hatched chicks have pale gray down, and their eyes open only a few hours after hatching. They begin feathering out in a few weeks, but their fledging period is still quite prolonged, usually lasting 75 to 85 days but, with variations in feeding rates, might range from 65 to 106 days.

This species is widespread but apparently declining rapidly across sub-Saharan Africa. With a recent global population of 6,700 to 67,000 individuals, it is considered to be vulnerable by the International Union for Conservation of Nature. A moderate number of eBird reports indicate that Ethiopian sightings have been scattered from as far north as near Lake Tana and Mile Serdo Wildlife Reserve south to nearly the Kenya border.

Suggested reading: Brown \& Amadon, 1968; Brown, Urban \& Newman, 1982; Burton, 1989; Chapin, 1932; Del Hoyo, Elliott \& Sargatal, 1994; Ferguson-Lees \& Christie, 2001; Grossman \& Hamlet, 1964; Steyn, 1961, 1982; Tarboton, 1989.

\section{Family Falconidae (Falcons)}

\section{Pygmy Falcon Polihierax semitorquatus}

This charming falcon is even smaller than the American kestrel (Falco sparverius) and more like that of a shrike (Lanius) in both size and appearance. Its Latin name means "gray hawk with a semi-collar," the latter name referring to the pale band around the back of the neck. The sexes differ as adults in that females have a chestnut rather than a gray back; immatures of both sexes resemble adult females but have buff-colored breasts. Like the world's other tiny falcons, it is relatively large headed and short tailed.

This tiny insect-eating raptor is usually found in scattered pairs, perching on low lookout points and making short sallies out to capture large insects, small lizards, and occasional small birds. They often roost in company with various colonial weaver finches and occasionally prey on the adults of these birds or their nestling young.

In northeastern Africa, pygmy falcons nest from June to December and perhaps are double brooded in some regions, depending on food supplies. Normally monogamous like most raptors, females have sometimes been reported to be polyandrous, the extra male presumably aiding in the rearing of two broods during a single season. With the start of the breeding season, a pair typically takes over an old nest of a weaver finch (Plocepasser, Philetairus, or Dinemelia), whose nests are usually located in densely thorny trees. The clutch consists of two to four white eggs, which are incubated by both sexes but mostly the female. After the four-week incubation period, there is another four- to six-week fledging period. Predation levels seem to be slight, perhaps owing to the species' thorny nest sites.

This species is common in semidesert habitats of Ethiopia and the Rift Valley of East Africa; a second widely separated population also occurs in the Kalahari Desert region of southwestern Africa. The pygmy falcon, as of 2016, was considered to be a species of least concern by the International Union for Conservation of Nature. A moderate number of eBird reports indicate that 

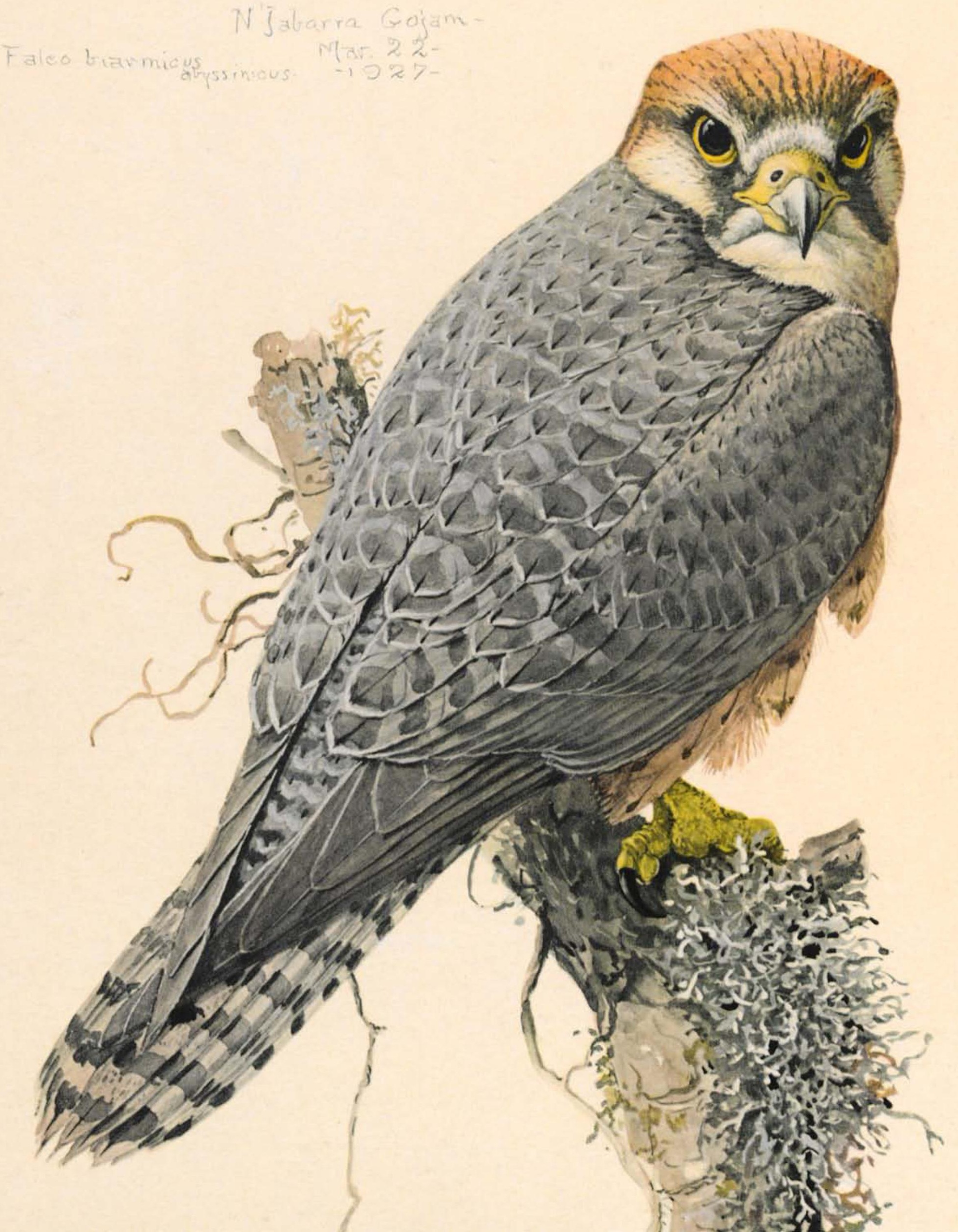
Ethiopian sightings have occurred south from the vicinity of Lake Tana to the country's southern borders, and west to Omo National Park.

Suggested reading: Brown \& Amadon, 1968; Brown, Urban \& Newman, 1982; Burton, 1989; Cade, 1982; Del Hoyo, Elliott \& Sargatal, 1994; Grossman \& Hamlet, 1964; Maclean, 1970; Newman, 1971; Steyn, 1982; Tarboton, 1989.

\section{Lanner Falcon Falco biarmicus abyssinicus}

This highly attractive falcon has a broad range through southeastern Europe, Arabia, and Africa, where it is the near counterpart of the peregrine falcon (Falco peregrinus). These two species overlap across much of their African range, but the lanner falcon extends into more desertlike habitats than the peregrine. It is on average also paler and has a brown crown and hindneck that is distinct from that of the dark-headed peregrine. Like the peregrine, its prey consists mainly of birds that are usually taken in flight during powerful stooping dives from as high as several hundred yards. It sometimes also takes mammals during low-altitude attacks similar to those typical of the North American prairie falcon (Falco mexicanus).

Lanner falcons are resident wherever they occur in Africa, with pairs occupying large breeding and hunting territories of close to 20 square miles (40-50 square $\mathrm{km}$ ). Within Ethiopia they are the most common large falcon, perhaps being more versatile in their prey spectrum than the similar-sized peregrine. Outside the breeding season lanner falcons become more insectivorous, gradually shifting to birds as the nesting season approaches. Birds the size of quails and doves are often taken and perhaps preferred.

Nesting is done in tall trees; often the old nest of a crow, kite, or other large raptor might be claimed. Few if any raptors are likely to challenge a pair of lanners for their chosen site, and none are tolerated anywhere near the nest. The clutch usually consists of two or three eggs, and only the female is known to incubate. The eggs hatch at staggered intervals after approximately
30 days, and thereafter the male brings food for both the female and their chicks. Fledging requires another 42 to 45 days.

Lanner falcon populations are currently increasing globally. As of 2016, this falcon was classified by the International Union for Conservation of Nature (IUCN) as a species of least concern. Numerous eBird reports indicate that Ethiopian sightings have occurred from the country's northern to southern borders, west to South Sudan and east almost to the Somalia border.

Suggested reading: Brown \& Amadon, 1968; Brown, Urban \& Newman, 1982; Burton, 1989; Cade, 1982; Chapin, 1932; Cramp \& Simmons, 1980; Del Hoyo, Elliott \& Sargatal, 1994; Grossman \& Hamlet, 1964; Steyn, 1982; Tarboton, 1989.

\section{Family Numididae (Guineafowl)}

\section{Helmeted Guineafowl Numida meleagris somaliensis}

This is by far the most widely recognized species of guineafowl, as it is the only one to have been domesticated. It is also very widely distributed in sub-Saharan Africa, occurring in savanna, semidesert, and other open-country habitats wherever a source of available water and elevated roost sites can be found. The Ethiopian race somaliensis is found in most arid habitats of Ethiopia and Somalia. The name "helmeted" refers to the hornlike casque on its head; Fuertes's name "tufted guineafowl" is more applicable to a related species that bears a feathery crest, although the Ethiopian race bears a tuft of long hairlike feathers on its forehead.

Helmeted guineafowl are highly social and roost colonially in traditional tree sites. Only during the breeding season do flocks fragment into pairs. Social living has the advantage of multiple eyes and ears for detecting predators; a frantic run to cover follows an alarm call from any of the flock members. During much of the year the birds forage on seeds and other vegetative mate- 
rials, supplemented by insects. With the breeding season onset, monogamous pair-bonds are formed, but no real territoriality exists. Rather, the male simply defends his mate from the attention of other males.

Nests are well hidden on the ground. Like many gallinaceous birds, the female guineafowl lays a fairly large clutch of 6 to 12 eggs. Most laying occurs during the relatively late rainy period of July and August, but variable rain cycles can modify this chronology. The male plays little or no role during the 24 to 27 days of incubation, but he returns after hatching to help rear the precocial chicks. By two weeks the chicks (which in East Africa are often called "keets") are flying weakly, and by a month of age they are strong fliers. There is usually a high mortality rate among the young, but a few might survive to join the flocking adults by the time they are a few months old.

This species is widespread across Africa and as of 2016 was considered to be a species of least concern by the International Union for Conservation of Nature. Numerous eBird reports indicate that Ethiopian sightings have occurred from the country's northern to southern borders, west to South Sudan and east to Mile Serdo Wildlife Reserve.

Suggested reading: Chapin, 1932; Cramp \& Simmons, 1980; Del Hoyo, Elliott \& Sargatal, 1994; Newman, 1971; Skead, 1962; Urban, Fry \& Keith, 1986.

\section{Family Phasianidae (Pheasants, Francolins, and Quails)}

\section{Clapperton's Francolin Francolinus (Pternistis) clappertoni}

The francolins of Africa are a large and diverse group of partridgelike birds, of which the Clapperton's francolin is one of the bigger species. Francolins are notable for the sharp spurs on the legs of males and, in many, bright red patches of bare skin around the eyes of adults. The generic name Francolinus comes from a French word meaning "little hen"; Pternistis refers to their sharply spurred legs. Their plumage is rather plain colored, but most species have loud, sometimes raucous, vocalizations.

The Clapperton's francolin was named after Hugh Clapperton, a nineteenth-century Scottish explorer of western and central Africa, and is usually found in quite arid and sandy grasslands, where its pale plumage makes effective camouflage. It is notable for its bright red legs, a rather "scaly" grayish plumage pattern, and a loud, grating call.

Adult Clapperton's francolin males are heavier than females by about 30 percent; females are not only smaller but have much shorter spurs. It is likely that spur length in males is age related and probably an important determinant in mate acquisition through sexual selection for dominance. Although presumably monogamous, social status and mate selection are likely to be established by male-to-male fighting.

Like guineafowl, francolins tend to roost socially in trees at night. During the day, they are found in small coveys or as separate pairs. Breeding records for Ethiopia mostly extend from April to December, through the wet season (June through August) and well into the dry season (December through February). Little is known of the details of breeding; the clutch size and incubation period are both unknown. However, in most francolins the clutch generally averages about six to eight eggs, and the incubation period lasts about three weeks. The young are highly precocial and are likely to fledge in only about two weeks, so it is possible that two or more broods could be raised in a single breeding season, or at least persistent renestings could occur. Adult francolin plumages are reached within a year, so presumably yearlings are potentially able to reproduce. In some other francolin species the percentage of young birds in postbreeding flocks averages about 30 to 35 percent, suggesting that this might approximate adult annual mortality rates in stable populations.

This species is widespread across tropical Africa from Niger to Ethiopia and as of 2016 was considered to be a species of least concern by the International Union for Conservation of $\mathrm{Na}$ ture. These birds are still fairly common in most 
of their Ethiopian range but are probably declining in the Rift Valley, owing to human-caused habitat changes. Numerous eBird reports indicate that Ethiopian sightings have occurred from the country's northern to southern borders, west to South Sudan and Sudan and east to Awash.

Suggested reading: Del Hoyo, Elliott \& Sargatal, 1994; Johnsgard, 1986; Urban, Fry \& Keith, 1986: 56.

\section{Family Gruidae (Cranes)}

\section{Common (European) Crane Grus g. grus}

Common cranes are so named because of their relative abundance in Europe, not Africa. Most of these European birds winter north of the Mediterranean Sea, but some also funnel down the Nile Valley to winter in the headwaters of the Blue Nile of Ethiopia and in the upper Nile basin of Sudan. It is uncertain where and when Fuertes painted his specimen; it is most likely that the one he painted was collected at Lake Tana in early April 1927. Recent eBird reports indicate that fall flocks of more than 100 birds have been seen at the south end of Lake Tana. The species' population has been increasing rapidly across Eurasia in recent decades, and perhaps its wintering range is also still expanding.

Cranes are richly associated with folklore and myth, and most of these tales involve the European crane. They are almost always associated with good fortune and prospective happiness, and often cranes are considered bellwethers of the changing seasons. In part this results from their large, almost humanlike shape and posture, but their longevity, strong pair-bonds, and family and flock unity also play an important role. Lastly, their clarion voices excite the human spirit in an almost instinctual way that somehow seems to remind and excite the subconscious of a time several million years ago when early humans and cranes shared the East African plains in harmony.
European cranes commonly winter in Africa from September to April, with most of the birds concentrating in the Sudan along the Nile Valley. There they gather in flocks sometimes numbering more than 1,000 birds, spending the daytime hours foraging in fields and wet meadows, gleaning from the ground surface or probing for food. In the evening they return to traditional safe roosting sites; often these are areas of shallow water in which the birds can easily stand and pass the hours of darkness in relative safety from terrestrial predators. Even during the darkest hours some birds remain awake and maintain low levels of conversational vocalizing, imparting information that we can only imagine.

Numerous eBird reports indicate that Ethiopian sightings have occurred from Lake Tana south through the Rift Valley lake region to Mago National Park. Lake Tana is the largest lake in Ethiopia, with 217 bird species reported, and is considered a globally significant Important Bird Area. Its surroundings are part of the Central Ethiopian Wetland Complex, which are of international importance to shorebirds and water birds. The common crane is considered to be a species of least concern as of 2016 by the International Union for Conservation of Nature and is probably the second-most abundant crane in the world (Johnsgard, 2015).

Suggested reading: Cramp \& Simmons, 1980; Del Hoyo, Elliott \& Sargatal, 1996; Johnsgard, 1983, 2015; Urban, Fry \& Keith, 1986.

\section{Family Otididae (Bustards)}

\section{Kori Bustard \\ Ardeotis kori struthiunculus (2 images)}

One of the birds I most wanted to see in the wild when first visiting East Africa was the kori bustard; it is one of the largest bustards, indeed one of the heaviest of flying birds. Its stately demeanor as it strides about the plains on its long legs reminds me of nothing so much as a Maasai warrior, and I will never forget seeing one standing statuelike in the golden dry-season grasses of 
the Serengeti plains with zebras and wildebeests as a backdrop. Its generic name means "heronbustard," and the specific epithet and vernacular name "kori" comes from a native name used in Botswana.

Kori bustards have rather long, almost heronlike necks, but the neck area is covered by long hacklelike feathers that resemble a Victorian ruff even when they are not erected. Indeed, male kori bustards spend a good deal of time during the breeding season standing in a stately posture with neck extended vertically and their feathers fully raised, producing a stovepipe or, if they are vocalizing, even a balloonlike outline. In this stance they utter a series of low-pitched notes that if they lack volume nevertheless carry well across the African plains and probably attract females. The acoustic effect is emphasized visually by a tail cocking that exposes their white undertail feathers.

These remarkable displays would suggest that the males are polygynous or promiscuous, and that they are nearly twice as heavy as femalesabout 22 pounds $(10 \mathrm{~kg})$ versus 13 pounds (5.9 $\mathrm{kg}$ - - supports this view. Like other arena-displaying birds, adult males sometimes gather in traditional display areas, or leks, to try to establish dominance and thus gain access to any and all females that might be attracted to the group.

Females closely resemble males in plumage but are much more wary and thus are hard to observe. Following mating they locate a nest site, which is simply a shallow scrape on the ground that is often hidden by grass clumps or a rock outcrop. They deposit one or two eggs and then undertake the 23- to 25-day incubation period. The chicks are precocial and able to walk about soon after hatching, but they continue to be fed occasionally by the female long after they are seemingly independent of such needs. In a related species of Otis the fledging period was found to be about 75 days. A hand-raised male was not observed mating until he was seven years old, and in another Otis species initial breeding might first occur among males at five to six years of age.

Kori bustards still have a fairly broad eastern and southern African range, but in 2016 they were listed as near-threatened by the Interna- tional Union for Conservation of Nature and were believed to be declining rapidly. A moderate number of eBird reports indicate that Ethiopian sightings have occurred from Aledeghi Wildlife Reserve south to the Kenya border.

Suggested reading: Ash, 1989; Chapin, 1939; Del Hoyo, Elliott \& Sargatal, 1996; Johnsgard, 1991, 1994; Newman, 1971; Urban, Fry \& Keith, 1986.

\section{Black-bellied Bustard Eupodotis melanogaster}

Unlike the kori bustard, the black-bellied bustard is little larger than a pheasant (Phasianus colchicus), up to about 25 inches $(63 \mathrm{~cm})$ in length. Its neck feathers are very short, producing a thinnecked but thick-bodied profile. Males are larger than females, averaging about four pounds (1.8 $\mathrm{kg})$, and females about three pounds $(1.3 \mathrm{~kg})$. This bird is quite common on the grasslands of sub-Saharan Africa, especially in moderately tall grasslands and savannas such as the Maasai Mara in Kenya.

Bustards are generally noted for their wariness, and I was surprised to see (at least in protected game parks) that males could be approached fairly closely during their display period. During this time males stand in conspicuous locations and utter a series of odd whistles and corkpopping and hiccupping sounds, accompanied by head-retracting and neck-extension movements.

Bustards reach their greatest abundance and diversity in Africa; they are distant relatives of cranes and share some cranelike attributes. However, unlike cranes they are superbly adapted to life in dry environments. They are also much less gregarious than cranes, perhaps because they live in areas of sparse food resources.

The black-bellied bustard contradicts the general protective-coloration principle of countershading that was proposed by Fuertes's mentor Abbott Thayer. There are some other curious exceptions to this principle, such as the blackbellied plover (Pluvialis squatarola) and some 


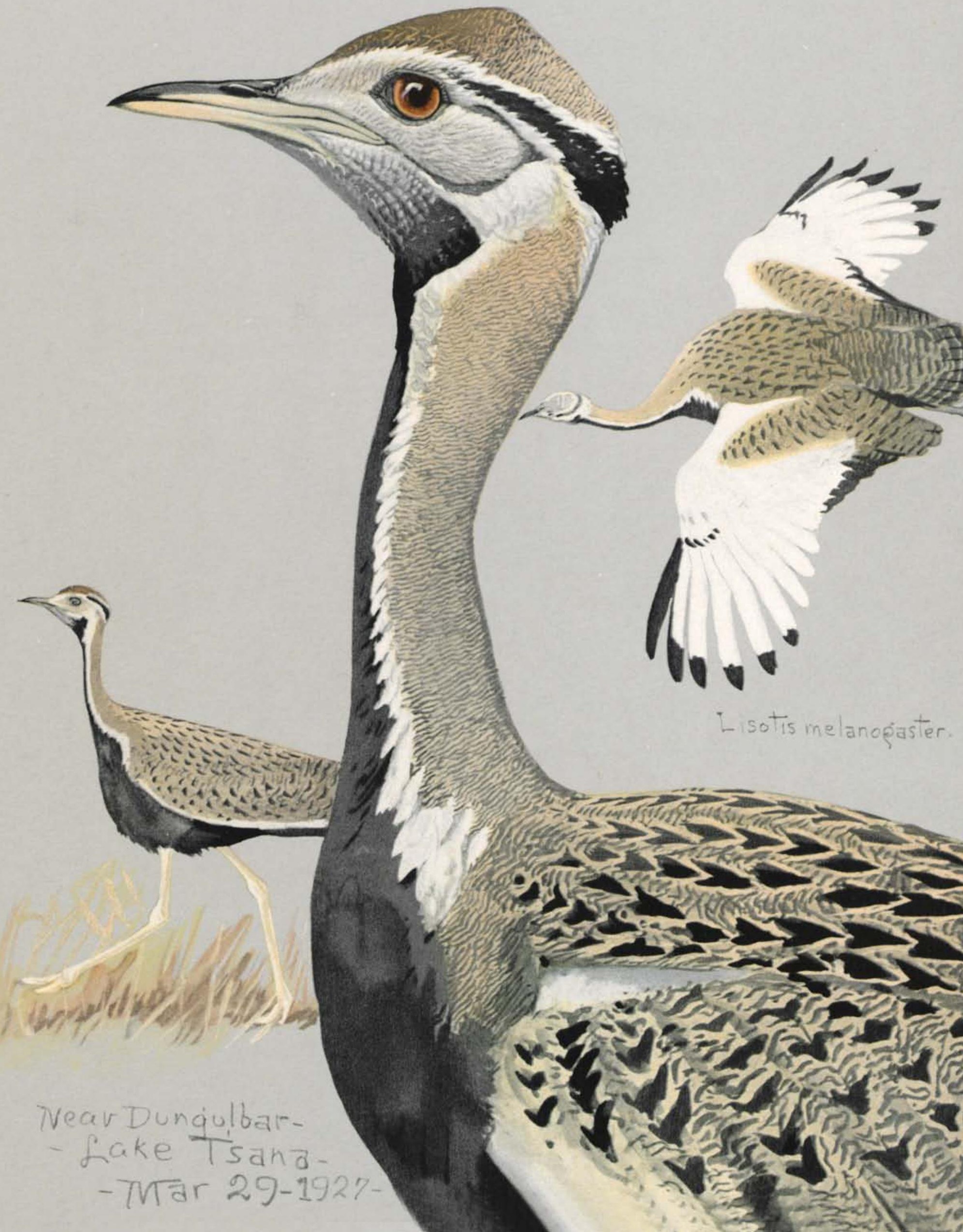


other tundra-nesting shorebirds, along with the ratel (Mellivora), or honey badger, among African mammals. Perhaps the ratel is aggressive enough so that it can ignore selective pressures for protective coloration, but it seems likely that the black underparts of plovers and several bustard species must have visual display functions (perhaps during aerial display) or other advantages not immediately apparent. It is of interest that females and immatures of the black-bellied bustard have white underparts, as might be expected for protective camouflage reasons.

Like other bustards, only the female plays a significant role in the nesting and parental phases of reproduction. Little is known of the breeding biology of these elusive birds. In the closely related white-bellied bustard (E. senegalensis), two eggs are the usual clutch size; rarely one or three eggs are laid. The nest is nothing but a shallow rounded ground scrape, and apparently only the female incubates. In one observation of the white-bellied bustard, the incubation period was found to be 23 days under conditions of artificial incubation. When the hatched young were 5 to 6 months old, they began to lose their juvenile plumage and started to develop an adultlike plumage. By then they also weighed about the same as adults. The period to sexual maturity is not known but is likely to be at least two years and probably three or more. Young white-bellied birds began to acquire adultlike plumages at 5 to 6 months and start to vocalize like adults, but it is still likely that sexual maturity is not attained for several years. Nothing is known of longevity in the wild.

Black-bellied bustard populations, like those of most if not all bustards, are decreasing, but they are widespread across sub-Saharan Africa, and as of 2016 the species was still classified by the International Union for Conservation of Nature as a species of least concern. A moderate number of eBird reports indicate that Ethiopian sightings have occurred from northernmost Ethiopia south to Lake Chamo and east to Awash.

Suggested reading: Ash, 1989; Chapin, 1939; Del Hoyo, Elliott \& Sargatal, 1996; Johnsgard, 1991; Newman, 1971; Urban, Fry \& Keith, 1986.

\section{Family Jacanidae (Jacanas)}

\section{African Jacana Actophilornis africana}

Jacanas are one of the most interesting of all shorebirds. They are one of the very few groups of shorebirds (phalaropes are the other) in which there is a reversal of sexual appearance and sex roles. Beyond that, jacanas have extraordinarily long toes and claws, which allow them to spread out their weight to the point that they can walk or run over lily pads and other floating vegetation without sinking. They are thus sometimes called lily-trotters. The term jacana is derived from a Portuguese version of a native Brazilian name for the group; the species' Latin name translates as "African beach-loving bird." Like other birds with sex-reversed biologies, females are appreciably larger than males, but female jacanas do not differ noticeably in brightness of their plumage or in the color of their blue frontal shields. The frontal shield above the bill varies in color with age and in adults becomes brighter during the breeding season.

Nearly all jacanas are rather retiring birds, associated with overgrown ponds, weedy marshes, and temporarily flooded lands. They forage on invertebrates caught at or just under the surface, either while walking on the surface vegetation or, in the African species, sometimes riding on the backs of hippopotami. Like coots (Fulica) and gallinules (Gallinula) of the same general wetland habitat type, they are strongly territorial and utter rather loud croaking or screeching notes when advertising or defending their "turfs."

Although some jacana females remain monogamous, many females acquire two or even as many as four males. These extra ("minor") males defend individual small territories surrounding that of the major male and the female and keep other males out. All, however, participate in repelling invaders from the group's collective territory. Females lay clutches of about four eggs (these presumably having been fertilized by the female's primary mate), and only the male performs incubation. The female might visit the nest periodically during the approximate three-week 
incubation period. The newly hatched chicks are charmingly gangly, their feet and toes are about as long as their entire body, and they are longitudinally striped from head to tail. The male cares for the chicks and is known to be able to pick up as many as three chicks and carry them under his wings for distances of up to 60 feet. Females evidently participate to some extent in brood defense, and in a related species ( $J$. spinosa) the young might be tended by the male for as long as ten weeks.

This species is widespread across the wetlands of Africa and as of 2016 was considered to be a species of least concern by the International Union for Conservation of Nature. Numerous eBird reports indicate that Ethiopian sightings have occurred from Lake Tana south to Stephanie Wildlife Sanctuary and west to the southern South Sudan border.

Suggested reading: Del Hoyo, Elliott \& Sargatal, 1996; Johnsgard, 1981; Newman, 1971; Tarboton, 1992; Urban, Fry \& Keith, 1986.

\section{Family Burhinidae (Thick-knees)}

\section{Senegal Thick-knee Burhinus senegalensis}

Thick-knees are named for their somewhat swollen "ankle" (tibiotarsal) joints; some species are called stone-curlews because of their association with bare sand and rocky pavement. They are a mostly Old World group of aberrant, mostly aridadapted shorebirds that reach their greatest diversity (four species) in Africa. The Senegal thickknee occurs across the semidesert Sahel zone just south of the Sahara but also extends northward up the Nile Valley to its delta.

All thick-knees have relatively large heads and eyes as well as cryptic plumage patterns that allow them to disappear in the sparsest of cover or even on bare sand. They have a distinctive wide-eyed but skulking appearance, and they hunt visually for invertebrates at or just below the ground surface. They also opportunistically take amphibians, small rodents, and the eggs or young of birds they might encounter. Most foraging occurs at night or at dawn and dusk, as is suggested by their large eyes.

The Senegal thick-knee is about the size of a small curlew (Numenius) and has a curlew-like wailing call that serves as a general alarm to all in the vicinity. A related migrant species is called the stone-curlew (Burhinus oedicnemus) because of its similar preference for stony grasslands, and it is also very similar in size and appearance to the Senegal thick-knee. The sexes are alike among thick-knees, and pairing is monogamous. The birds tend to be rather solitary or are only slightly colonial. They breed rather independently of the rain cycle but in some areas nest just prior to the rainy period. They typically nest on rather rocky or pebbly substrates, where the adults, the spotted brown and buff eggs, and the dappled brown young are all virtually impossible to detect visually.

Typically two eggs compose a clutch, surprisingly small for a shorebird. The eggs usually are surrounded by pebbles, rock or wood fragments, or other objects that probably help conceal the eggs when the incubating bird is away from the nest. At least in related species both sexes take their turns in incubating, and the eggs hatch in about 26 to 28 days. A nest defense display consists of spreading the wings and cocking the tail. Like other ground-nesting shorebirds, the adults are also adept at performing nestdistraction displays by feigning injury, thus effectively luring small mammals such as jackals away from the clutch or brood. The fledging period is uncertain; the birds prefer to run when alarmed and fly only quite rarely. In a related African species (B. capensis) the fledging period is about eight weeks.

This species is widespread across sub-Saharan tropical Africa, occurring locally north to Egypt. Its recent estimated world population is 13,000 to 33,000 , and as of 2016 it was considered to be a species of least concern by the International Union for Conservation of Nature. Numerous eBird reports indicate that Ethiopian sightings have occurred from the country's northern to southern borders, west to South Sudan and Sudan and east to Dire Dawa. 
Suggested reading: Cramp \& Simmons, 1984; Del Hoyo, Elliott \& Sargatal, 1996; Urban, Fry \& Keith, 1986.

\section{Family Charadriidae (Plovers and Lapwings)}

\section{African Wattled Lapwing Vanellus s. senegallus}

Lapwings are a group of shorebirds averaging slightly larger in size than the North American killdeer (Charadrius vociferus) that have their greatest species diversity and abundance in Africa. Like killdeers, they are noisy, alert birds that often have colorful facial wattles or crests, contrasting wing plumage patterns most visible during flight, and bony wrist protuberances or even spurs. The last-named feature is probably related to the need for establishment of individual social dominance and territoriality, and their other visual traits are probably also important in related social signaling. The wattled lapwing has distinctive yellow wattles hanging down from the base of its bill, a red and white forehead, and a black chin. Like other lapwings, its wing pattern is a strongly contrasting black and white. The sexes are alike, both in plumage and size.

Lapwings get their descriptive name from their rather deep-stroked, flapping flight; "flapwing" was gradually corrupted in the English language to become lapwing. Lapwings are sometimes also called "picket-plovers" since they maintain a sharp picketlike lookout for all possible signs of danger and loudly utter alarm calls when threatened. Some of the species are also called "blacksmith plovers" because their ringing cries resemble the sound of a blacksmith pounding on metal. Other species perhaps benefit from their constant and reliable alertness.

Wattled lapwings are monogamous, the pairs usually inhabiting generally moist grasslands and the edges of watery habitats but at times foraging on quite arid sites. They are not very gregarious and tend to be somewhat migratory, mov- ing about as the rains come and go. The birds are highly territorial, with the territories often a few hundred yards in diameter. Most territorial advertisement and defense are performed by the male, but he is sometimes aided by his mate. Both sexes incubate the three or four eggs for the month-long incubation period, and both help to rear their chicks during their 38- to 44-day fledging period.

This species is widespread across sub-Saharan tropical Africa and south to South Africa, and as of 2016 it was considered to be a species of least concern by the International Union for Conservation of Nature. Numerous eBird reports indicate that Ethiopian sightings have occurred from the country's northern to southern borders, west almost to South Sudan and Sudan, and east to about Awash.

Suggested reading: Del Hoyo, Elliott \& Sargatal, 1996; Johnsgard, 1981; Urban, Fry \& Keith, 1986.

\section{Spur-winged Lapwing Vanellus spinosus}

The spur-winged lapwing has short but sharp spurs at the bend of each wing; these are effective for driving off rival males but are of little value in defense against most predators. Like the other lapwings, this species is a highly attractive bird; adults of both sexes are contrastingly black and white on their head, body, and wings, although like other lapwings their back is the color of dry sand and provides a degree of concealment for crouching or incubating birds. Adults of the two sexes are virtually identical in size and appearance, but the female has brownish rather than reddish eyes.

The species is distributed just south of the Sahara in a range similar to that of the wattled lapwing, but it generally prefers drier habitats than does that species. It has a loud, screeching, and usually four-syllable call, sometimes transliterated as "Did he DO it?" The birds often forage on dry ground or at the edge of water, taking a variety of arthropods and occasionally small lizards. 
Like other lapwings, spur-winged lapwings are highly territorial, evicting not only other lapwings but also various other shorebirds from their territories. Because of their sharp wrist spurs, they can readily dominate wattled lapwings.

These monogamous birds seem to maintain permanent pair-bonds and are rather sedentary. In very favorable habitats, they might nest fairly close together but maintain definite territorial boundaries nonetheless. Courtship and precopulatory displays by the male include ceremonial nest-scraping, a hunched circling of the female while walking stiffly, and head-bobbing.

Typically three or four eggs are laid, and both sexes incubate. Breeding records in Ethiopia and Somalia are widely spread, from March to January. Incubation and fledging periods are similar to those of other lapwings, about 30 and 40 days, respectively. In some areas two broods might be produced per year, and although this seems probable given the long breeding period, it is apparently not proven for Ethiopia.

This species is widespread across sub-Saharan tropical Africa and occurs locally north to Egypt and Turkey. As of 2016 it was considered to be a species of least concern by the International Union for Conservation of Nature. Numerous eBird reports indicate that Ethiopian sightings have occurred from the country's northern to southern borders, west to South Sudan and Sudan, and east to Djibouti.

Suggested reading: Cramp \& Simmons, 1984; Del Hoyo, Elliott \& Sargatal, 1996; Johnsgard, 1981; Urban, Fry \& Keith, 1986; Ward, 1989.

\section{Crowned Lapwing Vanellus c. coronatus}

Of the three African lapwings depicted by Fuertes, the crowned lapwing is the most southerly and the only one with red legs and bill coloration. It is also one of the most common of the African lapwings, occurring in a variety of generally dry habitats, especially overgrazed grasslands. Therefore, it benefits from the spread of domesticated livestock and is often an indicator of poorly managed grazing land. This species lacks wing spurs and so is generally less aggressive than the spurwinged lapwing. The forehead is black, which extends back behind the eye, and a separate black "crown" is set off by a white margin. The wings and tail are also patterned with black and white. The sexes are alike in plumage, but females average slightly smaller in size than males.

The crowned lapwing reaches the northern edge of its range in central Ethiopia, but it tolerates very dry and even highly sandy substrates. Insects and their larvae are the standard food, and the birds are attracted to grass fires that might expose a variety of easily available insect prey. In some locations the birds might also make regular daily flights to foraging areas. Much foraging occurs at dusk and might continue on after nightfall.

Like other lapwings these birds are normally monogamous; breeding records from Somalia extend from January to October. In areas of high density, nests might be placed as close as about 25 to 30 yards $(23-27 \mathrm{~m})$ apart. Eggs are laid at intervals of one per day, and the usual clutch is of two or three eggs. The spotted eggs often perfectly match their pebbly background, and the nest site is also actively defended by the pair. At the first sign of danger the bird on the nest will quietly leave it and take up a defensive stance some distance away. Nest-distraction display might be used if the predator can't effectively be repelled through threats. Incubation and fledging periods are about 30 and 40 days, respectively, and both sexes participate equally in these activities.

This species is widespread across sub-Saharan Africa from Ethiopia to South Africa and as of 2016 was considered to be a species of least concern by the International Union for Conservation of Nature. Numerous eBird reports indicate that Ethiopian sightings have occurred from the vicinity of Addis Ababa south to the Kenya border, west to Stephanie Wildlife Sanctuary, and east nearly to the Djibouti and Somalia borders.

Suggested reading: Ade, 1979; Chapin, 1939; Del Hoyo, Elliott \& Sargatal, 1996; Ginn, McIlleron \& Milstein, 1989; Newman, 1971; Urban, Fry \& Keith, 1986. 


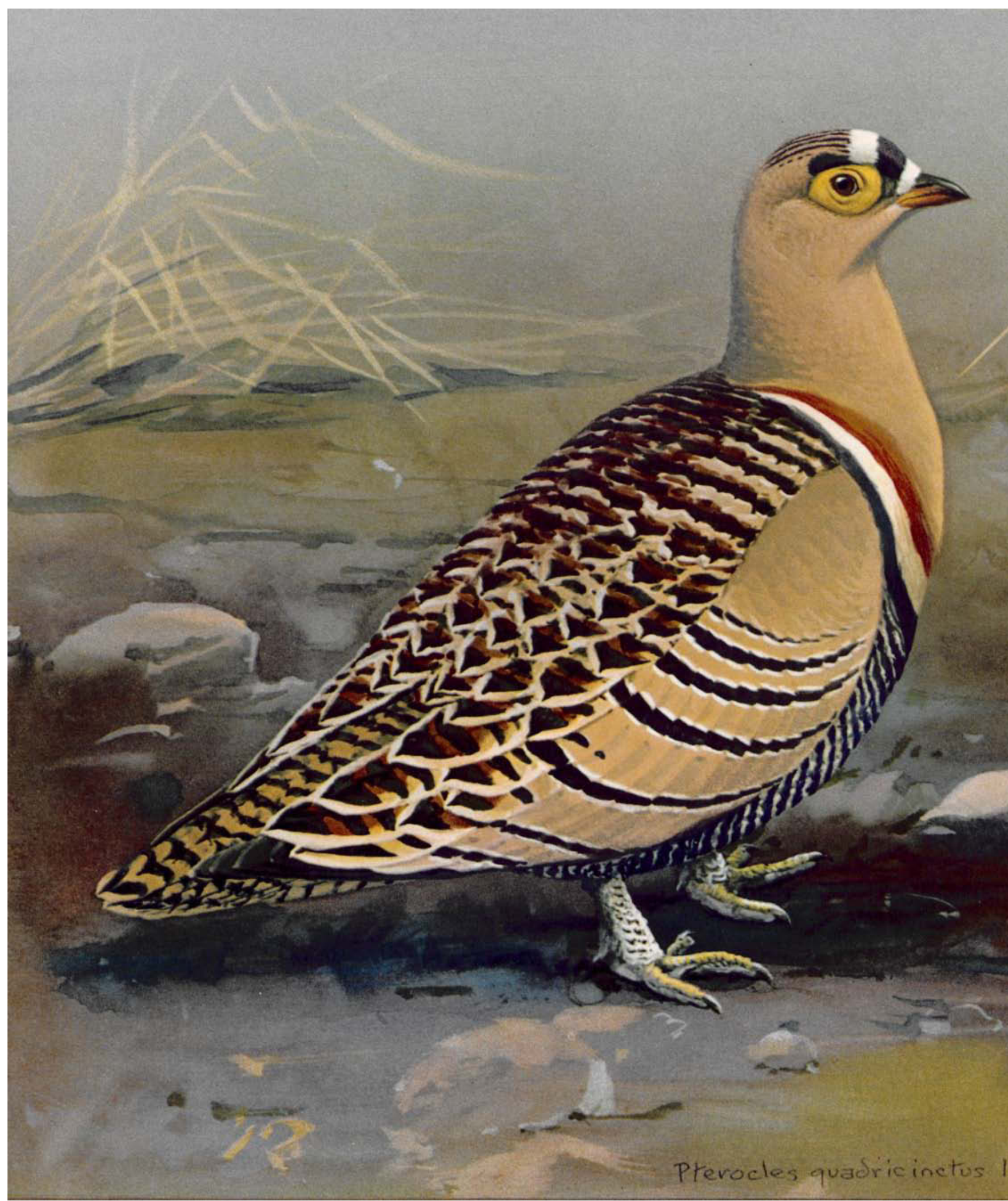




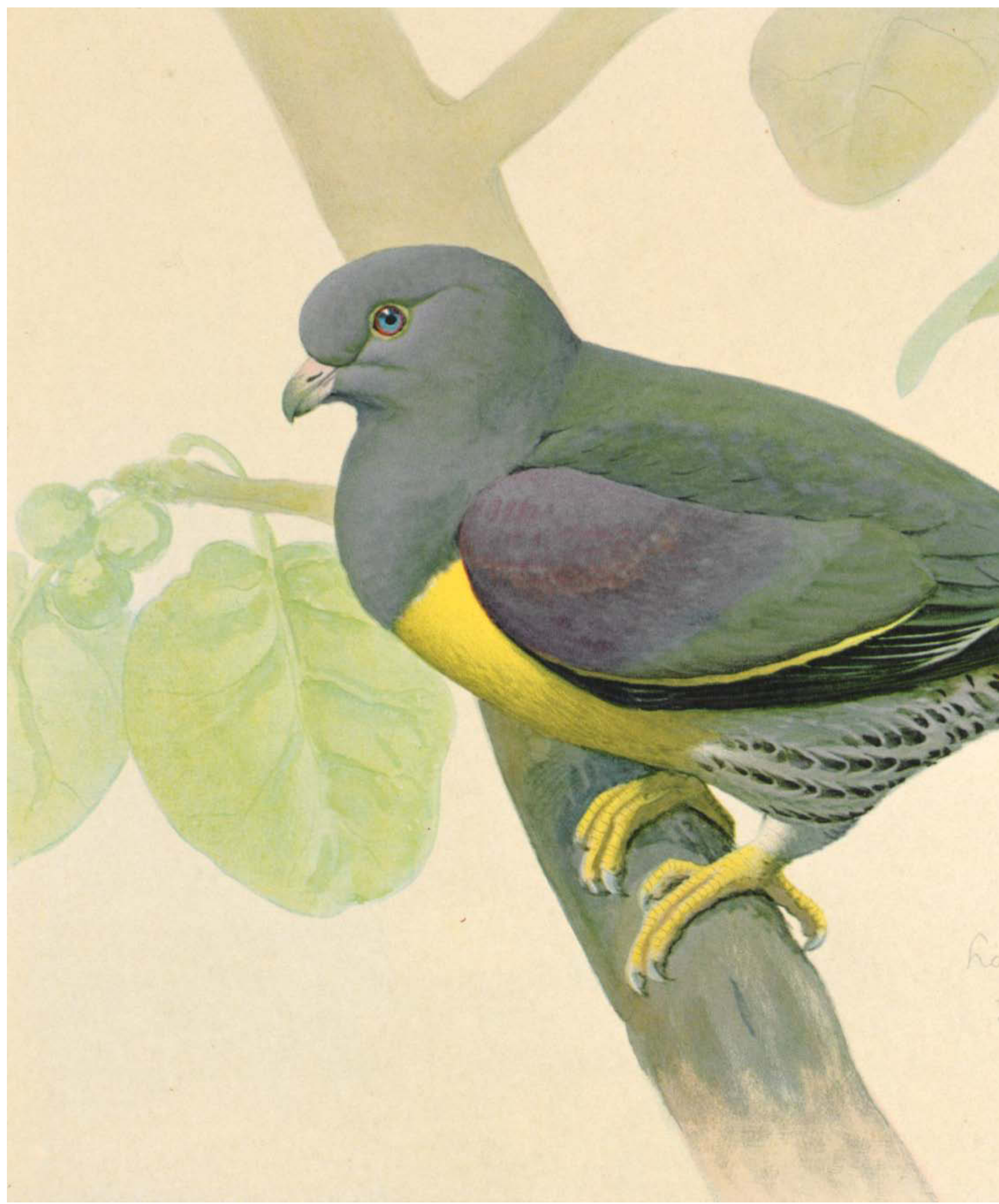


plovers. In the closely related Namaqua sandgrouse (Pterocles namaqua) of eastern Africa, the young are half grown and fully feathered at three weeks. They can fly a few yards at about a month of age, fly well by about six weeks, and probably begin to follow their parents and other adults to watering areas soon after that. At least in one species sexual maturity occurs within a year of hatching, and the laying of up to three clutches in a single season has been reported in captive birds.

This species is widespread across sub-Saharan tropical Africa and as of 2016 was considered to be a species of least concern by the International Union for Conservation of Nature. A moderate number of eBird reports indicate that Ethiopian sightings have occurred from the vicinity of Addis Ababa south to Lake Shala.

Suggested reading: Del Hoyo, Elliott \& Sargatal, 1997; Johnsgard, 1991; Urban, Fry \& Keith, 1986.

\section{Family Columbidae (Pigeons and Doves)}

\section{Bruce's Green-Pigeon Treron waalia}

This rather colorful pigeon was first collected near Lake Tana in 1793, and its odd species epithet waalia reflects the name applied to it by the local Abyssinian tribe. It is mostly confined to the sub-Saharan Sahel zone but reaches the coast of Somalia and also occurs on the Arabian Peninsula and Socotra Island in the western Indian Ocean. Both sexes are predominantly grayish green above and bright yellow below; the strange mauve-colored patch on the forewing of females is smaller than in males. This odd, if not bizarre, color combination would seem unlikely for any bird but nevertheless makes for an attractive appearance. Because of its leaf-green dorsal color, it becomes almost invisible when perched; like many parrots the yellow underparts seem to provide a more concealing hue as a result of countershading than would white. 
Fuertes called this species a "fig pigeon," and indeed it is a fig (Ficus) specialist. It is mostly found where fig trees also occur and so often can be seen in towns and villages. Green-pigeons are part of a large, tropical group of Old World pigeons usually referred to as fruit pigeons. They tend to be larger than most seed-eating pigeons and often exhibit strange color combinations that appear conspicuous among zoo-dwelling birds but are highly effective for concealment in the wild.

The structural basis for producing these colors needs additional study; presumably the yellows are produced by carotenoids, but the greens and mauves are more problematic. Probably it was these unusual plumage colors that stimulated Fuertes to paint this bird; nearly all of his other watercolors depict species with colorful or unusual soft parts, such as bare head skin.

Like other pigeons, these birds are monogamous and build flimsy platformlike nests in which one or two white eggs are laid. Breeding records from adjacent areas of Somalia are from March to June. Both sexes tend the nest and young; they feed the young squabs on regurgitated "pigeon milk." Incubation and fledging each require about 14 days.

This species is widespread across sub-Saharan tropical Africa and as of 2016 was considered to be a species of least concern by the International Union for Conservation of Nature. Numerous eBird reports indicate that Ethiopian sightings have occurred from the country's northern to southern borders, west to the borders of South Sudan and Sudan, and east to Dire Dawa.

Suggested reading: Del Hoyo, Elliott \& Sargatal, 1997; Goodwin, 1970; Urban, Fry \& Keith, 1986.

\section{Family Musophagidae (Turacos and Plantain-eaters)}

\section{Eastern Gray Plantain-eater Crinifer zonurus}

The turacos and plantain-eaters (Musophagidae translates as "plantain-eaters") are a large group of African species of perching birds found widely in trees and woodlands south of the Sahara desert. The English name turaco (and the genus Tauraco) are reportedly derived from a combination of two French words but originally probably came from a West African native name. Some turacos are called louries, especially in southern Africa, another word of uncertain origin. Turaco relationships are also uncertain at best; they have usually been allied with cuckoos.

The toe arrangement of turacos is peculiar; the outermost toe points neither forward nor backward but rather usually sticks out at a right angle from the foot axis. At times it can be reversed, or it might be brought forward, depending on perching needs or opportunities. Like cuckoos, turacos usually remain well hidden in trees; although I often heard them calling, especially during evening hours when they joined in a wild chorus with bush babies and hyraxes, I rarely saw them. Some of the species are called "goaway birds" because of their raucous and constantly repeated $g$-way calls. These calls are apparently used in territorial advertisement and are frequently uttered in asynchronous duets.

This species is essentially blackish gray and white in its plumage. Such plain plumage colors seem to be adapted to the open, relatively arid habitats of these birds. It also has a bushy gray crest in both sexes; its generic name means "hair-bearing." These crest feathers are rather bristly instead of being soft to the touch and are permanently raised. In spite of the vernacular name "plantain-eater," bananas and other plantains are never eaten by the species. It mainly consumes figs (Ficus), the fruit of the parasoltree (Musanga), and other fruits. Thus, the birds are important dispersal agents for the seeds of these trees.

Plantain-eaters are highly territorial and construct rather flimsy nests in thick foliage, especially acacias. Their usual clutch is of two or three eggs, incubated by both parents. Incubation might take about 20 to 25 days, and fledging probably occurs at about a month of age.

This species is common in tropical East Africa, and as of 2016 was considered to be a species of least concern by the International Union for Conservation of Nature. Numerous eBird reports 

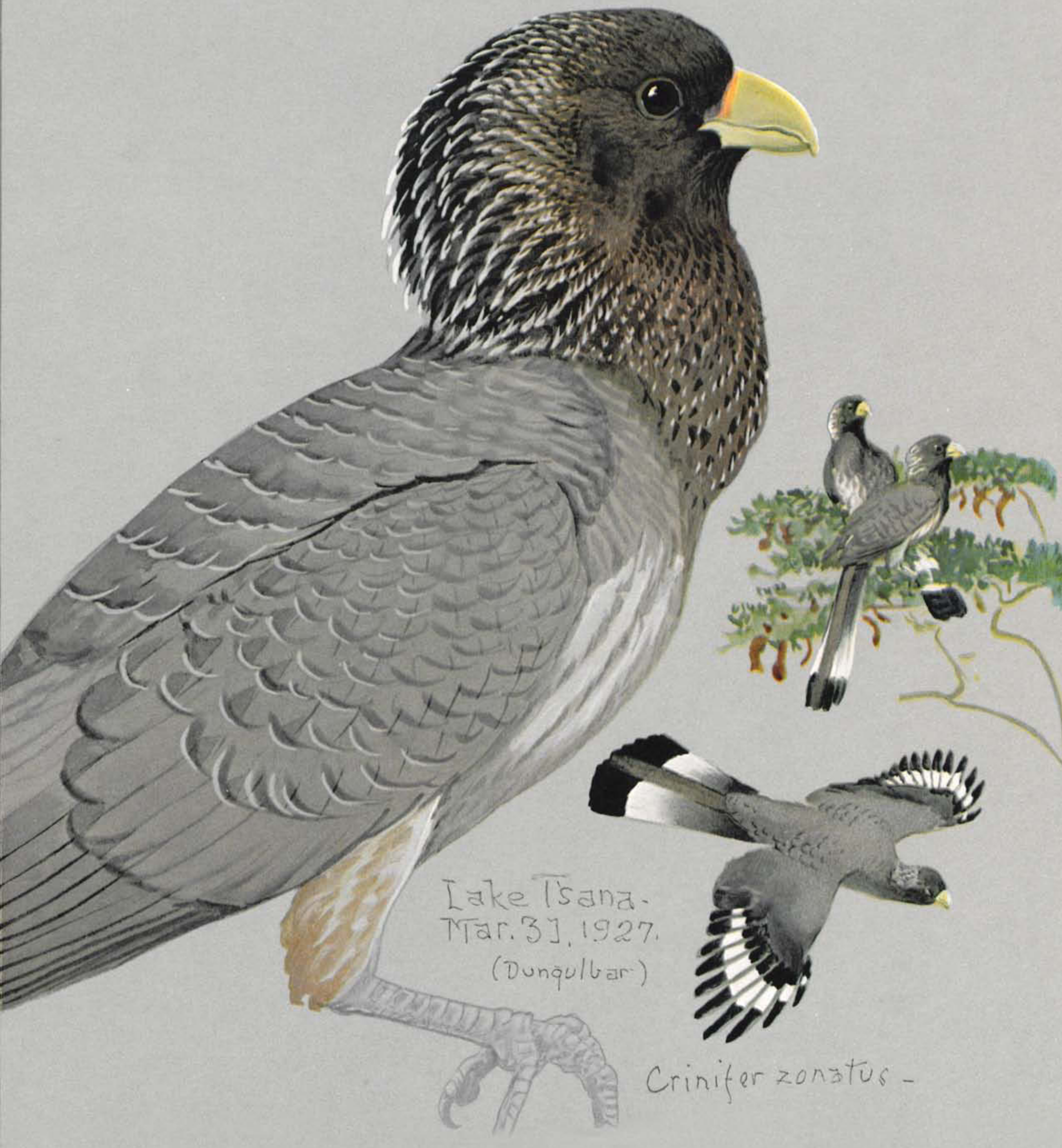
indicate that Ethiopian sightings have occurred from the country's northern border south to Yabelo Wildlife Sanctuary and Mago National Park, west to Sudan, and east to Dire Dawa.

Suggested reading: Chapin, 1939, 1963; Del Hoyo, Elliott \& Sargatal, 1997; Forshaw \& Cooper, 2002; Fry, Keith \& Urban, 1988; Moreau, 1938.

\section{White-cheeked Turaco Tauraco leucotis donaldsoni (2 images)}

Turacos are a strictly African group of some 23 species of mostly medium-sized birds with fairly short and rounded wings, long tails, and bushy crests. Like cuckoos and woodpeckers, their toes can be positioned with two pointing forward and two backward, although unlike these groups the outer front (fourth) toes are quite flexible and can face forward or backward. There is little apparent morphological reason, other than that shared and questionably significant trait, to associate turacos and cuckoos taxonomically.

Most of the 23 or so species belong to a group called "typical turacos," which includes the present species. Many of these are predominately leafgreen with bright red primary feather pigments and range from about 15 to 20 inches $(38-50 \mathrm{~cm})$ in length. These are fairly noisy birds, uttering raucous notes that probably relate to territorial advertisement or defense. The plantain-eaters, such as the previously described species, comprise five additional and less colorful species.

The white-cheeked turaco is mostly grassgreen to bluish green with a bushy crest, a long tail, a red bill and eye-ring, and, like all its near relatives, crimson flight feathers. The species name leucotis refers to the distinctive white ear stripe of adults. Another similar form (ruspoli) in southern Ethiopia lacks the white patch on the sides of the head and neck and is now considered a separate species.

Two racial variants (or very closely related species) of leucotis occur in Ethiopia; the race donaldsoni (identified as "Donaldson's turaco" by Fuertes, and also referred to as the Galla whitecheeked plantain-eater) has some crimson pres- ent in the crest. The more finished of the two paintings done by Fuertes of this turaco was painted after his return and is similar to one in Cornell's Lab of Ornithology that was painted only a few weeks before his death (Chapin, 1963).

Nearly all members of the turaco family, even those that are all gray, have at least some traces of a uniquely green feather pigment (turacoverdin), a copper-based pigment of the porphyrin type. A closely related blood-red pigment is turacin, which occurs on the primary and sometimes also secondary flight feathers of many turacos Although this pigment is water soluble, it does not simply "wash out" of wet feathers, as sometimes stated. However, immersing such feathers in a weak alkaline solution soon bleaches the red areas to the color of faded blood, proving their chemical nature.

Each year in my ornithology class I removed one red flight feather from a damaged and discarded turaco skin to demonstrate the watersoluble aspect of these feathers, so the skin became slowly but increasingly tattered every year. I eventually decided that when I had run out of these 30 or so colorful feathers it would be a signal to retire. I used the last of the specialized feathers about a decade before I finally retired, leaving the specimen too defeathered by then to be worth saving.

The white-cheeked turaco is almost entirely confined to Ethiopia and occurs in riverine forests, montane forest up to about 10,000 feet $(3,050 \mathrm{~m})$ in elevation, and bushlands. It is especially fond of the fruits of junipers (Juniperus) and yellowwood (Podocarpus) trees, but at least in captivity it will also eat insect larvae. The sexes are alike in size and appearance, except that the female has a duller bill during breeding.

Like most turacos, this is a noisy species that utters a variety of cackling calls, especially during the long breeding season from about June to November or December. The birds form monogamous pairs, which are well dispersed and probably territorial. They build shallow, platform-like twig nests of variable size in dense foliage.

During courtship the crimson-winged species of turacos perform wing-spreading displays, and many turacos also perform crest-raising, tailflicking, and exposure of their distinctive head 
markings. Mutual feeding also occurs as well as chasing from tree to tree. In one of the plantaineaters, tumbling dives by the male toward his perched mate are a part of the courtship rituals. Breeding is evidently spread out over much of the year, across both wet and dry seasons.

The species' nests are made of twigs and are quite fragile. The clutch size is two or three eggs, and incubation by both parents lasts 21 to 23 days. Fledging occurs at 25 to 30 days, and the full adult plumage is reached at about five months of age. One captive pair attempted to nest five times in as many months, and another pair produced seven young in seven months, during four nesting efforts.

This species is widespread in Ethiopia, where it is nearly endemic but common, and as of 2016 it was considered to be a species of least concern by the International Union for Conservation of Nature. Numerous eBird reports indicate that Ethiopian sightings have occurred from near the country's northern to southern borders, west nearly to Sudan, and east to Awash and the Bale Mountains.

Suggested reading: Borghesio, 1997; Chapin, 1963; Del Hoyo, Elliott \& Sargatal, 1997; Everitt, 1965; Forshaw \& Cooper, 2002; Foxall \& Burton, 1975; Fry, Keith \& Urban, 1988; Moreau, 1938.

\section{Family Cuculidae (Cuckoos and Coucals)}

\section{White-browed Coucal Centropus s. superciliosus}

The white-browed coucal is the only African cuckoo illustrated by Fuertes, and it is one of the very large cuckoos that are not brood parasites (species whose females deposit their eggs in the nests of other bird "hosts," depending on them to hatch and rear their young). Its genus consists of nearly 30 species of birds that occur throughout the Old World tropics. They are all large, semiterrestrial birds with elongated tails but rather short wings. As their common and specific no- menclatures suggest, this species has contrasting white eye-stripes (superciliary streaks) through their otherwise grayish heads. Their wings are bright rufous, and their blackish tails seem too long for their wings and bodies. The adult sexes are alike in size, about 16 inches $(40 \mathrm{~cm})$ long, and plumage, but immatures are tawnier on their head and breast.

In all coucals the females are slightly larger than the males, and the sex roles are reversed, with the males providing most of the parental care. Like all cuckoos, their toes are flexible, so that two toes often face forward and two backward, as in woodpeckers and barbets. The name coucal apparently is from the French, and is derived from coucou and alouette, which refers to their unusually long hind toe claws. The generic name Centropus, meaning sharp foot, probably has the same origin.

These birds reach the northern limit of their range in Ethiopia, where they extend into relatively arid habitats. More generally they are found in fairly moist savannas. They typically prefer to hide, walk, or run than to fly, which seems to be done with some difficulty. They have even been known to swim, but this must be quite rare. Such swimming ability, as well as their general proportions, reminds one of the strange South American hoatzin (Opisthocomus) of the Orinoco River basin, a species that is often distantly affiliated taxonomically with cuckoos.

Virtually all cuckoos have loud or distinctive voices, which in Centropus species are lowpitched and rather pigeon-like. Calling duets are common in these birds and, like some other cuckoos, this species has a "water-bottle" vocalization that sounds very much like water being poured out of a narrow-necked jug.

Coucals forage rather omnivorously on arthropods, crustaceans, and small vertebrates such as amphibians, lizards, and snakes, as well as the eggs or young of various birds. They pair monogamously, and apparently the male builds the nest and does most of the incubation. In a related species (C. sinensis) the clutch size varies from two to four eggs, and the incubation and fledging periods are 15 to 16 days and 18 and 22 days, respectively. The young of this and many other cuckoos are covered initially by dense hairlike down 
that could make an observer wonder what kind of strange animal is in the nest. Multiple broods per season are common, but breeding in Ethiopia is said to mostly occur during April and May.

This species is widespread from Sudan to South Africa and as of 2016 was considered to be a species of least concern by the International Union for Conservation of Nature. Numerous eBird reports indicate that Ethiopian sightings have occurred from Mile Serdo Wildlife Reserve south to the country's southern borders, west nearly to South Sudan, and southeast to the Bale Mountains.

Suggested reading: Chapin, 1939; Del Hoyo, Elliott \& Sargatal, 1997; Fry, Keith \& Urban, 1988.

\section{Family Trogonidae (Trogons)}

\section{Narina Trogon Apaloderma n. narina}

Only three trogon species occur in Africa, and the Narina trogon is the most widely distributed of them. The great majority of trogons occur in the New World tropics, and the quetzals (Pharomachrus) are the most famous of these. The word trogon is from Greek and means "to gnaw," which probably refers to this bird's gnawing of cavities into rotting trees for nesting. Trogon relationships are still obscure, but recent morphological and genetic data suggest that their nearest, albeit still distant, relatives might be the endemic and aberrant African mousebirds (Coliidae).

The Narina trogon was named in 1815 after the mistress of François Levallant, a French ornithologist and explorer who discovered and named many African bird species. It ranges from South Africa north to the Red Sea as well as to coastal West Africa, in savannas, rainforests, and montane forest habitats. Both sexes are brilliantly iridescent green above and crimson red below, the red color deriving from carotenoid pigments. Such pigments are normally obtained by redto yellow-colored birds through the ingestion of fruits and berries, but the African trogons are re- puted to be entirely dependent on animal foods, especially insects.

All trogons feed in a similar manner. They sit motionless on a branch for long periods, scanning the area around them for insects that might be crawling on or hiding among leafy vegetation, or in flight. Sighting an opportunity, they swoop down and then stall out as they hover, snatching their prey (or plucking arboreal fruit) in midair. They then return to their perch to subdue and consume their bounty. Their toes are long and quite flexible, with two oriented forward and two behind, but their legs are short and weak. Unlike the woodpeckers or parrots, the trogon does not use its $\mathrm{X}$-like toe arrangement for clinging to vertical surfaces.

The Narina trogon is much like most trogons in that it is far more easily heard than seen; the birds often utter rather loud monosyllabic notes in a monotonous series. In Costa Rica I have stood directly beneath a pair of periodically calling orange-bellied trogons (Trogon aurantiiventris) for several minutes before locating them no more than 50 feet directly above my head. The birds seemed to maddeningly and purposefully keep their glossy but inconspicuous green backs turned toward me, rather than exhibiting their brilliant red and orange underparts.

Pair-bonds are apparently long-term among many trogons, but in at least some species the start of the breeding season is marked by the male locating one or more potential nest sites (often abandoned woodpecker cavities) and advertising both the nest's location and his presence by frequent repetitive calling. These calls are often long series of wooden notes something like those of cuckoos. The incubation period is about 16 days, performed by the female, and the fledging period is about 25 days.

The Narina trogon is widespread across subSaharan Africa and as of 2016 was classified by the International Union for Conservation of $\mathrm{Na}$ ture as a species of least concern. A moderate number of eBird reports indicate that Ethiopian sightings have occurred from the vicinity of Addis Ababa southwest to Omo National Park, and southeast to the Bale Mountains. Several other members of the trogon family are in a more 
sobering population status, especially the splendidly plumaged resplendent quetzal (Pharomachrus mocinno) of the New World tropics, which is among the most beautiful of the world's birds and might also be the most threatened of all the world's trogons.

Suggested reading: Chapin, 1939; Del Hoyo, Elliott \& Sargatal, 2001; Forshaw \& Cooper, 2002; Fry, Keith \& Urban, 1988; Johnsgard, 2000.

\section{Family Alcedinidae (Kingfishers)}

\section{Gray-headed Kingfisher Halcyon l. leucocephala}

Kingfishers are wonderfully named with both their scientific and vernacular names. Few birds are better fishers than the kingfishers, and the generic name of this species calls to mind the gentle halcyon days of late fall. Alcyone was the daughter of Aeolus, the wind god, and her husband was Ceyx, king of Thessaly. Ceyx left one day on a sea voyage. Worried about him, Alcyone went to the seashore to search for him. When she found him lifeless on the shore, she threw herself into the sea in despair. On seeing this proof of love, the gods rewarded the pair by reviving and transforming them into kingfishers. These kingfishers laid their eggs on a nest of hollow fish bones and set them afloat near the start of winter. In order to protect their eggs from destruction, the wind god Aeolus calmed the seas during this time, thus bringing about the peaceful halcyon days of autumn.

The gray-headed kingfisher is the largest of the three kingfisher species painted by Fuertes, but it is still only of medium size in terms of the entire kingfisher group. Like many kingfishers, it is sky blue on the upper surface of the wings and tail. This species also has a contrasting gray head, black upperparts, and a chestnut belly. Its sharp, gradually tapering beak is bright red in adults.

This bird is part of a large species assemblage called woodland kingfishers, which feed mainly on the ground rather than from water, and on a variety of invertebrates and small vertebrates. Prey as large as small mice, lizards, and nestling birds that have fallen to the ground are taken. Hunting is done in much the same manner as by trogons: a period of patient waiting and watching, followed by a quick swoop down to catch the prey, and then a rapid return to the same or a different perch to subdue and eat it.

Gray-headed kingfishers are rather solitary, highly territorial birds that announce their presence with display singing and vibrating their opened wings while perching, thus exposing the brilliant color patterns effectively. Pair-bonds are monogamous and probably long-term, and nesting (May to June in Somalia) in done in selfexcavated ground tunnels, usually in steep riverbanks but sometimes in ravines or termite mounds. The clutch consists of two to four eggs, and the incubation period is about 20 days. The greater honeyguide (Indicator indicator) is a known brood parasite of this kingfisher (only one of at least 38 known host species [Johnsgard, 1997]).

This kingfisher is widespread across subSaharan Africa and as of 2016 was considered to be a species of least concern by the International Union for Conservation of Nature. Numerous eBird reports indicate that Ethiopian sightings have occurred from the vicinity of Lake Tana south to the country's southern border, west to South Sudan, and east to Dire Dawa.

Suggested reading: Clancey, 1992; Forshaw \& Cooper, 1983-85; Fry, Keith \& Urban, 1988; Grzimek, 1973; Johnsgard, 1997.

\section{Pygmy Kingfisher Corythornis (Ispidina) picta}

Pygmy kingfishers are one of Africa's smallest kingfishers, with adults averaging only about half an ounce in weight. They are jewellike sprites of the evergreen forests and gallery forests throughout much of sub-Saharan Africa except for the southern tip. They resemble the even smaller African dwarf kingfisher (Ispidina zecontei) but have an all-dark blue crown with slightly lighter 
blue barring. This same crown pattern separates them from the slightly larger malachite kingfisher, which lacks an orange eyebrow-like stripe below and whose crown is more clearly barred and elongated into a crest. Both species have stiletto-sharp crimson beaks about as long as their heads, and both catch a variety of insects and other arthropods from land as well as occasionally from shallow water or by aerial chases. Fuertes collected and painted this "tiny lavenderglossed kingfisher" on April 10, 1927, near Lake Tana (Fuertes \& Osgood, 1936).

In spite of their brilliant coloration, these tiny birds are quite inconspicuous when perched quietly and almost motionless among vegetation, awaiting their chances at any food items that might chance to pass by. Their calls are highpitched, weak, and mainly uttered while in flight. The birds are found singly or in pairs and, like other kingfishers, appear to be strongly territorial. They might occupy the same perches and use favorite hunting sites for extended periods. The sexes are identical in plumage, but immatures are paler throughout. They remain with their parents only a short time before dispersing and establishing their own hunting areas.

Pairs excavate nests in vertical slopes of stream banks, roadcuts, or similar locations, the tunnels usually being less than a yard in depth. Often the tunnel initially slopes slightly upward and then descends into a larger egg chamber. Like those of other kingfishers, the eggs are white and rather rounded; the clutch averages about three or four eggs. Incubation and fledging periods are apparently still unknown, but in the somewhat larger European common kingfisher (Alcedo atthis) the incubation and fledging periods are 19 to 20 days and 24 to 25 days, respectively. In that species two or three broods per year might be reared.

The pygmy kingfisher is widespread across sub-Saharan Africa and as of 2016 was considered to be a species of least concern by the International Union for Conservation of Nature. Numerous eBird reports indicate that Ethiopian sightings have occurred from the vicinity of Lake Tana south to the Kenya border, west to Mago National Park, and east to Dire Dawa.
Suggested reading: Chapin, 1939; Clancey, 1992; Forshaw \& Cooper, 1983-85; Fry \& Fry, 1992; Fry, Keith \& Urban, 1988; Grzimek, 1973; Newman, 1971.

\section{Malachite Kingfisher Corythornis (Alcedo) cristata}

Very similar to the pygmy kingfisher, the malachite kingfisher is only slightly larger and distinctly crested. Fuertes properly labeled his portrait as Corythornis c. cristata, but the published plate (FMNH, 1930) identified it as a "Pigmy kingfisher." The generic name Corythornis translates as "crested bird," and Fuertes's elegant portrait shows the forehead feathers raised in a vertical crest-but when the bird is at rest they lie flat along with the other crown feathers. Fuertes collected and painted his specimen, which he described (Fuertes \& Osgood, 1936) as a "tiny dark blue and deep chestnut kingfisher (about as big as a vireo) with a flopsy frontal crest," near Lake Tana on April 8, 1927. The crest feathers are sometimes erected and spread laterally as the bird is peering down from a hunting perch, perhaps to help shade the eyes when hunting from a sunny location, as painted by Fuertes.

This species is more closely associated with water than is the pygmy kingfisher; perhaps they thus avoid direct competition in areas where they co-occur. As a result, the malachite kingfisher's foods consist mostly of small fish, crustaceans, amphibians, and water-loving insects such as dragonflies, damselflies, and others. Frogs and semiterrestrial tadpoles are also taken from shorelines.

In the usual kingfisher manner, these birds are monogamous and strongly territorial; and a pair might defend as much as 200 yards of shoreline. Most prey items are captured by a sudden near-vertical dive into the water and being seized very near the surface. The item is then carried back to a nearby perch where it can be killed and swallowed headfirst. Fish up to about two inches in length can thus be handled. Probably nonbreeding birds capture and eat up to 20 such prey per day, but when feeding a large 


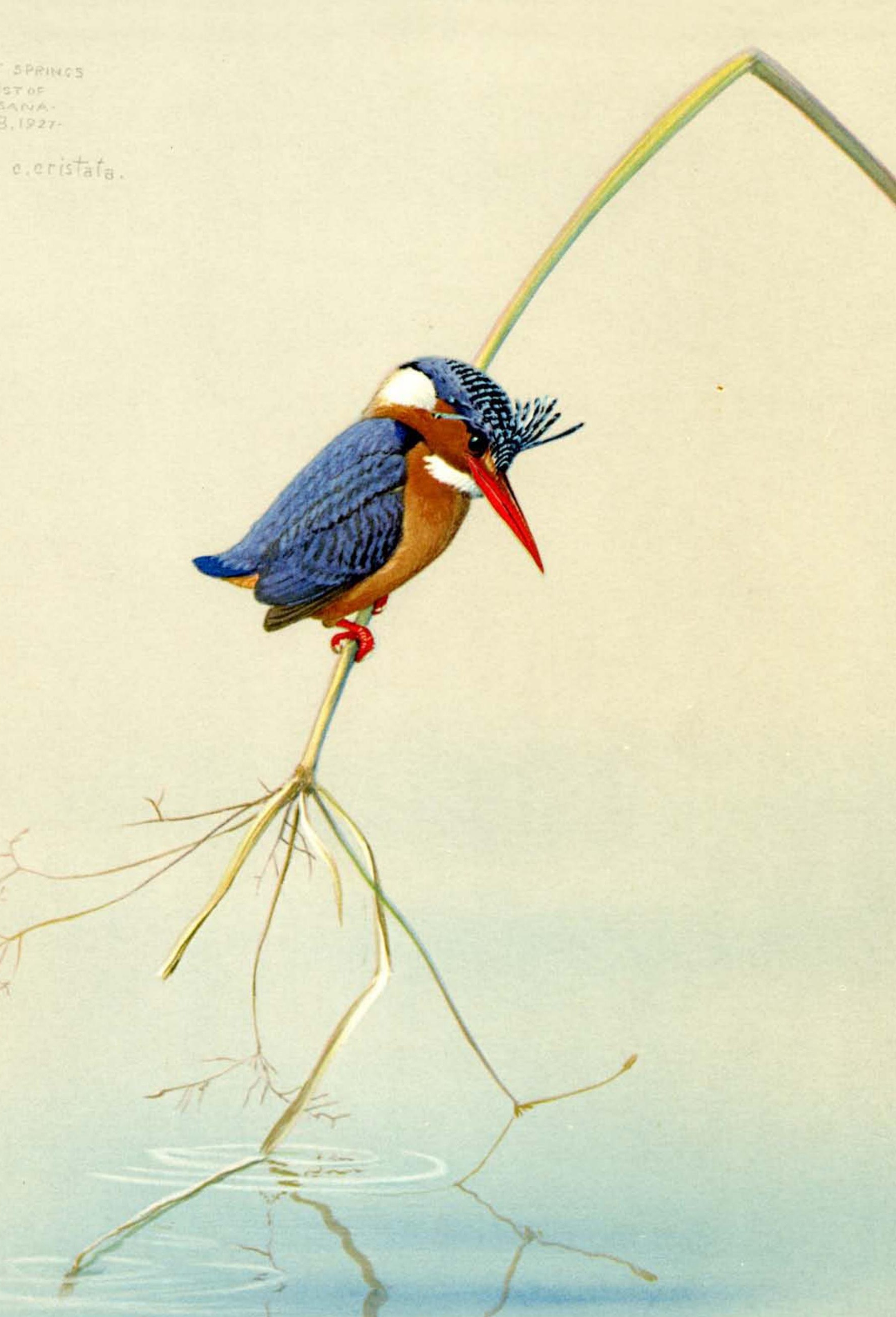


brood of nestlings the number captured might easily exceed 60.

It is likely that sexual maturity is attained by the end of the first year; yearling birds can breed in a plumage that is still not fully adultlike. Courtship consists of extended chases of the female by the male over water, the presentation of food items, and mutual crest-raising. The nesting tunnel is typically excavated in a clay bank near water and is normally less than a yard $(0.9 \mathrm{~m})$ long. Usually, four to six eggs make up a full clutch. Both sexes incubate throughout the 16- to 18-day period to hatching, the pair alternating the activity about every two hours, thus allowing each mate time to forage. The fledging period lasts at least three weeks, during which live prey are carried in by the parents for the young to kill and consume. A longer period of training the young to catch their own prey probably follows.

This species is widespread across sub-Saharan Africa and as of 2016 was considered to be a species of least concern by the International Union for Conservation of Nature. Numerous eBird reports indicate that Ethiopian sightings have occurred from the country's northern to its southern borders, west nearly to South Sudan, and east to Aledeghi Wildlife Reserve.

Suggested reading: Chapin, 1939; Clancey, 1992; Forshaw \& Cooper, 1983-85; Fry \& Fry, 1992; Fry, Keith \& Urban, 1988; Grzimek, 1973; Newman, 1971.

\section{Family Upupidae (Hoopoes)}

\section{Eurasian Hoopoe Upupa epops}

This widespread Eurasian species is notable for the fact that its English vernacular name as well as both of its generic (the Latin counterpart) and specific names (the Greek equivalent) are all variants of the same voice-based origin. The male's distinctive "hoo-poe" vocalization is its advertisement song, most frequently uttered shortly in advance of the breeding season, which in the Horn of Africa is from April to June. A wide variety of other vocalizations are also produced.

All three species of the world's hoopoes are quite similar and highly distinctive in appearance. Two species occur in Africa, including both a residential population (Upupa africana) and the migratory Eurasian species; the latter is depicted in Fuertes's plate. A third species is endemic to Madagascar. Hoopoes are currently believed to be most closely related to the hornbills and ground hornbills, and probably should be grouped with them in the order Bucerotiformes.

Probably part of the hoopoe's visual uniqueness and attraction lies in the fact that its long crest, when depressed, is about the same length and shape as the bird's bill, which produces a sort of optical illusion when seen at a distance. The feather tips of the erectile tan crest are patterned with black and white; when the crest is fully erect and spread horizontally, it produces a stunning fanlike visual effect. Hoopoes also somewhat resemble giant butterflies in flight, when their contrasting black-and-white wing patterning is most apparent. The early Egyptians considered the hoopoe to be sacred and of symbolic significance; they believed that old individuals bring their younger kin food while they are helpless and thereby could establish proof of parentage. The Arabs likewise considered the hoopoe to have medicinal or magical properties and used its body parts in amulets.

Hoopoes are mainly insectivorous, foraging on the ground surface and in the litter layer and by probing the bill into soft soil. The species is very tolerant of warm, sunny conditions and seemingly rarely drinks water. Nesting occurs in a wide variety of preexisting cavities, such as trees, cliffs, stone walls, nest boxes, haystacks, and abandoned mammal burrows. The clutch size varies with latitude, being smallest in the tropics (about 4 eggs) and largest in northern Europe (about 12 eggs). The female alone incubates, and the respective incubation and fledging periods are 15 to 18 days and 26 to 29 days. When disturbed on the nest, the nestlings direct streams of feces at intruders and utter snakelike hissing sounds. A foul-smelling secretion of the female's uropygial gland provides additional nest defense. 
European hoopoes migrate to Africa and winter just south of the Sahara from Senegambia in western Africa to Ethiopia in the east. In Asia some migration is related to seasonal rains; a migrant Eurasian hoopoe was once reportedly seen at 21,000 feet $(6,400 \mathrm{~m})$ on Mount Everest. The Eurasian hoopoe is a widespread migrant in northern and sub-Saharan Africa and as of 2016 was considered to be a species of least concern by the International Union for Conservation of Nature. A moderate number of eBird reports indicate that Ethiopian sightings have occurred from the country's northern to southern borders, west nearly to South Sudan, and east to Aledeghi Wildlife Reserve.

Suggested reading: Chapin, 1939; Cramp \& Simmons, 1985; Del Hoyo, Elliott \& Sargatal, 2001; Fry, Keith \& Urban, 1988; Grzimek, 1973; Newman, 1971; Skead, 1950.

\section{Family Bucerotidae (Hornbills)}

\section{Abyssinian Ground Hornbill Bucorvus abyssinicus}

Upon seeing one's first ground hornbill, it is hard to decide whether to gasp in surprise or laugh. Somehow the bird fails to fit the standard vision of a hornbill; its turkey-sized mass, longlegged profile, and an almost entirely black appearance would seem to fit a Walt Disney movie better than the African savanna. Further, the bird's vividly colored bare facial skin, an inflated bill casque, and a sleepy-eyed look accentuated by improbably long eyelashes add to the combined comic-tragic effect. Ground hornbills walk slowly and funereally about on tiptoe, often in pairs or trios, like unemployed actors all applying for the same role as a mortician. Indeed, in many parts of Africa the birds are associated with evil and death as well as with predicting drought and rainy seasons.

There are two species of ground hornbills. The one illustrated by Fuertes extends across subSaharan Africa from Mauritania to Ethiopia, mostly in savanna and dry grasslands. The other species is more southerly in its range and has more blue and less red in its facial skin. Unlike all other hornbills, of which there are 23 African species, ground hornbills are mostly carnivorous, foraging on a variety of small vertebrates as well as insects. At times this species is attracted to and feeds on carrion, heightening its morticianlike image, but it also will occasionally eat plant materials such as fruits and seeds.

Ground hornbills only rarely fly, but in flight they reveal contrasting white primary feathers. They also sometimes utter deep booming notes, something like those of a kori bustard but in more rapid sequence. Males often produce such booming calls during courtship as they walk around the smaller females. Other mating displays include mutual beak-slapping, nest-site inspection, and courtship feeding. Ground hornbills are cooperative breeders, with each group having a dominant pair that is assisted by adult and immature helpers.

Unlike the nesting behavior of other hornbills, the ground hornbill's nest entrance is not sealed up and no nest sanitation is performed. Although a tree hollow is often chosen for a nest site, the birds might also use hollow logs, other natural holes, or self-excavated cavities in earthen banks. Incubation lasts 40 to 45 days followed by an 80 - to 90 -day fledging period. As much as two years might be required for the young to gain independence from their parents. Probably four to six years are required to attain maturity and begin breeding at about ten years. The life expectancy of fledged young is thought to be about 30 years, and in captivity the birds might live up to 70 years.

The northern ground hornbill has a wide distribution in the Sahel region south of the Sahara, but its population is decreasing, and the species has been classified by the International Union for Conservation of Nature as vulnerable. The southern ground hornbill has been similarly classified, and in South Africa the decline has been sufficiently great so as to classify the species as endangered in that region. Numerous eBird reports indicate that Ethiopian sightings have occurred from the country's northern to its southern borders, west nearly to South Sudan and Sudan, and east to Dire Dawa. 
Suggested reading: Chapin, 1939; Del Hoyo, E1liott \& Sargatal, 2001; Forshaw \& Cooper, 1995; Fry, Keith \& Urban, 1988; Grzimek, 1973; Kemp, 1995.

\section{Red-billed Hornbill Tockus erythrorhynchus}

The red-billed hornbill was incorrectly identified as Hemprich's hornbill (Tockus hemprichii) on Fuertes's plate. That species is generally darker throughout and lacks white spotting on the upper wing coverts and secondary flight feathers. Both species have red to orange-red bills with no indication of a casque. The red-billed hornbill is much more widespread and common within its broad range, which includes nearly all of Ethiopia; the Hemprich's hornbill range extends from Eritrea south to Uganda.

Fuertes's plate shows an adult male; females have shorter bills and almost no black on the lower mandible. Most African hornbills have decurved, colorful beaks as adults, or the males have variously enlarged casques over the upper mandible. These bony but airy structures probably function mainly as social-sexual signals and probable sound resonators.

Red-billed hornbills are mostly found in open savanna, scrub woodland, or thorny scrub, especially where acacia trees are abundant. They can be found up to about 7,000 feet $(3,200 \mathrm{~m})$ in Ethiopia. These birds are also common in Kenya and northern Tanzania, where I have seen them in various locations. In all these areas they cooccur with the yellow-billed hornbill (Tockus flavirostris), which is somewhat larger and has a more yellowish bill and more distinctly banded tail.

Red-billed hornbills are mostly ground foragers that consume a variety of insects, especially dung beetles, but also many other terrestrial invertebrates. They additionally catch and eat geckos and the eggs and chicks of weaverbirds, and sometimes they consume carcasses of small mammals.

These birds are monogamous and territorial. Males courtship-feed their mates, and mated pairs call and display together, the birds uttering a series of accelerated clucks while simulta- neously bobbing their bodies up and down. Pairs are scattered at densities of about 250 acres (101 ha) per pair, and their nests are located an average of about 600 feet $(180 \mathrm{~m})$ apart. The nesting season is probably from February to August.

Nests of this hornbill are located in the natural cavities of trees or sometimes in old woodpecker or barbet holes. Any cracks or extra entrances are sealed over, and the female herself performs the final closure until only a small slit remains. The male brings her daubs of mud for closing the cracks; some droppings and insects might also be incorporated into the mix. The male also brings in green materials for nest lining and feeds his mate during her incarceration period of up to about three months. The incubation period is 23 to 26 days, and when the chicks are about 20 days old the female might break out and rebuild the nest, making it larger. After that both sexes help feed and tend the young for about six months. Their average lifespan in captivity is about 15 years.

The red-billed hornbill is widespread across sub-Saharan Africa and as of 2016 was considered to be a species of least concern by the International Union for Conservation of Nature. Numerous eBird reports indicate that Ethiopian sightings have occurred from the country's northern to southern borders, west to Sudan, and east to Dire Dawa.

Suggested reading: Del Hoyo, Elliott \& Sargatal, 2001; Forshaw \& Cooper, 1995; Fry, Keith \& Urban, 1988; Ginn, McIlleron \& Milstein, 1989; Kemp, 1995; Newman, 1971; Root \& Root, 1969.

\section{Silvery-cheeked Hornbill Bycanistes brevis (2 images)}

The silvery-cheeked hornbill is part of a group of seven hornbills that are endemic to Africa, and all are fairly large with lengths up to about 28 inches $(70 \mathrm{~cm})$, arboreal, and mostly fruit-eating. This species is notable for its large bill casque and the silvery streaking on the sides of its face. Adult males are both larger in overall size and in their degree of bill enlargement than the females. Adult males also have a white band around the base of their otherwise mostly brownish bill, and 
the horn-colored casque might be larger than the bill itself. Young birds have more brownish faces, and the casque is only slightly developed.

If not entirely unique in having bill casques, hornbills have diversified casque evolution to a remarkable degree and collectively offer an extraordinarily large range of species-specific shapes and colors that might be important in species recognition and mate selection. It is likely that the casques also serve as resonating chambers for the males' often loud, booming, or bellowing vocalizations, which are sometimes aided by inflatable throat air sacs.

This species' plumage is mostly black, except for a white rump and lower underparts and white markings at the tips of their outer tail feathers. Their outer primaries are distinctly narrowed toward the tips, which is probably why the wings produce an audible whooshing sound in flight as these feathers vibrate.

These hornbills are present throughout the Ethiopian highlands up to about 8,000 feet $(2,440 \mathrm{~m})$ in elevation, in montane and riparian forests and woodlands. Although usually found in pairs or family groups, they become quite social where food is abundant, such as at fruiting trees. They also might roost colonially, in flocks of as many as a few hundred individuals. During daylight hours, the roosting groups break up as the individuals disperse to forage. They are not only frugivorous but also sometimes consume small animals as well as insects, nestling birds, or small mammals. Prey as large as fruit pigeons and fruit bats might also be killed and eaten.

Like most hornbills, the adult silvery-cheeked birds are highly vocal, and various loud growls, barks, and braying sounds are uttered. Presumably at least some of these notes serve for courtship and sexual advertisement since definite territoriality seems to be absent. Breeding in Ethiopia extends from February to July, centering on the rainy season. Males court females through courtship-feeding, mutual preening, and probably other postural displays.

Hornbills are notable for being the only group of birds in the world in which the female is incarcerated within her nesting cavity throughout the entire incubation and rearing period. The origin of this remarkable behavior is speculative, but it probably reduces predation probabilities. Nest-site selection must begin months in advance of actual egg-laying, as the birds begin to seal up the entrance to a tree cavity or sometimes a hole in a rock. Sealing is achieved by the male bringing soil pellets to the female, who then takes these saliva-moistened pellets and applies them to the edge of the cavity entrance. Such activities continue until the entrance is so small the female can barely enter and leave. Finally she enters it a final time, and the entrance is further sealed until only a narrow slit remains through which the male can pass his bill and deliver food.

One to three eggs are laid and incubated for about 40 days. During that time the male delivers food, mostly small fruits, to the nest up to 14 times per day. Following hatching, the male increases his visits to as many as 24 times a day, perhaps visiting the nest as many as 16,000 times throughout the entire nesting cycle. Fledging is attained after nearly 80 days of nestling life.

During this long period, the male also delivers bark flakes and bark lining to the nest, probably to aid in nest sanitation. At fledging time the nest seal is broken and the female and their offspring emerge. Apparently the usual result is a single surviving chick, although two might occasionally be reared successfully. After the female's emergence she undergoes a wing and tail molt, replacing the badly worn and torn feathers of the incarceration period. Overall, pairs produce an average of about 0.4 to 0.6 fledged young per breeding attempt. In spite of this rather low success rate, the nest-sealing behavior of hornbills must certainly reduce the overall degree of nest predation by predators.

The silvery-cheeked hornbill is widespread from Ethiopia south to Zimbabwe and as of 2016 was considered to be a species of least concern by the International Union for Conservation of Nature. Numerous eBird reports indicate that Ethiopian sightings have occurred from the vicinity of Lake Tana south to Stephanie Wildlife Preserve, west nearly to South Sudan, and east to the Bale Mountains.

Suggested reading: Del Hoyo, Elliott \& Sargatal, 2001; Forshaw \& Cooper, 1995; Fry, Keith \& Urban, 1988; Grzimek, 1973; Kemp, 1995; Moreau \& Moreau, 1941. 


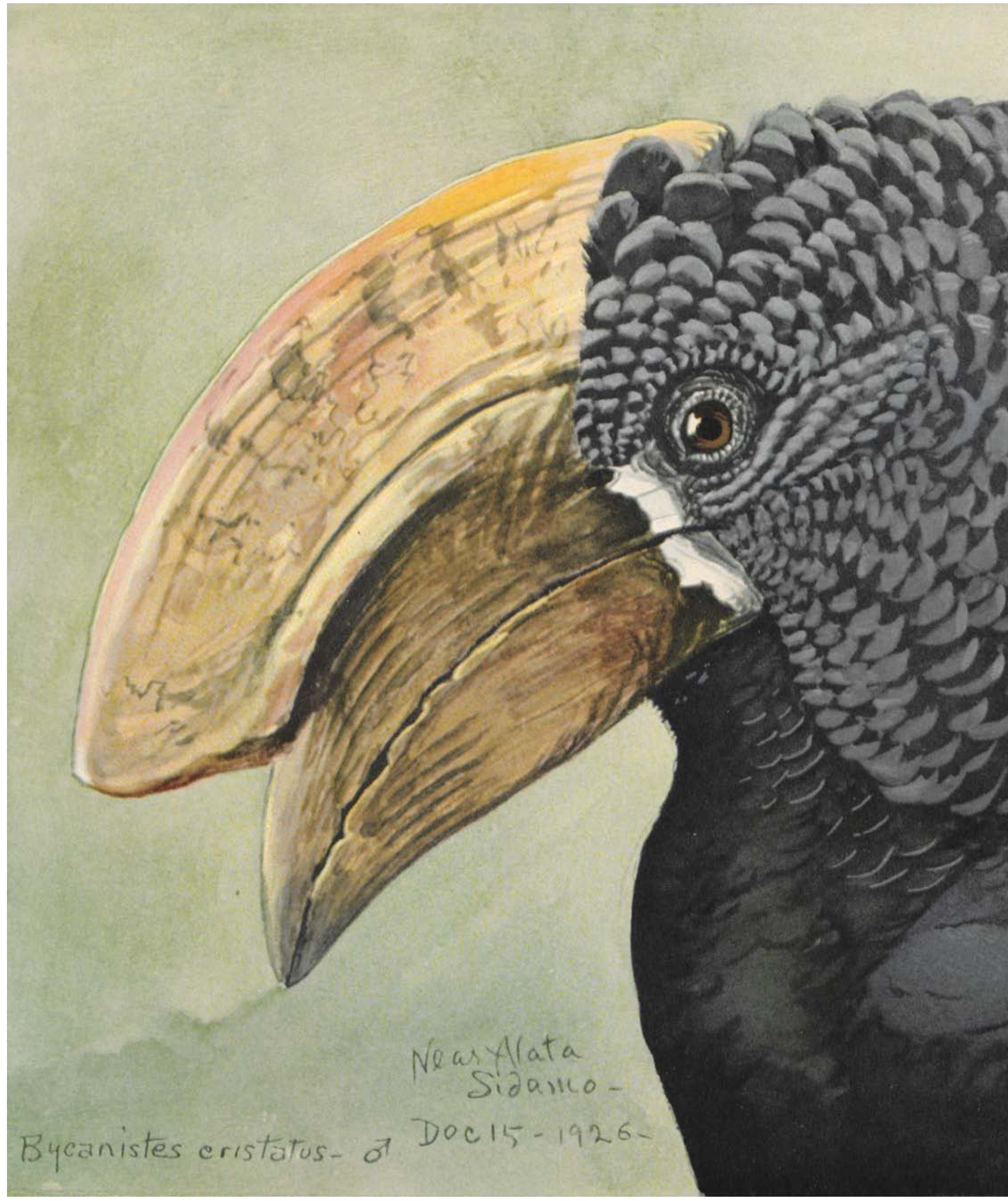




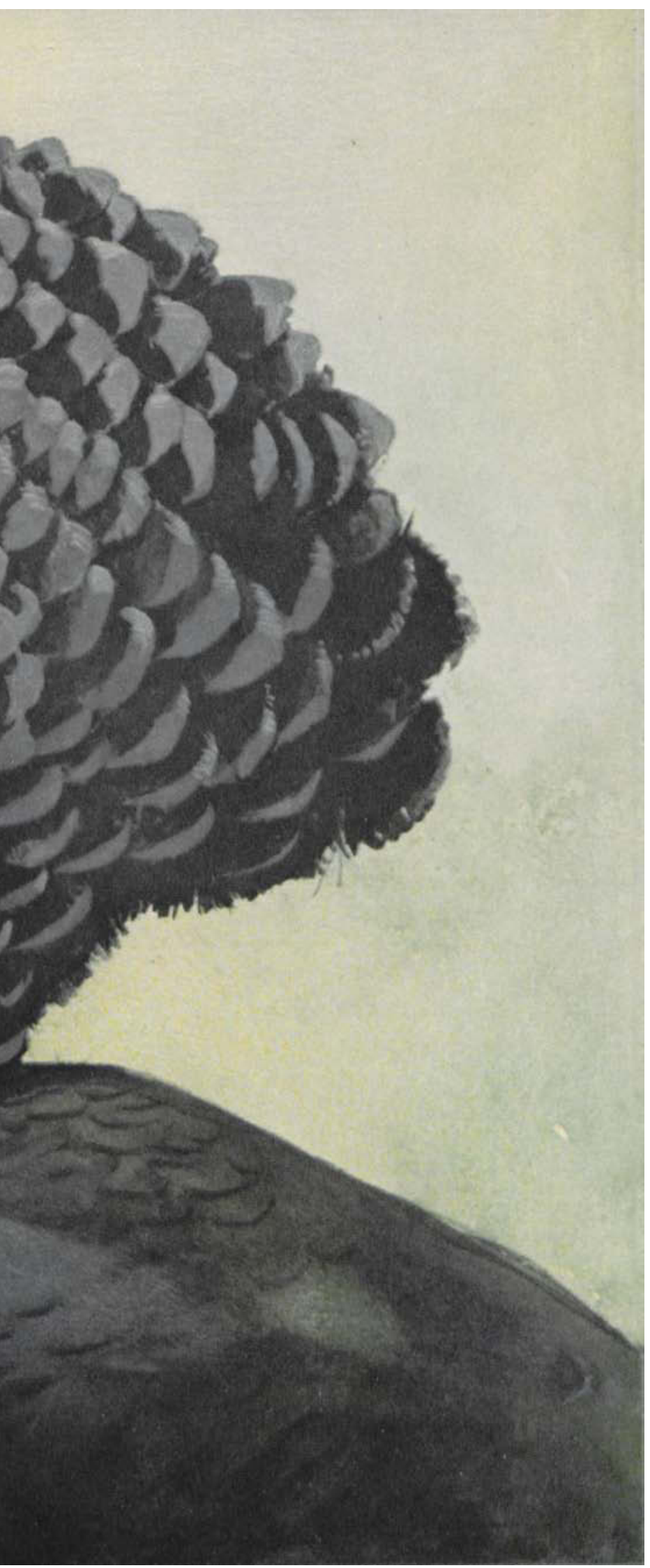

\section{Family Capitonidae (Barbets)}

\section{Double-toothed Barbet Lybius bidentatus aequatorialis}

The barbets are a group of small to medium-sized birds that are related to woodpeckers and share the X-like toe arrangement of that group. This is a climbing and clinging adaptation in which two toes (the first and fourth) face toward the front and two are directed behind. Some barbet species even peck at wood like woodpeckers to excavate nest cavities, or drum on the surface of trees for social signaling. Like woodpeckers, they not only nest in cavities but also roost in holes. These sites usually are tree cavities, but sometimes nesting occurs in holes in termite mounds or even in the ground. Largely insectivorous, some barbets will also eat fruits. The majority of the species occur in Africa, and all are limited to the eastern hemisphere.

The double-toothed barbet is named for two toothlike projections on each side of its upper mandible, which presumably are useful for crushing large insects. It is a rather large barbet, up to about 8.5 inches $(21.5 \mathrm{~cm})$ in length, with black upperparts; mostly bright red underparts; patches of white on the flanks; a large, bright yellow eye-ring; and a pale yellow bill. The sexes are nearly alike as adults. The birds occupy forest edges, savannas, and parklands and often glean for insects along tree surfaces. In Ethiopia, their ranges can extend up to almost 6,000 feet $(2,700$ $\mathrm{m})$ in elevation.

Like woodpeckers, barbets lack complex syringeal structures and are not musical, but this species does produce a variety of calls and utterances that evidently function as songs. The birds are social, and their small flocks probably represent family units that roost together. Paired birds maintain fairly large territories that typically include some fruiting trees, such as figs. The pairs excavate cavities in trees or snags, where for much of the year they roost together.

Breeding in Ethiopia probably occurs between August and November. Courtship activities include tail-cocking and tail-swinging movements, wing-flicking, mutual preening, and erection of 
their white patches of flank feathers. Clutches range from two to four eggs, and incubation is by both sexes, lasting about 13 days. Helpers often appear to assist with chick-rearing; these presumably are young of the previous year. Fledging occurs at 37 to 39 days.

This species is widespread across tropical central Africa, and as of 2016 was considered to be a species of least concern by the International Union for Conservation of Nature. Numerous eBird reports indicate that Ethiopian sightings have occurred from the vicinity of Lake Tana south to the Kenya border, west nearly to South Sudan and Sudan, and east to Awash.

Suggested reading: Del Hoyo, Elliott \& Sargatal, 2002; Fry, Keith \& Urban, 1988; Grzimek, 1973; Marshall \& Marshall, 1871.

\section{Family Platysteiridae (Batises and Wattle-eyes)}

\section{Common (Brown-throated) Wattle-eye Platysteira cyanea aethiopica}

Wattle-eyes are a curious group of African flycatchers that are small (about five inches long), short-tailed, and have a vivid and conspicuous eye-ring, or (as in this common wattle-eye species) a scarlet wattle above each eye. They behave, though, more like tits than flycatchers, gathering most of their food by searching about on leaf and twig surfaces and only at times catching insects in flight as the New World flycatchers do.

The generic name of wattle-eyes translates as "broad-keeled" and refers to the broad and flattened bills of these birds. There are four species of wattle-eyes; they are close relatives of the larger group of similar flycatchers called batis or puff-back flycatchers. Wattle-eyes perform a display of erecting their rump feathers similar to that of puff-backs, but they have fewer specialized rump feathers than the latter group's, which when they perform this display resemble small powder-puffs.
Adults of this species of wattle-eye are distinctive in that both sexes are mostly black above and white below and have white wing bars; females have dark chestnut chests rather than the white throats and black chests of males. The birds usually forage through juniper (Juniperus) and yellowwood (Podocarpus) forests in pairs, family groups, or mixed-species flocks. Their vocalizations include harsh notes and rattles, and both sexes duet simultaneously with descending clear whistles that seem to serve as territorial songs. Displaying males also courtship-feed females and produce churring, wing-flicking, and bill-snapping sounds.

During the breeding season, which is centered in the wetter months, the birds form monogamous pairs and construct inconspicuous cuplike nests of grasses, plant fibers, and lichens, often placed low in tree forks. Females lay only two eggs and do all the incubation, but males bring food to them. The incubation and fledgling periods are 17 and about 14 days, respectively, and the young are fed by their parents for up to 80 days after fledging.

This species is widespread across sub-Saharan tropical Africa and as of 2016 was considered to be a species of least concern by the International Union for Conservation of Nature. Numerous eBird reports indicate that Ethiopian sightings have occurred from the vicinity of Lake Tana south to Yabelo Wildlife Sanctuary, with a few sightings outside the central Rift Valley.

Suggested reading: Brosset \& Erard, 1986; Campbell \& Lack, 1985; Chapin, 1953; Ginn, McIlleron \& Milstein, 1989; Grzimek, 1973; Urban, Fry, \& Keith, 1997.

\section{Family Prionopidae (Helmetshrikes)}

\section{White-crested Helmetshrike Prionops plumatus concinnata}

The helmetshrikes of Africa are named for the projecting forehead feathers of some species, a 


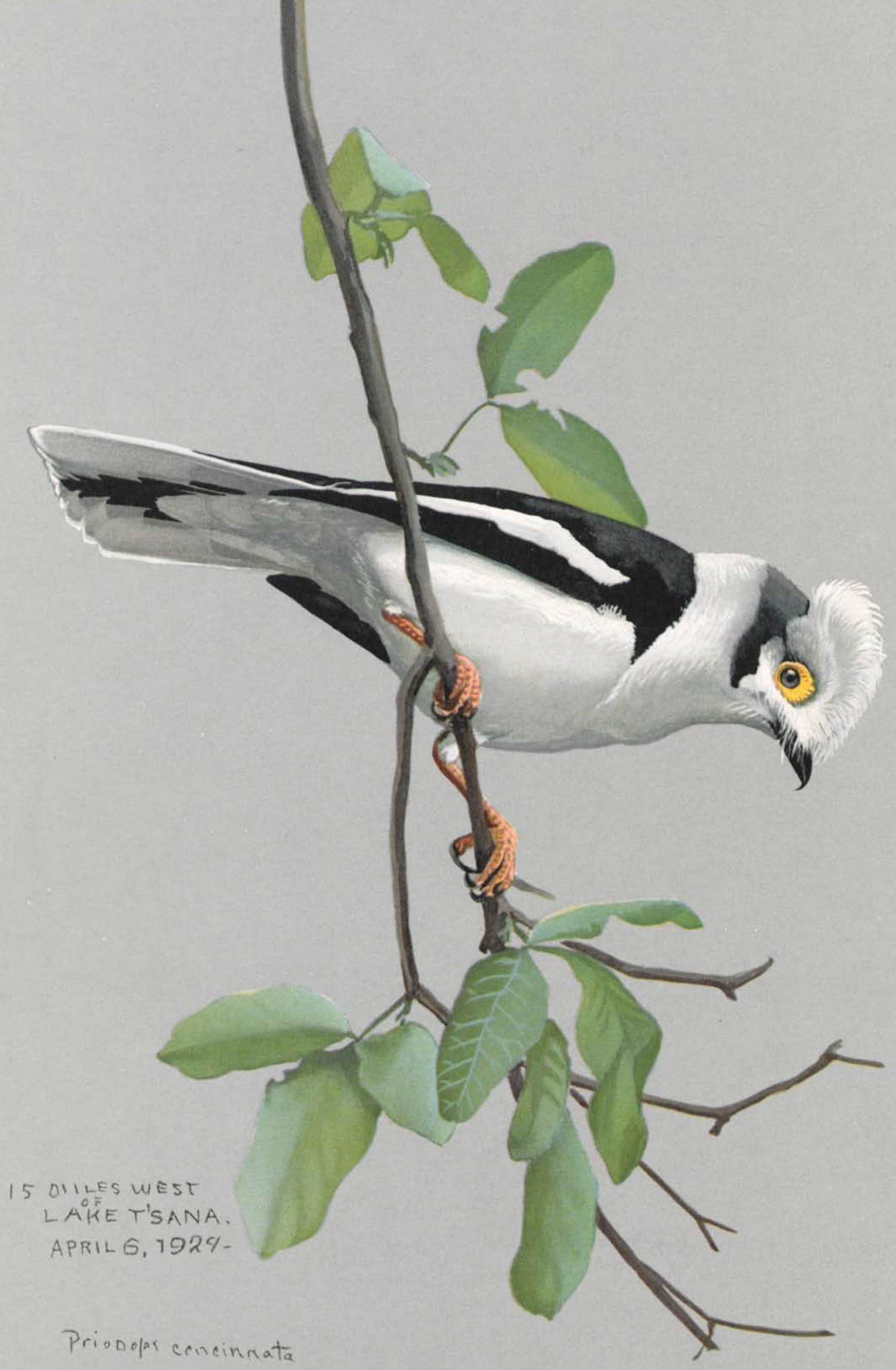


trait especially evident in the species painted by Fuertes. Several species, including the whitecrested helmetshrike, also have serrate-edged yellow wattles around their pale-colored eyes, which is the basis for their generic name, which means "saw-eyed." They are otherwise similar to shrikes, with heavy hooked bills, large heads, and a generally black-and-white plumage pattern. The sexes are identical as adults; young birds have greenish wattles and brown eyes. Recent evidence suggests that the helmetshrike family should be expanded to include the wattle-eyes and batises, or perhaps should be included within the Madagascan vangas, family Vangidae.

Helmetshrikes are gregarious, moving about in small flocks, usually feeding near the tops of trees, and making frequent chattering and billsnapping sounds. They forage on a variety of insects and probably some small vertebrates. They are quite fearless, and in some parts of equatorial Africa are called "leopard-birds" because of their tendency to mob leopards. They also respond to human hunters by making threatening calls and mobbing if not actual attacking. They most often occur in open woodland and are generally found at lower elevations.

Helmetshrikes appear to be nonterritorial; several nests might be located fairly close together. During the breeding season, the birds occur in small groups, which probably consist of closely related birds. They are cooperative breeders, with a life-bonded alpha pair selecting the nest site but the other group members involved in building the nest. As many as four birds have been seen building a single nest. Their nests are placed on lateral branches or at the crotches of trees and are located fairly close to the ground. They are inconspicuous and compact; lined with shredded bark, rootlets, and grass; and covered externally with cobwebs. The webs are alleged to be gathered by adults flying through a web and collecting its strands with their elongated forehead feathers-a seemingly unlikely behavioral adaptation!

Nests or young have been reported from March to October in Ethiopia and Somalia. Clutches have two to five eggs, which are incubated for about 12 to 14 days by the group members. Following hatching, several group members partici- pate in the feeding of the young as well as in nest defense. Fledging requires 17 to 22 days, and the young become independent by five months of age.

This species is widespread across sub-Saharan Africa and as of 2016 was considered to be a species of least concern by the International Union for Conservation of Nature. Numerous eBird reports indicate that Ethiopian sightings have occurred from Mile Serdo Wildlife Reserve south to the Kenya border, west nearly to South Sudan, and east to Dire Dawa.

Suggested reading: Bannerman, 1939; Campbell \& Lack, 1985; Chapin, 1954; Fry, Keith \& Urban, 2000; Ginn, McIlleron \& Milstein, 1989; Grzimek, 1973; Newman, 1971.

\section{Family Corvidae (Ravens, Crows, and Relatives)}

\section{Thick-billed Raven \\ Corvus crassirostris}

The ravens of Africa include several species of large crowlike birds, of which the thick-billed raven has the most massive bill (crassirostris means heavy-billed)-indeed, it has the largest bill of all corvids. It might also be the heaviest of all the world's species of passerine (perching) birds, or is at least equal to the largest, most northerly races of the common raven (Corvus corax). Weighing about 3.3 pounds $(1.5 \mathrm{~kg})$, it is the northern counterpart of the much more widespread African white-necked raven (C. albicollis). However, the Ethiopian species has an even more massive bill that enables it to crush large food items.

Thick-billed ravens occur from moderate elevations up to nearly 11,000 feet $(3,350 \mathrm{~m})$ and probably concentrate near human populations where offal and food scraps are readily available. They eat prey ranging from small vertebrates, such as lizards and snakes, to large insects, such as locusts and beetle larvae excavated from dung. They also cache excess food, a trait typical 


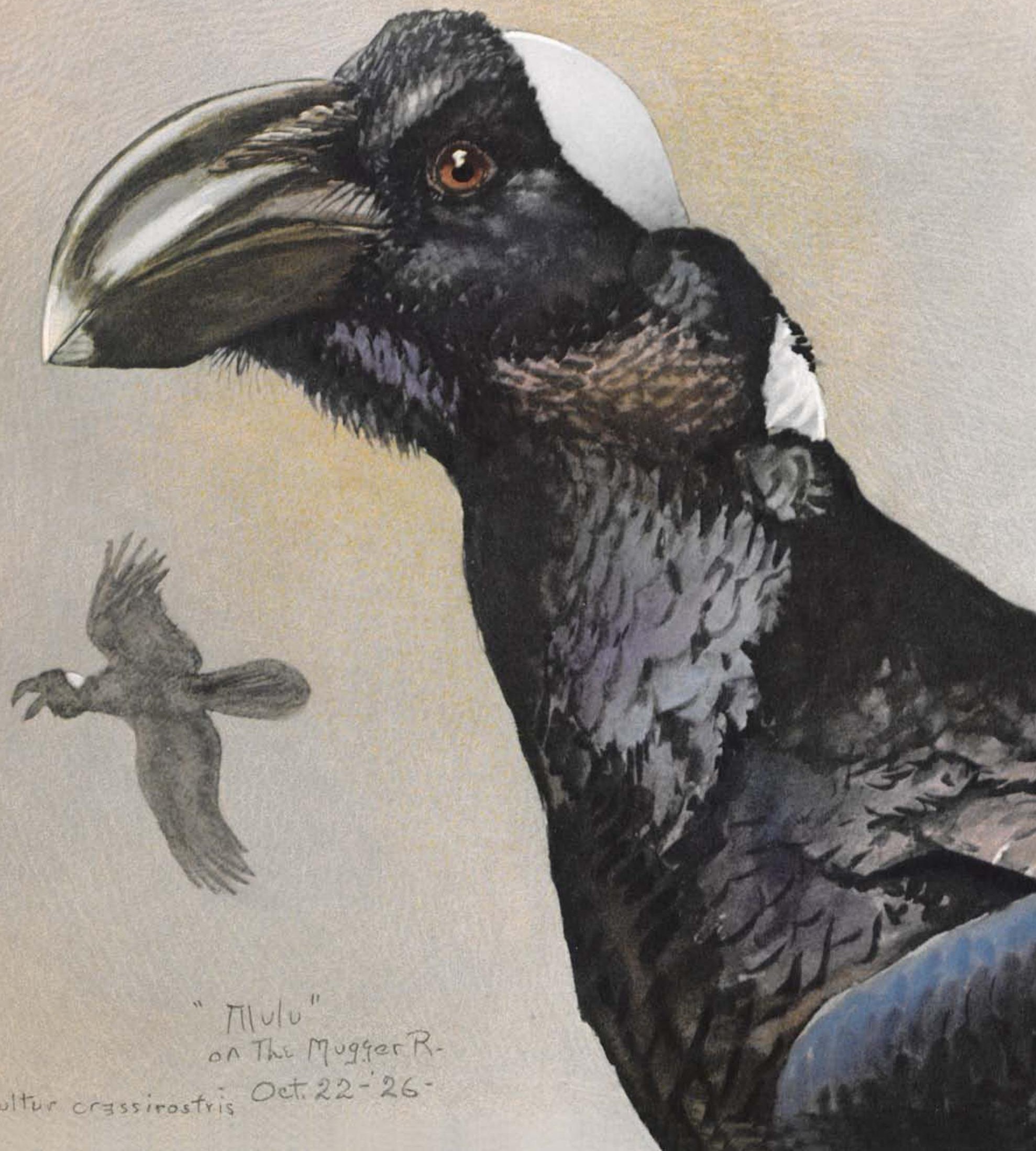


of corvids, and have been observed dunking dried food in water before eating it, one of many indications of their intelligent behavior.

Like many corvids, these ravens are alert and highly adaptable birds that often follow human camps and rapidly locate any carrion or even well-hidden foods. While doing fieldwork in the Teton mountains of Wyoming, I made repeated attempts to surreptitiously hide meat scraps in hopes of attracting and photographing an elusive pine marten (Martes americana). In spite of my best efforts at concealing both myself and the bait, a previously unseen common raven (Corvus corax) would suddenly, invariably appear, find, and carry off the meat within minutes of my hiding it. Studies of the common raven have shown that the birds have remarkable memories; they reportedly even save items that might be of future use, such as tools, as well as allegedly keep items of value that could possibly be used later for barter.

Territorial fighting has been reported in thickbilled ravens, and aerial aggressive or courtship displays are evidently performed, as in other ravens. Mutual preening, especially of the white nape area, is apparently also done. Just as the other ten or so other raven species do, nesting often occurs on steep cliff sides or in trees, the latter locations chosen where rocky sites are not available. In Ethiopia the birds nest during the drier period from December to February; nestlings might be present as late as the latter part of March. The usual clutch is of three to five eggs.

In most raven species and probably also the thick-billed raven, incubation lasts from about 18 to 20 days and is performed only by the female, who is fed by her mate. However, both sexes brood and feed the young, which fledge in about six weeks. The young birds remain with their parents for some time thereafter but eventually join groups of immature or nonbreeding birds.

This species is nearly endemic to Ethiopia, with its range boundaries reaching slightly into Sudan, Eritrea, and Somalia, but it is generally common and as of 2016 was considered to be a species of least concern by the International Union for Conservation of Nature. Numerous eBird reports indicate that recent Ethiopian sightings have occurred from near the Eritrea border south to the Stephanie Wildlife Sanctuary, west nearly to South Sudan, and east to Dire Dawa.

Suggested reading: Christie, Elliott \& Del Hoyo, 2008; Fry, Keith \& Urban, 2000; Ginn, McIlleron \& Milstein, 1989; Goodwin, 1976; Grzimek, 1973; Willmore, 1977.

\section{Cape Rook Corvus capensis kordofanensis}

The Cape rook is named for South Africa's Cape of Good Hope; it is also often called the Cape crow or black crow. It is similar in size and appearance to the American crow (C. brachyrhynchos) but has a much more slender bill and a rather distinctly ravenlike "beard" that is often expanded to produce a large-headed visual effect. Unlike ravens and typical crows, it also has bare whitish skin in front of the eyes and at the base of the bill.

These birds are fairly common from Ethiopia southward through much of eastern and southern Africa, but there is a range gap in the plains of east-central Africa. They occur in woodlands, savannas, and grasslands and are especially common near agricultural areas, where they become pests. Besides eating a variety of arthropods and other invertebrates, they also favor cultivated grains, fruits, and berries. Additionally, they probe in soft ground for insect larvae and plant bulbs, dissect cattle dung to find beetle larvae, and at times steal the eggs of poultry.

Adult Cape rooks are monogamous and strongly territorial, each pair defending an area of about 150 acres (61 ha). The boundaries are rigidly protected against conspecifics, and both roosting and nesting occur within the territory. Immature or unpaired birds lack territories, and they forage and roost in flocks. Like other crows, Cape rooks are highly vocal and noted for their remarkable ability for mimicry. Bill-touching, mutual preening, and courtship-feeding precede nesting. Aerial gliding displays, with the wings held at a fixed inclined angle and the primary feathers vibrating, also occur. 
Rooks are among the few birds that are able to use and modify tools (Bird and Emery, 2009) and experientially have been found able to work cooperatively to obtain a reward. They also understand the notion of water levels and even a limited sense of gravity. They have been found to be adept in tool use and in some circumstances have even outperformed chimpanzees.

Breeding in Ethiopia and adjacent northern Somalia has been noted from April to June, near the end of the rainy season. These birds nest near the tops of trees; the nest is a rather large cylindrical structure, well lined with grasses and roots and with dried dung incorporated into the layers of twigs. The clutch consists of three or four eggs, and it is possible that both sexes participate in incubation. After about 16 to 18 days the eggs hatch, and the young fledge at 32 to 40 days. The fledglings remain with their parents for a prolonged period, sometimes for several months after fledging.

This species occurs in two geographically isolated populations in eastern and southern Africa, and as of 2016 was considered to be a species of least concern by the International Union for Conservation of Nature. Numerous eBird reports indicate that Ethiopian sightings have occurred from near the Eritrea border south to the Kenya border, west nearly to Sudan, and east nearly to the Somalia border.

Suggested reading: Bird and Emery, 2009; Christie, Elliott \& Del Hoyo, 2008; Fry, Keith \& Urban, 2000; Goodwin, 1976; Grzimek, 1973; Skead, 1952; Willmore, 1977.

\section{Family Sturnidae (Starlings and Oxpeckers)}

\section{Red-billed Oxpecker \\ Buphagus e. erythrorhynchus}

The Latin name of this oxpecker amusingly translates as "red-billed oxen-eater." This species was first described by T. M. Stanley, of Stanley and Livingstone fame, and was initially identified in- correctly as a species of tanager rather than as part of the starling family. There are two species of oxpeckers, the red-billed, occurring in eastern Africa from Ethiopia south to South Africa, and the yellow-billed (B. africanus), which more generally occurs to the west from Senegal southward. There is little difference between the two other than bill color, but the red-billed species has a yellow eye-ring that is lacking in the other.

Oxpeckers have mastered the art of commensal living with ungulates as few other birds have done. It is rare to see any of the larger game mammals of Africa without also seeing oxpeckers riding on their backs or heads and industriously pecking at their skin. Both oxpecker species clamber about the bodies of their hosts, seeking out ticks and the larvae of bloodsucking flies. These specialized birds eat little else of consequence. One study revealed 2,291 ticks in the stomachs of 51 birds, or an average of about 45 per stomach. However, an adult bird might eat nearly 100 adult ticks or more than 12,000 larvae in a single day.

Tick-eating would seem to be a desirable activity from the standpoint of the mammals, and many do tolerate and even invite it, but the birds might also enlarge wounds made by the ticks and feed directly on the host's flesh and blood exposed after removing the tick or larva. Besides feeding on the host's ectoparasites, oxpeckers are notable for their alert response to danger, uttering churring calls as they take flight. With this behavior, they probably perform an additional useful service for their host mammals.

Breeding in Ethiopia and Somalia occurs from March to August or early September, during the wetter season. The birds resemble their cavitynesting relatives, the starlings, in that they nest in the hollows of trees, rock crevices, and gaps in stone walls or under eaves. Two to five eggs make up a clutch, and up to three broods might be produced per season. The incubation and fledging periods are about 12 and 30 days, respectively.

This species is widespread across eastern and southeastern Africa and as of 2016 was considered to be a species of least concern by the International Union for Conservation of Nature. However, it is believed to be declining because of reductions in wild game herd populations and the 
dipping of domestic cattle in insecticide-treated water. Numerous eBird reports indicate that Ethiopian sightings have occurred from near the Eritrea border south nearly to the Kenya border, west nearly to Sudan, and east to Dire Dawa.
Suggested reading: Attwell, 1966; Chapin, 1954; Christie, Elliott \& Del Hoyo, 2008; Feare and Craig, 1999; Fry, Keith \& Urban, 2000; Grzimek, 1990; Moreau, 1933; Mundy \& Hayes, 1997; Newman, 1971; Stutterheim, 1982; Yalden, Largen \& Kock, 1976-86. 


\section{Mammal Paintings and Drawings}

\section{Family Colobidae (Colobid Monkeys)}

\section{Guereza Colobus \\ Colobus g. guereza (7 images)}

The colobus monkeys must be counted among the charismatic fauna of Ethiopia, along with the visually stunning turacos, the stately bustards, the anatomically perplexing hyraxes, and dozens of other beautiful or compellingly interesting animals. I will never forget standing near the shoreline of Lake Naivasha in Kenya, on the property that once belonged to the ethnologist and artist Joy Adamson of Born Free fame. There I watched the colobus monkeys leaping through the trees, running wildly among the branches, and clambering down to the ground to collect their daily handout of bananas and other fruit. Their jet black pelage, decorated with long flashes of white on the flanks, a white face, and a tufted and white-tipped tail, is an artist's dream. Fuertes was obviously equally fascinated with the animals, repeatedly sketching and painting them in both repose and full activity.

When leaping, the monkey's elbows and arms are held outward and forward, the tail is lifted, and the long white flank pelage lifts above the sides like a reverse white parachute. Upon landing, the hands and feet are brought together, immediately ready for the next leap. The springing effect of the branches they land on might catapult them into the next jump, or the animals might even shake the branch into vertical motion to gain extra momentum. This branch-tobranch leaping must be a dangerous means of locomotion, and reportedly at times individuals do fall to the ground but usually with no ill ef- fects. Even mothers carrying their small, snowwhite young sometimes engage in such seemingly dangerous activity. The little babies cling tightly to their mother's underparts and are supported by one of her hands.

The scientific (and vernacular) name Colobus is from the Greek colobe and means "maimed" or "crippled." The term refers to the rudimentary thumb on the hands, which looks as if it might have been amputated. However, the other fingers are very long, hooklike, and well adapted to grabbing the handholds needed while the monkeys jump from branch to branch. The corresponding digits on their feet are well developed and provide for excellent grasping abilities. Including their long tails, adults are about five feet in length and weigh from 14 to 32 pounds $(6.4-14.5 \mathrm{~kg})$.

Because of their large size and spectacular pelages, colobus monkeys have long been hunted both by natives, such as the Maasai, for decorative capes and by foreigners for similar articles of apparel. Indeed the commercial trade in colobus skins is hundreds of years old, and several millions of animals have been made into skins for such purposes. As a result, colobus populations have greatly declined over much of their ranges, and they are now most likely to be seen in wellprotected localities.

There are several species of colobus monkeys, which are mostly confined to tropical lowland areas. These populations differ considerably in the amount of white on the shoulders and flanks, and one species is entirely black. However, the population found in the Ethiopian and East African highlands has a wonderfully long pelage with white extending from the shoulders to the base of the tail. This thick fur coat no doubt is 
an adaptation to cold temperatures; the conspicuous color must additionally be a significant social signaling device. Another conspicuous feature, the long tail, is not prehensile but rather is used like an acrobat's balance while in flight. Colobus monkeys also have conspicuous callosities on their rumps, used as pads when resting upright.

Their contrasting pelage pattern must make colobus monkeys highly visible to predators, and Fuertes noted that a colobus will hide behind vegetation or draw leafy branches around itself when trying to avoid attention. Known predators include the crowned hawk-eagle (Stephanoaetus coronatus), which specializes in hunting monkeys and other primates.

Colobus monkeys are essentially foliage eaters, living mostly on tree leaves, especially those of legumes. As noted earlier, they are also fond of fruits (especially green, unripe fruits) and flowers, when such items become available. Soil might also be eaten to obtain inorganic nutrients. Unlike the abundant, widespread, and more omnivorous Cercopithecus monkeys, colobus monkeys lack cheek pouches. In common with the leafeating langurs of Asia, colobus monkeys have complex chambered stomachs. This rumen-like stomach structure allows for the bacterial fermentation of cellulose. Their stomach complexity is also probably related to the fact that many of the leaves they consume are endowed with chemical components that protect them against consumption by most herbivores. They additionally have enlarged large intestines, which is also related to their intake of cellulose-rich foods.

During much of the daylight hours, colobus monkeys forage in treetops, but during afternoon hours they are likely to loll about, grooming one another or napping. They also enjoy sunbathing, especially during early morning hours when temperatures are still low. This generally "lazy" pattern of activity and their fairly small home ranges are probably related to the abundant but lowenergy foods that they consume. Much of their foraging occurs at lower and middle canopy levels, whereas resting and traveling occur in the middle and upper tree levels.

Like many primates, colobus monkeys are notable for their loud calls. The call of adult males is a resonating, low-frequency vocalization that might be described as a roar. In guerezas, the individual notes are widely spaced and very low in pitch. Roaring is especially frequent near dawn, at night, and when a potential predator is detected. It appears to facilitate spacing of troopsthe groupings of monkeys-but is not specifically a territorial challenge. Thus, calling by one troop is likely to stimulate a response by others within earshot, followed by a gradual reduction in noise level as the animals prepare to move to feeding areas. Once there they might call again, often bouncing on the branches or leaping from branch to branch, especially when other troops are in sight. These acoustic displays seem to keep troops from intermixing during foraging at commonly used feeding sites. Roaring is again common near sunset and might also be employed to try to intimidate predators. Only fully adult males roar, and when more than one is present in a troop they roar simultaneously.

The guereza social groups consist of one of more males (only one of which is dominant) and varying numbers of females plus their offspring. In most studies of this species, a single male has led the troops. In studies of Ethiopian river forest groups, usual troop size ranged from 9 to 15 , with averages of 2.3 adult males and 6 adult females plus their young. These troops typically live in small permanent territories or home ranges. A group studied on Mt. Kilimanjaro had a home range of about 37 acres (15 ha), but most of the members' time was spent within an area of only about 10 acres (4 ha). Such a home range might support 25 to 30 monkeys, but in well-protected areas the density might be much greater than this. Two studies in Ethiopia's Bole Valley and around Lake Shala resulted in estimated densities of 357 and 816 individuals per square mile (138 and 315 per square kilometer), one of the highest densities ever reported for any colobus monkey.

Although there are variations among other colobus species, the Ethiopian species seems to be characterized by having matrilineal social organization, namely, females living with related females rather than joining groups of unrelated females, forming troops that usually have a single adult male present. Females engage in frequent grooming interactions with other females, 
and mothers allow other females to serve as "infant handlers." These caretakers probably themselves learn how to handle infants properly, and the infant might thereby become better integrated into the troop. Furthermore, should the mother die prematurely, it might be more likely that others will adopt the infant within the troop. It has been suggested that the conspicuous white coat color of infants is related to facilitating such infant handling, as the white coat is lacking in colobus species that don't engage in such behavior. This active interest in young babies by other females diminishes as the infant loses its white pelage at three or four months.

Females are probably fully mature by four years of age and males by six, although some estimates suggest an earlier period of maturity. Seasonality of breeding varies in different regions, with births in some areas concentrated during the dry season and in others spread throughout the year.

In contrast to baboons and many other monkeys, colobus species do not exhibit visible genital swelling during estrus. Perhaps because of this, females in estrus actively solicit matings from the dominant male or other adult males in the group. Curiously, adult females regularly urinate on their tails, which tends to discolor them but perhaps has some sexual signaling function. Males often groom a receptive female before copulation. She then presents herself to the male with her tail held high above her back. The pair might thereafter associate for a few more hours but not for prolonged periods.

Pregnancy lasts 147 to 175 days, and a single offspring is produced that weighs about a pound $(0.5 \mathrm{~kg})$ at birth. Pregnant females become reclusive just before giving birth but might be accompanied by a male, perhaps for protective reasons. The day after giving birth the female returns to her troop, and within a few weeks she might be sharing its care with other female troop members. Weaning occurs at about two months. The average interbirth interval is about 20 months.

Although juvenile females remain in their troop after they mature, adolescent males either voluntarily leave or are expelled as they approach adulthood. For a time they might become solitary or perhaps join groups of other young males.
Eventually, when fully mature, they might manage to enter a new troop and challenge its leader for dominance. In some species, such as langurs, killing of newborns by the newly dominant male is fairly common, but such infanticide among colobus monkeys is not well documented. In captivity individuals are known to have survived for 20 to 30 years. Clearly, this is a case of remarkable longevity, and mortality in the wild must be substantial, especially in young animals, which are probably relatively susceptible to falls as well as to predation.

In Ethiopia, as many as 40,000 colobus monkeys were killed annually for their skins during earlier decades, and by the mid-1970s the colobus was listed as a protected species in Ethiopia. Probably the best remaining populations are in the relatively small Simien Mountains National Park. They also survive in Awash National Park, about 137 miles $(225 \mathrm{~km})$ east of Addis Ababa, where hamadryas and yellow baboons also occur. Rangewide, the species is still fairly common and is classified by the International Union for Nature Conservation as a species of least concern, although one Kenyan subspecies is listed as endangered.

Suggested reading: Davies \& Oates, 1994; Dunbar, 1987; Dunbar \& Dunbar, 1974b; Grzimek, 1990; Kingdom, 1971-1982, 1997; Macdonald and Norris, 2001; Marler, 1972; Nowak, 1991; Oates, 1977; Wolfheim, 1983; Yalden, Largen \& Kock, 1976-86.

\section{Family Cercopithidae (Cheek-pouch Monkeys) \\ Subfamily Papioninae (Baboon-macaques)}

\section{Yellow Baboon Papio cyanocephalus (2 images)}

The following descriptive account relates primarily to the yellow baboon; its Latin species name means "yellow-headed." In contrast, the hamadryas, or sacred, baboon was named after the 
hamadryad wood-nymph spirits of Roman and Greek mythology, who lived only as long as the tree that supported them.

The baboons of Africa form a series of geographic replacement populations that, like the savanna monkeys, compose a superspecies consisting of about five currently recognized baboon species. In Ethiopia, the sacred baboon (P. hamadryas) occurs in the mountainous northeastern part of the country, whereas the yellow baboon occurs in lower southwestern areas, with a zone of contact and hybridization along the Awash River east of Addis Ababa. This area is well to the northeast of the location where the specimens obtained during the expedition were collected near Lake Shala, so the drawings by Fuertes probably represent the yellow baboon, which was called the dog-faced baboon by W. H. Osgood.

All of the African baboons are fairly large, mostly terrestrial primates that occupy relatively open country and move about in a quadrupedal manner, foraging on a great variety of plant and animal foods. Fruits are eaten in forested habitats, and grasses are consumed in nonwooded areas, but the animals are highly opportunistic and flexible in their diet.

Among all the baboons, the males are substantially larger than the females; in the sacred baboon females weigh from about 22 to 33 pounds (10-15 kg) and males about 33 to 44 pounds (15$30 \mathrm{~kg}$ ), whereas in the yellow baboon females weigh 24 to 66 pounds $(11-30 \mathrm{~kg})$ and the males 48 to 110 pounds $(22-50 \mathrm{~kg})$. Because of this great sexual dimorphism, males can readily dominate females, and they also take the initiative in defending the troop from possible danger. Although a leopard might take an occasional sick or disabled individual, the effective group defensive behavior and arboreality of baboons protect them well against most large ground predators.

Group size in the yellow baboon is quite variable but usually ranges from about 30 to 60 individuals. These groups usually include several adults of both sexes plus a variable number of babies and adolescents. Among the males, there is a social dominance hierarchy established by fighting abilities and the male's capacity for establishing alliances, or developing friendly associ- ations, with other males. A male's position in the hierarchy is directly related to his mating opportunities. Additionally, females also form hierarchies, with the offspring of high-ranking females becoming dominant to those of lower-ranking females. Finally, groups that have a larger number of adult males can dominate those with fewer males, which favors the development of larger baboon assemblages.

Baboons forage during daytime hours, spreading out and consuming grass, fruit, insects, tree resin, and whatever else happens to be available at that time and place. Adult males establish the direction and rate of the troop's movement, although females might walk ahead of the males, and frequently a young male will take on the role of an advance scout, providing an early warning system in the event of danger.

Some regional differences in breeding cycles exist, but in most areas breeding occurs throughout the year, with seasonal peaks in some areas. Female baboons typically become sexually active at about four years of age and bear their first offspring at five. The gestation period is six months, and usually a single baby is born. Weaning occurs by six to eight months of age, and on average there is about a 15-month interval between successive births. Males mature later than females, at about five years, but an additional two to five years of experience is needed for them to achieve the social status required for successful breeding.

Yellow baboons apparently still occur in many areas of Ethiopia, such as Awash National Park, the Bale Mountains, the central and southern Rift Valley, the central and southwestern highlands, the western lowlands, and the northern plateau. The species' population is large, and it is considered to be a species of least concern.

Suggested reading: Grzimek, 1990; Kingdom, 1971-82, 1997; Macdonald and Norris, 2001; Nagel, 1973; Nowak, 1991; Wolfheim, 1983; Yalden, Largen \& Kock, 1976-86. 


\section{Gelada}

Theropithecus gelada (6 images)

Like the mountain nyala and the Ethiopian wolf, the gelada is an Ethiopian endemic, limited to the mountainous regions of the north-central part of the country. It is a fairly small baboon, with males usually weighing about 45 pounds $(20 \mathrm{~kg})$ and females about 30 pounds $(13.5 \mathrm{~kg})$. However, the "magnificent" male shot by Bailey and painted by Fuertes was estimated to be 50 to 60 pounds $(23-27 \mathrm{~kg}$ ) and required two young men to carry it back to camp. Geladas are rather heavy-bodied apes, with the male's apparent size increased by a long cape around the shoulders, The vernacular name gelada comes from an Arabic word meaning "maned," whereas Theropithecus is from Greek, meaning an "ape-beast."

The muzzle of the gelada is distinctively concave, producing a dished-in profile, as was well illustrated by Fuertes. The small nostrils tend to open toward the side rather than terminally, as is the case among other baboon species. Males have a backward-pointing crest and pale "whiskers" that produce a handlebar effect. The lips normally cover the long canine teeth, but by retracting the upper lip the pink upper mouth and canines are briefly exposed, producing a distinctive gelada "grin" or "lip-flip" display. In addition to these facial features, the male also has a large oval area of bare skin on the chest. The chest skin is mostly bluish gray but encloses a pink hourglass-shaped patch that seemingly mimics the larger and more colorful area of bare skin present on adult females.

Besides being smaller, females lack the crest, cape, whiskers, and long canines of males and are mostly uniform brown. Like males, they have a long and tufted tail, but below the tail is a large oval area of pink skin surrounding the paired bluish ischial pads that provide a cushion when sitting. The periphery of this pink area is tumescent with small swollen vesicles during estrus periods. Additionally, the breast area of adult females has a bare hourglass-shaped area of bare skin, which like their genital area is lined externally with pink vesicles (called "beading") that enlarge during estrus periods.
It has been suggested that this anterior exposure of her temporally variable genital skin color helps to advertise the sexual state of the female, even when she is sitting and her genitals are hidden from view. The penis of gelada males, unlike that of other baboons, is also usually hidden from view. Evidently the female-like signals present on the chest of the adult males represent a case of sexual mimicry and serve as a nonaggressive signal to females, which, like the female's chest markings, are readily visible most of the time.

Geladas are ecologically limited to rocky gorges and cliffs at elevations of about 1,400 to 14,000 feet $(420-4,400 \mathrm{~m})$. Steep gorges provide safe refuges from predators and safe, if precarious, sleeping sites. After daybreak the animals gradually move out of the gorges and away from the canyon edges, foraging almost exclusively on grasses and to a very limited degree on other herbaceous vegetation and insects. After spending the day foraging, the animals gradually work their way back to the gorges. Fuertes's wonderful unnumbered plate, probably painted or completed after his return home, provides a vision of this precipitous habitat along the spectacular Blue Nile canyon.

Predation is evidently a minor concern for geladas; large cats are rare in the region, jackals and wolves seem to pose no real threat, and hyenas are active at night when the geladas are safely back in their cliffside sites. Perhaps some large avian predators such as eagles are a threat to babies, but the watchful care given them by their mothers reduces this threat. Some mortality might result from accidental falls over cliff edges. One study suggested that, in a protected population, old age and disease are the major mortality factors, and that under favorable conditions a population can increase at a rate of about 16 percent per year, a very rapid rate of increase for any primate. Typical longevity is about 20 years.

Because of their largely grass-related foraging behavior, geladas can build up to fairly large densities in favorable areas, at least in undisturbed habitats. Thus, population densities as high as 28 to 31 animals per square mile (1012 per square $\mathrm{km}$ ) have been reported. This is a 


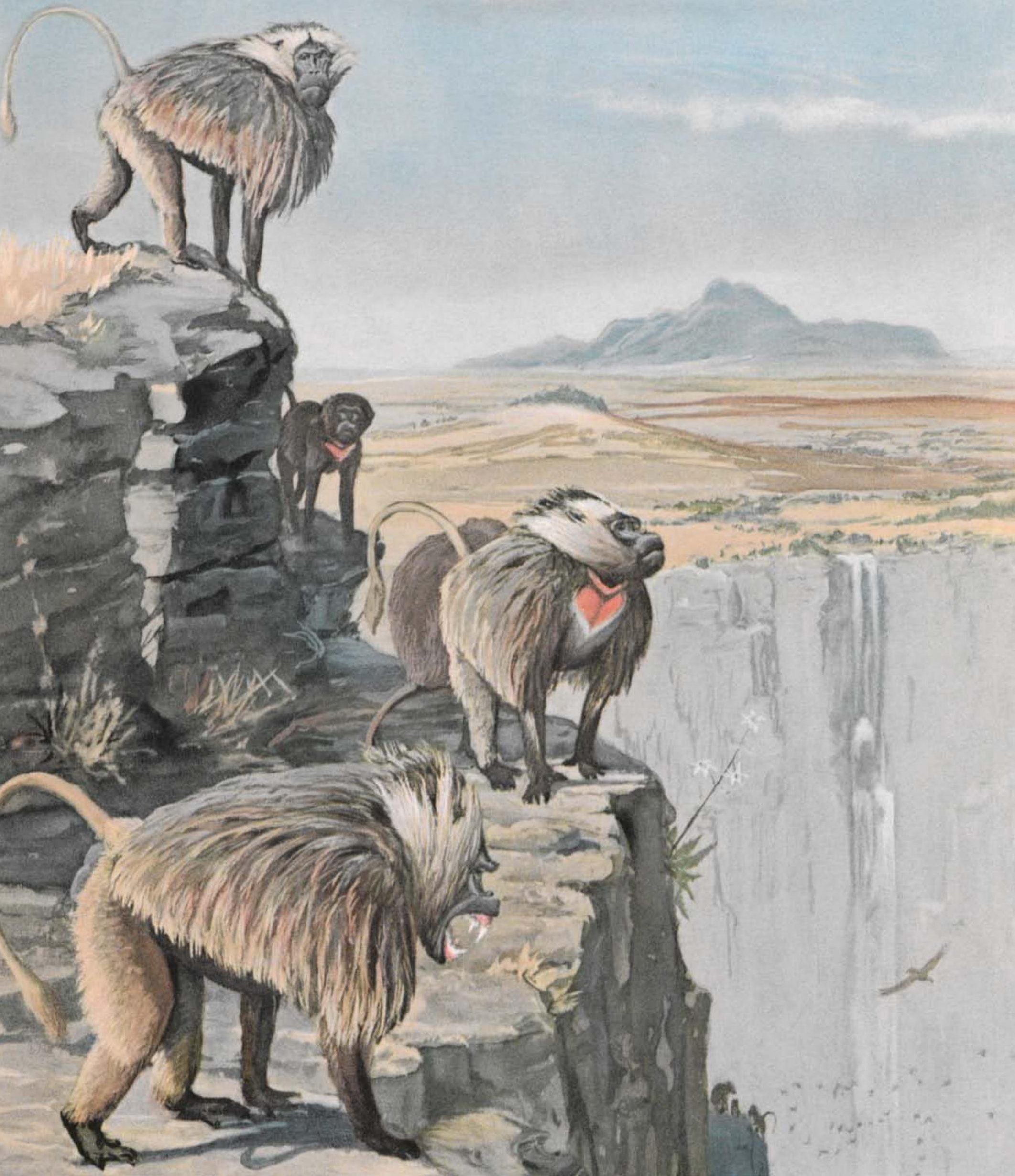


much higher density than is typical of Papio baboons. Within such large areas, the population is organized by social groups known as "bands." These bands of from 30 to more than 300 animals have largely nonoverlapping home ranges with other bands, although some habitat sharing might occur in favorable areas.

Gelada bands comprise two general social types: one consists of all-male groups and the other is made up of reproductive units. The allmale groups are mostly young individuals and average about eight individuals. The majority of reproductive units include a single adult male, up to eight females, and their dependent young. The most common number of adult females in one study was four. The cohesion of such groups is maintained by associations among the females, which are derived from mother-daughter bonds, rather than from the male's ability to dominate and physically control the activities of the females.

Social grooming between related females might help to maintain group cohesion, but some intergroup movement by the females also occurs, which probably reduces inbreeding. Additionally, females participate to some extent in group defense and might even form alliances against the male leader of the band, the so-called "harem male" or "unit leader." Occasionally, additional males-typically young adults-will attach themselves to reproductive units; these individuals are called "followers."

Much of the communication that goes on within social units of geladas consists of facial expressions, posturing, and vocalizations. An important facial expression mentioned earlier is the "grin" or "lip-flip," a brief exposure of the upper teeth and gum area that frequently serves as a threat display. As for other apes, the gelada's exaggerated yawn serves as a warning signal but also has simultaneous appeasement elements. Eyebrow-raising, which exposes a pink area above the eyelids, indicates a threat, as does staring with the head lowered. Looking away, teethchattering, and baring the teeth in a snarling manner are all indications of fear or submission. More than 50 postural or behavioral elements that carry communicative function are recog- nized, the largest number of which involve associative social or sexual signaling, maternal behavior and weaning, and threat and aggression.

Some 25 different vocalizations have been reported for geladas. These include a friendly or greeting call, a play call, 3 calls related to copulation or sexual invitation by females, 3 calls given by young animals in distress or during separation, 4 contact calls, and 11 vocalizations associated with alarm, threat, or fear.

Matings by females are almost entirely confined to unit leaders, with no apparent effort by either sex to search for other partners. Females orient strongly on their unit leader while in estrus; two females were observed to copulate nine times during less than ten hours of observation. However, the male does not similarly concentrate on a single female.

Studies in the Simien Mountains region indicate that the breeding season there is somewhat seasonal, with young mainly born in January and June, but some births also occur in every month except April and October. Elsewhere in this same general region the births seemed to be concentrated between February and April. It seems possible that the births in any single band tend to be synchronized, those of others are not. This apparent synchrony within bands might result from females of a single band influencing one another in setting their estrus cycles, a phenomenon that is fairly common in mammals.

The gestation period of the gelada lasts six months, and the average interbirth interval is two years. Weaning occurs at about six months. Females mature at 3 to 5 years of age and males at about 4 to 5 years, but males might not be able to successfully mate until they are 8 to 10 years old. An estimated maximum survival of 20 to 30 years has been made for wild individuals, and an average longevity is 19 years.

In spite of the geladas' apparent reproductive and survival potential, their population has suffered greatly since Fuertes depicted these wonderful animals. Agricultural expansion has encroached on their range, and they have been shot as crop pests. Countless thousands have been captured for laboratory research; more than 1,200 were imported into the United States 


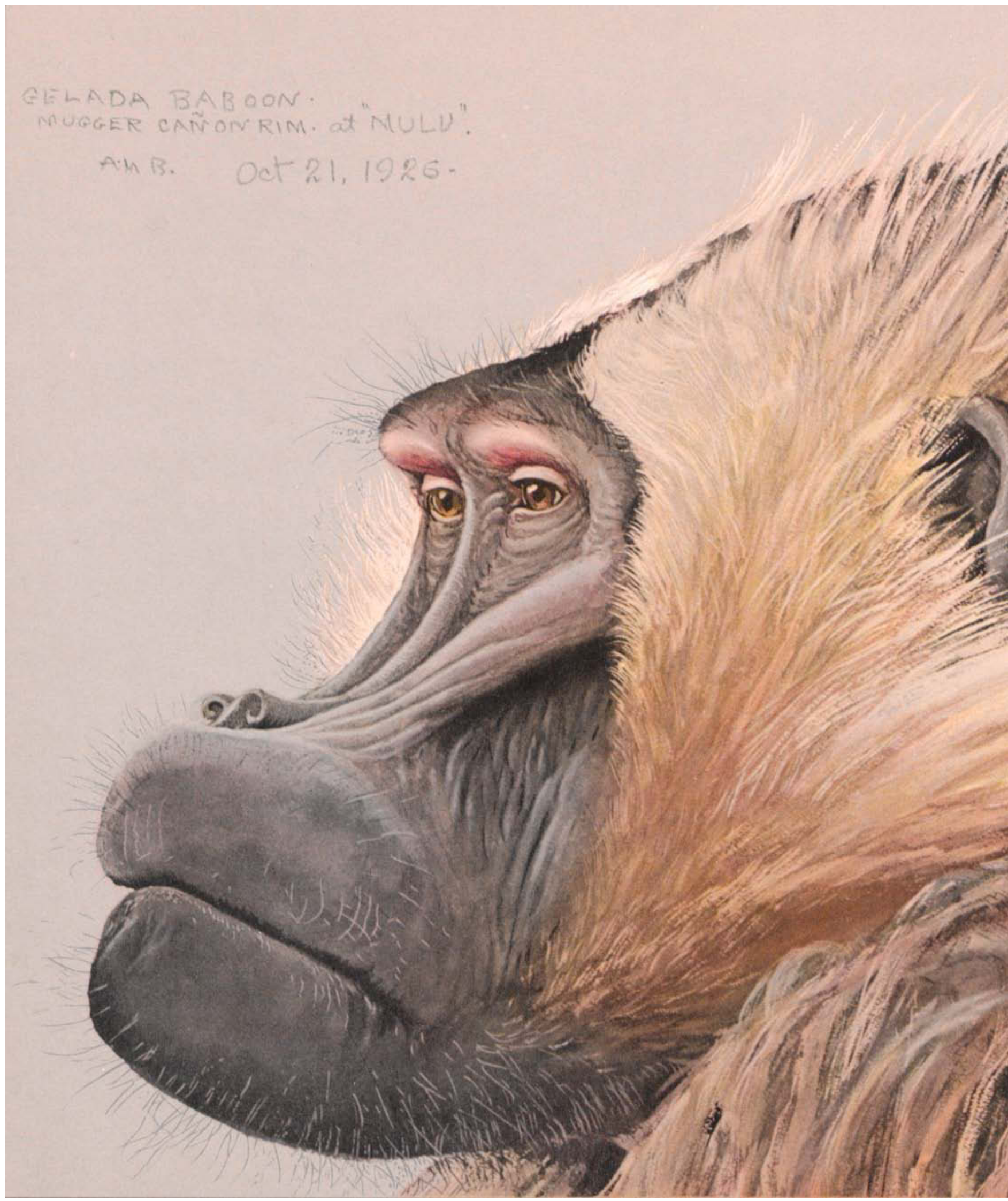




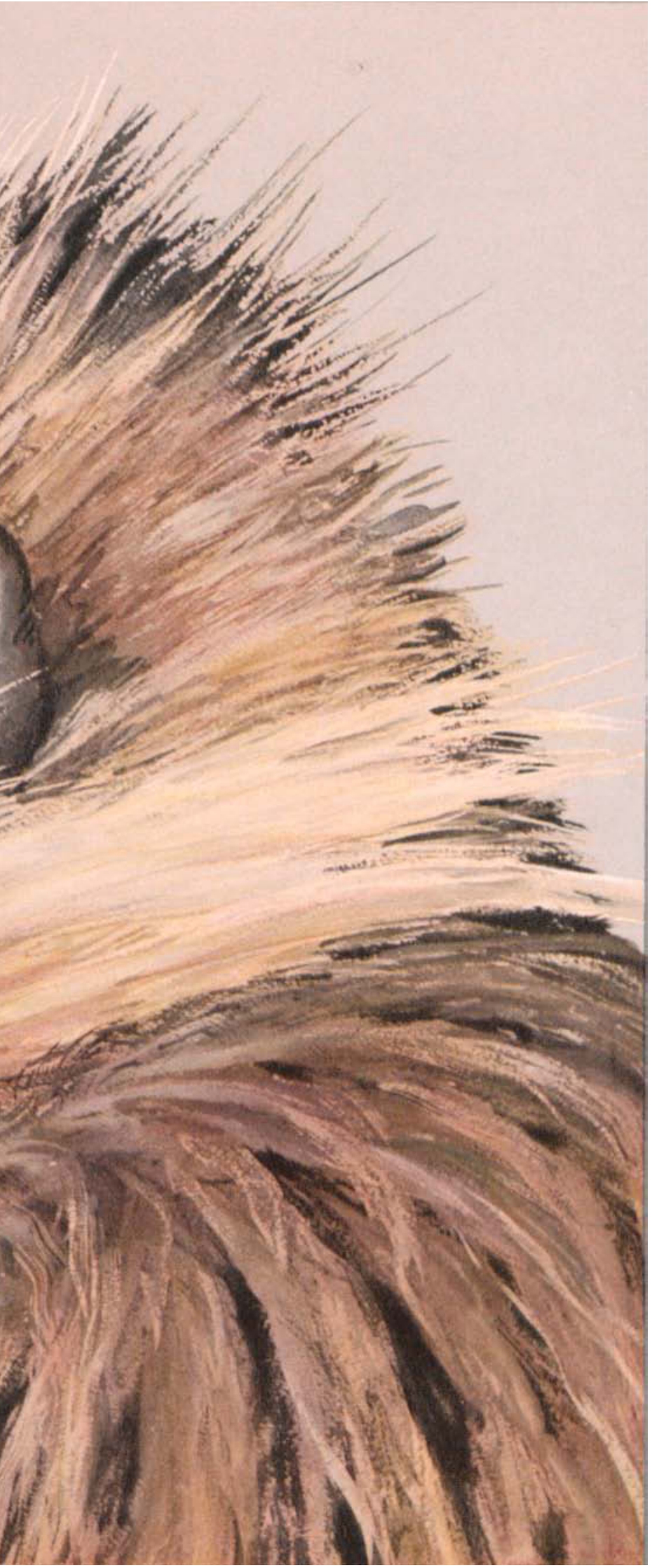

alone during a six-year period ending in 1973. The males have also been shot for their beautiful skins, their capes being made into fur hats to be sold to tourists or converted into ceremonial costumes or native headdresses.

The selective killing of males for such purposes has altered natural sex ratios and perhaps undesirably influenced the social organization of the species. Evidence exists that climatic changes, such as recent severe droughts, have had adverse effects on the population. Human activities might have reduced ecological barriers that traditionally existed between the Anubis baboon and this species, perhaps facilitating hybridization between them.

The gelada is the last surviving species of a grass-eating group of small baboons that was once more widespread in Africa, most of which became extinct toward the end of the Pleistocene epoch. Perhaps the gelada was forced to move into higher elevations as the larger and more omnivorous Papio baboons expanded their ranges in the lowlands. It is also possible that early humans found geladas to be fairly easy prey, at least as compared with the larger apes, and they progressively were forced into fewer and more inaccessible habitats, such as steep gorges.

The animals are currently protected in Simien Mountains National Park, and an important population would be protected in a proposed Blue Nile Gorges National Park. They do not now occur south of Addis Ababa. They are nationally protected from sport hunting, capture, and export but are not exempt from native hunting or shooting when found to be crop pests. The number killed as pests is probably low, but some illegal poaching for skins might still occur, especially of the adult males.

An estimate of gelada populations as of the 1970 s was about 600,000 animals, all on the Amhara Plateau north of the Blue Nile valley, where Simien National Park is located. In 1998 the population was estimated at slightly less than 250,000 animals, and the species had been placed on the International Union for Conservation of Nature's red list of threatened species by 2008. Geladas are also listed in Appendix 2 of the Convention on International Trade in Endangered 
Species (CITES), which makes international trade in them or their skins illegal.

Suggested reading: Crook, 1966; Crook \& Aldrich-Blake, 1968; Dunbar \& Dunbar, 1975; Grzimek, 1990; Kingdom, 1997; Macdonald and Norris, 2001; Nowak, 1991; Wolfheim, 1983; Yalden, Largen \& Kock, 1976-86.

\section{Subfamily Cercopithinae (Guenons)}

\section{Grivet Monkey \\ Cercopithecus aethiops (recently reclassified} as Chlorocebus spp.)

Few people visit Africa on wildlife safaris without seeing one or another species of Cercopithecus monkeys, collectively termed savanna monkeys (savannas are semiarid grasslands habitats with scattered trees, which in Africa are often acacias or other leguminous trees). This species' English vernacular name "grivet" is from French, meaning "grayish" or "grizzled." Cercopithecus is from Greek and means a "trick-playing monkey."

Grivets are the most widespread and abundant of all African monkeys and are especially numerous in grassland-forest edge habitats. These habitats provide trees that are important for escape as well as foraging and shade; acacia trees are especially favored because their seeds, flowers, leaves, and even gum are consumed. Grivets also gather seeds and insects at ground level and sometimes stray well away from trees or forest edges.

Grivets and other savanna monkeys are part of a large subfamily (Cercopithinae) of long-tailed monkeys collectively called guenons (which is apparently derived from French but is of uncertain meaning). Guenon monkeys have generally grizzled dorsal pelages and long tails but also have complex and colorful facial patterns, especially among males. Most of them have species-typical head markings that emphasize their facial expressions and provide important social signals for these highly visual animals. The blue areas of the genitalia of males provide another important source of visual signaling.
The grivet population illustrated by Fuertes is largely limited to Ethiopia and is notable for its individuals having large white cheek patches and a narrow white eyebrow line. Other populations, all of which have at times been considered to compose a single widespread and variable species, differ somewhat in their facial features and general pelage color, which varies from dark gray to greenish. Thus, these and other guenon monkeys are sometimes called "green monkeys."

Grivets and other savanna monkeys form bands that vary in size from about 5 to 75 animals and that consist of adults of both sexes as well as immatures. The animals are organized into a clear social hierarchy, with the males usually dominant, although sometimes females might form coalitions that modify this strict rank order. Independent juveniles might separate from the adults and form their own subgroup. Females occupy permanent territories, but individual male territories are variable in time and space. Territorial males advertise their own territories by visual and acoustic signaling, but females are fairly independent and might defend their territory against other groups of intruding females.

Home ranges of savanna monkeys vary from about 32 to 440 acres (13-178 ha). The timing of the births of their young varies regionally, but gestation lasts about 24 weeks. Young males, as they mature, join the groups of nearest neighbors, whereas females remain within their maternal group. The young mature rapidly, with females becoming sexually mature at two years of age and males by three years. Achieving full maturity and maximum weight of about 12 pounds $(5.6 \mathrm{~kg})$ in females and 15 pounds $(7 \mathrm{~kg})$ in males takes about an additional year for both sexes.

Suggested reading: Dunbar \& Dunbar, 1975; Gautier-Hion et al., 1988; Grzimek, 1990; Kingdom, 1971-82; 1997; Macdonald \& Norris, 2001; Nowak, 1991; Rowell, 1971; Struthsaker, 1967a, 1967b; Yalden, Largen \& Kock, 1976-86. 


\section{Family Muridae (Murid Rats and Mice)}

\section{Velvet Rat Colomys goslingi}

W. H. Osgood (1928) described this rather oddlooking rat as constituting a new genus and species (Nilopegamys plumbeus), but it has since been placed in a single-species genus adjacent to the long-footed rats (Malacomys). It is a longtailed rat with notably long vibrissae, or "whiskers." It also has a distinctly two-toned pelage that is dark brown above and white below, the two colors sharply demarcated rather than blending gradually, a feature common in aquatic birds and mammals. There is also a small white mark at the base of the ear. The entire pelage is velvety in texture, but the tail is only slightly haired. Adults average about two to three ounces (56-85 g) in weight, and the tail is longer than the rest of the head and body.

This unusual rat is highly adapted to a semiaquatic existence, similar to that typical of the Eurasian water shrew (Neomys). For example, its lips cover the incisors, which prevents exposing the mouth to water entry. It probably catches most of its food by wading in shallow water, using its long, sensitive vibrissae to detect prey and its large eyes to visually locate items. Aquatic insects, crustaceans, worms, and similar prey are all taken. It swims well, using its hind legs rather than its tail for propulsion, and it constructs small tunnels in stream banks. Evidently the species is essentially solitary and nocturnal. Osgood collected his single specimen along an unnamed stream. This rat is usually found near running water in wooded montane habitat.

Nothing is known of this species' breeding season in Ethiopia, but in Uganda and Zaire breeding evidently occurs between March and July. The gestation period and most other aspects of reproduction are still unknown. It is known that males have chest glands that produce a yellowish fluid when they are sexually active and that presumably serves as a sexual attractant.
Suggested reading: Kingdom, 1971-82, 1997; Macdonald \& Norris, 2001; Nowak, 1991; Osgood, 1928; Yalden, Largen \& Kock, 1976-86.

\section{Family Rhizomyidae (Root-rats)}

\section{Abyssinian Root-rat Tachyoryctes splendens}

Nearly 100 species of rats inhabit Africa, and the root-rats are one genus that occurs from Ethiopia south to Tanzania. Two species are found in Ethiopia; as mentioned in the account of the Ethiopian wolf, they provide important prey for that canid. The Abyssinian root-rat is the smaller of the two, weighing up to about half a pound $(0.4 \mathrm{~kg})$, whereas the other might approach two pounds $(0.9 \mathrm{~kg})$. In both, the body resembles that of a large mole, with reduced eyes and ears, a short tail, thick fur, and an abundance of tactile vibrissae on the muzzle. The legs are short and adapted for digging, and the incisors are long and protruding. In brief, the animals greatly resemble the pocket gophers of North America but without their cheek pouches. The generic name Tachyoryctes translates as "rapid digger."

These rats are often extremely abundant in areas of montane meadows and moorlands, where they excavate extensive underground tunnel systems and accumulate associated large mounds. These foraging tunnels are just below the surface and connect to nesting chambers. Roots, tubers, and stems are the root-rats' primary foods, which are pulled underground from the periphery of their tunnels. These food materials are then sorted, and nonedible materials are added to midden mounds. When excavating tunnels, the root-rats employ their incisors as their primary tools, with the feet being used to grasp the sides of the tunnel and also to push aside loosened soil. Sometimes the animals will come to the surface to collect vegetation for eating and for nesting material, but this is risky behavior in terms of their increased predation vulnerability.

Breeding evidently occurs throughout the entire year but is most intense during the wet 
season when maximum vegetation growth is occurring. Females reportedly have two litters in rather rapid succession, after gestation periods of about seven weeks. As many as three or four young per litter per year have been reported, but one or two are usual. Sexual maturity occurs by six months of age, so females might become mothers before their first birthday.

Suggested reading: Kingdom, 1997; Macdonald \& Norris, 2001; Nowak, 1991; Yalden, Largen \& Kock, 1976-86.

\section{Family Canidae (Dogs and Relatives)}

\section{Ethiopian Wolf \\ Canis simensis cistenii (2 images)}

The Ethiopian wolf has been called by a variety of names, such as the "Simien jackal," "Simien fox," and others. It was thus named for the region where it was first discovered, the Simien (also spelled Semyen and Simēn) Mountains in the northern Ethiopian highlands. A larger and darker subspecies also occurs in the Bale Mountains of southeastern Ethiopia. The specimen painted and drawn by Fuertes was from the southern population and was obtained on Mt. Albassa near Lake Zwai (Zway) in Arsi Province (Zone).

Although this species' rather pointed face and ears give it a somewhat foxlike appearance, it is distinctly wolflike in its long legs and substantial size, with adults weighing 30 to 40 pounds (13.6$18.2 \mathrm{~kg})$, about the weight of a large coyote $(\mathrm{Ca}-$ nis latrans). It has a black tail and is otherwise tawny red with white underparts. Females are smaller and paler than males. Its long drawn-out scream is wolflike, although yapping notes are sometimes also produced. Several other vocalizations have also been described, such as bleating, yelping, and barking.

Ethiopian wolves share their limited region with three species of jackals (Canis spp.) and two foxes (Vulpes spp.), all of which are smaller than the wolf and the larger wild dog (Lycaon), which is now

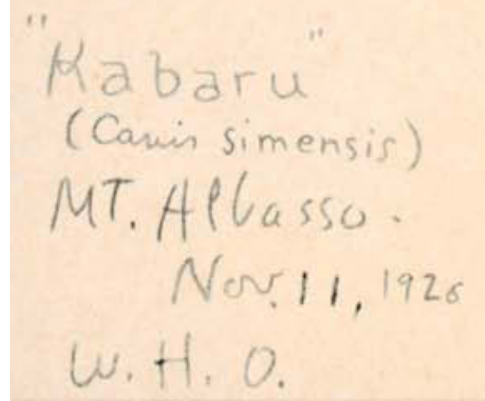




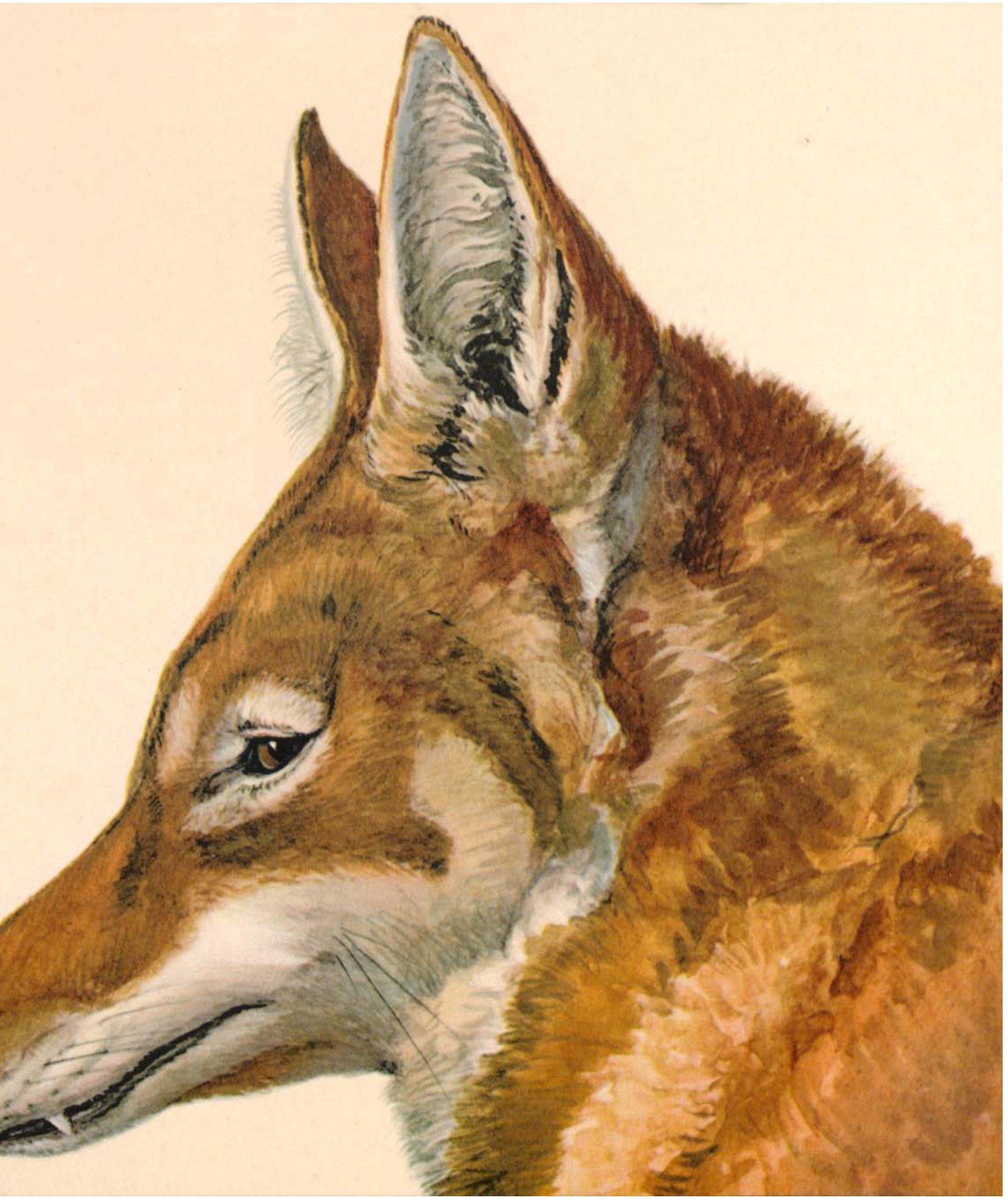


very rare. Relative to Ethiopian wolves, wild dogs concentrate on larger prey, such as small antelopes, whereas the foxes and jackals exploit an extremely wide variety of small mammals, birds, reptiles, invertebrates, insects, and carrion.

Molecular biology has provided recent evidence that this species is neither a fox nor a jackal, but instead its nearest relative is the Eurasian wolf (Canis l. lupus). It differs considerably from this larger and much more widespread species, especially in its foraging concentration on small rodents. Competition with the wild dogs of central and southern Africa quite possibly prevented it from expanding its range beyond northeast Africa following its original invasion, perhaps during Pleistocene times.

Ethiopian wolves typically occur on high meadows and moorlands where rodents are abundant, especially root-rats (Rhizomyidae) or mole-rats (Spalacinae). One of these species, the giant ("bigheaded") mole-rat (Tachyoryctes macrocephalus), is probably the most important single prey of this wolf in the Bale Mountains, where the mole-rat is endemic. Other prey includes various smaller rodents and hares. The wolves usually hunt solitarily and catch most of the rodents by ambush or chases rather than by digging them out of their burrows. At times they will hunt cooperatively to bring down hares, young antelopes, and lambs.

Like other wolves, Ethiopian wolves are organized into highly integrated packs of up to about 13 individuals, which consist of several females and a few closely related males, plus the offspring of the dominant pair. Such a pack might occupy a territory of up to about ten square miles (26 square $\mathrm{km}$ ). Foraging on their usual small prey is typically done individually, but much time is also spent by the group for resting, sleeping, or feeding dependent pups. The species' gestation period is 60 to 62 days, and in related species the average litter size is six pups.

Believed to be a sheep predator by settlers, the species has been greatly and unjustly persecuted, as has been the case with wolves generally worldwide. Ethiopian wolves were originally mainly daytime hunters, but with increasing human persecution they have become largely nocturnal and more elusive. Besides the effects of direct killing of these wolves by humans, the species has also suffered from habitat loss through conversion of meadows and moorlands to agriculture. Furthermore, it has been adversely affected by contact with domestic dogs, which have apparently introduced diseases, especially canine distemper, into the population.

This species is now Africa's most endangered carnivore. Around 1990 only about 50 individuals were estimated to remain in northern Ethiopia's Simien Mountains National Park, a small park of only 84 square miles (217 square $\mathrm{km}$ ). More importantly, about 300 individuals of the southern race were then believed to be present in the Bale Mountains National Park in the southern highlands, which encompasses 860 square miles $(2,230$ square $\mathrm{km})$ and supports the majority of the entire Ethiopian population. However, grazing still occurs in both parks, and the long-term survival of the wolf would seem to be quite questionable. It has been estimated that as of the early 2000s only about 400 individuals existed, which were of limited genetic diversity and occurred only in a few small isolated groups, mostly in Simien Mountains National Park and Bale Mountains National Park. It is now classified as highly endangered by the International Union for Conservation of Nature.

Suggested reading: Bueler, 1973; Fox, 1974; Grzimek, 1990; Kingdom, 1997; Macdonald \& Norris, 2001; Nowak, 1991; Yalden, Largen \& Kock, 1976-86.

\section{Family Herpestidae (Mongooses)}

\section{Slender Mongoose Herpestes sanguinea}

Mongooses are mammals that older Americans probably know mainly from the writings of Rudyard Kipling, and younger ones perhaps only from Walt Disney's film The Lion King. Neither is a very reliable portrait of these little carnivores, which are widespread in the Old World and include about two dozen African species. They are 
mostly about the size of small domestic cats and, like cats, tend to be both nocturnal and solitary. Most mongooses (not "mongeese"; "mongoose" is derived from a Dravidian word from the Indian subcontinent) tend to be grizzled gray in color, sometimes with darker back banding. All the species have large canines, a pointed muzzle, small ears and eyes, short legs, and long tails.

In spite of their short legs mongooses can be extremely agile and, as is well known to readers of The Jungle Book, are able to kill deadly snakes because they have astonishingly rapid reflexes. Their Latin name Herpestes translates as "an eater of crawling animals"; sanguinea apparently refers to their supposed blood-thirsty appetite. However, snakes are probably a minor part of their diets, which include a wide variety of small vertebrates. Many also roll and crack large bird eggs by smashing them against rocks or prey on various larger invertebrates.

Some mongoose species are social, especially the smaller diurnal ones, presumably as an antipredator device. The gray meerkat (Suricata suricatta), the familiar subject of many natural history films, is one of the more gregarious species. The banded mongoose (Mungos mungo) also lives in small packs, and it has been observed that when one member of the group is threatened or attacked, other pack members will come to its aid.

The slender mongoose depicted by Fuertes is one of the widespread and medium-sized species. It weighs 0.7 to 1.8 pounds $(350-800 \mathrm{~g})$ and is notable for its elongated body and tail and its semiarboreal behavior. The species is highly variable in pelage color, ranging from a typical gray or yellowish brown to red (in the Kalahari desert) to blackish, usually approximating the color of its substrate There are about 70 named subspecies, which occur in many habitats, especially in at least partly wooded areas. The animals feed on a great variety of prey, caught mostly during daylight hours.

Relatively solitary, both sexes maintain hunting territories, which are regularly marked with secretions from anal or cheek glands. An individual's home range might be less than half a square mile $(2.6$ square $\mathrm{km}$ ) in good habitat but is larger in desertlike habitats. Typically, periodic scan- ning of the environment in an erect standing posture is alternated with rapid running during daytime excursions. Males have home ranges that overlap those of several females, which males seek out when the females are in estrus. The young are born blind and helpless, like cats, after an approximate two-month gestation period. However, within ten weeks they are independent-but they will remain with their mother for the few months until she has her next litter. Typically two litters are produced each year.

The slender mongoose is very common throughout sub-Saharan Africa and is considered a species of least concern by the International Union for Conservation of Nature.

Suggested reading: Grzimek, 1990; Hinton \& Dunn, 1967; Kingdom, 1971-82, 1997; Macdonald \& Norris, 2001; Nowak, 1991; Taylor, 1975; Yalden, Largen \& Kock, 1976-86.

\section{Family Procavidae (Hyraxes)}

\section{Ethiopian Rock Hyrax Procavia capensis habessinica}

The hyraxes are a strange group of rodentlike animals that might remind North Americans of marmots or woodchucks (Marmota species). The name "hyrax" comes from the Greek and means "shrew mouse," whereas Procavia means "early rodent," implying a primitive type of rodent. Currently, three hyrax genera are recognized: the rock hyraxes (five species of Procavia), the bush hyraxes (three species of Heterohyrax), and the tree hyraxes (three species of Dendrohyrax).

Hyraxes were originally taxonomically classified with rodents and somewhat later with elephants and rhinoceroses. Based on their unique anatomical traits, they are currently placed in the anatomically diverse group Paenungulata, a clade of subungulates, along with elephants (Proboscidea) and the manatee-dugong group (Sirenia). Both modern and fossil hyraxes occur only in Africa and adjacent Arabia. 
Fuertes labeled his drawing with "cony," an ancient (biblical age) name for these highly aberrant mammals. He further identified his drawing as depicting the genus Dendrohyrax. However, Ethiopia is slightly north of the range limits of the only potentially occurring Ethiopian Dendrohyrax species, the southern tree hyrax $(D$. arboreus). It is thus most probable that Fuertes's image represents one of the rock hyraxes, of which at least two taxa occur in Ethiopia. The specimen depicted by Fuertes was collected in Arsi, south-central Ethiopia, within the ranges of both the black-necked rock hyrax (Procavia johnstoni) and the Ethiopian rock hyrax (P. capensis habessinica). Nine specimens of the latter were collected by Bailey and Osgood in Arusi (Arsi) (FMNH catalog records) during the expedition, so this species would seem to be the most likely identification.

Hyraxes have flat toenails and sharp, tusklike incisors (like those of elephants), and they lack canines, which are the basis of most mammalian elongated teeth. Thus, their gnawing functions are performed by the molars rather than by the incisors, as in rodents. One result of this is that the gnawing and chewing adaptations of hyraxes are less efficient than those of rodents, and over geologic time most of the early hyraxes disappeared.

All hyraxes have very short legs, stumpy tails, and weigh 3 to 11 pounds (1.5-5 kg). They also have naked dorsal skin glands that are surrounded by variously colored hair patches that can be fanned open to disperse scent. Their feet uniquely have rubbery suction pads containing moist sweat glands that reportedly improve the animal's rock-clinging abilities.

The inner toes of the back feet of hyraxes have blunt grooming claws rather than flattened nails, a feature quite rare in mammals but more frequent in birds. Hyraxes also are unusual among mammals but resemble birds in having a third eyelid, or nictitating membrane, that serves for sun protection and dust removal. Also like birds, hyraxes require very little water intake, and their urine crystalizes upon drying, leaving white stains on the substrate similar to the uric acid stains left by birds.
Rock hyraxes are the most widespread of the three hyrax groups. They inhabit rock outcrops, whereas bush hyraxes occur both in rocky and wooded areas, and tree hyraxes are the most arboreal of the three. Rock and bush hyraxes are diurnal, or most active at dawn and dusk, basking socially during midday, whereas tree hyraxes are mostly nocturnal and less gregarious. Rock hyraxes primarily eat coarse grasses; the bush and tree hyraxes consume a variety of softer green vegetation. All 11 species of hyraxes are social and highly vocal, uttering sounds ranging from grunts to loud screams, which are amplified or resonated by throat pouches.

Hyraxes have poor metabolic heat production and huddle together at night to retain body warmth. They are also highly social and often engage in contact behavior, such as rubbing against one another. Bush and rock hyraxes sometimes live together in close contact, even sleeping in the same holes, and their juveniles form common nursery groups. However, interbreeding between them is prevented by differences in male genital anatomy. Hyrax social groups consist of a dominant male, up to about seven females, and juveniles of both sexes. The gestation period of hyraxes is remarkably long for such a small mammal, lasting seven to eight months. The litter size consists of two or three young, which are highly precocial at birth. They become sexually mature at about 16 months and have been found to survive for as long as 12 years.

Of the three groups of hyraxes, the rock hyraxes are by far the most common. One of the three species of bush hyrax (Heterohyrax brucei) is extremely widespread and occurs in Ethiopia; the other two exist as isolated and small populations that are possibly rare if not endangered. The tree hyraxes are the most vulnerable of the three groups, and one species, Dendrohyrax validus, is classified as near threatened by the International Union for Conservation of Nature.

Suggested reading: Grzimek, 1990; Hoeck, Klein \& Hoeck, 1983; Kingdom, 1997; Macdonald, 1984; Macdonald \& Norris, 2001; Nowak, 1991; Yalden, Largen \& Kock, 1976-86. 


\section{Family Bovidae (Horned Artiodactyls)}

\section{Tribe Tragelaphini (Spiral-horned Bovines)}

\section{Mountain Nyala \\ Tragelaphus buxtoni}

This now-endangered antelope, the mountain nyala, is limited to the highlands of Ethiopia, and obtaining specimens of it was one of the primary goals of the Abyssinian expedition. The nyala (a word of Bantu origin) had been discovered only two decades earlier (1905) and was the last large ungulate to be discovered in Africa. It is classified with a group of other antelopes (such as the bushbuck, elands, and kudus) that have spotted and striped pelages and horns that form a graceful open spiral. Tragelaphus translates as "goat-deer."

Some members of this antelope group are quite large, weighing up to nearly 2,000 pounds (950 $\mathrm{kg}$ ) in the case of the eland (Taurotragus oryx). Males of the mountain nyala weigh about 400 to 650 pounds (180-295 kg) and females 330 to 440 pounds (150-200 kg). Fuertes's plate shows three males; the females are hornless. Females are also much paler than males, with a few faint stripes and spots on the back and sides. Both sexes also have white markings on the cheeks and the front of the neck and are more extensively white on the underparts and underside of the tail.

Mountain nyalas occupy montane forests and heathland mainly at about 9,300 to 12,000 feet $(2,800-3,650 \mathrm{~m})$ elevation; some of those collected during the Ethiopian expedition were taken at 11,200 feet $(3,400 \mathrm{~m})$ on Mount Albassa. They occur in groups numbering from a few up to 90 , with old males generally being solitary. During the dry season they are found mainly in the woodlands, where they browse on herbs and shrubs, but during wetter times they might move to more grassy areas at lower elevations. For much of the year the usual social groups are made up of females with dependent young, accompanied by one or more males. Young males form more mobile bachelor groups until they are old enough to compete with adults.
The breeding season peaks in about December, when males perform aggressive circling displays around one another. The gestation period lasts eight to nine months, with young being born around the end of the wet season. The fawns remain hidden between nursings for a few months and then gradually begin to move about with their mothers. After two years they are sexually mature.

The animals once roamed over much of the southern Ethiopian highlands but by the 1980s were limited to the Bale Mountains of southeastern Ethiopia. As of the late 1980s, about 3,000less than half the 1960s' numbers-still survived, with about a third protected in Bale Mountains National Park. The species was then classified as threatened by the International Union for Conservation of Nature. In 2016 its population was estimated at 1,500 to 2,500 individuals and was classified by the International Union for Conservation of Nature as endangered.

Suggested reading: Grzimek, 1990; Kingdom, 1997; Leuthold, 1977; Macdonald \& Norris, 2001; Nowak, 1991; Yalden, Largen \& Kock, 1976-86.

\section{Tribe Cephalophini (Duikers)}

\section{Bush Duiker \\ Sylvicapra grimmia abyssinica (2 paintings)}

Bush duikers are part of a large group of small antelopes that are widespread in sub-Saharan Africa. All but one of the 17 species of duikers are in the group called forest duikers (genus Cephalophus); the single and very widespread species of bush duiker (also called the common duiker) was illustrated by Fuertes and is more adapted to savannas, grasslands, and even alpine zones. The name "duiker" is from the German "Ducker," meaning "diving buck," and refers to the species' tendency to dive into heavy cover when threatened. Sylvicapra translates as "woodland goat." Compared with other African antelopes, duikers are not open-field runners and instead rely on concealment for protection. However, they have 


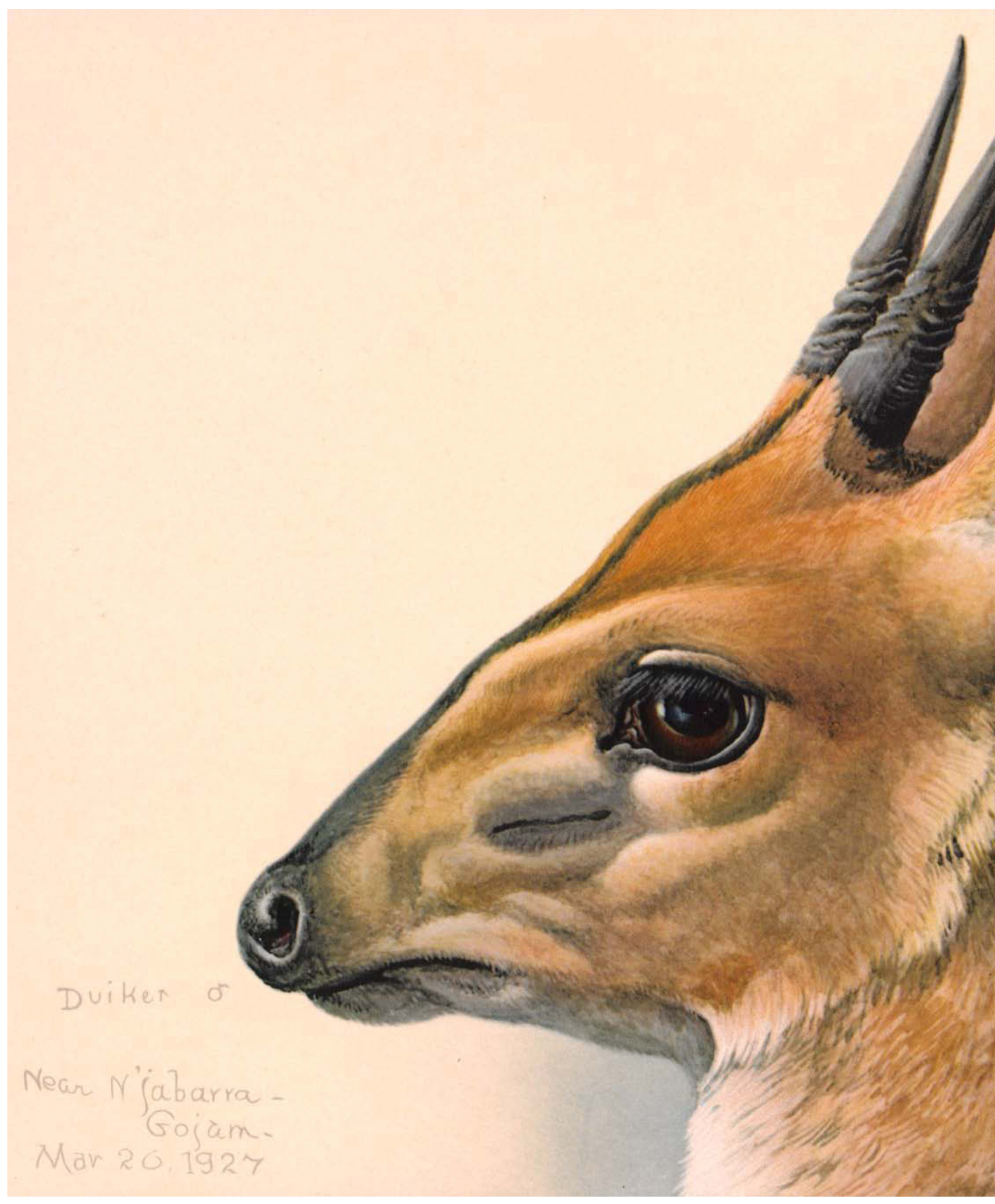




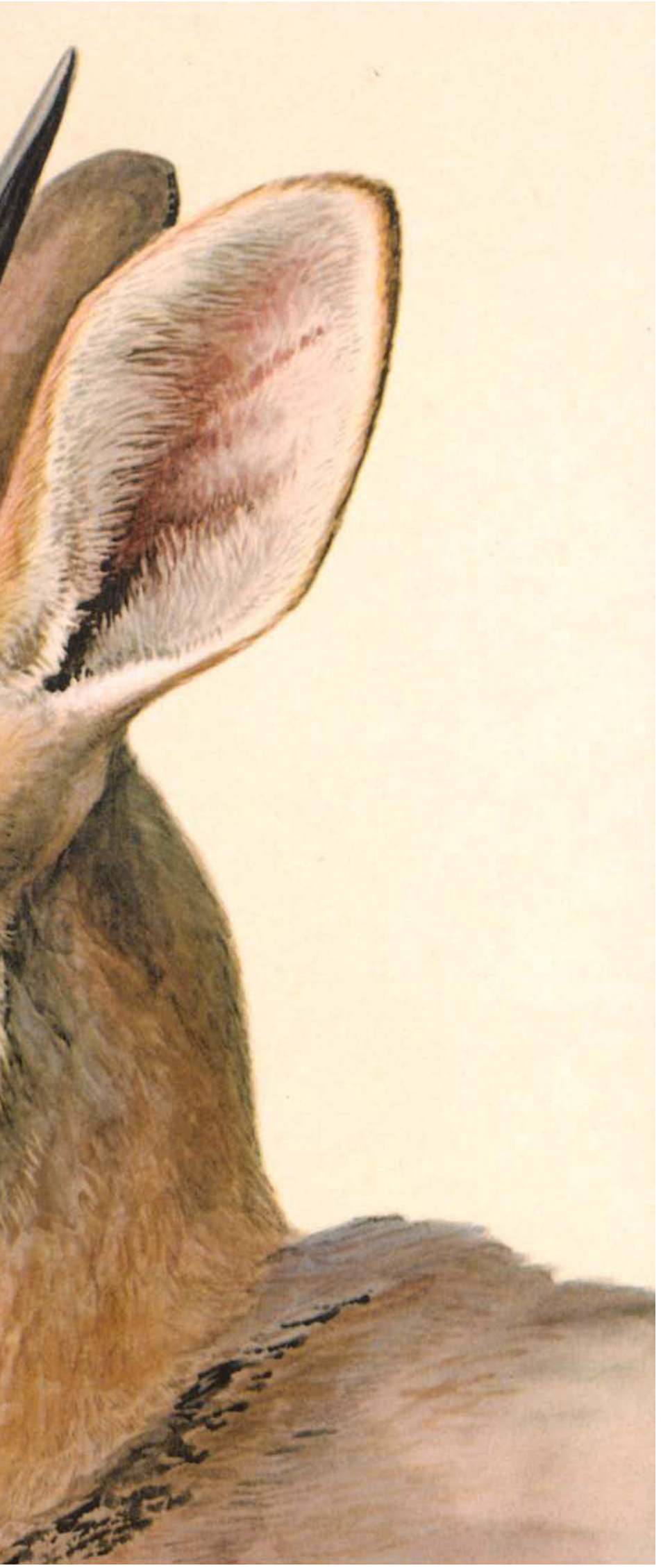

relatively large brains and are noted for their alertness and intelligent behavior. Adult bush duikers stand only about two feet $(0.6 \mathrm{~m})$ tall at the shoulder and weigh about 25 to 50 pounds (13.6-22.7 kg), the females averaging somewhat heavier than males. Although among the forest duikers both sexes are horned, only male bush duikers possess horns. These are short, nearly straight, very sharp, and are probably important in territorial sparring as well as in defensive behavior. A conspicuous preorbital gland is located just below and in front of each of the animal's large eyes, and its secretions are important in territorial marking.

The bush duiker's overall pelage is mostly rich tawny brown on the head and foreparts, becoming more grayish on the back and rump. The tail is short with a black upper surface and white underside. The conspicuous black muzzle streak and white of the tail are presumably important visual signals that supplement the glandular secretions and excretory scents used in social and sexual interactions. Males use the secretions of their pro-orbital glands to mark territories.

The ears of bush duikers are longer and more pointed than those of forest duikers. Bush duikers also have longer legs than forest duikers and not only can run rapidly but also can leap explosively when threatened. The animals are adapted for browsing rather than grazing and consume the leaves of trees and bushes, fruits, flowers, bark, and some animal materials, including even carrion. In the case of forest duikers, small animals-especially birds-might at times be killed and eaten, but fruits and leafy materials probably make up most of the usual diet.

Bush duikers can survive indefinitely without access to water. The sexes spend little time together, males preferring to select higher and more open areas that provide unrestricted visibility for resting, whereas females are more likely to be found in lower, better vegetated areas where more opportunities exist for effective hiding. During the bush duiker's breeding season, a good deal of chasing occurs along with aggression and fighting among the competing males. Males defend breeding territories that have little or no overlap and that might enclose the home range of more than a single female. Gestation probably lasts about six 
months, with the birth of a single fawn being typical. Although these tiny babies are vulnerable to attack from a variety of predators, their mothers actively defend them by butting and kicking the foes. Males will also come to the defense of the young. Adult size is reached in little more than six months, and often females produce their first offspring when they are only about a year old.

Bush duikers are still common over much of Africa; however, some of the forest duikers are rare, vulnerable, or endangered. Their small size makes duikers poor trophies, but natives hunt them for consumption, and forest habitat destruction has been a serious influence for some of these species.

Collectively, forest duikers show a considerable range in size and ecology, subdividing their habitats according to usual food type, relative diurnality or nocturnality, and body size. The smallest species are seemingly the most generalized ecologically; they forage from the forest floor on a variety of herbaceous materials. Other species are variably more fruit-adapted or omnivorous, but probably all depend to some extent on the availability of foods dropped by monkeys and birds from the overhead canopy.

The bush duiker is widespread across subSaharan Africa and, although its numbers are decreasing, its population is thought to be in the millions. It is considered a species of least concern by the International Union for Conservation of Nature.

Suggested reading: Dunbar \& Dunbar, 1979; Grzimek, 1973; Kingdom, 1997; Leuthold, 1977; Macdonald \& Norris, 2001; Nowak, 1991; Yalden, Largen \& Kock, 1976-86.

\section{Tribe Neotragini (Dwarf Antelopes)}

\section{Klipspringer Oreotragus oreotragus saltatrixoides}

The klipspringer is a tiny antelope weighing only about 20 to 40 pounds $(9-18 \mathrm{~kg})$ and standing about 20 inches $(0.5 \mathrm{~m})$ high at its shoulders. Males have short horns that are nearly straight but ringed at the base. Females are usually hornless, but in Ethiopia females occasionally also possess horns. Klipspringers (their name is German and translates as "cliff-jumper") are adapted to rocky habitats. They walk on the tips of their hooves and are able to stand on tiny rocky outcrops (Oreotragus translates as "mountain goat"). Their pelage is unusually thick, and the individual hairs are hollow, which probably provide excellent insulation for life at altitudes as high as nearly 14,500 feet $(4,420 \mathrm{~m})$. The pelage color of the arid-adapted subspecies illustrated by Fuertes is mostly creamy yellow, dappled with olive, and grades to grayish below, providing a concealing pattern in the animal's rocky background.

Klipspringers browse on herbs, shrubs, and woody plants, with grasses making up only a small part of their diet. Rocky ground and short, abundant vegetation are primary habitat needs. The animals are usually found in small groups consisting of a male, a female, and her offspring. These family groups establish home ranges within the male's permanent territory, which ranges from about 20 to 100 acres (8-40 ha). The pairs remain in nearly constant contact by whistling. Facial glands in front of the eyes of both sexes are also certainly important during social interactions; territories are marked by secretions of these glands as well as by stool deposits. Whistling is a major means of communication in pairs and families, and the animals' large preorbital glands and mutual face-rubbing between mates suggest the importance of olfactory signaling.

Females become sexually mature at the end of their first year; males mature somewhat later. The breeding season in Ethiopia occurs during August and September. Probably only those males able to establish and maintain territories of 19 to 121 acres (7.5-49 ha) are able to obtain mates. The gestation period lasts about seven months, and a single fawn is born in April or May. Since the newborn fawn weighs only about two pounds $(1 \mathrm{~kg})$, it could be easy prey for eagles and other predators. It remains well hidden for the first two or three months and becomes 
weaned by about two months later. The young males leave the family group at sexual maturity when a year old, but females remain longer and might even mate with their fathers.

The klipspringer is widespread in central and eastern Africa and is considered to be a species of least concern by the International Union for Conservation of Nature. It has been estimated that almost 25 percent of the species' population occurs in protected areas.

Suggested reading: Dunbar \& Dunbar, 1974a; Grzimek, 1990; Kingdom, 1997; Leuthold, 1977; Macdonald \& Norris, 2001; Nowak, 1991; Yalden, Largen \& Kock, 1976-86.

\section{Tribe Reduncini (Reduncine Antelopes and Kobs)}

\section{Bohor Reedbuck Redunca redunca fulvorufula}

Bohor reedbucks are medium-sized antelopes weighing about 75 to 160 pounds (34-72 kg) as adults, with males being about a third heavier than females. They approach the size and pelage color of white-tailed deer (Odocoileus virginianus), with a similarly white and bushy tail. Also in common with white-tailed deer, reedbucks lift their tails when alarmed and while fleeing. Males have dark glandular patches just below their ears as well as groin glands. Whistles and ritualized bounding behavior are important components of acoustic and visual communication, and the glandular ear patches are probably sources of pheromones important to both sexes. The male's horns are ringed and curved, pointing backward basally but recurved forward toward their tips. Females are hornless, slightly smaller and more slender than males, and also have glandular ear patches that identify their sexual condition.
The species occurs from Ethiopia south to South Africa; in most regions, it is associated with wide river valleys and floodplains, where the animals graze on grass, reeds, and other herbaceous vegetation. I have seen reedbucks in Kenya only in rather tall reedy vegetation. There they probably hide for much of the daylight hours, foraging only near dawn and dusk or during the night. Most of their acoustic communication is seemingly achieved by whistles and loud bounding noises.

Although some herding might occur during stressful periods when water could be in short supply, for much of the year the animals live in small groups consisting of a territorial male and a few females and their young. The females and their dependent young tend to remain rather isolated in small areas, within the male's territory, which includes a source of water, grazing areas, and resting sites. Not all males are able to find suitable breeding territories, and hostile displays or fighting between competing males sometimes occurs. Males defending the best grassy habitats are sought out by females for mating.

In some regions breeding might occur throughout the year, but generally most young are born during the wet season. Females mature at one year of age, and pregnancy lasts about eight months, producing a single fawn. The fawn is tended by its mother until shortly before the birth of her next offspring. Young males sometimes form bachelor groups. Probably these antelopes are fairly easy prey for leopards and other predators, as they are not very wary and are defenseless against large predators.

The reedbuck is widespread in central and eastern Africa and is considered to be a species of least concern by the International Union for Conservation of Nature.

Suggested reading: Grzimek, 1990; Hendrichs, 1975; Kingdom, 1997; Leuthold, 1977; Macdonald \& Norris, 2001; Nowak, 1991; Yalden, Largen, \& Kock, 1976-86. 


\section{Appendix 1}

\section{Fuertes's Abyssinian Art, Listed Alphabetically by Generic Names*}

Latin Name, English Name
Image No. Province; Location**

\section{Graphite Drawings}

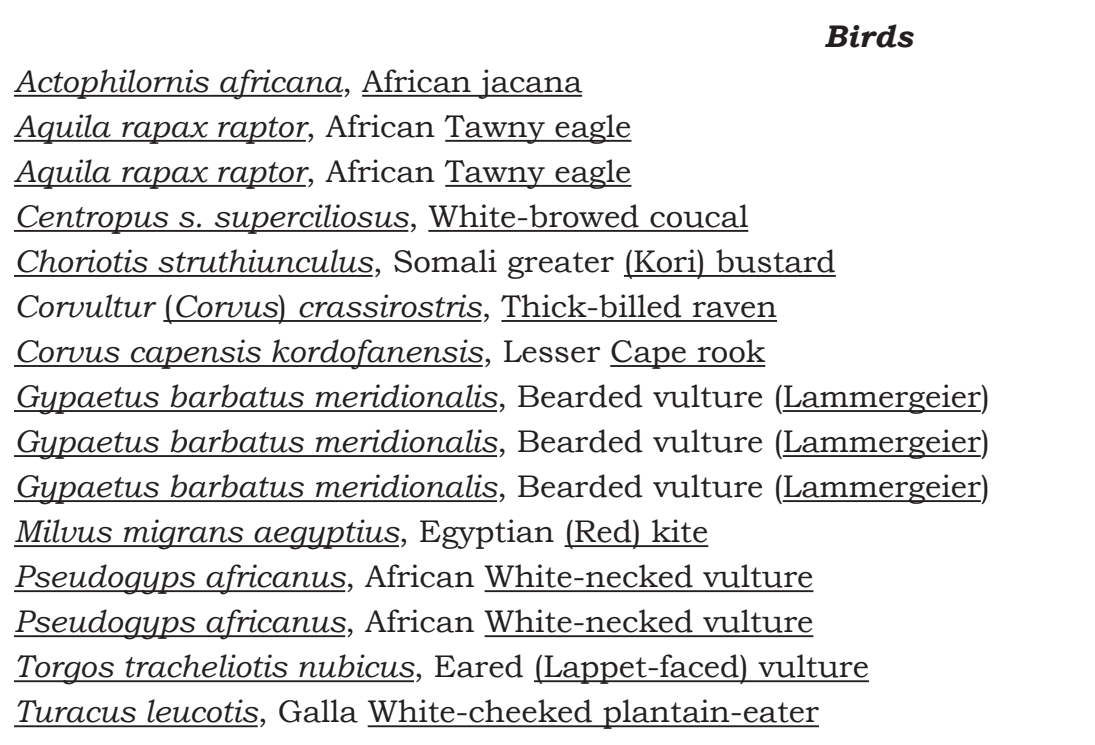

\section{Mammals}

Canis simensis, Abyssinian (Ethiopian) wolf

Cephalophus (Sylvicapra) grimmia abyssinica, Abyssinian (Bush) duiker Cercopithecus (aethiops) djamdjamensis, Bale (Grivet) monkey

Colobus polykomos (guereza) abyssinicus, Guereza (colobus)

Colobus polykomos (guereza) abyssinicus, Guereza (colobus)

Colomys goslingi, Abyssinian water (Velvet) rat

Dendrohyrax. See Procavia capensis habessinica

Herpestes sanguinea, Slender mongoose

Mungos gracilis. See Herpestes sanguinea

Nilopegamys plumbeus. See Colomys goslingi

Oreotragus oreotragus saltatrixoides, Abyssinian klipspringer

Papio cynocephala, Dog-faced (Yellow) baboon

Papio cynocephala, Dog-faced (Yellow) baboon

Procavia capensis habessinica, Ethiopian rock hyrax

Redunca bohor, Bohar reedbuck

Tachyoryctes splendens, Abyssinian (Northeast African) mole-rat

Theropithecus gelada, Gelada baboon

Theropithecus gelada, Gelada baboon

Theropithecus gelada, Gelada baboon

Theropithecus gelada, Gelada baboon

Theropithecus gelada, Gelada baboon 73

$\begin{array}{cl}46 & \text { Gojjam; Dundulbar } \\ 24 & \text { Gojjam; Njabara } \\ 71.2 & \text { Gojjam; Njabara } \\ 55 & \text { Galla; Gidu River camp } \\ 44 & \text { Galla; Gidu River camp } \\ 71.3 & \text { Gojjam; Njabara } \\ 67 & \text { Alla; Awash River } \\ 27 & \text { Arsi; Mt. Albassa } \\ 28 & \text { Arsi; Mt. Albassa } \\ 29 & \text { Arsi; Mt. Albassa } \\ 71.1 & \text { Gojjam; Njabara } \\ 34 & \text { Gojjam; Njabara } \\ 71.4 & \text { Gojjam; Njabara } \\ 32 & \text { Bale; SE of Dodolo } \\ 53 & \text { Arsi; Wadago }\end{array}$

Arsi; Mt. Albassa Gojjam; near Njabara Sidamo; Mt. Guramba ? (Probably Shewa) ? (Probably Gojjam) Gojam; Little Abbai River
Gojjam; near Dambracha

\author{
Shewa; Mulu \\ ? (Probably Awada River) \\ Galla; Awada River \\ Arsi; Wadago \\ Arsi; Mt. Albassa \\ Shewa; Addis Ababa \\ Shewa; Mulu \\ Shewa; Mulu \\ Shewa; Mulu \\ Shewa; Mulu \\ Shewa; Mulu
}




\section{Watercolors}

\section{Birds}

Afribyx (Vanellus) s. senegalus, (African) wattled plover

Anas capensis, Cape teal

Anas undulata rueppelli, (Abyssinian) Yellow-billed duck

Apaloderma n. narina, Narina trogon

Aquila rapax raptor, African Tawny eagle

Ardea melanocephala, Black-headed heron

Bostrychia carunculata, Wattled ibis

Bucorvus abyssinicus, Abyssinian ground hornbill

Buphagus e. erythrorhynchus, Red-billed oxpecker

Burhinus sengalensis, Senegal stone curlew (Thick-knee)

Bycanistes cristatus, Crested (Silver-cheeked) hornbill (adult male)

Bycanistes cristatus, Crested (Silver-cheeked) hornbill (female)

Chelictinia riocourii, African swallow-tailed (Scissor-tailed) kite

Choriotis (Ardeotus) struthiunculus, Somali greater (Kori) bustard

Corvultur (Corvus) crassirostris, Thick-billed raven

Corythornis (Alcedo) cristata, Crested pigmy (Malachite) kingfisher

Crinifer zonurus, Abyssinian (Gray) plantain eater

Cuncuma (Haliaeetus) vocifer, African sea (fish) eagle (adult)

Cuncuma (Haliaeetus) vocifer, African sea (fish) eagle (immature)

Elanus caeruleus, Black-shouldered (Black-winged) kite

Epihippiorhynchus senegalensis, Saddle-billed stork

Eremialector quadricinctus lowei, Lowe's (Four-banded) sandgrouse

Falco biarmicus abyssinicus, (Abyssinian) Lanner falcon

Francolinus clappertoni sharpii, Clapperton's francolin

Gymnogenys typicus typicus, African harrier-hawk

Gymnogenys typicus typicus, African harrier-hawk (immature)

Gypaetus barbatus meridionalis, Bearded vulture (Lammergeier) (adult)

Gypaetus barbatus meridionalis, Bearded vulture (Lammergeier)

Halcyon l. leucocephala, Gray-headed kingfisher

Hoplopterus (Vanellus) spinosus, Spur-winged plover

Ispidina p. picta, Pygmy kingfisher

Lissotis (Eupodotus) melanogaster, Black-bellied bustard

Lophaetus occipitalis, Crested (Long-crested) hawk-eagle (morphology)

Lophaetus occipitalis, Crested (Long-crested) hawk-eagle (portrait)

Lophoceros erythrorhynchus, Red-billed hornbill

Lophoceros hemprichii, Hemprich's hornbill. See Lophoceros erythrorhynchus

Lybius bidentatus aethiops, Abyssinian Double-toothed barbet

Megalornis (Grus) grus, Common (Eurasian) crane

Necrosyrtes monarchus, Common African vulture. See Hooded vulture (appendix 2)

Neophron p. percnopterus, Egyptian vulture

Numida m. major, Uganda tufted (Helmeted) guinea-fowl

35

Nycticorax (Gorsachius) leuconotus, African (White-backed) night heron

Phoenicopterus ruber antiquorum, Greater flamingo $\begin{array}{cl}47 & \text { Gojjam; S of Debra Markos } \\ 9 & \text { Galla; Hora Abyata }\end{array}$

10 Galla; Awash River

56 Sidamo; Mt. Guramba

23
Sidamo; Ladu Near Lake Shala

Gojjam; Bichana

Gojjam; Njabara, Dangila

Shewa; N of Addis Ababa

Sidamo; Ladu

Gidu River, Lake Shala

Sidamo; near Alata

Sidamo; near Alata

Gojjam; near Matemma

Galla; Gidu River camp

Shewa; Mulu, Mugger River

Gojjam; W of Lake Tana

Gojjam; Lake Tana

Galla; Lake Zwei

Galla; Lake Zwei

Gojjam; Bichana

Galla; Hoya, Suksuk River

Gojjam; Metemma

Gojjam; Njabara

Gojjam; Metemma

Sidamo; near Ladu

Shewa; Mulu

Arsi, Mt. Albassa

Arsi, Mt. Albassa

Gojjam; W of Lake Tana

Galla; Gidu River camp

Gojjam; near Gendoa

Gojjam; Lake Tana

Sidamo; Shushumana

Gojjam; Lake Tana

Galla; Lake Zwei

Gojjam; Bichana

Galla; Awada River

Gojjam; Ambo

Galla; Bulbula 
Latin Name, English Name

Platysteira cyania, Brown-throated (Common) wattle-eye

Plectropterus g. gambensis, Spur-winged goose

Polihierax semitorquatus castanotus, (Abyssinian) Pygmy falcon

Poliocephalus (Tachybaptus) ruficollis, (African) Little grebe

Prionops concinnata, Nile (White-crested) helmetshrike

Pseudogyps africanus. See Hooded vulture (appendix 2), Necrosyrtes monarchus

Sagittarius serpentarius, Secretary bird

Sagittarius serpentarius, Secretary bird

Stephanibyx (Vanellus) coronatus, Crowned lapwing

Terathopius ecaudatus, Bateleur eagle

Terathopius ecaudatus, Bateleur eagle

Terathopius ecaudatus, Bateleur eagle

Terathopius ecaudatus, Bateleur eagle

Threskiornis a. aethiopicus, Sacred ibis

Torgos tracheliotis nubicus, Eared (Lappet-faced) vulture

Trigonoceps occipitalis, White-headed vulture

Turacus leucotis, (Galla) White-cheeked plantain-eater

Turacus leucotis, (Galla) White-cheeked plantain-eater (group)

Upupa e. epops, European hoopoe

Vinago waalia, (Bruce's) Green fruit pigeon
Image No. Province; Location**

Sidamo; Sisha, Mt. Gura

Gojjam; Lake Tana

Galla; Lake Shala

Galla; Awash River

Gojjam; Lake Tana

Gojjam; Dengela

Gojjam; Dengela

Galla; Gidu River camp

Gojjam; near Njabara

Gojjam; near Njabara

Gojjam; near Njabara

Gojjam; near Njabara

Gojjam; Mescala Christo

Bale; Gedab Mts.

Bale; Gedab Mts.

Arsi; Wedago

Painted after return?

60 Gojjam

51 Wello; Lake Zwai

\section{Mammals}

Canis simensis, Abyssinian (Ethiopian) wolf

Cephalophus (Sylvicapra) abyssinicus, Abyssinian bush duiker

Colobus polykomos abyssinicus, Pied (Guereza) colobus

Colobus polykomos abyssinicus, Pied (Guereza) colobus

Colobus polykomos abyssinicus, Pied (Guereza) colobus (group)

Theropithecus gelada, Gelada baboon

Theropithecus gelada, Gelada baboon

Theropithecus gelada, Gelada baboon
74 Arsi; Mt. Albassa

89 Gojjam; near Njabara

106 Gojjam; Amedamit Mts.

109 Gojjam; Amedamit Mts.

- Painted after return?

102 Shewa, Mulu

103 Shewa, Mulu

108 Gojjam

* Prioritized English bird names are those present on Fuertes's images in the Album of Abyssinian Birds (FMNH, 1930) or in associated literature (Fuertes \& Osgood, 1936). Corresponding English and Latin names in current use are underlined.

** The chaotic political geography of Ethiopia, with its historically unstable boundaries and multiple spellings of place names, makes determination of many locations almost impossible. Some of the so-called "provinces" mentioned as expedition collection sites use updated (post-1930s) spellings here (e.g., Arusi = Arsi; Shoa = Shewa). Additionally, Galla was not a province but instead the name evidently alludes to sites where the expedition was closely associated with Galla natives, in what were then Arusi and Sidamo provinces. During the later 1900s, these rather indefinite geopolitical regions were replaced by new administrative entities, and the older names no longer appear on recent maps, further complicating an understanding of 1920s regional geography. 


\section{Appendix 2}

\section{Fuertes's Abyssinian Art, Listed Alphabetically by English Names*}

English Name, Latin Name
Image No.

Date

Province

\section{Birds}

Abyssinian brown-throated (Common) wattle-eye, Platysteira cyanea Abyssinian Clapperton's francolin, Francolinus clappertoni sharpii Abyssinian double-toothed barbet, Lybius bidentatus aethiops Abyssinian (Eastern) gray plantain-eater, Crinifer zonurus Abyssinian ground hornbill, Bucorvus abyssinicus Abyssinian klipspringer, Oreotragus oreotragus saltatrixoides** Abyssinian lanner falcon, Falco biarmicus abyssinicus Abyssinian pygmy falcon, Polihierax semitorquatus castanotus Abyssinian tawny eagle, Aquila rapax raptor Abyssinian tawny eagle, Aquila rapax raptor** Abyssinian tawny eagle, Aquila rapax raptor** Abyssinian yellow-billed duck, Anas undulata rueppelli African harrier-hawk, Gymnogenys typicus African harrier-hawk, Gymnogenys typicus (immature) African jacana, Actophilornis africana** African little grebe, Poliocephalus (Tachybaptus) ruficollis African sea (fish) eagle, Cuncuma (Haliaeetus) vocifer African sea (fish) eagle, Cuncuma (Haliaeetus) vocifer African swallow-tailed (Scissor-tailed) kite, Chelictinia riocourii African tawny eagle, Aquila rapax raptor African (White-backed) night heron, Gorsachius leuconotus African white-necked vulture, Pseudogyps (Gyps) africanus African white-necked vulture, Pseudogyps (Gyps) africanus** African white-necked vulture, Pseudogyps (Gyps) africanus** Bateleur eagle, Terathopius ecaudatus (4 images) Bearded vulture (Lammergeier), Gypaetus barbatus Bearded vulture (Lammergeier), Gypaetus barbatus Bearded vulture (Lammergeier), Gypaetus barbatus Bearded vulture (Lammergeier), Gypaetus barbatus** Bearded vulture (Lammergeier), Gypaetus barbatus** Black-bellied bustard, Lissotis (Eupodotus) melanogaster Black-headed heron, Ardea melanocephala Black-winged kite, Elanus caeruleus (Bruce's fruit) green-pigeon, Vinago waalia Cape teal, Anas capensis

Common African vulture. See Hooded vulture Common (Eurasian) crane, Megalornis (Grus) grus Crested (Long-crested) hawk-eagle, Lophaetus occipitalis Crested (Long-crested) hawk-eagle, Lophaetus occipitalis Crested (Long-crested) hawk-eagle, Lophaetus occipitalis Crested pigmy (Malachite) kingfisher, Corythornis (Alcedo) cristata Crested (Silvery-cheeked) hornbill, Bycanistes (brevis) cristatus Crested (Silvery-cheeked) hornbill, Bycanistes (brevis) cristatus

\begin{tabular}{|c|c|c|}
\hline 68 & 24 Dec 1926 & Sidamo \\
\hline 40 & 16 Apr 1927 & Gojjam \\
\hline 65 & 26 Dec 1926 & Sidamo \\
\hline 54 & 31 Mar 1927 & Gojjam \\
\hline 61 & 14 Feb 1927 & Sidamo \\
\hline 76 & 22 Oct 1926 & Shewa \\
\hline 39 & 22 Mar 1927 & Gojjam \\
\hline 38 & 2 Jan 1927 & Galla \\
\hline 23 & 23 Mar 1927 & Gojjam \\
\hline 24 & 23 Mar 1927 & Gojjam \\
\hline 71.2 & 23 Mar 1927 & Gojjam \\
\hline 10 & 18 Jan 1927 & Galla \\
\hline 36 & 26 Dec 1926 & Sidamo \\
\hline 37 & 21 Oct 1926 & Shewa \\
\hline 46 & 1 Apr 1927 & Gojjam \\
\hline 1 & 18 Jan 1927 & Galla \\
\hline 15 & 10 Jan 1927 & Galla \\
\hline 16 & 12 Jan 1927 & Galla \\
\hline 14 & 15 Apr 1927 & Gojjam \\
\hline 23 & ? Mar 1927 & Gojjam \\
\hline 37 & Apr 1927 & Gojjam \\
\hline$?$ & 29 Nov 1926 & Sidamo \\
\hline 34 & 21 Mar 1927 & Gojjam \\
\hline 71.4 & 20 Mar 1927 & Gojjam \\
\hline $17-20$ & 20 Mar 1927 & Gojjam \\
\hline 25 & 13 Nov 1926 & Arsi \\
\hline 26 & 12 Nov 1926 & Arsi \\
\hline 27 & 13 Nov 1926 & Arsi \\
\hline 28 & Nov 1926? & Arsi? \\
\hline 29 & 13 Nov 1926 & Arsi \\
\hline 45 & 29 Mar 1927 & Gojjam \\
\hline 2 & 20 Feb 1927 & Gojjam \\
\hline 13 & 1 Mar 1927 & Gojjam \\
\hline 51 & 13 Jan 1927 & Galla \\
\hline 9 & 8 Jan 1927 & Galla \\
\hline 42 & Apr 1927 & Gojjam \\
\hline 21 & 30 Dec 1926 & Gojjam \\
\hline 21 & 30 Dec 1926? & Gojjam? \\
\hline 22 & 31 Mar 1927 & Gojjam \\
\hline 58 & 8 Apr 1927 & Gojjam \\
\hline 63 & 15 Dec 1926 & Sidamo \\
\hline 64 & 15 Dec 1926 & Sidamo \\
\hline
\end{tabular}


Image No.

Crowned lapwing, Stephanibyx (Vanellus) coronatus

Egyptian (Red) kite, Milvus migrans aegyptius**

Egyptian vulture, Neophron percnopterus

European hoopoe, Upupa e. epops

Galla White-cheeked plantain-eater, Turacus leucotis donaldsoni

Galla White-cheeked plantain-eater, Turacus leucotis donaldsoni

Galla White-cheeked plantain-eater, Turacus leucotis donaldsoni

Gray-headed kingfisher, Halcyon leucocephala

Greater flamingo, Phoenicopterus ruber antiquorum

Hemprich's hornbill. See Red-billed hornbill

Hooded vulture, Necrosyrtes monarchus

Lappet-faced (Eared) vulture, Torgos tracheliotis

Lesser Cape rook, Corvus capensis kordofanensis**

Lowe's (Four-banded) sand grouse, Eremialector (Pterocles) q. lowei

Narina trogon, Apaloderma narina

Nile (White-crested) helmetshrike, Prionops (plumatus) concinnata

Northern lappet-faced (Eared) vulture, Torgos tracheliotis nubicus

Northern lappet-faced (Eared) vulture, Torgos tracheliotis nubicus**

Pigmy (Pygmy) kingfisher, Corythornis (Ispidina) picta

Red-billed hornbill, Tokus erythrorhynchus

Red-billed oxpecker, Buphagus e. erythrorhynchus

Sacred ibis, Threskiornis a. aethiopicus

Saddle-billed stork, Epihippiorhynchus senegalensis

Secretary bird, Sagittarius serpentarius

Secretary bird, Sagittarius serpentarius

Senegal stone curlew (Thick-knee), Burhinus sengalensis

Senegal wattled plover, Afribyx (Vanellus) s. senegallus

Somali greater (Kori) bustard, Choriotis (Ardeotis) struthiunculus

Somali greater (Kori) bustard, Choriotis (Ardeotis) struthiunculus**

Spur-winged goose, Plectropterus gambensis

Spur-winged plover, Hoplopterus (Vanellus) spillosus

Thick-billed raven, Corovulture (Corvus) crassirostris

Thick-billed raven, Corovulture (Corvus) crassirostris**

Uganda tufted (Helmeted) guinea-fowl, Numida meleagris major

Wattled ibis, Bostrychia carunculata

White-browed coucal, Centropus s. superciliosus**

White-headed vulture, Trigonoceps (Aegypius) occipitalis

\begin{tabular}{|c|c|c|}
\hline 48.1 & 3 Jan 1927 & Galla \\
\hline 71.1 & 21 Mar 1927 & Gojjam \\
\hline 35 & 21 Feb 1927 & Gojjam \\
\hline 60 & 6 Apr 1927 & Gojjam \\
\hline 52 & 19 Nov 1926 & Arsi \\
\hline 53 & 19 Nov 1926 & Arsi \\
\hline- & Painted after return & - \\
\hline 57 & 7 Apr 1927 & Gojjam \\
\hline 7 & 8 Jan 1927 & Galla \\
\hline 33 & 7 Dec 1926 & Bale \\
\hline 31 & 7 Dec 1926 & Bale \\
\hline 67 & 18 Jan 1927 & Galla \\
\hline 50 & 17 Apr 1927 & Gojjam \\
\hline 56 & 24 Dec 1926 & Sidamo \\
\hline 69 & 6 Apr 1927 & Gojjam \\
\hline 31 & 7 Dec 1926 & Bale \\
\hline 32 & 7 Dec 1926 & Bale \\
\hline 59 & 10 Apr 1927 & Gojjam \\
\hline 62 & 14 Jan 1927 & Galla \\
\hline 70 & 26 Dec 1926 & Sidamo \\
\hline 5 & 3 Apr 1927 & Gojjam \\
\hline 4 & 17 Apr 1927 & Galla \\
\hline 11 & 25 Mar 1927 & Gojjam \\
\hline 12 & 25 Mar 1927 & Gojjam \\
\hline 49 & 5 Jan 1927 & Galla \\
\hline 47 & 5 Mar 1927 & Gojjam \\
\hline 43 & 3 Jan 1927 & Galla \\
\hline 44 & 3 Jan 1927 & Galla \\
\hline 8 & 4 Apr. 1927 & Gojjam \\
\hline 48.2 & 3 Jan 1927 & Galla \\
\hline 66 & 22 Oct 1926 & Gojjam \\
\hline 71.3 & 22 Oct 1926 & Gojjam \\
\hline 41 & 31 Dec 1926 & Galla \\
\hline 6 & 24 Mar 1927 & Gojjam \\
\hline 55 & 5 Jan 1927 & Galla \\
\hline 30 & 7 Dec 1926 & Bale \\
\hline
\end{tabular}


Province

\section{Mammals}

\begin{tabular}{|c|c|c|c|}
\hline Abyssinian (Bush) duiker, Cephalophus grimmia abyssinicus** & 88 & 20 Mar 1927 & Gojjam \\
\hline Abyssinian (Bush) duiker, Cephalophus grimmia abyssinicus & 89 & 20 Mar 1927 & Gojjam \\
\hline Abyssinian (Ethiopian) wolf, Canis simensis** & 73 & 11 Nov 1926 & Arsi \\
\hline Abyssinian (Ethiopian) wolf, Canis simensis & 74 & 11 Nov 1926 & Arsi \\
\hline Abyssinian (Northeast African) root-rat, Tachyoryctes splendens** & 77 & 18 Oct 1926 & Shewa \\
\hline Abyssinian water (Velvet) rat, (Colomys goslingi)** & 87 & 21 Mar 1927 & Gojjam \\
\hline Bohor reedbuck, Redunca bohor** & 75 & 10 Nov 1926 & Arsi \\
\hline \multicolumn{4}{|l|}{ Cony, Dendrohyrax. See Ethiopian rock hyrax } \\
\hline Dog-faced (Yellow) baboon, Papio cynocephala** & 104 & Dec $1926 ?$ & Galla? \\
\hline Dog-faced (Yellow) baboon, Papio cynocephala** & 105 & 31 Dec 1926 & Galla \\
\hline Ethiopian rock hyrax, Procavia capensis habessinica & 96 & 22 Nov 1926 & Arsi \\
\hline Gelada baboon, Theropithecus gelada** & 95 & 21 Oct 1926 & Shewa \\
\hline Gelada baboon, Theropithecus gelada** & 96 & 21 Oct 1926 & Shewa \\
\hline Gelada baboon, Theropithecus gelada** & 99 & 21 Oct 1926 & Shewa \\
\hline Gelada baboon, Theropithecus gelada** & 101 & 21 Oct 1926 & Shewa \\
\hline Gelada baboon, Theropithecus gelada & 102 & 21 Oct 1926 & Shewa \\
\hline Gelada baboon, Theropithecus gelada & 108 & 21 Oct $1926 ?$ & Shewa? \\
\hline Guenon (Bale) monkey, Cercopithecus (aethiops) djamdjamensis & 93 & Oct $1926 ?$ & Gojjam? \\
\hline Guereza (colobus), Colobus polykomos (guereza) abyssinicus** & 78 & March 1927? & Gojjam? \\
\hline Guereza (colobus), Colobus polykomos (guereza) abyssinicus** & 91 & March 1927? & Gojjam? \\
\hline Guereza (colobus), Colobus polykomos (guereza) abyssinicus & 106 & 17-18 Mar 1927 & Gojjam \\
\hline Guereza (colobus), Colobus polykomos (guereza) abyssinicus & 109 & Mar 1927? & Gojjam? \\
\hline Guereza (colobus), Colobus polykomos (guereza) abyssinicus (group) & 一 & Painted after return? & - \\
\hline Long-tailed (Slender) mongoose, Herpestes sanguinea & 107 & 6 Mar 1927 & Gojjam \\
\hline Mountain nyala, Tragelaphus buxtoni & - & Painted after return? & - \\
\hline
\end{tabular}

* English names used by Fuertes or in Artist and Naturalist in Ethiopia (Fuertes \& Osgood, 1936) are given sequential priority, with currently used English synonyms indicated by parentheses and underlining. Fuertes's Latin names are also prioritized, with current synonyms shown within parentheses.

** Graphite drawings 


\section{Appendix 3}

\section{Miscellaneous Graphite Sketches and Small Watercolors}

Yellow (“Dog-faced”) baboon (graphite) (\#110)

Gelada morphology (graphite) (\#94)

Gelada morphology (graphite) (\#97)

Gelada morphology (graphite) (\#89)

Gelada morphology (graphite) (\#100)

Galla ox (graphite) (\#80)

Felid (leopard?) head (graphite) (\#86)

Native child (Galla?) (graphite) (\#84)

Horse (Galla?) (graphite) (\#82)

Unidentified insect (Hemiptera, Pentatomidae?) (watercolor) (\#79)

Unidentified plant (watercolor) (\#81)

Unidentified plant (watercolor) (\#83)

Unidentified plant (watercolor) (\#90)

\section{Appendix 4}

\section{Summary of Fuertes's Abyssinian Art Collection in the Field Museum}

Total bird watercolors: $\quad 62$, illustrating 55 species

Total mammal watercolors: 8 , illustrating 4 species

Total watercolors:

Total bird drawings:

Total mammal drawings:

Total drawings:

Total image sheets:
70 , illustrating 59 species. Four small and unidentified watercolors listed in Appendix 3 are excluded from this total, as are three unnumbered, larger, and probable post-expedition watercolors.

15, illustrating 11 species

19, illustrating 13 species. Nine sketches listed in Appendix 3 are excluded from this total.

34, illustrating 24 species, plus 9 sketches

104 (120, if the 13 images listed in Appendix 3 and three unnumbered and probable post-expedition watercolors are included) 


\section{References}

\section{Bird Artists and Some Associated Publications}

Anker, J. 1990. Bird Books and Bird Art. Maurice Martino, New York, NY.

Chapman, F. M. 1929. My Tropical Air Castle. D. Appleton, New York, NY.

-1933. Autobiography of a Bird Lover. D. Appleton, New York, NY.

Coues, E. 1903. Key to North American Birds. 5th ed. 2 vols. Dana Estes, Boston, MA.

Cutright, P. R., and M. Broadhead. 1981. Elliott Coues: Naturalist and Frontier Historian. University of Illinois Press, Urbana, IL.

Devlin, J. C., and G. Naismith. 1977. The World of Roger Tory Peterson: An Authorized Biography. Times Books, New York, NY.

Eaton, E. H. 1910-1914. The Birds of New York. 2 vols. New York State Museum, Albany, NY.

Eckelbery, D. R. 1963. Birds in art and illustration. The Living Bird (Cornell University Laboratory of Ornithology) 2:69-82.

Elphick, J. 2017. Birds: The Art of Ornithology. Skira Rizzoli, Italy.

Forbush, E. H. 1925-29. Birds of Massachusetts and Other New England States. 3 vols. Massachusetts Department of Agriculture, Boston, MA.

Gilbert, A. 1984. The history of animals in art and illustration: An overview. Zoonooz (San Diego Zoological Society) 41(11):4-7.

Graham, F. B. 1981. Signals from the wild: The art and science of George Miksch Sutton. Audubon 83(4):35-45.

Grinnell, G. B. 1919. The Game Birds of California. University of California Museum of Zoology, Berkeley, CA.

Hammond, N. 1986. Twentieth-Century Wildlife Artists. Overlook Press, New York, NY.

- 1998. Modern Wildlife Painters. Pica Press, Mountfield, UK.

Hanley, W. 1977. Natural History in America. Quadrangle/New York Times, New York, NY.

Henshaw, H. 1918. A Book of Birds. National Geographic Society, Washington, DC.
Harriman, E. R. 1975. I Reminisce. Doubleday, Garden City, NY.

Johnsgard, P. A. 1998. Baby Bird Portraits by George Miksch Sutton: Watercolors in the Field Museum. University of Oklahoma Press, Norman, OK. 80 pp.

Kennan, G. 1922. E. H. Harriman, A Biography. 2 vols. Houghton Mifflin, Boston, MA.

Laing, H. M. 1979. Allan Brooks: Artist Naturalist. British Columbia Provincial Museum Special Publication No.3, Vancouver, BC, Canada.

Lambourne, M. 1990. The Art of Bird Illustration. Wellfleet, Secaucus, NJ.

Lindwall, B., and L. Liljefors. 1960. Bruno Liljefors. Rabén \& Sjögren, Stockholm, Sweden.

Lysaght, A. M. 1975. The Book of Birds: Five Centuries of Book Illustrations. Collins, London, UK.

Mearns, B., and R. Mearns. 1998. The Bird Collectors. Academic Press, San Diego, CA.

Mengel, R. M. 1980. Beauty and the beast: Natural history and art. The Living Bird (18th Annual Report, Cornell University Laboratory of Ornithology), pp. 27-67.

Muir, J. 1916. Edward Henry Harriman. Doubleday, Page \& Co., Garden City, NY.

Norelli, M. R. 1975. American Wildlife Painting. Watson Guptill, New York, NY.

Oberholser, H. C. 1974. The Bird Life of Texas. 2 vols. University of Texas Press, Austin, TX.

Pasquier, R. F., and J. Farrand. 1991. Masterpieces of Bird Art: 700 Years of Ornithological Illustration. Abbeville Press, New York, NY.

Peterson, R. T., and V. M. Peterson. 1981. Audubon's Birds of America - The Baby Elephant Folio. Artabras/Harrison House, New York, NY.

Sampson, J. G. 1976. The Worlds of Ernest Thompson Seton. Knopf, New York, NY.

Seton, E. T. 1940. Trail of an Artist-Naturalist. Charles Scribner's Sons, New York, NY.

Skipwith, P. 1979. The Great Bird Illustrators and Their Art, 1730-1930. A \& W Publishers, New York, NY. 
Sutton, G. M. 1933. Fifty years of progress in American bird art. Pp. 181-197, in Fifty Years of Progress of American Ornithology: 1883-1933. American Ornithologists' Union, Lancaster, PA.

- 1962. Is bird art art? The Living Bird (1st Annual Report, Cornell University Laboratory of Ornithology, Ithaca, NY), pp. 73-78.

- 1980. Bird Student: An Autobiography. University of Texas Press, Austin, TX.

Thayer, G. H. 1909. Concealing-Coloration in the Animal Kingdom. Macmillan, New York, NY.

Books and References Associated with Fuertes

\section{A Selection of Books Illustrated Partly or Entirely by Fuertes (arranged by date)}

A-Birding on a Bronco. F. A. Merriam. 1896. (22 pen and ink cuts)

Citizen Bird. M. O. Wright and E. Coues. 1896. (111 black-and-white drawings)

Bird Craft. M. O. Wright. 1897. (80 black-and-white plates)

The Woodpeckers. F. H. Eckstorm. 1901. (5 color plates)

Birds of the Rockies. L. S. Keyse. 1902. (4 color, 4 black-and-white plates)

Handbook of Birds of the Western United States. F. M. Bailey. 1902. (30 full-page black-and-white plates)

Upland Game Birds. E. Sandys and T. S. Van Dyke. 1902. (7 black-and-white plates)

Key to North American Birds. E. Coues. 1903. (200plus wash drawings)

The Water-Fowl Family. L. C. Sanford, L. B. Bishop, and T. S. Van Dyke. 1903. (14 halftone drawings)

Handbook of Birds of Eastern North America. F. M. Chapman. 1904. (8 color, 7 black-and-white plates)

Harriman Alaska Series. C. H. Merriam (ed.). 1904 et seq. 12 of 14 planned volumes published. (bird and landscape paintings)

The Warblers of North America. F. M. Chapman. 1907. (24 color plates)

Birds of New York. E. H. Eaton. 1910-14. (106 color plates)

Birds of North America. T. G. Pearson (ed.). 1917 and later editions. (106 color plates)

Wild Animals of North America. E. W. Nelson. 1918. (127 color plates)

The Book of Birds. H. Henshaw and National Geographic Society. 1918. (250 color plates)

The Burgess Bird Book for Children. T. W. Burgess. 1919. (32 color plates)
The Game Birds of California. G. B. Grinnell. 1919. (16 color plates)

The Book of Dogs: An Intimate Study of Man's Best Friend. E. H. Baynes. 1919. (78 color plates)

The Burgess Animal Book for Children. T. W. Burgess. 1920. (74 color plates)

A Natural History of the Ducks. J. C. Phillips. 192226. (10 color, 15 black-and-white plates)

Birds of Massachusetts and Other New England States. 3 vol. E. H. Forbush. 1925-29. (68 color plates)

Artist and Naturalist in Ethiopia. L. A. Fuertes and W. H. Osgood. 1936. (16 colored plates)

Natural History of the Birds of Eastern and Central North America. E. H. Forbush and J. B. May. 1939. (96 color plates by L. A. Fuertes, Allan Books, and R. T. Peterson)

Louis Agassiz Fuertes and the Singular Beauty of Birds. F. G. Marcham. 1971. (59 color plates and ca.140 black-and-white drawings, washes, sketches)

The Bird Life of Texas. H. C. Oberholser. 1974. (35 color plates and 35 black-and-white illustrations)

A Celebration of Birds: The Life and Art of Louis Agassiz Fuertes. R. M. Peck. 1981. (60 color plates)

North American Owls: Biology and Natural History. P. A. Johnsgard. 1988. (10 color plates)

Les Oiseaux: Aquarelles de Louis Agassiz Fuertes. F. Roux. 1996. (80 color and black-and-white illustrations)

\section{References Relating to Fuertes's Life and Art}

Allen, A. A. 1927. The passing of a great teacher. Bird-Lore 29: 372-376.

Bailey, A. M. 1926-27. Field Journal of Alfred M. Bailey: The Field Museum-Chicago Daily News Abyssinian Expedition 1926-1927.

Bailey, A. M. 1977. With Fuertes in Abyssinia. The Living Bird (Cornell University Laboratory of Ornithology) 16: 103-122.

Baum, J. 1927. Savage Abyssinia. Doubleday, Doran $\&$ Co., New York, NY.

- 1935. Unknown Ethiopia. Grosset \& Dunlap, New York, NY.

Berge, C. 1994. One man's treasure. The Living Bird (Cornell University Laboratory of Ornithology) 13(4): 10-11.

Boynton, M. F. 1954. Louis Agassiz Fuertes. The Conservationist (New York State Conservation Department) 7(4): 10-12.

- 1956. Louis Agassiz Fuertes: His Life Briefly Told and His Correspondence Edited. Oxford University Press, New York, NY. 
1979. Fuertes remembered. Pp. 59-64, in Frontiers Annual, Academy of Natural Sciences, Philadelphia, PA.

Chapman, F. M. 1915. Louis Agassiz Fuertes: Painter of bird portraits. Bird-Lore 17:277-284. (Reprinted from the American Museum Journal 15: 220-224 [1915].) 1927. Louis Agassiz Fuertes, 1874-1927. Bird-Lore 29: 359-369.

- 1928. In Memoriam: Louis Agassiz Fuertes, 1874-1927. Auk 45: 1-26. (See also Ibis, 12th series, 3(4): 741-742 [1927].)

-1937. Fuertes and Audubon: A comparison of the work and personalities of two of the world's greatest bird artists. Natural History 39: 205-213.

-1939. Memories of Louis Fuertes. Bird-Lore 41: 3-10.

FMNH (Field Museum of Natural History). 1930. Abyssinian Birds and Mammals: Painted from Life by Louis Agassiz Fuertes. 32 color plates. Special Publication of the Field Museum of Natural History, Chicago, IL. https://digitalcommons.unl. edu/biosciornithology/49/

Fuertes, L. A. 1913-14. Impressions of the voices of tropical birds. Bird-Lore 15: 341-344; 16: 1-4, 96101, 161-169, 342-349, 421-428.

- 1920. Falconry, the sport of kings. National Geographic 38(6): 429-626.

Fuertes, L. A., and W. H. Osgood. 1936. Artist and Naturalist in Ethiopia. Doubleday, Doran \& Co., New York, NY.

Hadley, A. H. 1931. With Fuertes in Florida. American Forests 37: 71-73, 128.

Johnsgard, P. A. 2009. Louis A. Fuertes and the Zoological Art of the 1926-1927 Abyssinian Expedition of the Field Museum of Natural History. 121 pp. University of Nebraska Digital Commons, Papers in the Biological Sciences, Papers in Ornithology. http://digitalcommons.unl.edu/ biosciornithology/44/

Leakey, R. E. 1981. The Making of Mankind. E. P. Dutton, New York, NY.

Marcham, F. G. 1963. Louis Agassiz Fuertes revisited. The Living Bird (Cornell University Laboratory of Ornithology) 2: 83-92.

Marcham, F. G. (ed.). 1971. Louis Agassiz Fuertes and the Singular Beauty of Birds. Harper \& Row, New York, NY.

Osgood, W. H. 1927. Louis Agassiz Fuertes. Science 46: 469-472. (Reprinted in Fuertes \& Osgood, 1936).

Palmer, E. L. 1928. Louis Agassiz Fuertes. Nature Magazine 12: 177-179.

Pavitt, P. 2001. Africa's Great Rift Valley. Harry N. Abrams, New York, NY.
Peck, R. M. 1982. A Celebration of Birds: The Life and Art of Louis Agassiz Fuertes. Walker Publishing, New York, NY. 178 pp.

Peck, R. M. 1983. Louis Agassiz Fuertes (18741927). Southwest Art, November 1983, pp. 138, 140-146.

Roux, F. 1996. Les Oiseaux: Aquarelles de Louis Agassiz Fuertes. Frankreich, Bibliotheque de l'Image, Paris. 95 pp. (80 plates, 64 in color; 18 from the Abyssinian expedition)

Sutton, G. M. 1941. Louis Fuertes, teacher. Audubon 42: 521-524.

- 1942a. Louis Fuertes at work. Audubon 44: 37-40.

- $1942 \mathrm{~b}$. Fuertes and the young bird artist. Audubon 44: 82-85.

- 1979. To a Young Bird Artist: Letters from Louis Agassiz Fuertes to George Miksch Sutton. University of Oklahoma Press, Norman, OK.

Wells, D. T. 1909. Drawing wild birds in their native haunts: A sketch of the personality and methods of Louis Agassiz Fuertes, the bird artist. Outing Magazine 54: 565-573.

\section{Species Accounts References}

\section{Bird References}

Ade, B. 1979. Some observations on the breeding of the crowned plover. Bokmakierie 31: 9-16.

Ash, J. S. 1980. Breeding of the spur-winged goose, Plectropterus gambensis, in Ethiopia. Scopus 52: 52.

-1989. An atlas of the past and present distribution of bustards in Ethiopia and Somalia. Bustard Studies 4: 1-34.

Ash, J. S., J. Adkins, and J. D. Adkins. 2009. Birds of Ethiopia and Eritrea: An Atlas of Distribution. A \& C Black, London, UK. 463 pp.

Ash, J. S., and J. E. Miskell. 1998. Birds of Somalia. Pica Press, Mountfield, Sussex, UK.

Attwell, R. I. G. 1966. Oxpeckers, and their association with mammals in Zambia. Puku 4: $17-48$.

Bannerman, D. A. 1939. The Birds of Tropical West Africa. Vol. 5. Crown Agents for the Colonies, London, UK.

Bartram, S., and W. Boland. 2001. Chemistry and ecology of toxic birds. ChemBioChem 2: 809-811.

Bird, C. D., and N. J. Emery. 2009. Insightful problem solving and creative tool modification by captive nontool-using rooks. Proceedings of the National Academy of Sciences. 106(25): 10370-10375. 
Borghesio, L. 1997. Observations on the ecology of Tauraco rueppellii and T. leucotis in southern Ethiopia. Bulletin of the British Ornithologists' Club 117: 11-16.

Brosset, A., and C. Erard. 1986. Les Oiseaux des Régions Forestières du Nord-est du Gabon. Vol. 1, Écologie et comportement des espèces. Société nationale de protection de la nature, Paris, France.

Brown, C. P. 1990. Breeding biology of the bearded vulture in southern Africa. Ostrich 61: 24-49.

Brown, L. H. 1958. The breeding of the greater flamingo Phoenicopterus ruber at Lake Elmenteita, Kenya Colony. Ibis 100: 388-420.

- 1971. African Birds of Prey. Houghton Mifflin, Boston, MA.

- 1972. The breeding behaviour of the African harrier hawk Polyboroides typus in Kenya. Ostrich 43: 169-175.

Brown, L. H., and D. Amadon. 1968. Eagles, Hawks, and Falcons of the World. 2 vols. McGraw Hill, New York, NY.

Brown, L. H., D. Powell-Cotton, and J. B. D. Hopcraft. 1973. The biology of the greater flamingo and great white pelican in East Africa. Ibis 115: 352-374.

Brown, L. H., E. K. Urban, and K. Newman. 1982. The Birds of Africa. Vol. 1. Academic Press, London, UK.

- 1997. The Birds of Africa. Vol. 6. Academic Press, London, UK.

- 2004. The Birds of Africa. Vol. 7. Academic Press, London, UK.

Burton, P. 1989. Birds of Prey. Gallery Books, New York, NY.

Cade, T. 1982. The Falcons of the World. Cornell University Press, Ithaca, NY.

Campbell, B., and E. Lack (eds.). 1985. A Dictionary of Birds. T. \& A. D. Poyser, Calton, UK.

Chapin, J. P. 1932. The birds of the Belgian Congo. Part 1. Bulletin of the American Museum of Natural History 65: 1-756.

- 1939. The birds of the Belgian Congo. Part 2. Bulletin of the American Museum of Natural History 75: 1-632.

- 1953. The birds of the Belgian Congo. Part 3. Bulletin of the American Museum of Natural History 75A: 1-821.

- 1954. The birds of the Belgian Congo. Part 4. Bulletin of the American Museum of Natural History 75B: 1-846.

- 1963. The turacos: An African bird family. The Living Bird (2nd Annual Report, Cornell University Laboratory of Ornithology) 57-67.
Christie, D. A., A. Elliott, and J. Del Hoyo (eds.). 2008. Handbook of the Birds of the World, Vol. 14., Bush-shrikes to Old World Sparrows. Lynx Edicions, Barcelona, Spain.

Clancey, P. A. 1992. Kingfishers of Sub-Saharan Africa. J. Ball \& A. Donker, Johannesburg, South Africa.

Clark, A. 1980. Notes on the breeding biology of the spur-winged goose. Ostrich 51: 179-182.

Cramp, S., and K. E. L. Simmons (eds.). 1977. Handbook of the Birds of Europe, the Middle East and North Africa: The Birds of the Western Palearctic. Vol. 1. (Ostrich to Ducks). Oxford University Press, Oxford, UK.

- 1980. The Birds of the Western Palearctic. Vol. 2. (Hawks to Bustards). Oxford University Press, Oxford, UK.

- 1984. The Birds of the Western Palearctic. Vol. 3. (Waders to Gulls). Oxford University Press, Oxford, UK.

-1985. The Birds of the Western Palearctic. Vol. 4. (Terns to Woodpeckers). Oxford University Press, Oxford, UK.

Del Hoyo, J., A. Elliott, and D. A. Christie (eds.). 2006. Handbook of the Birds of the World, Vol. 11., Old World Flycatchers to New World Warblers. Lynx Edicions, Barcelona, Spain.

Del Hoyo, J., A. Elliott, and G. Sargatal (eds.). 1992. Handbook of the Birds of the World, Vol. 1, Ostrich to Ducks. Lynx Edicions, Barcelona, Spain.

- 1994. Handbook of the Birds of the World, Vol. 2, New World Vultures to Guineafowl. Lynx Edicions, Barcelona, Spain.

-1996. Handbook of the Birds of the World, Vol. 3, Hoatzin to Auks. Lynx Edicions, Barcelona, Spain.

-1997. Handbook of the Birds of the World, Vol. 4, Sandgrouse to Cuckoos. Lynx Edicions, Barcelona, Spain.

-1999. Handbook of the Birds of the World, Vol. 5, Barn Owls to Hummingbirds. Lynx Edicions, Barcelona, Spain.

- 2001. Handbook of the Birds of the World, Vol. 6, Mousebirds to Hornbills. Lynx Edicions, Barcelona, Spain.

- 2002. Handbook of the Birds of the World, Vol. 7, Jacamars to Woodpeckers. Lynx Edicions, Barcelona, Spain.

Dowsett, R. J., and F. Dowsett-Lemaire. 1993. Checklist of Birds of the Afrotropical and Malagasy Regions, Vol. 1, Species Limits and Distributions. Tauraco Press, Liege, Belgium.

Everitt, C. 1965. Breeding the white-necked turaco. Avicultural Magazine 71: 24-27. 
Feare, C., and A. Craig. 1999. Starlings and Mynas. Princeton University Press, Princeton, NJ.

Ferguson-Lees, J., and D. A. Christie. 2001. Raptors of the World. Houghton Mifflin, Boston, MA.

Forshaw, J. M. 2009. Trogons: A Natural History of the Trogonidae. Lynx Editions and Princeton University Press, Princeton, NJ.

Forshaw, J. M., and W. T. Cooper. 1983-85. Kingfishers and Related Birds. Vol. 1. Alcedinidae, Ceryle to Cittura and Vol. 2. Halcyon to Tanysiptera. Lansdowne Editions, Melbourne, Australia.

-1995. Kingfishers and Related Birds. Vols. 5 and 6. Bucerotidae. Lansdowne Editions, Melbourne, Australia.

- 2002. Turacos: A Natural History of the Musophagidae. Nokomis Editions, Melbourne, Australia.

Foxall, I., \& P. J. K. Burton. 1975. Notes on the nesting of the white-cheeked tauraco, Turacus leucotis. Bulletin of the British Ornithologists' Club 95: 27-29.

Friedmann, H. 1930. Birds collected by the Childs Frick Expedition to Ethiopia and Kenya Colony. Bulletin of the US National Museum 153: 1-515.

Fry, C. H., and K. Fry. 1992. Kingfishers, Bee-eaters and Rollers: A Handbook. Princeton University Press, Princeton, NJ.

Fry, C. H., S. Keith, and E. K. Urban (eds.). 19822004. The Birds of Africa. 7 vols. Academic Press, London, UK.

-1988. The Birds of Africa. Vol. 3. Parrots to Woodpeckers. Academic Press, London, UK.

- 2000. The Birds of Africa. Vol. 6. Picathartes to Oxpeckers. Academic Press, London, UK.

Ginn, P. J., W. C. McIlleron, and P. S. Milstein. 1989. The Complete Book of Southern African Birds. Struik Winchester, Cape Town, South Africa.

Goodwin, D. 1970. Pigeons and Doves of the World. British Museum (Natural History), London, UK.

- 1976. Crows of the World. British Museum (Natural History), London, UK, and Cornell University Press, Ithaca, NY.

Grossman, M. L., and J. Hamlet. 1964. Birds of Prey of the World. Bonanza Books, New York, NY.

Grzimek, B. (ed.). 1973. Grzimek's Animal Life Encyclopedia. Vols. 7-9, Birds; Vols. 10-13, Mammals. Van Nostrand Reinhold, New York, NY.

Hall, B. P., \& R. E. Moreau. 1970. An Atlas of Speciation in African Passerine Birds. British Museum (Natural History), London, UK.

Hancock, J. J., and H. Elliott. 1978. The Herons of the World. Harper \& Row, New York. NY.
Hancock, J. J., J. A. Kushian, and M. P. Kahl. 1992. Storks, Ibises and Spoonbills of the World. Academic Press, London, UK.

Houston, D. C. 1976. Breeding of the white-backed and Rüppell's griffin vultures, Gyps africanus and G. rueppellii. Ibis 118: 14-40.

Hustler, K., and W. W. Howells. 1988. Breeding biology of the white-headed vulture in Hwange National Park, Zimbabwe. Ostrich 59: 21-24.

Johnsgard, P. A. 1965. Handbook of Waterfowl Behavior. Cornell University Press, Ithaca. NY.

-1978. Ducks, Geese and Swans of the World. University of Nebraska Press, Lincoln, NE.

- 1981. The Plovers, Sandpipers and Snipes of the World. University of Nebraska Press, Lincoln, NE.

- 1983. The Cranes of the World. Indiana University Press, Bloomington, IN.

- 1986. The Quails, Partridges and Francolins of the World. Oxford University Press, Oxford, UK.

- 1991. Bustards, Hemipodes and Sandgrouse: Birds of Dry Places. Oxford University Press, Oxford, UK.

- 1994. Arena Birds: Sexual Selection and Behavior. Smithsonian Institution Press, Washington, DC.

- 1997. The Avian Brood Parasites: Deception at the Nest. Oxford University Press, New York.

- 2000. Trogons and Quetzals of the World. Smithsonian Institution Press, Washington, DC.

- 2015. A Chorus of Cranes: The Cranes of North America and the World. University Press of Colorado, Boulder, CO. 242 pp.

Johnson, A., and F. Cézilly. 1975. The Greater Flamingo. T \& A. D. Poyser, London, UK.

Kahl, M. P. 1973. Comparative ethology of the Ciconiidae. Part 6. The blacknecked, saddlebill, and jabiru storks (genera Xenorhynchus, Epihippiorhynchus, and Jabiru). Condor 75: 17-27.

Keith, S., E. K., Urban, and C. H. Fry. 2002. The Birds of Africa. Vol. 4. Broadbills to Chats. Academic Press, London, UK.

Kemp, A. 1976. A study of the ecology, behaviour and systematics of Tockus hornbills (Aves: Bucerotidae). Transvaal Museum Memoir, 20: $1-125$.

- 1995. The Hornbills: Bucerotiformes. Oxford University Press, Oxford, UK.

Mackworth-Praed, C. W., and C. H. B. Grant. 1960. Birds of Eastern and North Eastern Africa. 2nd ed. 2 vols. Longman, London, UK.

Maclean, G. L. 1970. The pygmy falcon. Koedoe 13: $1-21$. 
Marshall, C. H. T., and G. F. L. Marshall. 1871. A Monograph of the Capitonidae, or Scansorial Barbets. Published by the authors, London, England.

Mendelsohn, J. M., and Y. Leshim. 1983. Observations on reproduction and growth of Old World vultures. Pp. 214-241, in Vulture Biology and Management (S. R. Wilbur and J. A. Jackson, eds.). University of California Press, Berkeley, CA.

Moreau, R. E. 1933. The food of the red-billed oxpecker, Buphagus erythrorhynchus (Stanley). Bulletin of Entomological Research 24: 325-335.

. 1938. A contribution to the biology of the Musophagiformes, the so-called plantain-eaters. Ibis 2(4): 639-671.

-1945. On the bateleur, especially at the nest. Ibis 87: 224-249.

Moreau, R. E., and W. M. Moreau. 1941. Breeding biology of the silvery-cheeked hornbill. Auk 58: 13-27.

Mundy, P. J., and G. Hayes. 1997. Oxpeckers and elephants. Ostrich 67: 85-87.

Newman, K. (ed.). 1971. Birdlife in Southern Africa. Purnell \& Sons, Johannesburg, South Africa.

North, M. E. W. 1963. Breeding of the black-headed heron at Nairobi, Kenya, 1958-1962. Journal of East African Natural History 106: 34-63.

Ogilvie, M., \& C. Ogilvie.1986. Flamingos. Alan Sutton Publishing, Gloucester, UK.

Pennycuick, C. J. 1976. Breeding of the lappetfaced and white-headed vultures, Torgos tracheliotus and Trigonoceps occipitalis, on Serengeti plains, Tanzania. East African Wildlife Journal 14: 67-84.

Poll, J. L. V. 2001. A Guide to Endemic Birds of Ethiopia and Eritrea. Shama Books, Addis Ababa, Ethiopia.

Redman, N., T. Stevenson, and J. Fanshaw. 2016. Birds of the Horn of Africa: Ethiopia, Eritrea, Djibouti, Somalia, and Socotra. Princeton University Press, Princeton NJ.

Root, J., and A. Root. 1969. Inside a hornbill's walled-up nest. National Geographic 136: 846-855.

Rowan, M. K. 1963. The yellowbill duck, Anas undulata Dubois, in southern Africa. Ostrich Suppl. 1: 1-56.

Rudebeck, G. 1961. Observations on the bearded vulture (Gypaetus barbatus) in South Africa, with notes on behaviour and field characters. Pp. 406414, in South African Animal Life. Almqvist \& Wiksell, Stockholm, Sweden.

Skead, C. J. 1950. A study of the African hoopoe. Ibis 92: 435-463.
-1952. A study of the black crow, Corvus capensis. Ibis 94: 434-451.

-1962. A study of the crowned guineafowl, Numida meleagris coronata Gurney. Ostrich 33: 51-65.

Snow, D. W. (ed.). 1978. An Atlas of Speciation in African Non-Passerine Birds. British Museum (Natural History), London, UK.

Steyn, P. 1960. Observations on the African fish eagle. Bokmakierie 12: 21-28.

- 1961. Observations on the secretary bird. African Wildlife 15: 191-198.

- 1965. Some observations on the bateleur. Ostrich 36: 203-213.

- 1970. Observations on the tawny eagle. Ostrich 41: 1-22.

- 1978. Observations on the long-crested eagle. Bokmakierie 30: 3-10.

-1980. Breeding and food of the bateleur in Zimbabwe (Rhodesia). Ostrich 51: 168-178.

-1982. Birds of Prey of Southern Africa: Their Identification and Life Histories. David Philip, Cape Town, South Africa, and Croom Helm, Beckenham, UK.

Stutterheim, C. J. 1982. Breeding biology of the redbilled oxpecker in Kruger National Park. Ostrich 53: 79-90.

Tarboton, W. 1989. African Birds of Prey. Cornell University Press, Ithaca, NY.

- 1992. Aspects of breeding biology of the African jacana. Ostrich 63: 141-157.

Todd, F. 1996. Natural History of the Waterfowl. Ibis Press, Vista, CA.

Urban, E. K. 1974. Breeding of sacred ibis, Threskiornis aethiopica, at Lake Shala, Ethiopia. Ibis 116: 263-277.

Urban, E. K., and L. H. Brown. 1994. A Checklist of the Birds of Ethiopia. 2nd ed. Ethiopian Wildlife and Natural History Society, Addis Ababa, Ethiopia.

Urban, E. K., Fry, C. H., and S. Keith (eds.). 1986. The Birds of Africa. Vol. 2. Academic Press, London, UK.

- 1997. The Birds of Africa. Vol. 5. Academic Press, London, UK.

Van Perlo, B. 2009. Birds of Eastern Africa. Princeton University Press, Princeton, NJ.

Ward, D. 1989. Behaviour associated with breeding of crowned, black-winged and lesser black-winged plovers. Ostrich 60: 141-150. (See also Ostrich 60: 49-54 and 97-102.)

Watson, R. T. 1990. Breeding biology of the bateleur. Ostrich 61: 13-23.

Willmore, S. B. 1977. Crows, Jays, Ravens and their 
Relatives. David \& Charles, Newton Abbot, UK.

Winterbottom, J. M. 1974. The Cape teal. Ostrich 45: $110-132$.

World Institute for Conservation and Environment. 2019. Birds of Ethiopia [checklist]. Nature Worldwide: Birds. http://www.birdlist.org/ ethiopia.htm

Zimmerman, D., D. Turner, and D. Pearson. 1996. Birds of Kenya and Northern Tanzania. Princeton University Press, Princeton, NJ.

\section{Mammal References}

Bueler, L. E. 1973. Wild Dogs of the World. Stein \& Day, New York, NY.

Crook, J. H. 1966. Gelada herd structure and movement. Symposia of the Zoological Society of London 18: 237-58.

Crook, J. H., and P. Aldrich-Blake. 1968. Ecological and behavioral contrasts between sympatric ground dwelling primates in Ethiopia. Folia Primatologica 8: 192-227.

Davies, A. G., and J. F. Oates (eds.). 1994. Colobine Monkeys: Their Ecology, Behaviour and Evolution. Cambridge University Press, Cambridge, UK.

Dunbar, R. I. M. 1987. Habitat quality, population dynamics, and group composition in colobus monkeys (Colobus guereza). International Journal of Primatology 8: 299-330.

Dunbar, R. I. M., and E. P. Dunbar. 1974a. Social organization and ecology of the klipspringer (Oreotragus oreotragus) in Ethiopia. Zeitschrift für Tierpsychologie 35: 481-493.

- 1974b. Ecology and population dynamics of Colobus guereza in Ethiopia. Folia Primatologica 21: 188-208.

-1975. Social dynamics of gelada baboons. Contributions to Primatology 6: 1-156.

-1979. Observations on the social organization of the common duiker in Ethiopia. African Journal of Ecology 17: 249-252.

Estes, R. D., and D. Otte. 2012. The Behaviour Guide to African Mammals: Including Hoofed Mammals, Carnivores, Primates. Rev. ed. University of California Press, Berkeley, CA.

Fox, M. W. 1974. The Wild Canids: Their Systematics, Behavioural Ecology, Evolution. Van Nostrand Reinhold, New York, NY.

Gautier-Hion, A., F. Bourlière, J. P. François, J. Gautier, and J. Kingdom. 1988. A Primate Radiation: Evolutionary Biology of the African Guenons. Cambridge University Press, Cambridge. UK.

Goodman, M., C. A. Porter, J. Czelusniak, S. L. Page,
H. Schneider, J. Shoshani, G. Gunnell, and C. P. Groves. 1998. Toward a phylogenetic classification of primates based on DNA evidence complemented by fossil evidence. Molecular Phylogenetics and Evolution 9(3): 585-598.

Grzimek, B. (ed.). 1990. Grzimek's Encyclopedia of Mammals. 5 vols. McGraw Hill, New York, NY.

Hendrichs, H. 1975. Observations on a population of Bohor reedbuck, Redunca redunca (Pallas 1767). Zeitschrift für Tierpsychologie 38: 44-54.

Hinton, H. E., and A. M. S. Dunn. 1967. Mongooses: Their Natural History and Behaviour. Oliver \& Boyd, Edinburgh, UK.

Hoeck, H. N., H. Klein, and P. Hoeck. 1983. Flexible social organization in hyrax. Zeitschrift für Tierpsychologie 59: 265-298.

Kingdom, J. S. 1971-82. East African Mammals: An Atlas of Evolution in Africa. 7 parts. Academic Press, London, UK.

- 1997. The Kingdom Field Guide to African Mammals. Natural World (Academic Press), San Diego, CA. (2nd ed., 2015, not seen)

Leuthold, W. 1977. African ungulates: A comparative review of their ethology and behavioural ecology. Zoophysiology \& Ecology 8: 1-307.

Macdonald, D. W. (ed.). 1984. The Encyclopedia of Mammals. Facts on File, New York, NY.

Macdonald, D. W., and S. Norris (eds.). 2001. The New Encyclopedia of Mammals. Oxford University Press, Oxford, UK.

Marler, P. 1972. Vocalizations of East African monkeys. II. Black and white colobus. Behaviour 42: 175-197.

Nagel, U. 1973. A comparison of anubis baboons, hamadryas baboons, and their hybrids at a species border in Ethiopia. Folia Primatologica 19: 104-165.

Nowak, R. M. (ed.). 1991. Walker's Mammals of the World. 5th ed. 2 vols. Johns Hopkins University Press, Baltimore. MD.

Oates, J. F. 1977. The social life of a black-and-white colobus monkey, Colobus guereza. Zeitschrift für Tierpsychologie 45: 1-60.

Osgood, W. H. 1928. A new genus of aquatic rodent from Abyssinia. Publications Field Museum of Natural History, Zoological Series 12: 185-189. (Description of Nilopegamys plumbeus, now Colomys goslingi, velvet rat.)

Rowell, T. E. 1971. Organization of captive groups of Cercopithecus monkeys. Animal Behavior 19: 625-645.

Struhsaker, T. 1967a. Behavior of vervet monkeys (Cercopithecus aethiops). University of California Publications in Zoology 82: 1-74. 
1967b. Social structure among vervet monkeys. Behaviour 29: 6-121.

Taylor, M. 1975. Herpestes sanguineus. Mammalian Species 65: 1-5.

Wilson, D. E., and D. M. Reeder (eds.). 2005. Mammal Species of the World: A Taxonomic and Geographic Reference. 2 vols. 3rd ed. Johns Hopkins University Press, Baltimore, MD.

Wolfheim, J. 1983. Primates of the World: Distribution, Abundance, and Conservation. University of Washington Press, Seattle, WA. Yalden, D. W., M. J. Largen, and D. Kock. 197686. Catalogue of the mammals of Ethiopia. Italian Journal of Zoology 8: 1-118; 9: 1-52; 13: 169-272; 19: 67-221; 21: 31-103.

\section{Internet Sources}

Biodiversity Heritage Library: Includes literature citations and sources for 39 books and other publications illustrated by Fuertes. https://www.biodiversitylibrary.org/search?searc $\underline{\text { hTerm=Louis }+ \text { Agassiz+Fuertes\&stype }=\mathrm{C} \# / \text { titles }}$

\section{Cornell University Library Rare and Manuscript} Collections: Louis Agassiz Fuertes Papers, 18921954,-1892-1927 (bulk), Collection Number: 2662, Division of Rare and Manuscript Collections, Cornell University Library. https://rmc.library. cornell.edu/EAD/htmldocs/RMM02662.html

\section{Digital Commons at the University of Nebraska-Lincoln:}

1. Louis A. Fuertes and the Zoological Art of the 1926-1927 Abyssinian Expedition of the Field Museum of Natural History, Paul A. Johnsgard, 2008. https://digitalcommons.unl.edu/ biosciornithology/44/

2. Album of Abyssinian Birds and Mammals: Painted from Life by Louis Agassiz Fuertes. 32 color plates. Special Publication of the Field Museum of Natural History, Chicago, IL. 1930. https://digitalcommons.unl.edu/ biosciornithology/49/
Joel Oppenheimer, Inc.: Abyssinian Birds and Mammals: High quality limited-edition reproductions $(20 \times 15$ inches $)$ from 20 of Fuertes's Abyssinian prints are available from the Joel Oppenheimer Natural History Art Gallery: https://www.audubonart.com

The Online Books Page: A list of online books that were illustrated by Louis Agassiz Fuertes. http:// onlinebooks.library.upenn.edu/webbin/book/ lookupname?key=Fuertes $\% 2 \mathrm{C} \% 20$ Louis $\% 20$ Agassiz\%2C\%201874-1927

Project Gutenberg: http:/ / www.gutenberg.org/ browse/authors/f\#a4612

Works illustrated by Louis Agassiz Fuertes accessible at Project Gutenberg, include:

1. Bird Stories from Burroughs: Sketches of Bird Life Taken from the Works of John Burroughs (1911) http://www.gutenberg.org/ ebooks / 26046

2. Citizen Bird: Scenes from Bird-Life in Plain English for Beginners (1896) http:/ / www. gutenberg.org/ebooks/11896

3. Wild Animals of North America: Intimate Studies of Big and Little Creatures of the Mammal Kingdom (1918) http://www.gutenberg.org/ ebooks/59475

Wikimedia Commons: Louis Agassiz Fuertes. Seventy-five paintings, including four from the Album of Abyssinian Birds and Mammals (1930). http://commons.wikimedia.org/wiki/ Louis Agassiz Fuertes

Wikipedia: Louis Agassiz Fuertes. https://en.wikipedia.org/wiki/ Louis Agassiz Fuertes 


\section{Index to Species Accounts}

Abyssinian brown-throated wattle-eye.

See common wattle-eye

Abyssinian Clapperton's francolin. See

Clapperton's francolin

Abyssinian double-toothed barbet. See double-toothed barbet

Abyssinian gray plantain-eater. See eastern gray plantain-eater

Abyssinian ground hornbill, 89-90

Abyssinian lanner. See lanner falcon

Abyssinian pygmy falcon. See pigmy (pygmy) falcon

Abyssinian tawny eagle. See tawny eagle

Abyssinian wolf. See Ethiopian wolf

Abyssinian yellow-billed duck. See

yellow-billed duck

Actophilornis africana, 70-71

Aegypius occipitalis, 48-50

Aegypius tracheliotis, 46-48

African fish eagle, 33-36

African harrier-hawk, 54-56

African jacana, 70-71

African lammergeyer. See lammergeier

African little grebe. See little grebe

African night heron. See white-backed

night heron

African pigmy kingfisher. See pigmy

(pygmy) kingfisher

African sea eagle. See African fish eagle

African swallow-tailed kite. See

scissor-tailed kite

African wattled lapwing, 72

African white-backed vulture, 45

Alcedo cristata. See Corythornis cristata

amphibious rat. See velvet rat

Anas capensis, 25-27

Anas undulata, 27-28
Apaloderma narina, 82-84

Aquila rapax, 57-59

Ardea melanocephala, 19-20

Ardeotis kori, 67-68

Banded mongoose. See slender mongoose

bateleur, 50-54

bearded vulture. See lammergeier

black-bellied bustard, 68-69

black-headed heron, 19-20

black kite, 32-33

black-shouldered kite, 28-30

bohor reedbuck, 121

Bostrychia carunculata, 21

brown-throated wattle-eye. See common

wattle-eye

Bruce's green pigeon, 76-78

Bucorvus abyssinicus, 89-90

Buphagus erythrorhynchus, 99-100

Burhinus sengalensis, 71-72

bush (common) duiker, 117-120

bush hyrax, 115-116

Bycanistes cristatus, 90-91

Calherodius leuconotus, 19

Canis simensis, 112-114

Cape crow. See Cape rook

Cape rook, 98-99

Cape teal, 25-27

Centropus superciliosus, 81-82

Ceratogymna brevis, 90-91

Cercopithecus aethiops, 110

Ceyx picta, 84-86

Chelictinia riocourii, 30-32

Clapperton's francolin, 66-67

Colobus guereza, 101-103

Colomys goslingi, 111

Note: The English and scientific names indexed here are those that appeared in the FMNH (1930) album and their modern equivalents. They are limited to those species for which drawings or paintings exist. 
common African vulture. See hooded vulture common crane. See European (Eurasian) crane common wattle-eye, 94

Corvus capensis, 98-99

Corvus crassirostris, 96-98

Corythornis cristata, 86-88

crested hawk-eagle. See long-crested eagle crested hornbill. See silvery-cheeked hornbill crested pigmy kingfisher. See malachite

kingfisher

Crinifer zonurus, 78-80

crowned lapwing, 73

Dendrohyrax, 115-116

dog-faced baboon. See yellow baboon

double-toothed barbet, 93-94

eared vulture. See lappet-faced vulture

eastern four-banded sandgrouse. See four-

banded sandgrouse

eastern gray plantain-eater, 78-80

Egyptian kite. See black kite

Egyptian vulture, 41-43

Elanus caeruleus, 28-30

Epihippiorhynchus senegalensis, 20

Eupodotis melanogaster, 68-69

Ethiopian wolf, 112-114

European (Eurasian) crane, 67

Eurasian hoopoe, 88-89

Falco biarmicus, 65

four-banded sandgrouse, 74-77

Francolinus clappertoni, 66-67

Galla white-cheeked plantain-eater. See white-cheeked turaco

gelada, 105-110

Gorsachius leuconotus, 19

gray-headed kingfisher, 84-85

gray plantain-eater. See eastern gray

plantain-eater

greater flamingo, 22-23

green pigeon. See Bruce's green pigeon

grivet monkey, 110

Grus grus, 67

guereza colobus, 101-103

Gypaetus barbatus, 37-41

Gyps africanus, 45
Halcyon leucocephala, 84-85

Haliaeetus vocifer, 33-36

hamadryas baboon, 103-104

helmeted guineafowl, 65-66

Helotarsus ecaudatus, 50-54

Hemprich's hornbill. See red-billed hornbill

Herpestes sanguinea, 114-115

hooded vulture, 43-45

hoopoe. See Eurasian hoopoe

hyrax. See bush hyrax, rock hyrax, tree hyrax

klipspringer, 120-121

kori bustard, 67-68

lammergeier (or lammergier), 37-41

lanner falcon, 65

lappet-faced vulture, 46-48

lesser Cape rook. See Cape rook

little grebe, 17

long-crested eagle, 59-62

long-tailed mongoose. See slender mongoose

Lophaetus occipitalis, 59-62

Lowe's sand grouse. See four-banded

sandgrouse

Lybius bidentatus, 93-94

malachite kingfisher, 86-88

Megalornis grus, 67

Milvus migrans, 32-33

mole-rat, 114

mountain nyala, 117

Narina trogon, 82-84

Necrosyrtes monachus, 43-45

Neophron percnopterus, 41-43

Nettion capense. See Anas capensis

Nile helmetshrike. See white-crested

helmetshrike

northern lappet-faced vulture. See lappet-faced vulture

Numida meleagris, 65-66

nyala. See mountain nyala

Nycticorax leuconotus. See Calherodius leuconotus

olive baboon. See yellow baboon

Oreotragus oreotragus, 120-121 
Papio anubis, 109

Papio cyanocephalus, 103-104

Papio hamadryas, 104

Phoenicopterus ruber, 22-23

pigmy crested kingfisher. See malachite

kingfisher

pigmy (pygmy) falcon, 63-65

Platysteira cyanea, 94

Plectropterus gambensis, 23-25

Polihierax semitorquatus, 63-65

Polyboroides typus, 54-56

Prionops plumatus, 94-96

Procavia, 115-116

Pterocles quadricinctus, 74-77

pygmy kingfisher, 84-86

red-billed hornbill, 90

red-billed oxpecker, 99-100

Redunca redunca, 121

rock hyrax, 115-116

root-rat, 111-112

sacred baboon, 103-104

sacred ibis, 21-22

saddle-billed stork, 20

Sagittarius serpentarius, 62-63

scissor-tailed kite, 30-32

secretary bird, 62-63

Senegal stone curlew. See Senegal thick-knee

Senegal thick-knee, 71-72

Senegal wattled plover. See African wattled

lapwing

silvery-cheeked hornbill, 90-91

slender mongoose, 114-115

Somali greater bustard. See kori bustard southern hooded vulture. See hooded vulture spur-winged goose, 23-25

spur-winged lapwing, 72-73

spur-winged plover. See spur-winged lapwing swallow kite. See scissor-tailed kite

Sylvicapra grimmia, 117-120

Tachybaptus ruficollis, 17

Tachyoryctes splendens, 111-112

Tauraco leucotis, 80-81

tawny eagle, 57-59

Terathopius ecaudatus, 50-54

Theropithecus gelada, 105-110

thick-billed raven, 96-98
Threskiornis aethiopica, 21-22

Tockus erythrorhynchus, 90

Tockus hemprichii, 90

Tragelaphus buxtoni, 117

tree hyrax, 115-116

Treron waalia, 76-78

Uganda tufted guinea-fowl. See helmeted guineafowl

Upupa epops, 88-89

Vanellus coronatus, 73

Vanellus senegallus, 72

Vanellus spinosus, 72-73

velvet rat, 111

water rat. See velvet rat

wattled ibis, 21

white-backed night heron, 19

white-backed vulture, 43-44

white-browed coucal, 81-82

white-cheeked turaco, 80-81

white-crested helmetshrike, 94-96

white-headed vulture, 48-50

white-necked vulture. See hooded vulture

yellow baboon, 103-104

yellow-billed duck, 27-28 
